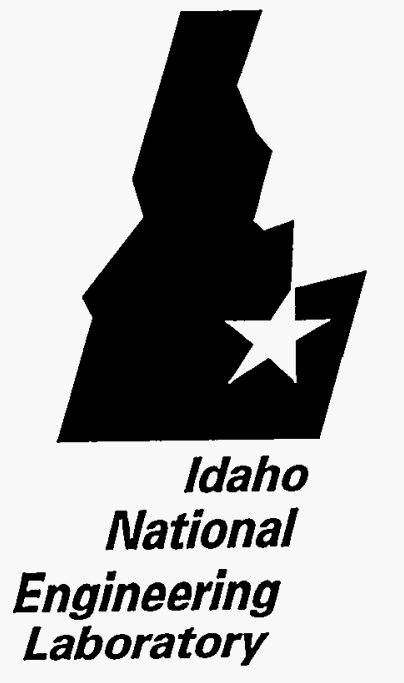

RECENED

OCT 201995

OSTI

Waste Management Facilities

Cost Information for

Transuranic Waste

David Shropshire

Michael Sherick

Chuck Biagi

June 1995
(Formerly EGG-WM-11274)

Revision 1

1995 
This report was prepared as an account of work sponsored by an agency of the United States Government. Neither the United States Government nor any agency thereof, nor any of their employees, makes any warranty, express or implied, or assumes any legal liability or responsibility for the accuracy, completeness, or usefulness of any information, apparatus, product, or process disclosed, or represents that its use would not infringe privately owned rights. Refer-

INEL-95/0015

(Formerly EGG-WM-11274)

Revision 1 ence herein to any specific commercial product, process, or service by trade name, trademark manufacturer, or otherwise does not necessarily constitute or imply its endorsement, recommendation, or favoring by the United States Government or any agency thereof. The views and opinions of authors expressed herein do not necessarily state or reflect those of the United States Government or any agency thereof.

\title{
Waste Management Facilities Cost Information for Transuranic Waste
}

\author{
David Shropshire \\ Michael Sherick \\ Chuck Biagi
}

Published June 1995

\author{
Idaho National Engineering Laboratory \\ Lockheed Martin Idaho Technologies \\ Radioactive Waste Technical Support Program \\ Idaho Falls, Idaho 83415
}

Prepared for the

U.S. Department of Energy

Office of Environmental Management

Under DOE Idaho Operations Office

Contract DE-AC07-94ID13223 


\section{DISCLAIMER}

\section{Portions of this document may be illegible in electronic image products. Images are produced from the best available original document.}


Waste Management Facilities

Cost Information

for Transuranic Waste

INEL-95/0015

Prepared by:

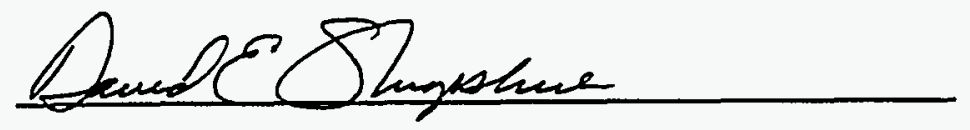

David Shropshire

Economic and Systems Analysis

Lockheed Martin Idaho Technologies
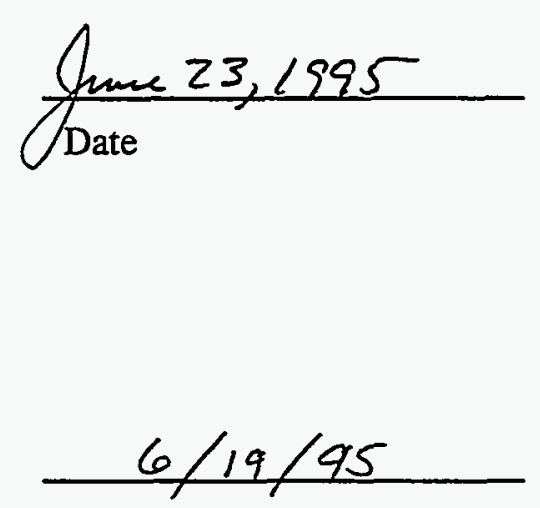

Date

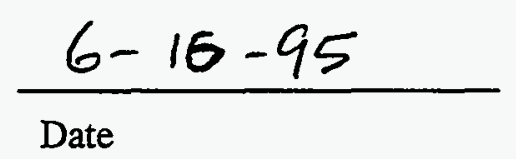

Derek Bolton

Environmental Services Division

Morrison Knudsen Corporation

Reviewed and approved by:

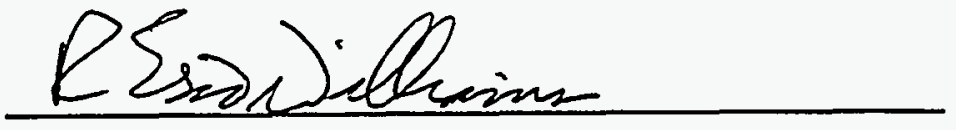

R. Eric Williams, Manager

Radioactive Waste Technical Support Program

Lockheed Martin Idaho Technologies

$$
6-19-95
$$

Date 


\begin{abstract}
This report contains preconceptual designs and planning level life-cycle cost estimates for managing transuranic waste. The report's information on treatment and storage modules can be integrated to develop total life-cycle costs for various waste management options. A procedure to guide the U.S. Department of Energy and its contractor personnel in the use of cost estimation data is also summarized in this report.
\end{abstract}


- 


\section{CONTENTS}

ABSTRACT $\ldots \ldots \ldots \ldots \ldots \ldots \ldots \ldots \ldots \ldots \ldots \ldots \ldots \ldots \ldots \ldots \ldots \ldots \ldots \ldots$

ACRONYMS $\ldots \ldots \ldots \ldots \ldots \ldots \ldots \ldots \ldots \ldots \ldots \ldots \ldots \ldots \ldots \ldots \ldots \ldots \ldots$

PREFACE $\ldots \ldots \ldots \ldots \ldots \ldots \ldots \ldots \ldots \ldots \ldots \ldots \ldots \ldots \ldots \ldots \ldots \ldots \ldots \ldots \ldots$

1. INTRODUCTION AND SUMMARY $\ldots \ldots \ldots \ldots \ldots \ldots \ldots \ldots \ldots \ldots \ldots \ldots$

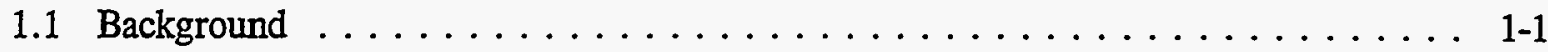

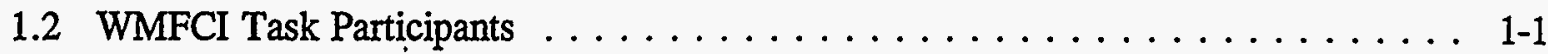

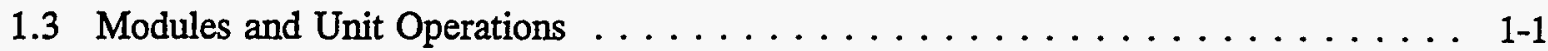

1.4 Technical and Cost Estimate Bases and Assumptions $\ldots \ldots \ldots \ldots \ldots \ldots$ 1-2

1.4.1 General Assumptions for Fixed Facilities $\ldots \ldots \ldots \ldots \ldots \ldots \ldots$ 1-2

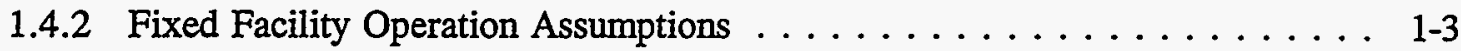

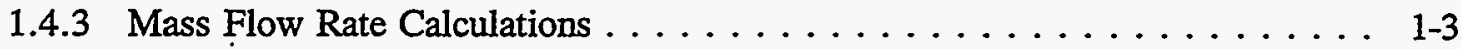

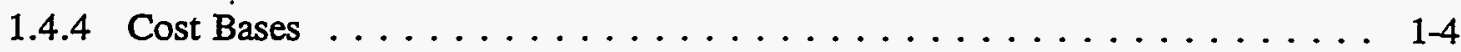

1.4 .5 Portable Facilities $\ldots \ldots \ldots \ldots \ldots \ldots \ldots \ldots \ldots \ldots \ldots \ldots \ldots \ldots \ldots$

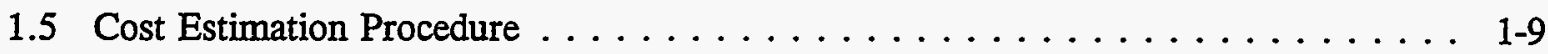

1.6 Cost Assessment Activities $\ldots \ldots \ldots \ldots \ldots \ldots \ldots \ldots \ldots \ldots \ldots \ldots \ldots$

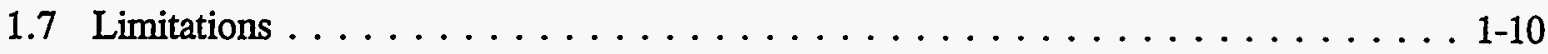

2. STORED WASTE RETRIEVAL (MODULE RETRV) $\ldots \ldots \ldots \ldots \ldots \ldots \ldots .2-1$

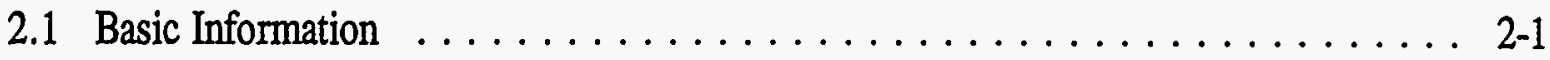

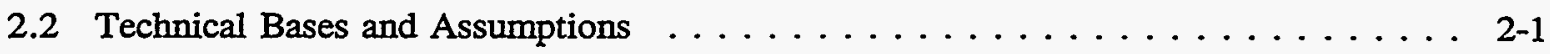

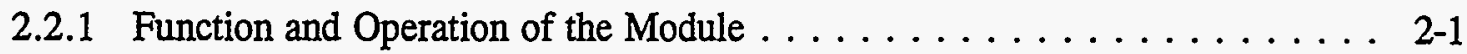

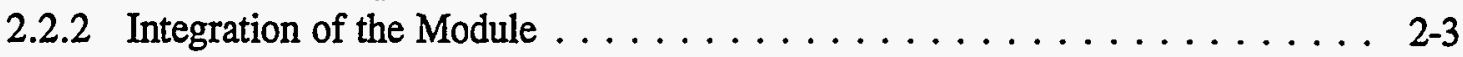

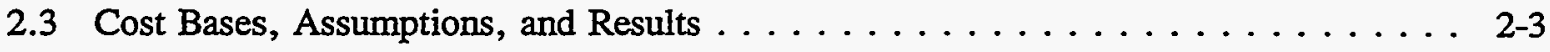

3. WASTE CHARACTERIZATION (MODULE WCHAR) $\ldots \ldots \ldots \ldots \ldots \ldots$. $\ldots$.

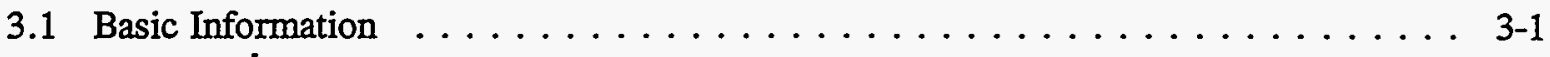

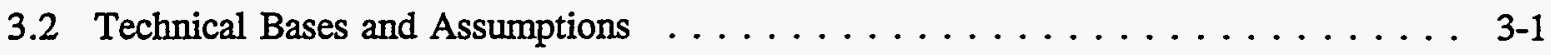


3.2.1 Function and Operation of the Module . . . . . . . . . . . . . 3-1

3.2.2 Integration of the Module . . . . . . . . . . . . . . 3-2

3.3 Cost Bases, Assumptions, and Results . . . . . . . . . . . . . . 3-2

4. TREATMENT ADMINISTRATION (MODULE TADMN) . . . . . . . . . . . . . 4-1

4.1 Basic Information $\ldots \ldots \ldots \ldots \ldots \ldots \ldots \ldots \ldots \ldots \ldots \ldots \ldots \ldots \ldots$

4.2 Technical Bases and Assumptions $\ldots \ldots \ldots \ldots \ldots \ldots \ldots$. . . . . . . . .

4.2.1 Function and Operation of the Module . . . . . . . . . . . . 4-1

4.2 .2 Integration of the Module $\ldots \ldots \ldots \ldots \ldots \ldots \ldots \ldots \ldots \ldots \ldots$

4.3 Cost Bases, Assumptions, and Results . . . . . . . . . . . . . . . 4-1

5. RECEIVING AND INSPECTION (MODULE RCINS) $\ldots \ldots \ldots \ldots \ldots \ldots \ldots$

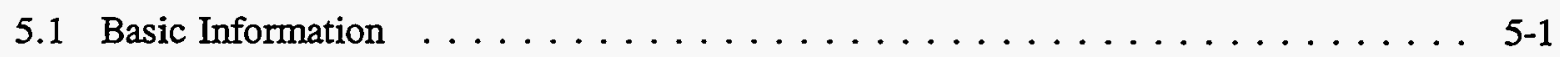

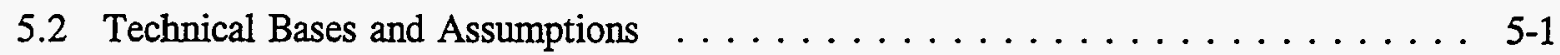

5.2 .1 Function and Operation of the Module . . . . . . . . . . . . 5-1

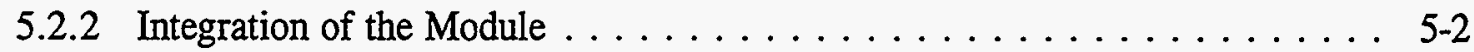

5.3 Cost Bases, Assumptions, and Results . . . . . . . . . . . . . . . . 5-2

6. OPEN, DUMP, AND SORT (MODULE OSORT) $\ldots \ldots \ldots \ldots \ldots \ldots$

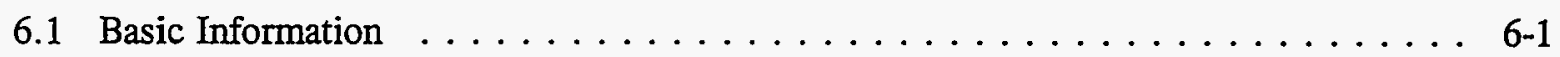

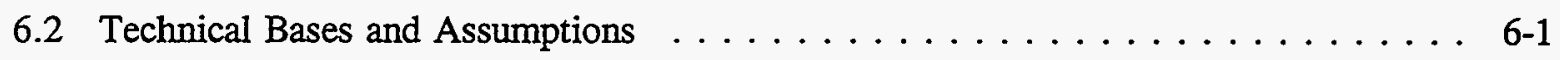

6.2 .1 Function and Operation of the Module ................ $6-1$

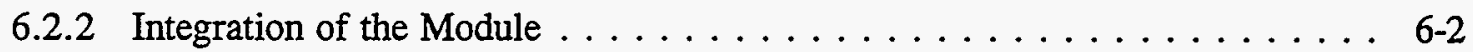

6.3 Cost Bases, Assumptions, and Results . . . . . . . . . . . . 6 6-2

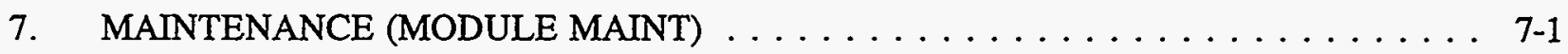

7.1 Basic Information $\ldots \ldots \ldots \ldots \ldots \ldots \ldots \ldots \ldots \ldots \ldots \ldots \ldots \ldots$

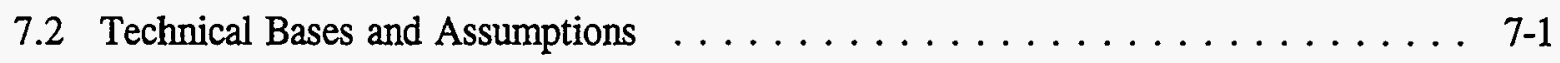

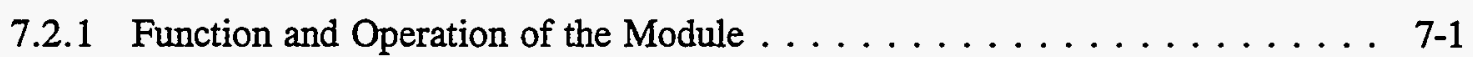

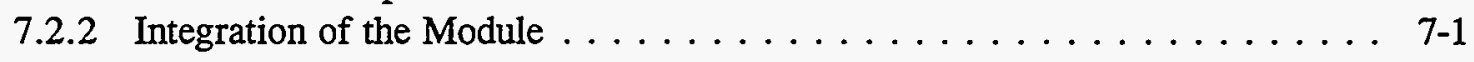


7.3 Cost Bases, Assumptions, and Results . . . . . . . . . . . . 7-1

8. INCINERATION (MODULE INCIN) $\ldots \ldots \ldots \ldots \ldots \ldots \ldots \ldots \ldots \ldots$

8.1 Basic Information $\ldots \ldots \ldots \ldots \ldots \ldots \ldots \ldots \ldots \ldots \ldots \ldots$

8.2 Technical Bases and Assumptions $\ldots \ldots \ldots \ldots \ldots \ldots \ldots \ldots \ldots \ldots$

8.2.1 Function and Operation of the Module . . . . . . . . . . . 8-1

8.2 .2 Integration of the Module $\ldots \ldots \ldots \ldots \ldots \ldots \ldots \ldots \ldots \ldots$

8.3 Cost Bases, Assumptions, and Results . . . . . . . . . . . . . 8-3

9. DEACTIVATION (MODULE DEACT) $\ldots \ldots \ldots \ldots \ldots \ldots \ldots \ldots \ldots \ldots$

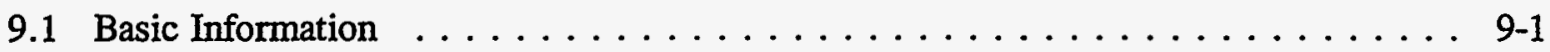

9.2 Technical Bases and Assumptions $\ldots \ldots \ldots \ldots \ldots \ldots \ldots \ldots \ldots \ldots . \ldots \ldots$

9.2.1 Function and Operation of the Module . . . . . . . . . . . . 9-1

9.2 .2 Integration of the Module $\ldots \ldots \ldots \ldots \ldots \ldots \ldots \ldots \ldots . \ldots \ldots$ 9-2

9.3 Cost Bases, Assumptions, and Results . . . . . . . . . . . . . . 9-2

10. NEUTRALIZATION (MODULE NEUTR) . . . . . . . . . . . . . . . . . . . 10-1

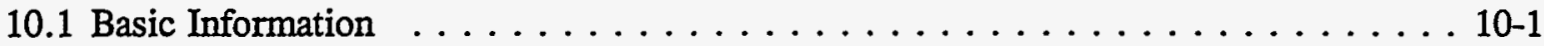

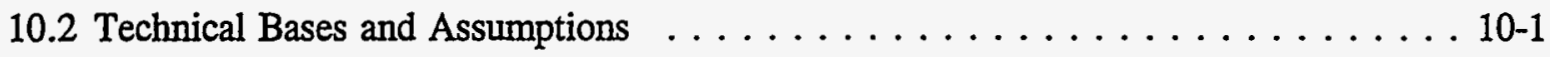

10.2.1 Function and Operation of the Module . . . . . . . . . . . . 10-1

10.2.2 Integration of the Module . . . . . . . . . . . . . . 10-2

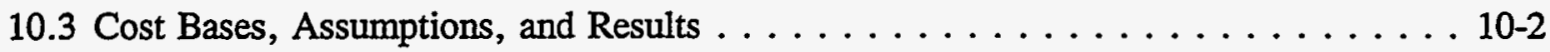

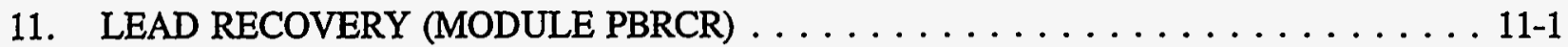

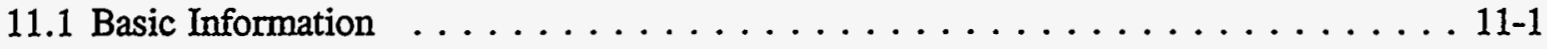

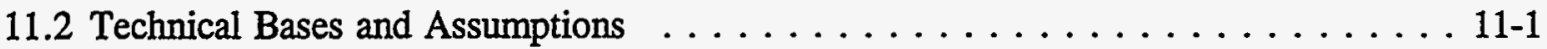

11.2.1 Function and Operation of the Module $\ldots \ldots \ldots \ldots \ldots \ldots \ldots \ldots \ldots \ldots$

11.2.2 Integration of the Module . . . . . . . . . . . . . . . . 11-2

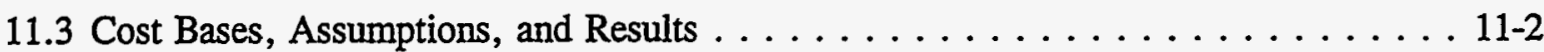


12. MERCURY SEPARATION (MODULE RMERC) $\ldots \ldots \ldots \ldots \ldots \ldots \ldots$. . . . . . . . . .

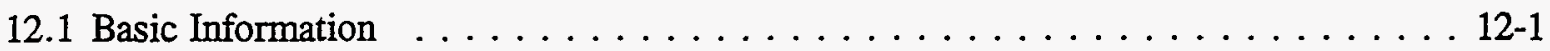

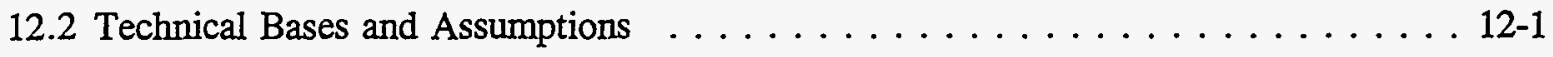

12.2.1 Function and Operation of the Module . . . . . . . . . . . . 12-1

12.2.2 Integration of the Module . . . . . . . . . . . . . . . 12-2

12.3 Cost Bases, Assumptions, and Results . . . . . . . . . . . . . 12-2

13. SHREDDING AND COMPACTION (MODULE CMPCT) . . . . . . . . . . 13-1

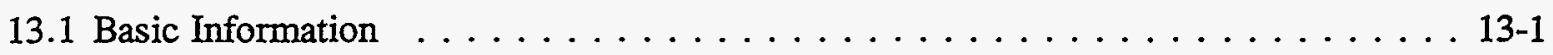

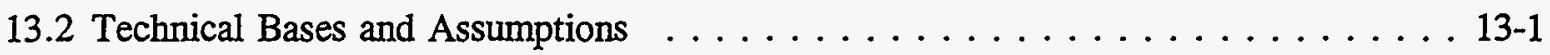

13.2.1 Function and Operation of the Module . . . . . . . . . . . . 13-1

13.2.2 Integration of the Module . . . . . . . . . . . . . . 13-1

13.3 Cost Bases, Assumptions, and Results . . . . . . . . . . . . . 13-2

14. AQUEOUS WASTE TREATMENT (MODULE AQWTR) . . . . . . . . . . . . . . . . . 14-1

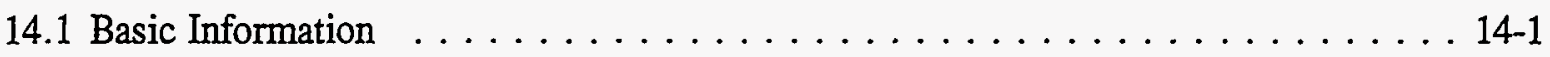

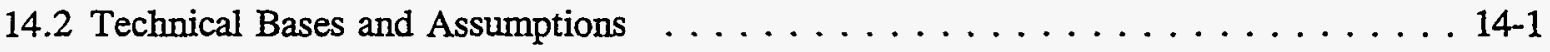

14.2.1 Function and Operation of the Module . . . . . . . . . . . . 14-1

14.2.2 Integration of the Module . . . . . . . . . . . . . . .

14.3 Cost Bases, Assumptions, and Results . . . . . . . . . . . . . 14-3

15. GROUT STABILIZATION (MODULE GROUT) $\ldots \ldots \ldots \ldots \ldots \ldots \ldots$. . . . . . . . 15-1

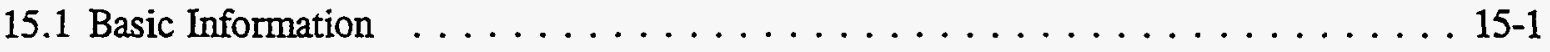

15.2 Technical Bases and Assumptions $\ldots \ldots \ldots \ldots \ldots \ldots \ldots \ldots \ldots \ldots \ldots \ldots \ldots$

15.2.1 Function and Operation of the Module . . . . . . . . . . . 15-1

15.2.2 Integration of the Module . . . . . . . . . . . . . 15-2

15.3 Cost Bases, Assumptions, and Results . . . . . . . . . . . . . . . . . . 15-2

16. VITRIFICATION (MODULE VITRF) $\ldots \ldots \ldots \ldots \ldots \ldots \ldots \ldots \ldots \ldots$. . . . . . . . . .

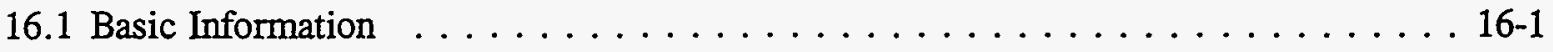

viii 


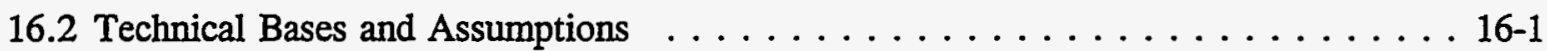

16.2.1 Function and Operation of the Module . . . . . . . . . . . . 16-1

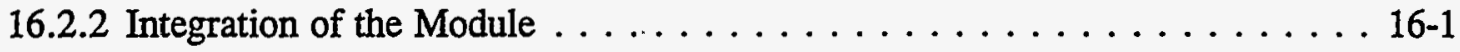

16.3 Cost Bases, Assumptions, and Results . . . . . . . . . . . . . 16-2

17. ORGANIC STABILIZATION (MODULE ORGSB) $\ldots \ldots \ldots \ldots \ldots \ldots \ldots \ldots$

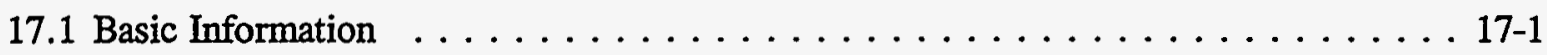

17.2 Technical Bases and Assumptions $\ldots \ldots \ldots \ldots \ldots \ldots \ldots \ldots \ldots \ldots . \ldots \ldots$

17.2.1 Function and Operation of the Module $\ldots \ldots \ldots \ldots \ldots \ldots \ldots \ldots$ 17-1

17.2.2 Integration of the Module $\ldots \ldots \ldots \ldots \ldots \ldots \ldots \ldots \ldots \ldots \ldots \ldots \ldots .17-1$

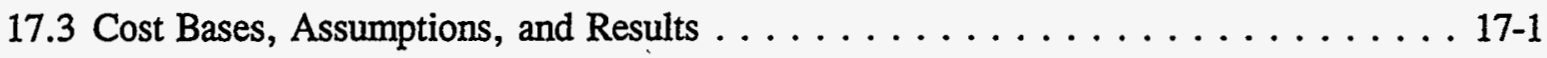

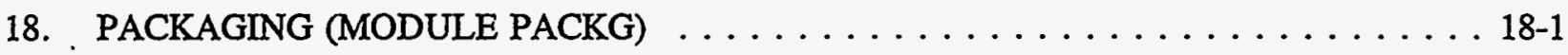

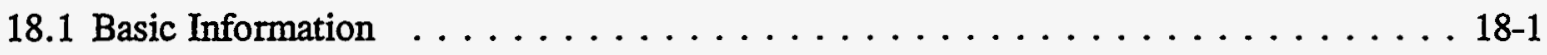

18.2 Technical Bases and Assumptions $\ldots \ldots \ldots \ldots \ldots \ldots \ldots \ldots \ldots \ldots \ldots \ldots \ldots \ldots$

18.2.1 Function and Operation of the Module $\ldots \ldots \ldots \ldots \ldots \ldots \ldots \ldots$ 18-1

18:2.2 Integration of the Module $\ldots \ldots \ldots \ldots \ldots \ldots \ldots \ldots \ldots \ldots \ldots \ldots \ldots \ldots$

18.3 Cost Bases, Assumptions, and Results . . . . . . . . . . . . . 18-1

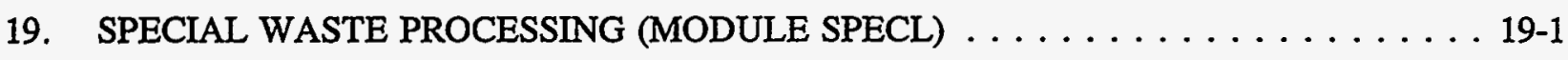

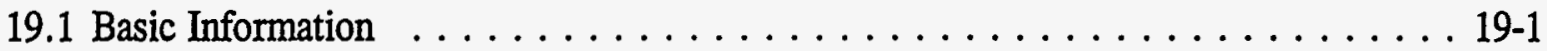

19.2 Technical Bases and Assumptions $\ldots \ldots \ldots \ldots \ldots \ldots \ldots \ldots \ldots \ldots \ldots \ldots$ 19-1

19.2.1 Function and Operation of the Module . . . . . . . . . . . . 19-1

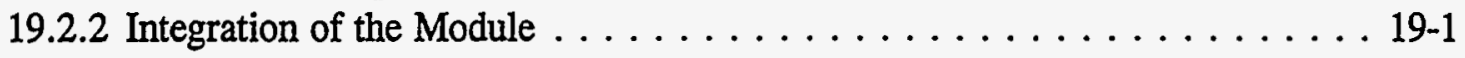

19.3 Cost Bases, Assumptions, and Results . . . . . . . . . . . . . 19-1

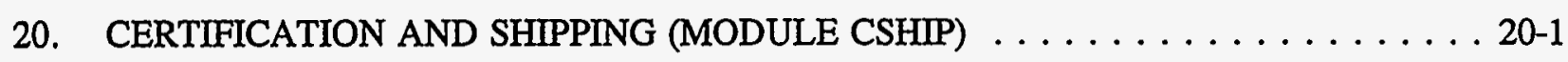

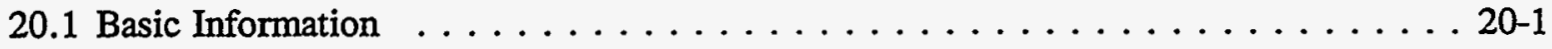

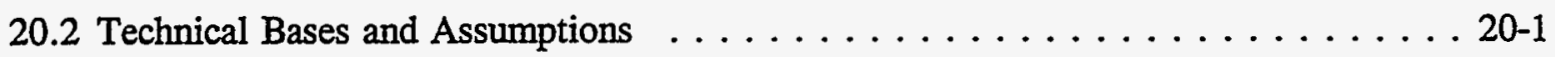

20.2.1 Function and Operation of the Fixed Module $\ldots \ldots \ldots \ldots \ldots \ldots 20-1$ 
20.2.2 Function and Operation of the Portable Module . . . . . . . . . . . 20-2

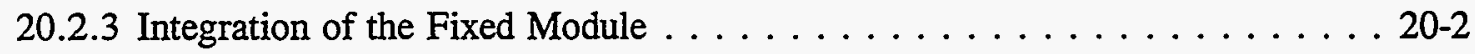

20.2.4 Integration of the Portable Module . . . . . . . . . . . 20-2

20.3 Cost Bases, Assumptions and Results . . . . . . . . . . . . . . . 20-2

20.3.1 Fixed Module . . . . . . . . . . . . . . . . . . . . 20-2

20.3.2 Portable Module . . . . . . . . . . . . . . . 20-3

21. STORAGE ADMINISTRATION (MODULE SADMN) . . . . . . . . . . . . . 21-1

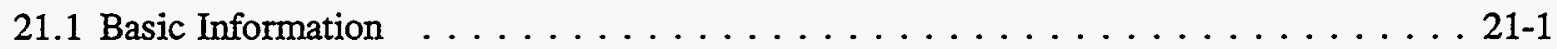

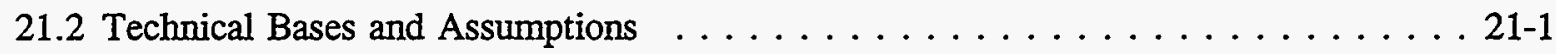

21.2.1 Function and Operation of the Module . . . . . . . . . . . . 21-1

21.2.2 Integration of the Module . . . . . . . . . . . . . . 21-1

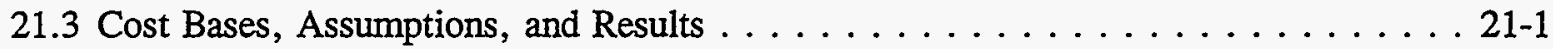

22. STORAGE RECEIVING AND SHIPPING (MODULE SRCSH) $\ldots \ldots \ldots \ldots$

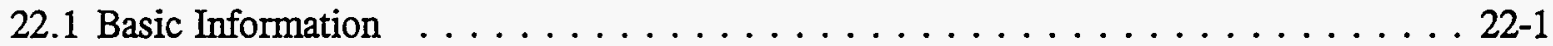

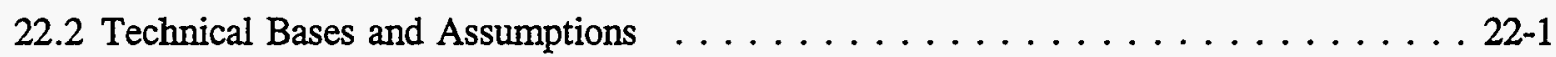

22.2.1 Function and Operation of the Module . . . . . . . . . . . . 22-1

22.2 .2 Integration of the Module . . . . . . . . . . . . . . 22-1

22.3 Cost Bases, Assumptions, and Results . . . . . . . . . . . . . 22-1

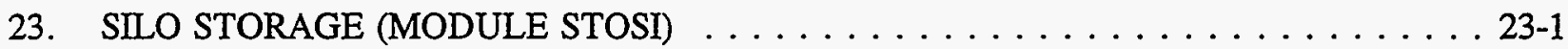

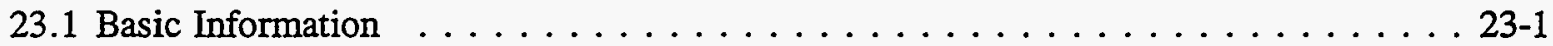

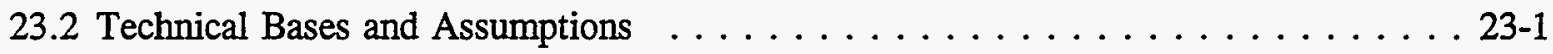

23.2.1 Function and Operation of the Module . . . . . . . . . . . . 23-1

23.2.2 Integration of the Module . . . . . . . . . . . . 23-1

23.3 Cost Bases, Assumptions and Results . . . . . . . . . . . . . 23-2

24. STORAGE (MODULE STORE) . . . . . . . . . . . . . . . . . . 24-1

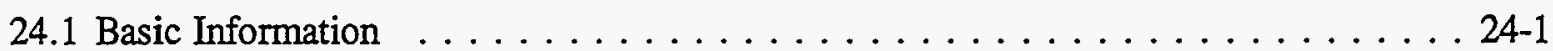




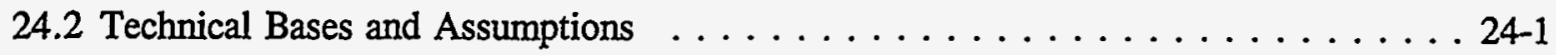

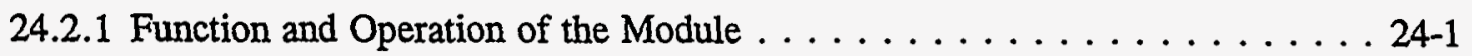

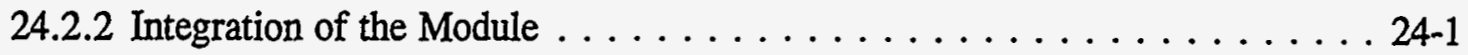

24.3 Cost Bases, Assumptions and Results $\ldots \ldots \ldots \ldots \ldots \ldots \ldots \ldots \ldots \ldots \ldots$ 24-1

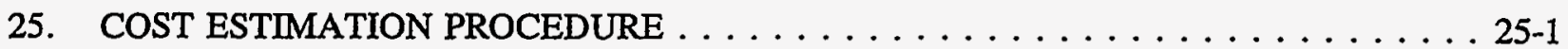

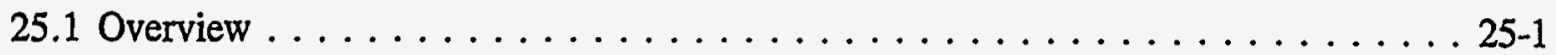

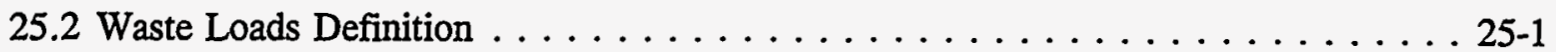

25.2.1 Retrieval, Characterization, and Interim Storage Waste Loads . . . . . . 25-2

25.2.2 Treatment Waste Loads . . . . . . . . . . . . . . . 25-3

25.2.3 Portable Treatment Waste Loads $\ldots \ldots \ldots \ldots \ldots \ldots \ldots \ldots . . \ldots \ldots . \ldots \ldots$

25.2.4 Storage Waste Loads . . . . . . . . . . . . . . . . .

25.3 Estimating Treatment Storage and Disposal Facility Cost and FTEs $\ldots \ldots \ldots .25-4$

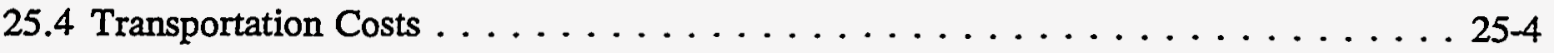

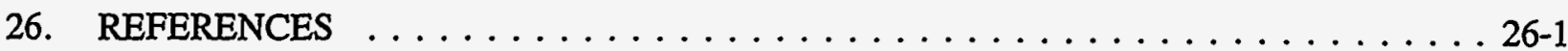

FIGURES

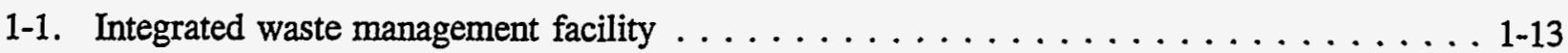

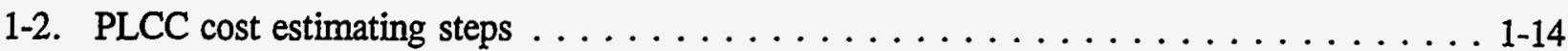

2-1. Equipment layout for the stored waste retrieval (RETRV) module $\ldots \ldots \ldots \ldots .4$

2-2. Process flow diagrams for the stored waste retrieval (RETRV) module $\ldots \ldots \ldots$ 2-5

2-3. FTE workers versus capacity for the stored waste retrieval (RETRV) module $\ldots \ldots$ 2-6

2-4. Cost versus capacity for the stored waste retrieval (RETRV) module $\ldots \ldots \ldots \ldots$ 2-7

2-5. Cost versus capacity including unit rates for the stored waste retrieval

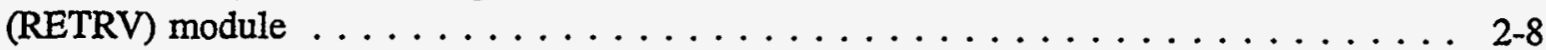

3-1. Equipment layout for the waste characterization (WCHAR) module $\ldots \ldots \ldots \ldots$ 3-3

3-2. Process flow diagram for the waste characterization (WCHAR) module $\ldots \ldots \ldots$. . .

3-3. FTE workers versus capacity for the waste characterization (WCHAR) module $\ldots \ldots$ 3-5 
3-4. Cost versus capacity for the waste characterization (WCHAR) module . . . . . . . . 3-6

3-5. Cost versus capacity including unit rates for the waste characterization

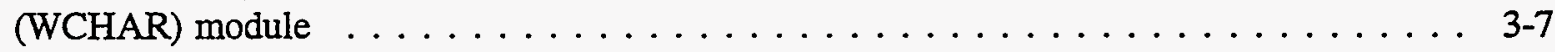

4-1. FTE workers versus capacity for the treatment administration (TADMN) module . . . . . 4-3

4-2. PLCC versus capacity for the treatment administration (TADMN) module . . . . . . . 4-4

4-3. PLCC versus capacity including unit rates for the treatment administration

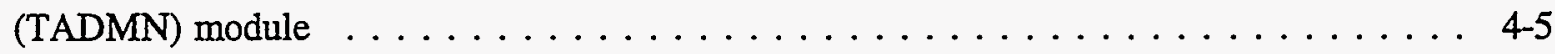

5-1. Equipment layout for the receiving and inspection (RCINS) module $\ldots \ldots \ldots$

5-2. Process flow diagram for the receiving and inspection (RCINS) module $\ldots \ldots \ldots$. . . . 5-4

5-3. FTE workers versus capacity for the receiving and inspection (RCINS) module $\ldots \ldots$. . 5-5

5-4. PLCC versus capacity for the receiving and inspection (RCINS) module $\ldots \ldots \ldots$

5-5. PLCC versus capacity including unit rates for the receiving and inspection (RCINS) module . . . . . . . . . . . . . . . . . . . . . . 5-7

6-1. Equipment layout for the open, dump, and sort (OSORT) module . . . . . . . . . . 6-3

6-2. Process flow diagram for the open, dump, and sort (OSORT) module . . . . . . . . 6-4

6-3. FTE workers versus capacity for the $\mathrm{CH}$ open, dump, and sort (T-OSORT) module . . . 6-5

6-4. FTE workers versus capacity for the RH open, dump, and sort (U-OSORT) module . . . 6-6

6-5. PLCC versus capacity for the $\mathrm{CH}$ open, dump, and sort (T-OSORT) module . . . . . . 6-7

6-6. PLCC versus capacity for the RH open, dump, and sort (U-OSORT) module . . . . . . 6-8

6-7. PLCC versus capacity including unit rates for the open, dump, and sort (OSORT) module . . . . . . . . . . . . . . . . . . . . 6 6-9

7-1. FTE workers versus capacity for the maintenance (MAINT) module $\ldots \ldots \ldots$. . . . 7-3

7-2. PLCC versus capacity for the maintenance (MAINT) module . . . . . . . . . . . 7-4

7-3. PLCC versus capacity including unit rates for the maintenance (MAINT) module . . . . 7-5

8-1. Equipment layout for the incineration (INCIN) module $\ldots \ldots \ldots \ldots \ldots$

8-2. Process flow diagram for the incineration (INCIN) module $\ldots \ldots \ldots \ldots$. . . . . $8-5$ 
8-3. FTE workers versus capacity for the $\mathrm{CH}$ incineration (T-INCIN) module $\ldots \ldots \ldots$. . . 8-6

8-4. FTE workers versus capacity for the RH incineration (U-INCIN) module . . . . . . . . 8-7

8-5. PLCC versus capacity for the $\mathrm{CH}$ incineration (T-INCIN) module . . . . . . . . . 8 8-8

8-6. PLCC versus capacity for the $\mathrm{RH}$ incineration (U-INCIN) module $\ldots \ldots \ldots$. . . . . 8 8-9

8-7. PLCC versus capacity including unit rates for the incineration (INCLN) module $\ldots \ldots$. . 8-10

9-1. Equipment layout for the deactivation (DEACT) module . . . . . . . . . . . . 9-4

9-2. Process flow diagram for the deactivation (DEACT) module $\ldots \ldots \ldots \ldots \ldots$. . . . . $9-5$

10-1. Equipment layout for the neutralization (NEUTR) module . . . . . . . . . . . . 10-3

10-2. Process flow diagram for the neutralization (NEUTR) module $\ldots \ldots \ldots \ldots \ldots$

10-3. FTE workers versus capacity for the $\mathrm{CH}$ neutralization (T-NEUTR) module $\ldots \ldots \ldots$ 10-5

10-4. FTE workers versus capacity for the RH neutralization (U-NEUTR) module $\ldots \ldots \ldots$. . . 10-6

10-5. PLCC versus capacity for the CH neutralization (T-NEUTR) module . . . . . . . . . . 10-7

10-6. PLCC versus capacity for the RH neutralization (U-NEUTR) module $\ldots \ldots \ldots$. . . 10-8

10-7. PLCC versus capacity including unit rates for the neutralization (NEUTR) module . . . . 10-9

11-1. Equipment layout for the lead recovery (PBRCR) module $\ldots \ldots \ldots \ldots \ldots$. . . . . . . 11-4

11-2. Process flow diagram for the lead recovery (PBRCR) module $\ldots \ldots \ldots \ldots \ldots$

11-3. FTE workers versus capacity for the $\mathrm{CH}$ lead recovery (T-PBRCR) module $\ldots \ldots \ldots$ 11-6

11-4. FTE workers versus capacity for the RH lead recovery (U-PBRCR) module $\ldots \ldots \ldots$ 11-7

11-5. PLCC versus capacity for the $\mathrm{CH}$ lead recovery (T-PBRCR) module $\ldots \ldots \ldots \ldots$

11-6. PLCC versus capacity for the RH lead recovery (U-PBRCR) module . . . . . . . . . . . 11-9

11-7. PLCC versus capacity including unit rates for the lead recovery (PBRCR) module $\ldots$ 11-10

12-1. Equipment layout for the mercury separation (RMERC) module . . . . . . . . . . . . . 12-4

12-2. Process flow diagram for the mercury separation (RMERC) module $\ldots \ldots \ldots \ldots$

12-3. FTE workers versus capacity for the $\mathrm{CH}$ mercury separation (T-RMERC) module $\ldots . .12-6$ 
12-4. FTE workers versus capacity for the RH mercury separation (U-RMERC) module . . . . 12-7

12-5. PLCC versus capacity for the $\mathrm{CH}$ mercury separation (T-RMERC) module . . . . . . . 12-8

12-6. PLCC versus capacity for the RH mercury separation (U-RMERC) module . . . . . . . 12-9

12-7. PLCC versus capacity including unit rates for the mercury separation (RMERC) module . . . . . . . . . . . . . . . . . . . . . . . . 12-10

13-1. Equipment layout for the shredding and compaction (CMPCT) module . . . . . . . . 13-3

13-2. Process flow diagram for the shredding and compaction (CMPCT) module $\ldots \ldots$. . . 13-4

13-3. FTE workers versus capacity for the $\mathrm{CH}$ shredding and compaction

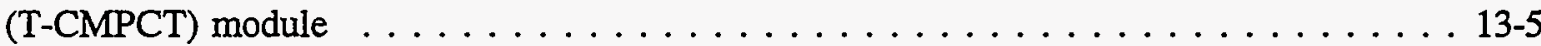

13-4. FTE workers versus capacity for the RH shredding and compaction

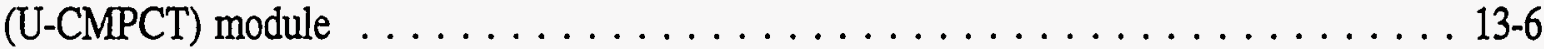

13-5. PLCC versus capacity for the $\mathrm{CH}$ shredding and compaction (T-CMPCT) module $\ldots \ldots$. 13-7

13-6. PLCC versus capacity for the RH shredding and compaction (U-CMPCT) module $\ldots . .13-8$

13-7. PLCC versus capacity including unit rates for the shredding and compaction (CMPCT) module . . . . . . . . . . . . . . . . . . . . . . . . . . . . . . . .

14-1. Equipment layout for the aqueous waste treatment (AQWTR) module $\ldots \ldots \ldots$. . . . 14-4

14-2. Process flow diagram for the aqueous waste treatment (AQWTR) module $\ldots \ldots \ldots$. . . $\ldots$ 14-5

14-3. FTE workers versus capacity for the $\mathrm{CH}$ aqueous waste treatment (T-AQWTR) module . . . . . . . . . . . . . . . . . . . . . 14-7

14-4. FTE workers versus capacity for the $\mathrm{RH}$ aqueous waste treatment (U-AQWTR) module . . . . . . . . . . . . . . . . . . 14-8

14-5. PLCC versus capacity for the $\mathrm{CH}$ aqueous waste treatment (T-AQWTR) module . . . . 14-9 14-6. PLCC versus capacity for the RH aqueous waste treatment (U-AQWTR) module . . . . 14-10

14-7. PLCC versus capacity including unit rates for the aqueous waste treatment (AQWTR)

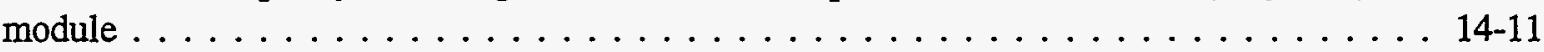

15-1. Equipment layout for the grout stabilization (GROUT) module . . . . . . . . . . . 15-3

15-2. Process flow diagram for the grout stabilization (GROUT) module $\ldots \ldots \ldots$. . . . . 15-4

15-3. FTE workers versus capacity for the $\mathrm{CH}$ grout stabilization (T-GROUT) module $\ldots \ldots$ 15-5 
15-4. FTE workers versus capacity for the RH grout stabilization (U-GROUT) module . . . . 15-6

15-5. PLCC versus capacity for the $\mathrm{CH}$ grout stabilization (T-GROUT) module $\ldots \ldots \ldots \ldots$ 15-7

15-6. PLCC versus capacity for the RH grout stabilization (U-GROUT) module $\ldots \ldots \ldots \ldots$ 15-8

15-7. PLCC versus capacity including unit rates for the grout stabilization

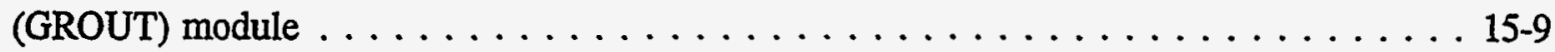

16-1. Equipment layout for the vitrification (VITRF) module $\ldots \ldots \ldots \ldots \ldots \ldots \ldots$ 16-3

16-2. Process flow diagram for the vitrification (VITRF) module $\ldots \ldots \ldots \ldots \ldots \ldots$ 16-4

16-3. FTE workers versus capacity for the $\mathrm{CH}$ vitrification (T-VITRF) module $\ldots \ldots \ldots$ 16-5

16-4. FTE workers versus capacity for the RH vitrification (U-VITRF) module $\ldots \ldots \ldots$ 16-6

16-5. PLCC versus capacity for the $\mathrm{CH}$ vitrification (T-VITRF) module $\ldots \ldots \ldots \ldots$ 16-7

16-6. PLCC versus capacity for the RH vitrification (U-VITRF) module $\ldots \ldots \ldots \ldots \ldots$ 16-8

16-7. PLCC versus capacity including unit rates for the vitrification (VITRF) module $\ldots \ldots$ 16-9

17-1. Equipment layout for the organic stabilization (ORGSB) module $\ldots \ldots \ldots \ldots \ldots$ 17-2

17-2. Process flow diagram for the organic stabilization (ORGSB) module $\ldots \ldots \ldots \ldots$ 17-3

17-3. FTE versus workers capacity for the organic stabilization (ORGSB) module $\ldots \ldots \ldots$ 17-4

17-4. PLCC versus capacity for the organic stabilization (ORGSB) module $\ldots \ldots \ldots \ldots$ 17-5

17-5. PLCC versus capacity including unit rates for the organic stabilization

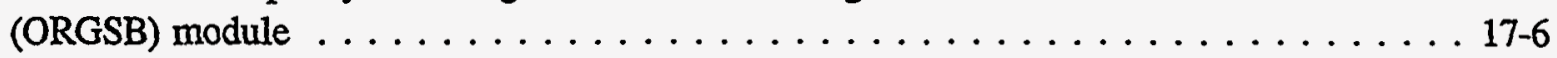

18-1. Equipment layout for the packaging (PACKG) module $\ldots \ldots \ldots \ldots \ldots \ldots \ldots$ 18-2

18-2. Process flow diagram for the packaging (PACKG) module $\ldots \ldots \ldots \ldots \ldots \ldots$ 18-3

18-3. FTE workers versus capacity for the $\mathrm{CH}$ packaging (T-PACKG) module $\ldots \ldots \ldots$ 18-4

18-4. FTE workers versus capacity for the RH packaging (U-PACKG) module $\ldots \ldots \ldots$ 18-5

18-5. PLCC versus capacity for the $\mathrm{CH}$ packaging (T-PACKG) module $\ldots \ldots \ldots \ldots \ldots$ 18-6

18-6. PLCC versus capacity for the $\mathrm{RH}$ packaging (U-PACKG) module $\ldots \ldots \ldots \ldots \ldots$ 18-7

18-7. PLCC versus capacity including unit rates for the packaging (PACKG) module $\ldots \ldots \ldots$ 18-8 
19-1. Equipment layout for the special waste processing (SPECL) module . . . . . . . . . 19-2

19-2. Process flow diagram for the special waste processing (SPECL) module . . . . . . . . 19-3

19-3. FTE workers versus capacity for the $\mathrm{CH}$ special waste processing

(T-SPECL) module . . . . . . . . . . . . . . . . . . . . 19-4

19-4. FTE workers versus capacity for the RH special waste processing

(U-SPECL) module

19-5. PLCC versus capacity for the $\mathrm{CH}$ special waste processing (T-SPECL) module . . . . . 19-6

19-6. PLCC versus capacity for the RH special waste processing (U-SPECL) module . . . . . 19-7

19-7. PLCC versus capacity including unit rates for the special waste processing (SPECL) module

20-1. Equipment layout for the fixed certification and shipping (CSHIP) module . . . . . . 20-4

20-2. Equipment layout for the portable certification and shipping (CSHIP) module $\ldots \ldots$. . 20-5

20-3. Process flow diagram for the certification and shipping (CSHIP) module . . . . . . 20-6

20-4. FTE workers versus capacity for the $\mathrm{CH}$ certification and shipping

(T-CSHIP) module

20-5. FTE workers versus capacity for the RH certification and shipping

(U-CSHIP) module . . . . . . . . . . . . . . . . . . . . . . 20-8

20-6. PLCC versus capacity for the CH certification and shipping (T-CSHIP) module . . . . . 20-9

20-7. PLCC versus capacity for the RH certification and shipping (U-CSHIP) module . . . . 20-10

20-8. PLCC versus capacity including unit rates for the certification and shipping

(CSHIP) module . . . . . . . . . . . . . . . . . . . . . . . . . 20-11

21-1. FTE workers versus capacity for the storage administration (SADMN) module $\ldots \ldots$. . 21-2

21-2. PLCC versus capacity for the storage administration (SADMN) module $\ldots \ldots \ldots$. . . 21-3

21-3. PLCC versus capacity including unit rates for the storage administration

(SADMN) module

22-1. FTE workers versus capacity for the storage receiving and shipping

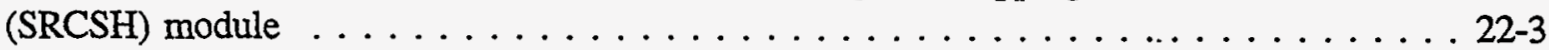

22-2. PLCC versus capacity for the storage receiving and shipping (SRCSH) module $\ldots . \ldots$. . 22-4 
22-3. PLCC versus capacity plus unit rates for the storage receiving and shipping

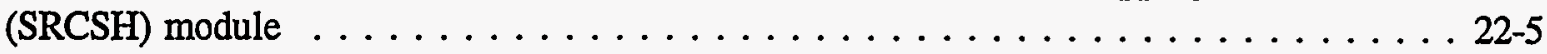

23-1. Equipment layout for the silo storage (STOSI) module . . . . . . . . . . . . . . . 23-3

23-2. Process flow diagram for the silo storage (STOSI) module $\ldots \ldots \ldots \ldots$. . . . . . . 23-4

23-3. FTE workers versus capacity for the silo storage (STOSI) $\ldots \ldots \ldots \ldots \ldots \ldots$

23-4. PLCC versus capacity for the silo storage (STOSI) module $\ldots \ldots \ldots \ldots \ldots \ldots$

23-5. PLCC versus capacity including unit rates for the silo storage (STOSI) module $\ldots . .$. 23-7

24-1. Equipment layout for the storage (STORE) module $\ldots \ldots \ldots \ldots \ldots \ldots$. . . . . . 24

24-2. FTE workers versus capacity for the storage (STORE) module . . . . . . . . . . 24-3

24-3. PLCC versus capacity for the storage (STORE) module $\ldots \ldots \ldots \ldots \ldots \ldots$. . . . . 24-4

24-4. PLCC versus capacity including unit rates for the storage (STORE) module $\ldots \ldots \ldots$. . . 24-5

25-1. Combined modules based on the WIPP WAC requirements $\ldots \ldots \ldots \ldots \ldots$

25-2. Integrated facility based on the WIPP WAC requirements $\ldots \ldots \ldots \ldots \ldots$

25-3. Integrated facility based on the $\mathrm{RCRA}$ requirements $\ldots \ldots \ldots \ldots \ldots \ldots$

25-4. Integrated facility based on a vitrified waste form $\ldots \ldots \ldots \ldots \ldots$

25-5. Retrieval, characterization, and interim storage module waste loads . . . . . . . . 25-9

25-6. Treatment waste loads $\ldots \ldots \ldots \ldots \ldots \ldots \ldots \ldots \ldots \ldots \ldots \ldots \ldots$. . . . . . . . . . . . .

\section{TABLES}

1-1. Capacity ranges of modules developed for transuranic waste $\ldots \ldots \ldots \ldots \ldots \ldots$. . . . . . .

1-2. Sample PLCC estimate summary for incineration module . . . . . . . . . . . . 1-12

4-1. Plan dimensions of treatment administration module (TADMN) $\ldots \ldots \ldots \ldots$. . . . . 4-2

7-1. Plan dimensions of maintenance module (MAINT) $\ldots \ldots \ldots \ldots \ldots \ldots \ldots$

9-1. DEACT FTEs (for both contact- and remote-handled transuranic waste) . . . . . . . 9-3

9-2. DEACT costs (for both contact- and remote-handled transuranic waste) $\ldots \ldots \ldots$. . . 9-3 
21-1. Plan dimensions of the storage administration module (SADMN) $\ldots \ldots \ldots \ldots \ldots$

22-1. Plan dimensions of storage receiving and shipping module (SRCSH) $\ldots \ldots \ldots$. . . . 22-2 


\section{ACRONYMS}

\begin{tabular}{|c|c|}
\hline AEA & Atomic Energy Act \\
\hline $\mathrm{CH}$ & contact-handled \\
\hline $\mathrm{D} \& \mathrm{D}$ & decontamination and decommissioning \\
\hline DOE & U.S. Department of Energy \\
\hline FFCA & Federal Facilities Compliance Act \\
\hline FTE & full-time equivalent \\
\hline HEPA & high-efficiency particulate air \\
\hline HVAC & heating, ventilation, and air conditioning \\
\hline INEL & Idaho National Engineering Laboratory \\
\hline MK & Morrison Knudsen Corporation, Environmental Services Division \\
\hline MLLW & mixed low-level waste \\
\hline MWIR & Mixed Waste Inventory Report \\
\hline NDE & nondestructive examination \\
\hline NEPA & National Environmental Policy Act \\
\hline O\&M & operations and maintenance \\
\hline PAN & passive/active neutron \\
\hline PEIS & Programmatic Environmental Impact Statement \\
\hline PFD & process flow diagram \\
\hline PLCC & planning level life-cycle cost \\
\hline ppm & part(s) per million \\
\hline PTM & portable treatment module \\
\hline RCRA & Resource Conservation and Recovery Act \\
\hline RF & remote-handled \\
\hline
\end{tabular}


RTR

SGS

TCLP

TDS

TOC

TRUW

TSCA

TSD

VOC

WAC

WIPP

WMFCI real-time radiography

segmented gamma scanning

toxicity characteristic leaching procedure

total dissolved solids

total organic carbon

transuranic waste

Toxic Substances Control Act

treatment, storage, and disposal

volatile organic compound

waste acceptance criteria

Waste Isolation Pilot Plant

Waste Management Facilities Cost Information 


\section{PREFACE}

This report was prepared for use in the U.S. Department of Energy Programmatic Environmental Impact Statement Project and site treatment plans in compliance with the Federal Facilities Compliance Act. This report provides a readily useable catalog of developed cost information.

This version of the report (INEL-95/0015, Rev. 1) replaces the interim report (Feizollahi and Shropshire 1994). Some of the cost information contained in the report has been updated to reflect more current estimating data. Specifically, decontamination and decommissioning costs for most of the modules have been adjusted to correspond to costs recommended to be used by Gilbert/Commonwealth, Inc. for the various types of facilities. Also, the cost and full-time equivalent curves presented in the report have been standardized to a format that is consistent with the Waste Management Facilities Cost Information Reports for Hazardous Waste, (Shropshire et al. 1995a), Low-Level Waste (Shropshire et al. 1995b) and Mixed Low-Level Waste (Shropshire et al. 1995c). Part of this standardization includes changing the operating life for the total cost and unit cost calculations from 10 years (the timeframe that was used in the interim report) to 20 years. This change results in a net decrease in the unit cost of the modules because the capital costs are now amoratized over a longer timeframe. The 20-year life cycle is more representative of life expectancy of the modules.

The method presented in this report is for planning level life-cycle cost estimates (accuracy of plus or minus $30 \%$ ). Estimates based on this report are useful for comparative evaluation of alternatives. The cost information is not site-specific, and any alternative selection based on the estimates derived from this method would warrant further study. Therefore, these estimates should not be used to determine funding requirements.

This report is organized according to distinct modules that can be assembled in various ways to create different types of treatment and storage facilities. Each module is represented by an abbreviation that is repeated throughout the discussion of the module. For the reader's convenience, these abbreviations are printed on the section tabs. 


\section{Waste Management Facilities Cost Information for Transuranic Waste}

\section{INTRODUCTION AND SUMMARY}

\subsection{Background}

This Waste Management Facilities Cost Information (WMFCI) Report is for transuranic waste (TRUW) in U.S. Department of Energy (DOE) complex waste streams that are being addressed by the DOE in the Environmental Management Programmatic Environmental Impact Statement (PEIS). The report covers treatment and storage facilities that will be needed for the management of TRUW.

This report describes the cost information for the alternatives involving treatment and storage modules needed for managing contact-handled (CH) and remote-handled (RH) TRUW. These modules are designed to be part of an integrated treatment facility. ${ }^{2}$ The cost information is for two different applications: (a) fixed facility modules using new buildings and equipment and (b) modules placed in existing buildings or transported from one site to another.

\subsection{WMFCI Task Participants}

The WMFCI task was performed by a project team from Lockheed Martin Idaho Technologies (formerly EG\&G Idaho) and the Environmental Services Division of Morrison Knudsen Corporation (MK). Lockheed Martin and MK were selected for this task because of their combined expertise in design, construction, and operation of TRUW management facilities for DOE sites and for the nuclear industry.

\subsection{Modules and Unit Operations}

For cost estimating flexibility, the TRUW facility has been divided into several distinct modules. Figure 1-1 shows the TRUW facility as a whole. The modules can be assembled in various ways to create different types of integrated TRUW facilities. In addition, each TRUW module is divided into several distinct functions, referred to as unit operations. Each unit operation consists of all buildings, equipment, and accessories needed to accomplish a given function.

The estimator must know the appropriate modules for the particular waste stream. The selection of the modules may be determined by use of the Federal Facilities Compliance Act (FFCA) Treatment Technology Selection Guide or with knowledge of the site-specific processing requirements.

Section 25 provides more information on which modules are appropriate for a specific waste matrix category.

a. Technologies used in the treatment modules presented in this report are based on commercially available equipment selected for the purpose of developing typical costs of treating various waste streams analyzed by the PEIS. This is not to be construed as adoption of a given technology for DOE installations. Others will select the technology for treating alpha and nonalpha waste stored at, or generated by, various DOE installations as part of the current DOE efforts pursuant to the Federal Facilities Compliance Act. 


\subsection{Technical and Cost Estimate Bases and Assumptions}

For larger production-oriented waste generator facilities, modules with at least three different capacities were estimated to generate a cost versus capacity curve. For small generator sites, some of the modules can be constructed to support transportation of TRUW from one site to another.

Portable modules for small generator sites are provided only for selected treatment options (see Table 1-1). Costs have been estimated for all modules indicated in the table. Modules are stationary (fixed) unless stated as portable.

Modules developed for TRUW are very similar to those developed for alpha mixed low-level radioactive waste (MLLW). The exceptions are that in developing TRUW modules, provisions have been made to reduce the risk of criticality and to control the amount of heat generated in TRUW containers. The resulting provisions are as follows:

- Reconfiguring a number of unit operations to avoid uncontrolled concentration of TRUW

- Repackaging of TRUW where necessary to control criticality risk, and to limit the heat generation rates

- Allowing additional equipment costs to account for increased material handling requirements

- $\quad$ Allocating additional operation and maintenance full-time equivalents (FTEs) to capture costs associated with the increased administrative control required for TRUW.

The life-cycle cost of the modules are based on three shift operations, and 4,032 operating hours per year. To estimate the life-cycle cost of a module operating other than three shifts per year, the operation and maintenance costs must be prorated. All other costs will remain unchanged.

\subsubsection{General Assumptions for Fixed Facilities}

Facility construction and ownership. It is assumed that all facility equipment will be new and placed within totally new structures. Site development costs such as utilities and road work are included only to within $30 \mathrm{~m}$ (100 ft) of the facility. Site infrastructure costs are not included. All facilities are assumed to be government owned and contractor operated.

Throughput. For large generator facilities, a broad capacity range is selected to cover the requirements of the PEIS alternatives. Module throughput range is shown in Table 1-1.

Modular facility. The planning level life-cycle cost (PLCC) estimates in the WMFCI reports are based on a set of facility modules; each module may be used alone or in combination with others.

Technology availability. Cost information in this report is based on available technologies. The basic rule employed in using the technologies is that at least one vendor must commercially offer the given technology without incurring upfront basic research and development costs. Information 
and data used in this report are based on the best available knowledge about waste processing requirements, technology availability, and cost data. The information in this report may require updating when additional information is obtained.

Cost bases. Estimates for new facility construction are based on conditions at the Idaho National Engineering Laboratory (INEL), including utility, labor, and the related design, construction, operation, and management factors. The INEL costs are considered to represent the mid-range costs within the DOE complex. Site-specific evaluations should be performed to improve the cost estimating accuracy.

Escalation rates. The PLCC estimates are developed based on 1994 dollars. The time value of money or escalation for expenditures occurring at different time frames has not been considered in the estimates. The costs have been summarized by major program elements [i.e., preoperation, construction, operations and maintenance (O\&M), and decontamination and decommissioning (D\&D) so that the user can apply appropriate escalation rates to represent the specific schedule requirements.

\subsubsection{Fixed Facility Operation Assumptions}

For large generator facilities, the PLCC estimates are based on the assumption that the operating period of the facility is 20 years. New facilities would have a total operational life of 30 years. During this period, the facility may operate a maximum of 24 hours/day, 240 days/year, and at $70 \%$ availability during operation. This is equivalent to 168 days/year or 4,032 hours/year of operation.

This report assumes that TRUW is handled only at fixed facilities. Only a characterization module using nondestructive examination (NDE) methods is available in portable design as the portable CSHIP module. This is due to the complex and therefore expensive handling techniques and equipment required for TRUW handling and treatment.

\subsubsection{Mass Flow Rate Calculations}

To facilitate variations in the waste type and quantities, all processing mass flow rates given in this report are uniformly calculated based on $45 \mathrm{~kg}(100 \mathrm{lb})$ of input waste. This information, which is presented in the process flow diagrams (PFDs), may be used to calculate the site-specific mass-flow rates. 


\subsubsection{Cost Bases}

Figure 1-2 shows a block diagram of the steps used in the estimating process. Whenever possible, the baseline capacities were selected to be the same as those of an existing facility or one estimated earlier in the WMFCI task. This approach, referred to as anchoring, ${ }^{b}$ provided a reference point that could be used as the basis for estimating the various cost elements. Furthermore, anchoring provides a comparison of the estimates in this report with either the actual costs incurred by an operating facility or estimates of facilities that are in an advanced state of design and construction. Data from the study were based on "bottom-up" cost estimates of three different facility sizes: small, medium, and large. Whenever possible, the baseline capacities are the same as at an existing facility.

Using the given capacities, a preconceptual design package for each facility is used as the basis for the PLCC estimates. Each preconceptual design package includes a PFD with mass flow rates, a layout, and a summary of functional and operational requirements. The PFD and layout drawings identify necessary unit operations. After unit operations are defined, major equipment lists and building configurations are shown for each of these operations. The design packages are based as much as possible on data from existing or planned commercial and DOE (anchor) facilities. New designs were generated only when existing data were not available.

The PLCC estimate for each facility was divided into six elements (see Figure 1-2). Costs for the first and second elements (studies and bench-scale tests, and demonstration) were obtained by estimating research manpower and equipment needs.

The third cost element (facility construction) consists of two key subelements: major equipment costs and building costs. Cost estimates for major equipment were obtained either from a similar facility or an anchor facility, by soliciting costs from the suppliers, or by making engineering judgments. Building costs were estimated either by multiplying building unit costs by the square footage allocated to each unit operation in the layouts, or by developing building material and labor requirements and multiplying them by the appropriate unit rates.

Once the equipment and building costs were estimated for each facility, they were totalled and multiplied by a factor to allow for the construction contractor's indirect costs. The sum of the equipment, building, and indirect costs were then multiplied by applicable factors to allow for design, inspection, construction management, and project management costs. Allowances were also included for management reserve and contingencies.

The fourth cost element (operation-budget-funded activities) includes conceptual design, safety assurance, National Environmental Policy Act (NEPA) compliance efforts, permitting, preparation for

b. In this report, the term anchor facility denotes reference facilities that are either operating or are in advanced stages of design and construction. Anchoring denotes using technical data and capital, operating, and maintenance costs incurred by an anchor facility as a yardstick in the development of the PLCC estimates.

Before comparing costs from an anchor facility, they were adjusted to account for any differences in technical requirements and cost escalation. The manual Construction Cost Trends, published by the Bureau of Reclamation, U.S. Department of Interior, was used as the basis for escalation data. 
operation, and project management costs. ${ }^{c}$ All other subelements of the cost of operation-budgetfunded activities were estimated as a percentage of the construction cost.

The fifth cost element (O\&M) consists of four subelements: operating labor, utilities, consumable materials, and maintenance (parts, equipment, and labor). The first three subelements were estimated by analyzing the requirements of each facility at the unit-operations level. The maintenance costs were estimated as a percentage of the original equipment installed at the facility. Allowances were also included for management reserve and contingencies.

The sixth cost element (D\&D at facility closure) was estimated by multiplying a D\&D unit rate by the facility square footage.

The total facility PLCC estimates were obtained by taking the sum of the six cost elements.

Cost estimating backup data for the modules are provided in Shropshire et al. $1995 .^{\text {d }}$

1.4.4.1 Cost Curve Development Approach. For large generator facilities, unique parametric cost equations were developed for the preoperations, facility construction, O\&M, and D\&D cost elements of each module. These equations were developed based on the baseline WMFCI bottom-up estimates regressed over a range of facility capacities for each cost module. There are approximately 400 equations that describe CH-TRUW and RH-TRUW costs and FTEs.

Linear and nonlinear approaches were used to provide the best cost curves. The curves were developed to represent the full range of facility costs over the estimated capacity range. Costs should not be extrapolated for facilities outside the defined range of capacities without a careful analysis of the specific application.

1.4.4.2 Cost Curve Applications. Cost curves have been provided for the majority of cost modules to describe the major manpower (FTE) components, cost elements, total life-cycle costs, and total life-cycle unit costs. Separate FTE and cost curves are provided for alpha and nonalpha facilities (as applicable). ${ }^{c}$

As many as five FTE and cost figures may be presented for each module, as follows:

1. Full-time equivalent workers versus capacity for CH-TRUW

2. Planning level life-cycle cost versus capacity for CH-TRUW

c. Please note that NEPA costs of $\$ 6$ million are included in only the receiving and inspection module (RCINS) for the large facility cost estimates.

d. Shropshire, D., M. Sherick, and C. Biagi, 1995, Waste Management Facilities Cost Information Estimating Data for Transuranic Waste, INEL-95/0297, in preparation.

e. Separate cost figures are only provided for RH-TRUW when there is a significant difference in FTEs or cost for CH- and RH-TRUW. When no significant difference is noted, the cost figures are combined for $\mathrm{CH}$ and RH TRUW. 
3. Full-time equivalent workers versus capacity for RH-TRUW (as applicable)

4. Planning level life-cycle cost versus capacity for RH-TRUW (as applicable)

5. Planning level life-cycle cost versus capacity including unit rates for $\mathrm{CH}$ - and RH-TRUW.

The curves in the first four of these figures were developed to represent only the major FTE and cost elements. These cost figures can be used to derive the four primary costs required to estimate the individual module costs. The six estimated cost elements listed in Section 1.4.4 were simplified and reduced to four cost elements. These four elements and the manner in which they were combined are described below:

1. Preoperations. The preoperations cost element includes the first (studies and bench-scale test), second (demonstration), and fourth (operation-budget-funded activities) cost elements described in Section 1.4.4. These cost elements were combined because the first and second cost elements are relatively small and would be completed on or about the same schedule as the fourth cost element. Graphically, the small FTE and cost values for the first and second cost elements do not fall on a common scale with the other cost elements.

2. Facility construction. The facility construction cost element is identical to the third cost element in Section 1.4.4 (facility construction). This cost element requires capital equipment and line item funding.

3. Operations and maintenance. The operations and maintenance cost element is equivalent to the fifth cost element in Section 1.4.4. The cost and FTE figures are based on one year of O\&M. The estimator may need to multiply the number of FTEs or costs from the curves by the appropriate number of years of O\&M to derive a specific estimate.

4. Decontamination and decommissioning. The D\&D costs are identical to the sixth cost element in Section 1.4.4.

These four cost elements should be used to determine the required module costs. Existing facility costs would only require the $O \& M$ and $D \& D$ costs. New facilities will include all preoperation, facility construction and equipment, O\&M, and D\&D costs. The O\&M costs can be factored from the cost curves to obtain operating costs for periods other than one year.

The fifth cost figure (PLCC estimates versus capacity including unit rates for CH-TRUW and RH-TRUW) provides the total life-cycle cost curve including preoperation, facility construction, operations and maintenance, and decontamination and decommissioning. The total life-cycle unit cost curve is also provided in Metric (e.g., $\$ / \mathrm{kg}, \$ / \mathrm{m}^{3}$ ) and English (e.g., $\$ / \mathrm{lb}, \$ / \mathrm{ft}^{3}$ ) units for maximum utility. These summary level curves should only be used when the operation and maintenance period of 20 years is required.

The capacity units of measure for the WMFCI modules have been provided in terms of processing rates $\left(\mathrm{kg} / \mathrm{hr}, \mathrm{m}^{3} / \mathrm{hr}\right)$ for front-end, treatment, and back-end support modules. The capacity units of measure for the storage modules have been provided in terms of total capacity (total $\mathrm{m}^{3}$ ). Table 1-2 shows an example of a module cost estimate data sheet. This table illustrates the major 
Work Breakdown Structure cost elements including the simplified version (reduction from six to four cost elements).

\subsubsection{Portable Facilities}

1.4.5.1 General Assumptions. The portable facility will consist of one or more trailermounted characterization modules that can be dispatched to the DOE laboratory installations to treat their waste.

Facility and waste type. The portable small-sized facility is designed to characterize minimal quantities of waste generated at DOE laboratory installations. The portable receiving and inspection module is most suitable for treating waste streams that are not generated on a regular basis. It can also be used to augment available treatment processes. Portable treatment processes were considered only for certain processes because of inherent technical difficulties in licensing and decontaminating portable treatment modules (PTMs).

Facility construction and ownership. The PTMs consist of equipment mounted in enclosed 8- by 40 -ft trailers. These modules will be stored at a central location and moved to a DOE installation to treat stored waste. Once on site, PTMs will be set up on existing pads that are equipped with secondary containment. It is assumed that the PTMs will be government owned and contractor operated.

Throughput. Portable treatment modules are used on a campaign basis. Campaigns are planned activities necessary to treat an accumulated quantity set at $2.5 \mathrm{~m}^{3}\left(88.3 \mathrm{ft}^{3}\right)$ of waste. It is estimated that each campaign will require a total of 14 days to transport, mobilize, set up, process the waste, decontaminate, disassemble, and demobilize. Each PTM is assumed to complete 12 campaigns per year.

Mobilization and startup. The PTMs will be transported from the storage site to the desired DOE installation by a licensed commercial firm with drivers certified for interstate travel. The total loaded trailer weight will not exceed the legal highway weight limit of $29,500 \mathrm{~kg}(65,000 \mathrm{lb})$. Once at a treatment site, PTMs will be interconnected to form an integrated treatment facility and utilities such as service water and electrical power will be connected. Preoperational check out and safety checks will be performed to ensure operation readiness of the integrated treatment facility.

Interface availability. It is assumed that the host site will provide the space, utilities (water and electrical power), and other services (i.e., a paved operating pad with secondary containment) needed for operating the PTMs.

Decontamination. At the end of each campaign, the module will be decontaminated by treating all waste through the facility, and completely flushing and draining each piece of equipment that has been in contact with waste. Waste generated during decontamination will be treated and disposed as required. After decontamination, the interior and exterior of PTMs will be assayed and inspected before disassembly and removal from the treatment site.

Demobilization. After decontamination, the trailers will be disassembled, all flexible lines will be disconnected, loose components will be tied down, and the trailer doors will be locked. A 
radiological survey of the trailers will be performed and the shipment certification and manifest documents will be prepared. Truck tractors will be connected to the trailers and the modules will be shipped back to their storage locations. A one-way distance of 500 miles is assumed between the treatment site and the module storage location.

Maintenance. General maintenance will be performed at the storage location on a routine basis.

1.4.5.2 Facility Operation Assumptions. All operations will be performed on a batch basis to compensate for the over-capacity of the PTMs and to accommodate differences in treatment capacity requirements at each treatment site. The PLCC estimates are based on the assumption that the operating life of all PTMs and control trailers is five years. The PTMs are assumed to complete 12 campaigns per year or 60 campaigns during the total life of the facility. Safety assurance, NEPA compliance efforts, and permitting are assumed to be part of the location activities and have not been included in the cost estimates.

1.4.5.3 Cost Estimating Methods. The general technical and cost estimate assumptions and the PLCC estimating methods used for the portable minimum modules are the same as for fixed facilities described earlier in this document. The methods for estimating the first and second elements also remain the same.

The third element (facility construction) consists of only one key subelement: major equipment. Buildings are not required since the equipment is mounted on fully enclosed trailers. Cost estimates for major equipment were obtained both from vendors that supplied PTMs and by making engineering judgments. Trailer costs were obtained from suppliers and were adjusted to account for special process requirements.

Once the equipment costs (including trailers) were estimated for each facility, they were totalled and multiplied by a factor to allow for the construction contractor's indirect costs. The sum of the equipment, trailer, and indirect costs were further multiplied by appropriate factors to allow for design, inspection, construction management, and project management costs. Allowances were also included for management reserve and contingencies.

The fourth cost element (operation-budget-funded activities) includes conceptual design, preparation for operation, and project cost. The NEPA compliance and permitting costs are not included.

The fifth cost element (O\&M) is the same as for the new, small-sized facility (except for frontend and back-end support, which is part of normal installation operation), with additional costs for transporting the trailers to and from a location, and decontaminating the module before leaving the treatment location. It is also assumed that (a) utilities are available at the installation and only tie-ins are necessary, (b) a parking pad within a secondary containment area is available, and (c) administrative support is provided by the host DOE installation.

The sixth cost element (D\&D at the end of module life) was estimated by multiplying a D\&D unit rate by the trailer's total square footage. 
The total facility PLCC estimates for the portable minimum-sized facility were obtained by adding the six elements. Campaign costs were determined based upon 12 campaigns per year for five years of operation.

\subsection{Cost Estimation Procedure}

A detailed cost estimation procedure and examples are presented in Section 25 of this report. Applying estimates in this report requires the following basic steps:

1. Define the treatment process selection based on waste stream requirements (waste type), treatment and storage requirements, final waste form, and operating parameters. Utilize integrated flow sheets containing modules. Define support module requirements.

2. Define the total capacity requirements for each module (define if new or existing facility).

3. Prepare cost estimates for each module required to provide treatment and storage for the waste stream, using the module cost curves.

4. Add the individual module costs to obtain a total waste stream cost.

5. Add transportation costs for offsite shipments to obtain the total option cost.

Estimators preparing costs for the FFCA draft site treatment plans should refer to specific FFCA cost guidance instructions and worksheets for those plans.

\subsection{Cost Assessment Activities}

To the extent possible, equipment costs for each module were compared with data from anchor facilities to establish a cost confidence level within the boundaries established for the PLCC estimates. DOE is now planning or operating similar facilities. These facilities were surveyed to obtain capacity, cost data, and other information needed to support the WMFCI data. Before using these costs, the data were adjusted to account for capacity differences and escalation.

Additional assessment activities have included a review of existing DOE facility capital and operating costs for comparison with the WMFCI. Existing DOE facilities that have been evaluated include: the Waste Experimental Reduction Facility (incineration, shredding, and compaction) at INEL, the Controlled Air Incinerator at Los Alamos National Laboratory, the Toxic Substances Control Act (TSCA) incinerator at Oak Ridge National Laboratory, the Supercompactor and Repackaging Facility at Rocky Flats, the Radioactive Waste Management Complex (low-level radioactive waste disposal) at INEL, and the Transportable Waste Water Treatment Unit from the Uranium Mill Tailings Remedial Action Project. Planned DOE facility costs at INEL were also evaluated for the Radioactive Waste Storage Facility, the Waste Characterization Facility, the Idaho Waste Processing Facility, and the Mixed Low-Level Waste Treatment Facility.

Other facilities evaluated include: the Illinois Compact Low-Level Waste Engineered Disposal facility, and the Commonwealth of Massachusetts Low-Level Radioactive Waste Disposal. 


\subsection{Limitations}

This section and Appendix A of the WMFCI report (Feizollahi and Shropshire 1992) can be consulted regarding limitations and qualifications that apply to development of PLCC estimates. To apply cost data from this report, the reader must ensure that the front-end and back-end support module and any linked treatment modules (e.g., stabilization and aqueous waste treatment modules required for secondary waste) are currently available at the installation. If not available, the PLCC estimates for a new module, as presented in this report, must be incorporated in the overall facility estimates. When using existing facilities, the appropriate operating and maintenance costs must be added to the overall facility costs. 
Table 1-1. Capacity ranges of modules developed for transuranic waste.

\begin{tabular}{|c|c|c|c|c|}
\hline & & $\begin{array}{c}\text { Contact- } \\
(T\end{array}$ & waste & $\begin{array}{l}\text { Remote-handled waste } \\
\text { (U modules) }\end{array}$ \\
\hline Module name & $\begin{array}{c}\text { Module } \\
\text { abbreviation }\end{array}$ & Portable & Fixed & Fixed \\
\hline
\end{tabular}

Treatment front-end common functions

Stored waste retrieval

Waste characterization

Treatment administration

Receiving and inspection

Open, dump, and sort

Maintenance

Primary treatment

Incineration

Deactivation

Neutralization

Lead recovery

Mercury separation

Shredding and compaction

Aqueous waste treatment

Special waste processing

Secondary treatment and stabilization

Grout stabilization

Vitrification

Organic stabilization

Packaging

Treatment back-end common functions

Certification and shipping

$\begin{array}{llrr}\text { RETRV } & - & 68-204 \mathrm{~kg} / \mathrm{hr} & 68-204 \mathrm{~kg} / \mathrm{hr} \\ \text { WCHAR } & - & 91-181 \mathrm{~kg} / \mathrm{hr} & 91-181 \mathrm{~kg} / \mathrm{hr} \\ \text { TADMN } & - & 91-5,670 \mathrm{~kg} / \mathrm{hr} & 91-5,670 \mathrm{~kg} / \mathrm{hr} \\ \text { RCINS } & - & 680-5,670 \mathrm{~kg} / \mathrm{hr} & 680-5,670 \mathrm{~kg} / \mathrm{hr} \\ \text { OSORT } & - & 408-5,670 \mathrm{~kg} / \mathrm{hr} & 408-5,670 \mathrm{~kg} / \mathrm{hr} \\ \text { MAINT } & - & 204-8,255 \mathrm{~kg} / \mathrm{hr} & 204-8,255 \mathrm{~kg} / \mathrm{hr}\end{array}$

\begin{tabular}{llrr} 
INCIN & - & $45-907 \mathrm{~kg} / \mathrm{hr}$ & \multicolumn{1}{c}{$45-907 \mathrm{~kg} / \mathrm{hr}$} \\
DEACT & - & - & - \\
NEUTR & - & $39-1,179 \mathrm{~kg} / \mathrm{hr}$ & $39-1,179 \mathrm{~kg} / \mathrm{hr}$ \\
PBRCR & - & $27-91 \mathrm{~kg} / \mathrm{hr}$ & $27-91 \mathrm{~kg} / \mathrm{hr}$ \\
RMERC & - & $27-91 \mathrm{~kg} / \mathrm{hr}$ & $27-91 \mathrm{~kg} / \mathrm{hr}$ \\
CMPCT & - & $136-1,814 \mathrm{~kg} / \mathrm{hr}$ & $136-1,814 \mathrm{~kg} / \mathrm{hr}$ \\
AQWTR & - & $45-1,361 \mathrm{~kg} / \mathrm{hr}$ & $45-1,361 \mathrm{~kg} / \mathrm{hr}$ \\
SPECL & - & $14-113 \mathrm{~kg} / \mathrm{hr}$ & $14-113 \mathrm{~kg} / \mathrm{hr}$
\end{tabular}

Storage

Storage administration ${ }^{2}$

Storage receiving and shipping ${ }^{2}$

Silo storage $e^{2, b}$

Storage ${ }^{2, b}$

$\begin{array}{llrr}\text { GROUT } & - & 181-1,814 \mathrm{~kg} / \mathrm{hr} & 181-1,814 \mathrm{~kg} / \mathrm{hr} \\ \text { VITRF } & - & 18-454 \mathrm{~kg} / \mathrm{hr} & 18-454 \mathrm{~kg} / \mathrm{hr} \\ \text { ORGSB } & - & 0-9 \mathrm{~kg} / \mathrm{hr} & 0-9 \mathrm{~kg} / \mathrm{hr} \\ \text { PACKG } & - & 77-3,629 \mathrm{~kg} / \mathrm{hr} & 77-3,629 \mathrm{~kg} / \mathrm{hr}\end{array}$

CSHIP $\quad 18 \mathrm{~kg} / \mathrm{hr} \quad 204-8,255 \mathrm{~kg} / \mathrm{hr} \quad 204-8,255 \mathrm{~kg} / \mathrm{hr}$

$\begin{array}{llrr}\text { SADMN } & - & 0-2 \mathrm{~m}^{3} / \mathrm{hr} & 0-2 \mathrm{~m}^{3} / \mathrm{hr} \\ \text { SRCSH } & - & 0-2 \mathrm{~m}^{3} / \mathrm{hr} & 0-2 \mathrm{~m}^{3} / \mathrm{hr} \\ \text { STOSI } & - & 46-13,474 \mathrm{~m}^{3} & 46-13,474 \mathrm{~m}^{3} \\ \text { STORE } & - & 11,419-198,688 \mathrm{~m}^{3} & -\end{array}$

a. Capacities for all four storage modules are expressed in $\mathrm{m}^{3} / \mathrm{hr}$ or $\mathrm{m}^{3}$. A density of $1,792 \mathrm{~kg} / \mathrm{m}^{3}$ was used to convert from weight to volume.

b. Capacities for storage module and silo storage module are 20-year life-cycle capacities, expressed in $\mathrm{m}^{3}$. 
Table 1-2. Sample PLCC estimate summary for incineration module.

Mocule Name: Incinerator

Option Name: Example

Waste Type:

alpha

EIW $\square$ M-TRU

Don-alpha

contact bacaled

remote haxdled

Modulo Location: Example

Module Status:

Existing

Now

On-Site

Off-Site

Small generator .

Portable $\square$ Commercial $\square$ R\&D

Referenco Capacity Requirement:

$1.81 \mathrm{~kg} / \mathrm{hr}$

$\left(\mathrm{kg} / \mathrm{hr}, \mathrm{m}^{3} / \mathrm{hr}, \mathrm{m}^{3}\right)$

WBS EIEMENT

$(s \times 1000)$

SUUB S

$(s \times 1000)$

Pro-Operations

1.1 Studies and bench seale Test Costs

1.2 Dernonstration Costs

1.3 Operations Budget Funded Activities

1.3.1 Concepual Design

1.3.2 Safety Assurance Documentation

1.3.3 Permitting

1.3.4 Preparation for Operations

1.3.5 Project Managerment

\begin{tabular}{|c|}
\hline $\begin{array}{ll}5 \quad 206 \\
5 \quad 588\end{array}$ \\
\hline 5311 \\
\hline 50 \\
\hline $\begin{array}{ll}5 \quad 0 \\
550\end{array}$ \\
\hline $\begin{array}{ll}5 & 759 \\
& 107 \\
\end{array}$ \\
\hline
\end{tabular}

TOTAI PRE-OPERATIONS

$\$ 1,971$

2.0 Facility Construction Costs

2.1 Design (Tritle I and II)

22 Inspection

2.3 Projecr Management

24 Building Construction (inci. indirect)

2.5 Equipine (inc. indiroct)

2.6 Cosssruction Management

2.7 Oiber (ive. reservo and contingency)

$\$ 1.293$

\$ 754

$\$ 1.078$

$\$ 1,843$

$\$ 4,008$

$\$ 6,767$

$\$ 5,219$

TOTAL FACIITY CONSTRUCTION COSTS

$\$ 20,962$

3.0 Operations and Maintenance

3.1 Amoual Operating Iabor

3.2 Annual Utilities

3.3 Annual Materiais

3.4 Anmal Maintenance

3.5 Arrous Other (inc. reserve and contingency)

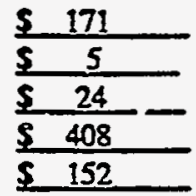

TOTAI ANBTUAI, O\&M

$X$ NOMBER OF YEARS OF OPERATION TOTAL OPERATIONS AND MAINTENANCE -

$\$ 759$

$\times 10$ years

$\$ 7,590$

4.0 Decontamination and Decommissioning

4.1 Facility D\&D

4.2 Closure, Post-Closure, Monitoring

$\$ 2,167$

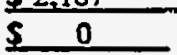

TOTAI DECONTANINATION AND DECOMMISSIONING

$\$ 2,167$

TOTAI COST FOR INCINERATOR MODULE (1994 Dollars) 


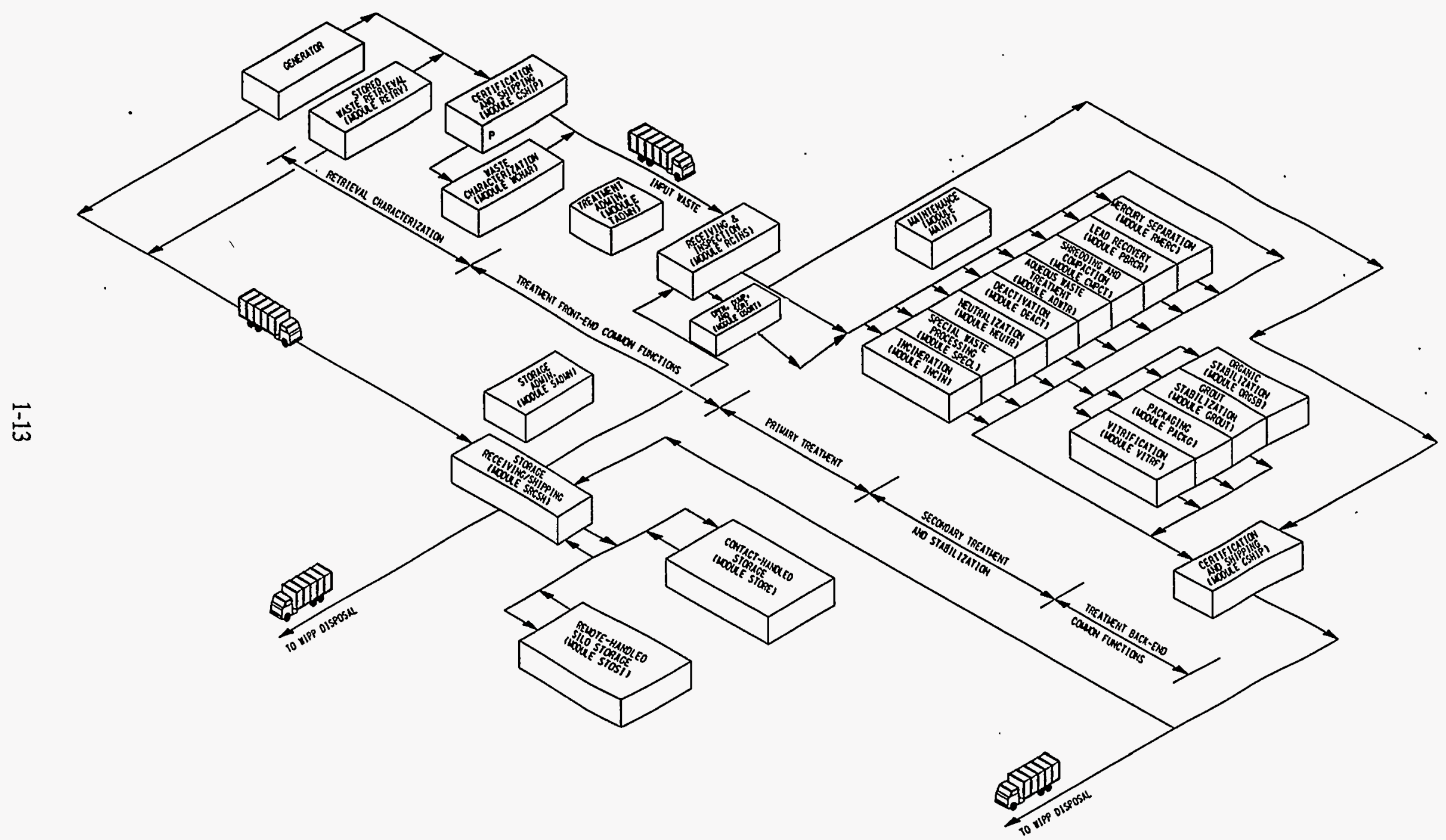

Figure 1-1. Integrated waste management facility. 


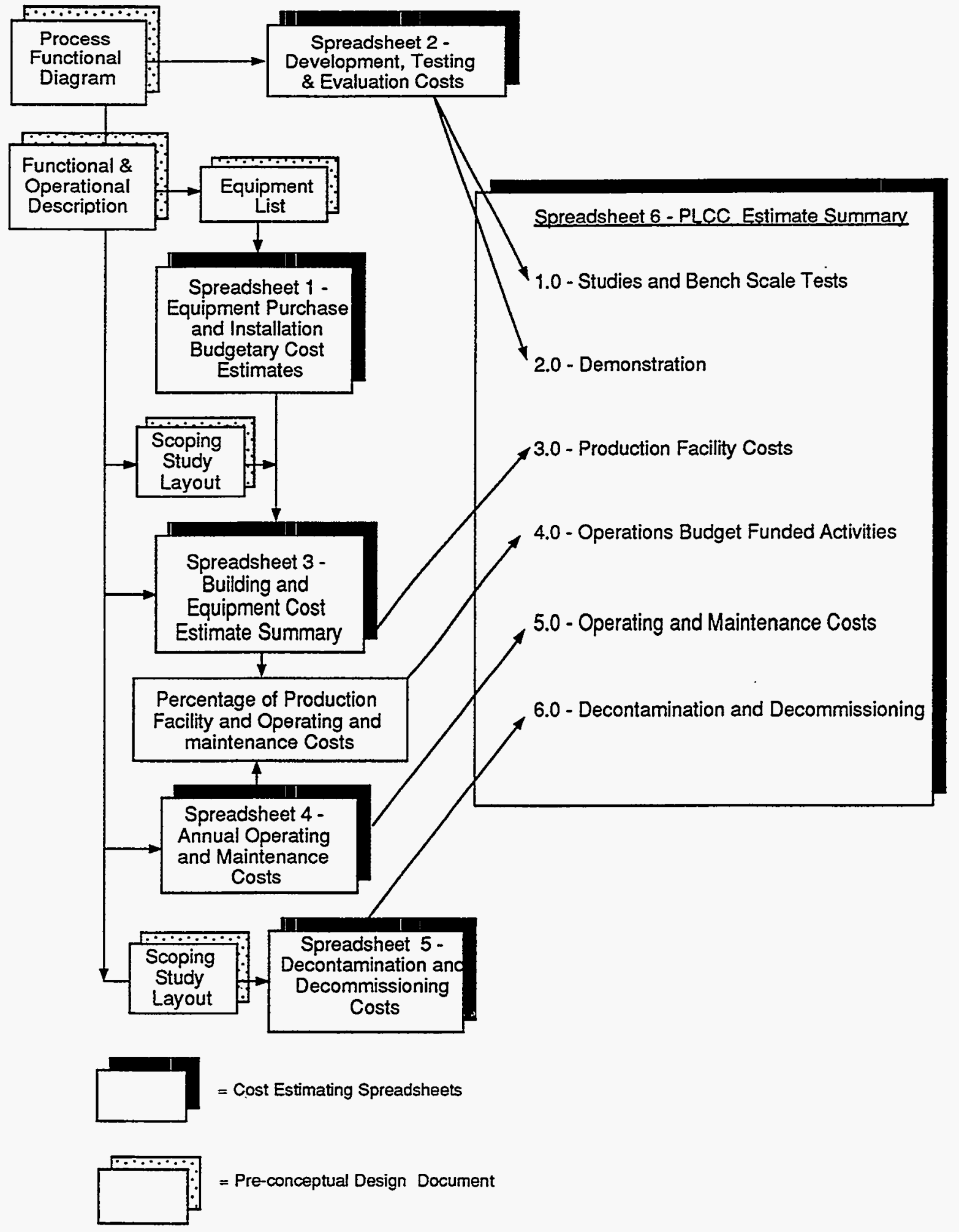

Figure 1-2. PLCC cost estimating steps. 


\section{STORED WASTE RETRIEVAL (MODULE RETRV)}

\subsection{Basic Information}

The stored waste retrieval module, shown in Figure 2-1, is used for year-round, all-weather excavation, inspection, and repackaging of TRUW stored in bermed pads (such as the Transuranic Storage Area at the INEL Radioactive Waste Management Complex). The module consists of three principal unit operations: earthen cover excavation and decontamination, waste container retrieval and inspection, and packaging and staging for shipment. Figure 2-2 shows the PFD for the RETRV module.

This module can be used in conjunction with facilities for characterizing, treating, storing and shipping waste material.

The earth-covered waste storage facility uses a multilayered protective cover, which is placed on top of waste containers stacked on an aboveground asphalt or concrete pad. It typically consists of outer earthen materials 1-2-m (3.2-6.4-ft) thick, overlying geotextile, which covers a framework of wood or metal, and plywood, metal, or fiberglass panels. The protective earthen cover is removed in an atmospherically controlled environment. Earthen material removed from around the containers is checked for contamination and sampled, if necessary. Exhumed waste containers are checked for integrity and are either overpacked or readied for shipment. All containers are identified with bar code self-adhesive labels and then loaded onto semi-truck flatbed trailers and transported out of the excavation and retrieval structure.

\subsection{Technical Bases and Assumptions}

\subsubsection{Function and Operation of the Module}

The stored waste retrieval module is a system for removing the protective earthen cover, identifying and examining the waste containers, preparing the containers for shipment, and decontaminating the area. The stored waste retrieval module consists of a modular, airtight, lightweight structure that permits year-round retrieval operations. The structure is outfitted with equipment and personnel airlocks; a remote air breathing system; a heating, ventilation, and air conditioning (HVAC) system; and a high-efficiency particulate air (HEPA) pollution system. Negative air pressure is maintained within the retrieval structure. All air is filtered and monitored for radioactive particles before release to the atmosphere. Two internal, moveable excavation aluminum shrouds are used within the stored waste retrieval module during the work activities. The internal shrouds furnish close containment of the excavation areas through a controlled air environment and provide added protection for workers and the environment.

Waste container retrieval is accomplished by first excavating all slough materials from the

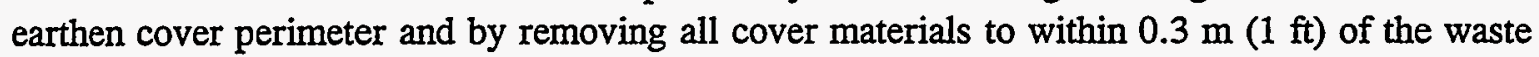
storage containers. The retrieval building is then constructed over the earthen cover area and checked for atmospheric integrity. The remaining earthen cover is excavated by a front-end loader from within the moveable internal excavation shroud. Additional cover materials, such as fiberglass or plywood sheeting, geotextile, and wood or metal support frameworks, are systematically removed and 
screened for contamination. Materials free from contamination are size-reduced for disposal or stockpiled for reuse in areas outside of the retrieval enclosure. Once the containers are exposed, interstitial earthen materials are removed by portable HEPA vacuums.

When the waste containers are completely exposed, they are removed from the storage piles with a forklift or by using the front-end loader. Once a waste container is retrieved, it is examined while being held by the retrieval equipment. All surfaces of retrieved waste containers are wipe tested for chemical and radiological contamination. The containers are cleaned to expose any identifying labels or integrity failure. Containers in satisfactory condition and meeting criteria for handling and transport are moved to a loading area or placed directly on a transport vehicle.

If a container fails to meet labeling or integrity criteria, it is inspected and assayed, and identified with a new self-adhesive vinyl bar code label. Containers requiring overpacking are placed in overpack containers at this time. Any contamination or spilled contents are sampled and packaged appropriately. Similarly, the overpack containers are identified with a bar code label and placed on the transport vehicle.

The packaged wastes, including overpacked containers, are inspected for surface contamination and transported out of the retrieval enclosure through an equipment airlock. All personnel must pass through airlocks for entry and exit. The retrieval enclosure is monitored by closed-circuit television; area alpha-, beta-, and gamma-radiation monitors; continuous air radiation monitors; and porthole radiation monitors. Each worker wears a minimum of Level B personal protective equipment with continuous remotely supplied air. Personnel exposure is monitored by fall-out coupons; chemical exposure monitors; personnel full-body alpha-, beta-, and gamma-radiation monitors; and portable frisking monitors. A trailer adjacent to the retrieval enclosure provides site access; personnel, equipment, and environmental radiation monitoring; decontamination support; and utilities control.

Excavation of earthen covers generates two types of waste: radiologically-contaminated soil and building material, and non-contaminated soil and building material. Clean soils are stockpiled to be used as fill material. Clean building materials may be recycled or size-reduced and disposed in a landfill. Contaminated materials are size-reduced within the retrieval enclosure, packaged in appropriate containers, labeled, and loaded for transport for treatment or disposal.

The waste container retrieval process itself generates four waste streams. These are comprised of contaminated personal protective equipment, sampling equipment, portable HEPA vacuum filters, and failed waste containers that cannot be overpacked. Waste produced during the container retrieval process is packaged in suitable containers, labeled, and placed on a transport vehicle within the retrieval enclosure.

The retrieval structure air filtering by the HVAC and HEPA systems produces waste consisting of spent filters and particulates. The spent filters are packaged in separate waste containers for treatment or direct disposal. The particulates are accumulated by a baghouse dust collection system and are packaged for shipment, treatment, or disposal. 


\subsubsection{Integration of the Module}

Input to the stored waste retrieval module consists of empty waste containers used for overpackaging failed containers at a waste disposal site. Output consists of retrieved waste containers, and containers of waste generated during the retrieval process. All containers are transported to either the receiving and inspection module, storage administration and storage receiving and shipping modules, or waste characterization module. Operation and maintenance consumables, such as filters and personal protective equipment, must be purchased.

\subsection{Cost Bases, Assumptions, and Results}

The stored waste retrieval module is based on a design for retrieval of TRUW at the INEL Radioactive Waste Management Complex, Transuranic Storage Area, Pad R. The waste containers are 30-, 55-, and 80-gal drums; truck-trailer cargo containers; fiberglass reinforced plywood boxes; and M-3 metal bins. All container handling is performed by electric forklifts with a variety of container handling fork-end effectors.

It was assumed that the surface radiation of $\mathrm{CH}$ containers does not exceed the dosage limits for $\mathrm{CH}$ wastes. In addition, it was assumed that the $\mathrm{RH}$ wastes are packaged in containers that limit the surface radiation to levels that can be $\mathrm{CH}$. Hence, the estimated life-cycle cost of CH-TRUW retrieval module is the same as the estimated life-cycle cost of the RH-TRUW retrieval module.

Estimates for equipment costs are based on the following: vendor quotes from Caterpillar for Caterpiller 235-class front-end, shovel excavator, and fork lift trucks; Fruehauf for the bottom hopper dump trailer; Ingersoll-Rand for hand power tools; and Eberline for personnel and radiation monitoring devices. Additional costs were obtained from INEL's design estimates; and other vendors including Atlan-Tech and 3-M. The major capital items are the excavator, HVAC, and HEPA systems and the personnel and area radiation monitoring devices.

Decontamination and decommissioning costs were estimated by assuming that all structure and equipment exposed to radiation and other hazardous materials will be surveyed for contamination and radiation levels. Contaminated materials will then be manually wiped, surfaces are vacuumed, and spray cleaned when necessary. Surfaces will then be surveyed once again to ensure that the documentation is complete. Surfaces will then be surveyed once again to ensure that the decontamination is complete. The estimated cost for D\&D is $\$ 450$ per square feet of area. Estimated FTEs and cost versus capacity are shown in Figures 2-3 through 2-5. 

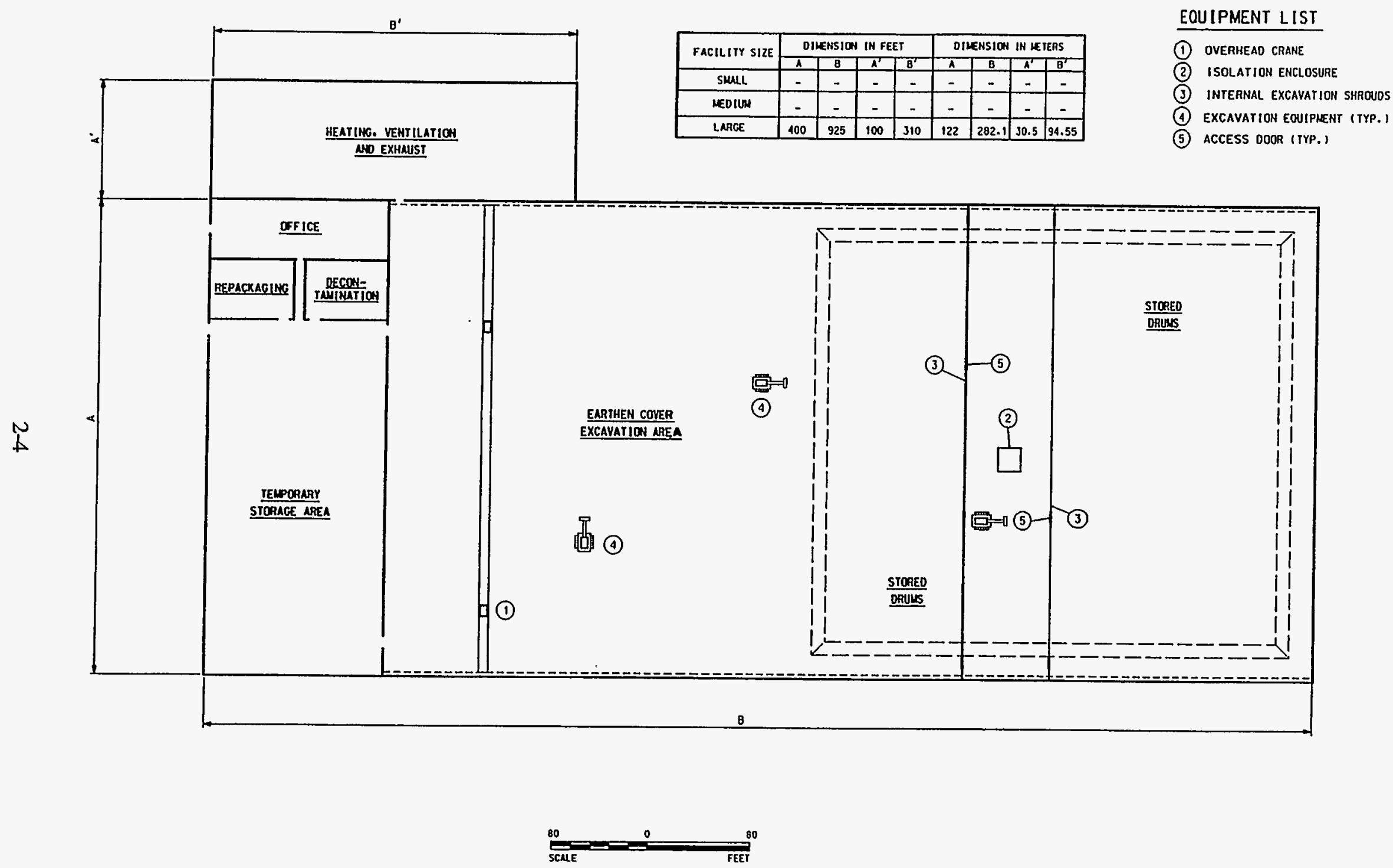

Figure 2-1. Equipment layout for the stored waste retrieval (RETRV) module. 


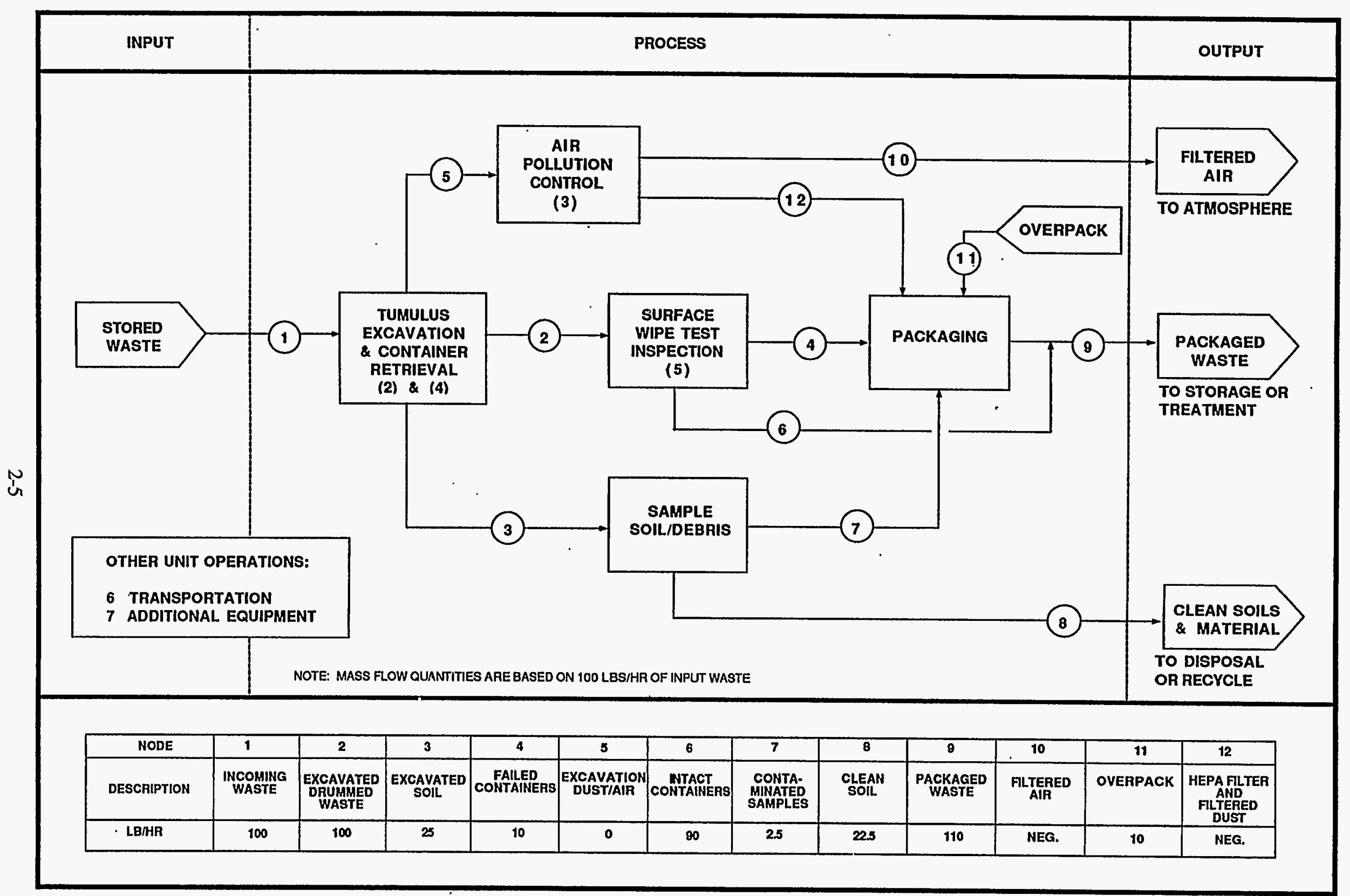

Figure 2-2. Process flow diagrams for the stored waste retrieval (RETRV) module. 


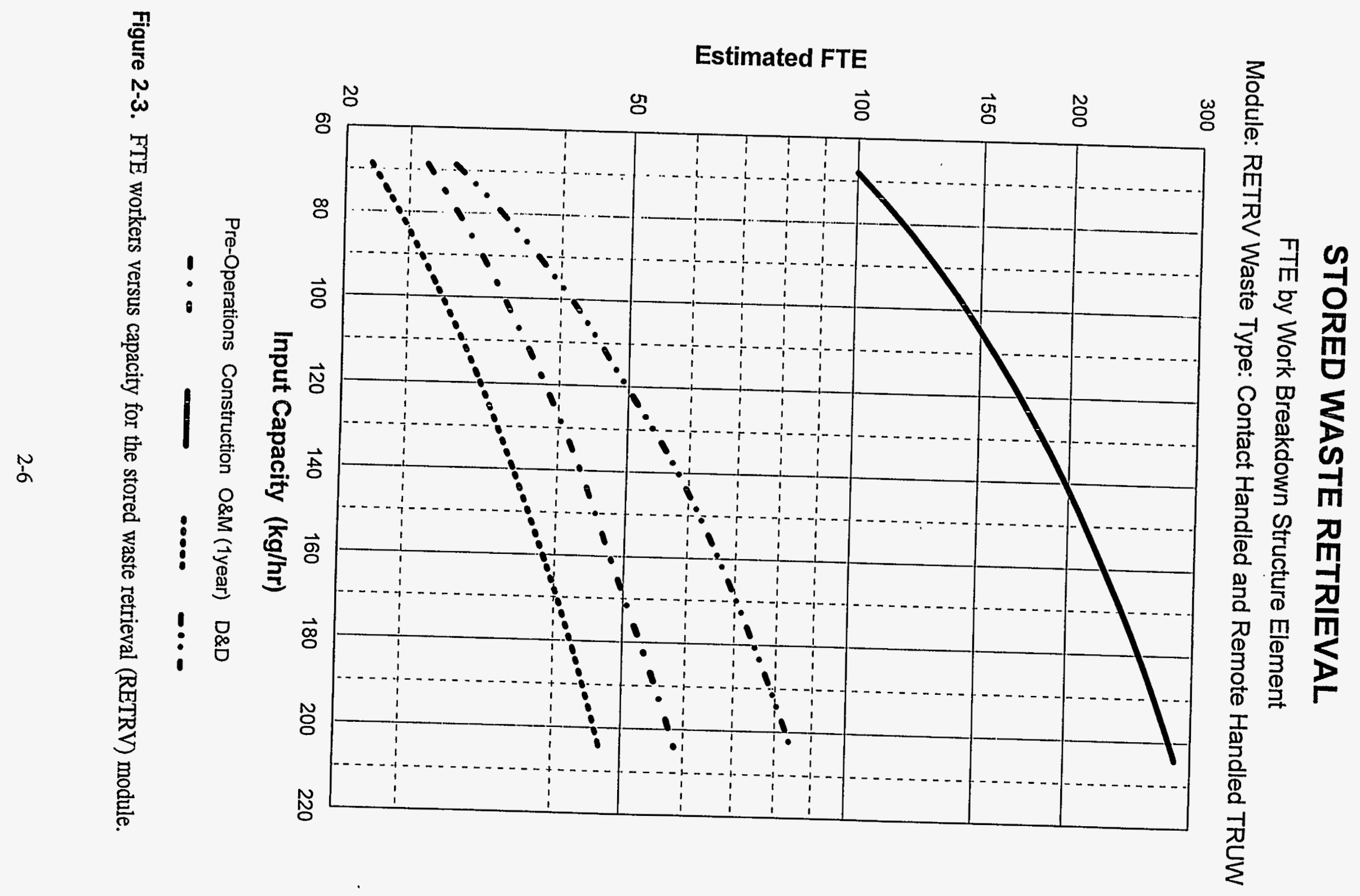




\section{STORED WASTE RETRIEVAL}

\section{Costs by Work Breakdown Structure Element}

Module: RETRV Waste Type: Contact Handled and Remote Handled TRUW

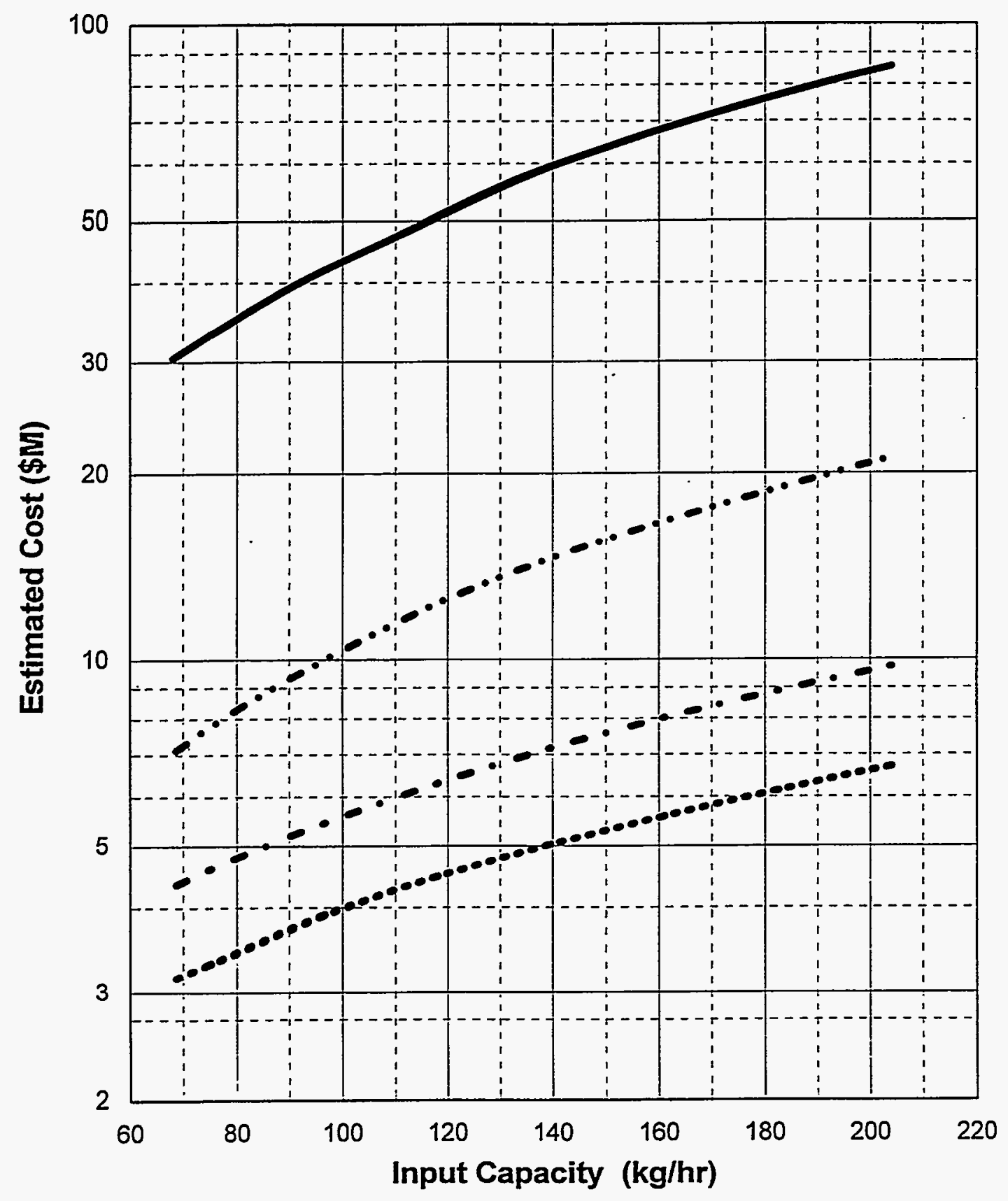

Pre-Operations Construction O\&M (1year) D\&D

Figure 2-4. Cost versus capacity for the stored waste retrieval (RETRV) module. 


\section{STORED WASTE RETRIEVAL}

\section{Total Life Cycle Costs}

Module: RETRV Waste Type: Contact Handled and Remote Handled TRUW

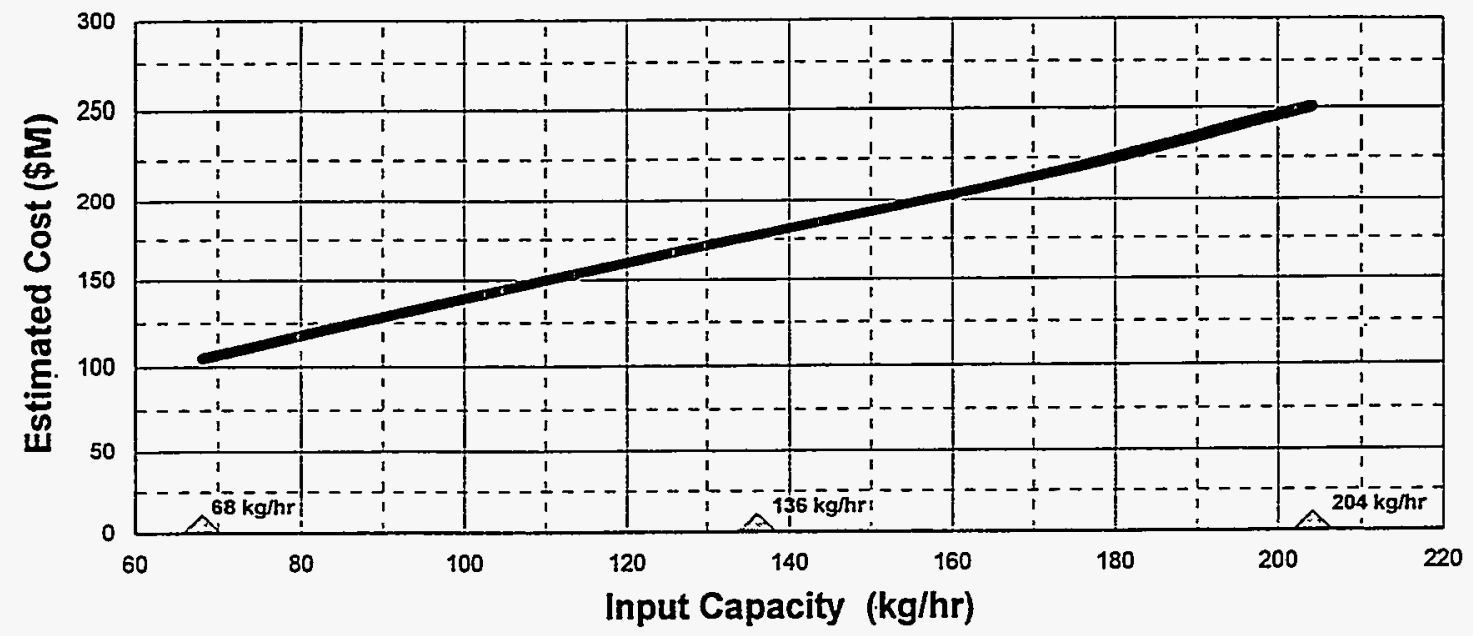

Contact Handled, Remote Handled

NOTE: Basis indudes 20 years O\&M

Triangles indicate capacities where detailed cost estimates were developed.

\section{STORED WASTE RETRIEVAL}

Total Life Cycle Unit Costs

Module: RETRV Waste Type: Contact Handled and Remote Handled

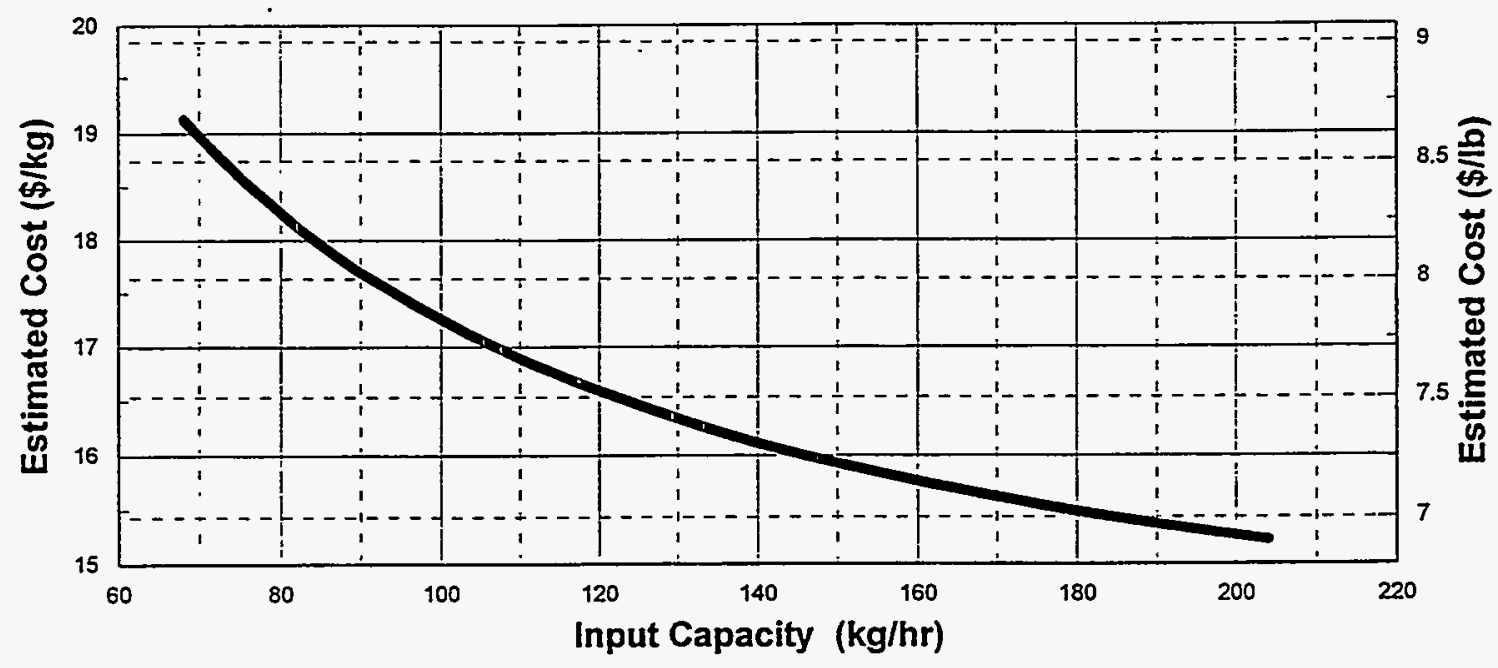

Contact Handled, Remote Handled

NOTE: Basis includes 20 years O\&M

Figure 2-5. Cost versus capacity including unit rates for the stored waste retrieval (RETRV) module. 


\section{WASTE CHARACTERIZATION (MODULE WCHAR)}

\subsection{Basic Information}

The waste characterization module, shown in Figure 3-1, is an independent self-contained facility that performs waste characterization by opening the containers, extracting physical samples of the waste, and conducting chemical, physical, and radiological sampling of the waste. The main function of this module is to perform a quality check of the waste containers, characterized on the basis of process knowledge or by nondestructive assay techniques. Quality verification is performed by sending a selected portion of the incoming containers to the characterization module.

Other functions of the characterization module are: physical examination of waste to verify realtime radiography (RTR), passive/active neutron (PAN), and segmented gamma scanning (SGS) characterization results, characterization of unknown or undetermined waste, and repackaging of selected drums or boxes to remove and stabilize noncompliant waste.

The input to the module is drums or boxes containing uncharacterized waste. The output is waste containers certified according to TRUW requirements. Figure 3-2 shows the PFD for module WCHAR.

\subsection{Technical Bases and Assumptions}

\subsubsection{Function and Operation of the Module}

Containers are received by forklift in the receiving area and are weighed, radiologically assayed, and labeled with an adhesive bar code label. Containers are transferred by conveyor to the assay and sampling gallery and into one of two container opening cells that are at the front of the assay and sampling glove boxes. Opened containers are staged in the waste assay and sampling glove box for sample recovery, sample preparation, and sample distribution; then are covered with a temporary cover and held until the sample material is returned.

Liquid and solid samples are distributed by an air tight transfer tube to analytical equipment. Sample analyses are performed using a gas chromatograph, ion chromatograph, light spectrophotometer, mass spectrometer, X-ray fluorescence, or a purge-and-trap sampler. Analytical results are transmitted to a laboratory data station located in a low-hazard area. The remaining portions of the waste samples are returned to their respective waste containers to reduce the generation of secondary waste.

After completing sample extraction operations, the container is conveyed through a transfer tunnel to a dump, sort, and packing gallery. In this area, the container is either repackaged or is dumped out. The dumped waste is sorted to remove and stabilize the nonconforming material. After stabilization, the waste is packaged into drums. The waste dump, sort, and packing gallery is equipped with a sorting table, transfer conveyors, compactor, drum capping and inspection booth, and a drum decontamination booth. The waste sort and packing area is supported by two stations located outside of the sorting and packing gallery. The stations are located at the waste sorting table and the compactor to manually feed new drums for packing secondary waste and for repacking received 
waste. Waste received in drums considered unacceptable or in nonstandard packaging are repacked into new drums. Discarded containers are sorted by type of material and contamination, are compacted, and are placed in new drums. All sealed waste containers are surface decontaminated, and a new bar code label is applied with updated information before the container is transferred to the stage and store operation.

The stage and store operation certifies the processed waste containers and accumulates assayed waste for shipment. The stage and store operation can receive trucks to facilitate offsite waste shipments.

The waste characterization module produces six secondary waste streams: (a) drum lids removed from received waste containers, (b) discarded or unsatisfactory waste containers, (c) waste sampling equipment and containers, (d) personal protective equipment, (e) contaminated rinse water from the drum capping and decontamination operations, and (f) supplies and material generated during module maintenance. Waste generated during module maintenance makes up the balance of the secondary waste. All secondary waste is assayed and separately packed for treatment at another module or for disposal.

\subsubsection{Integration of the Module}

Input waste to the waste characterization module comes from the stored waste retrieval module or other onsite sources of TRUW at sites where inadequate treatment facilities are available. Output consists of drummed waste that is transported offsite for treatment or disposal. Operation and maintenance consumables, such as personal protective equipment, must be purchased.

\subsection{Cost Bases, Assumptions, and Results}

The facility design and cost estimates are based on the Waste Characterization Facility at INEL, with modifications needed to meet functions specified in this section. Input is $75 \%$ 55-gal drums, $15 \% 85$-gal overpack containers, and $10 \%$ metal or wood shipping containers. Samples are collected in 1 -liter and $1 / 2$-liter containers. Six samples are collected from each container for sampling and analysis in the small module, and 12 samples are collected from each container for sampling and analysis in the large module. All container lids, overpack containers, and nonstandard shipping containers are processed as secondary waste. Ten percent of the 55-gal drum waste containers are assumed to be unsuitable for reuse and become part of the secondary waste stream. Most containers are reused as received. Nonspecific secondary waste, such as personal protective equipment, is estimated to be $2 \%$ of the total incoming waste.

The major costs are for the glove box equipment in the sampling and analysis operating gallery. Estimated FTEs and cost versus capacity for this module are shown in Figures 3-3 through 3-5. 


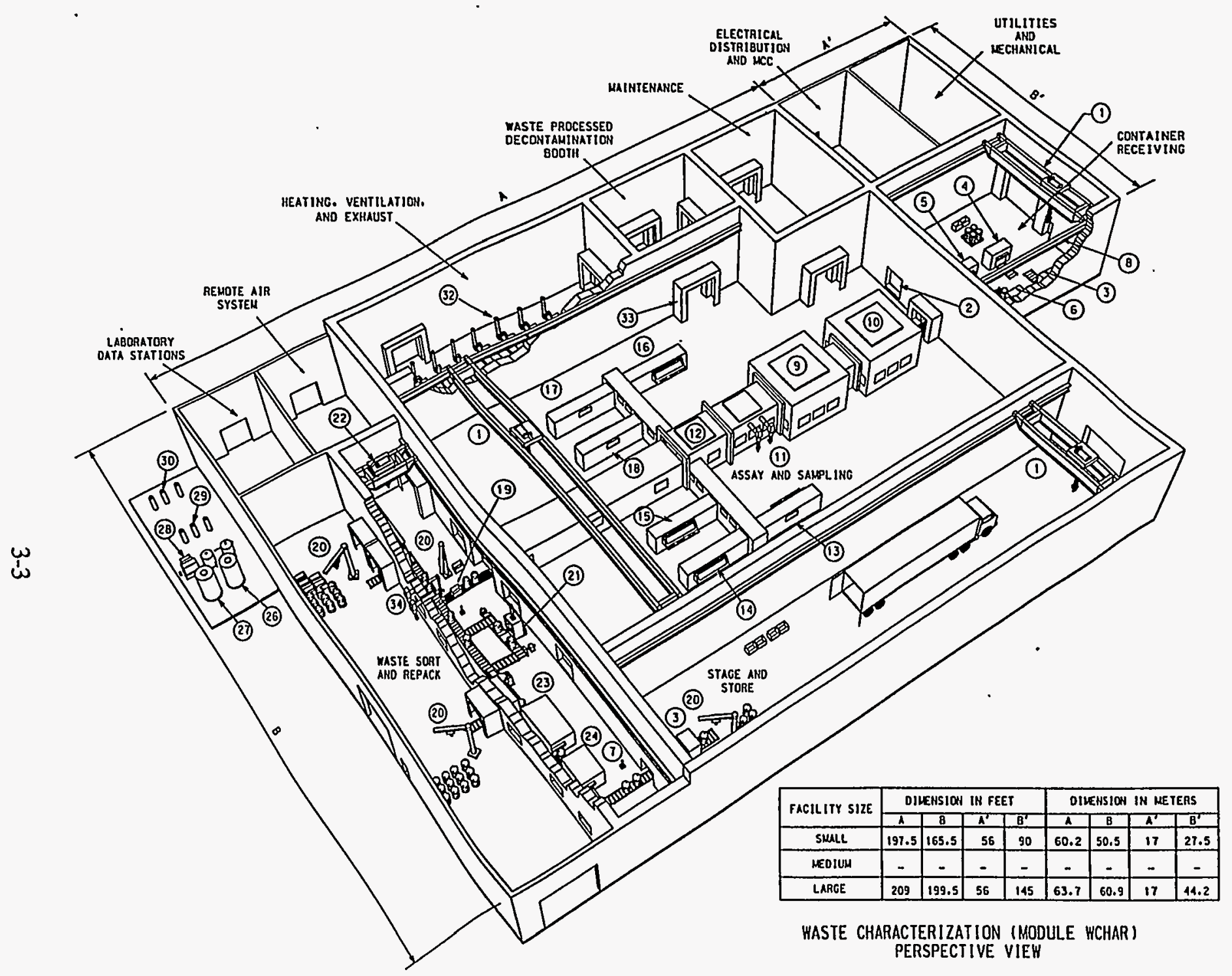

EOUIPMENT LIST

(1) bridoe crane

(2) VIETIho WINODX (TTPICAL)

(3) MEIGHING DEVICE

(4) REAL-TIME RADIOGRAPHY

(5) GavaA DETECtCR

(6) ALPHA DETECTOR

(7) barcode labeler and reader (typical)

(8) monorall system

(9) orum opening cell

(10) BOX OPENING CELL

(ii) MASTER-SLAVE MANIPULATOR (TYPICAL)

(112) CHARACTERIZATION BOX

(13) GaS CHROMUTOCRAPH

(14) ION CHROMATOCRAPH

(15) UV \& VISIBLE LIGHT SPECTROPHOTONETER

(16) IV \& VISIBLE LICHT SPECT

(17) $x$-rAY FLUORESCENCE

(19) puage ano trap auto salplef

(19) SORT TABLE

(20) manual hotst crane

(21) COMPACTOR

(22) TON BRIDGE CRANE

(23) DRUM CAPPING ano InSPECtION

(24) ORUM DECONTAMINATION

(25) oecon rinsematea tank ano puisp

(26) $\mathrm{CO}_{2}$ TANK

(27) ARGON TANK

(22) PURE ALRTANIS AN

(29) HeL JuM tanks

(30) HYDRDgen tanks

(3i) LaboratoRY DATA StatIONS

(32) LABORATORY DATA

(33) AlRLOCK OOOR (TYPICAL)

(34) IYORAULic manipulator

Figure 3-1. Equipment layout for the waste characterization (WCHAR) module. 


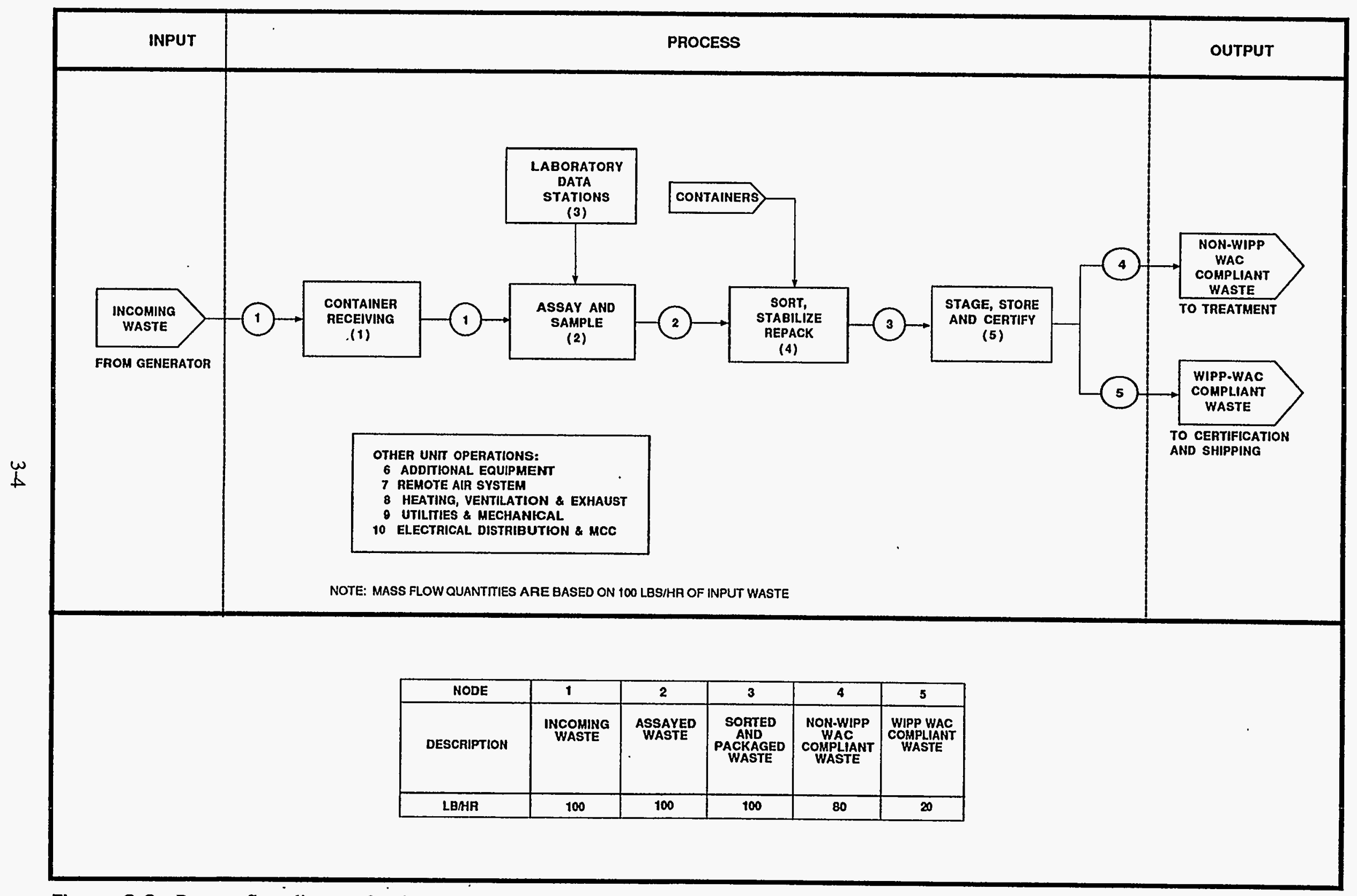

Figure 3-2. Process flow diagram for the waste characterization (WCHAR) module. 


\section{WASTE CHARACTERIZATION}

FTE by Work Breakdown Structure Element

Module: WCHAR Waste Type: Contact Handled and Remote Handled TRUW

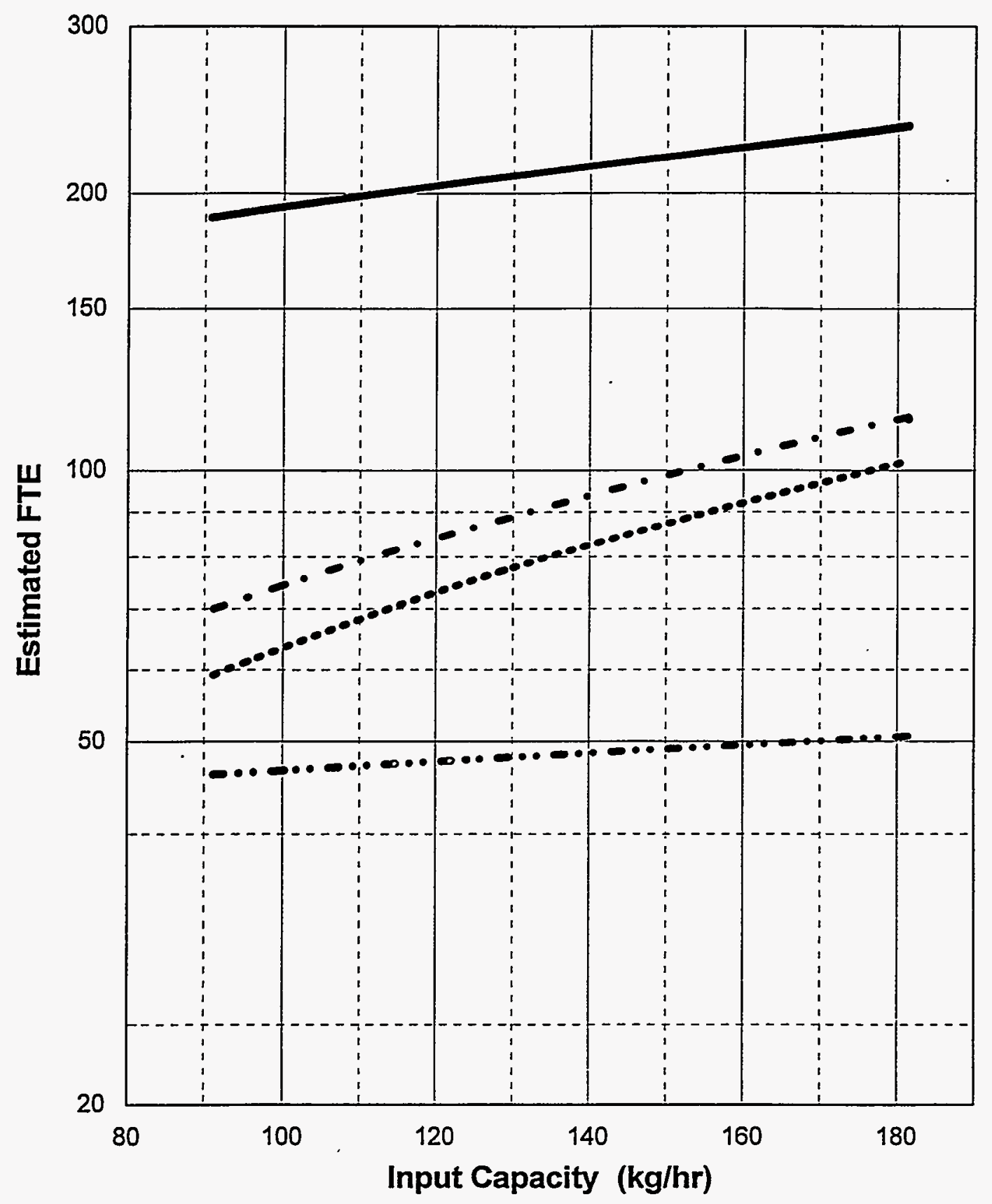

Pre-Operations Construction O\&M (1year) D\&D

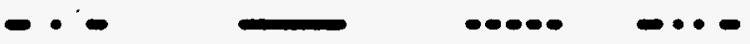

Figure 3-3. FTE workers versus capacity for the waste characterization (WCHAR) module. 


\section{WIASTE CHARACTERIZATION}

Costs by Work Breakdown Structure Element

Module: WCHAR Waste Type: Contact Handled and Remote Handled TRUW

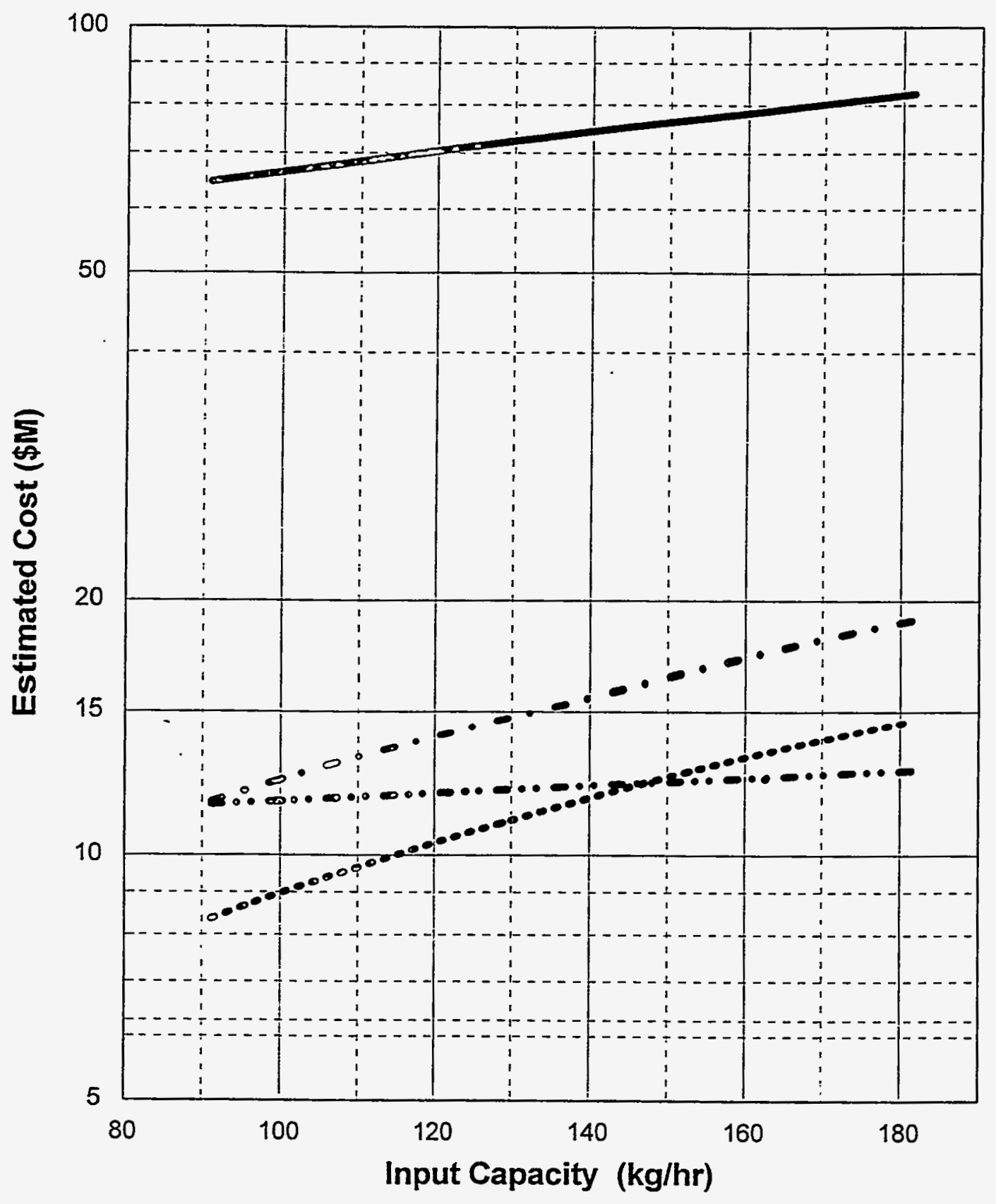

Pre-Operations Construction O\&M (1year) D\&D

Figure 3-4. Cost versus capacity for the waste characterization (WCHAR) module. 


\section{WASTE CHARACTERIZATION}

Total Life Cycle Costs

Module: WCHAR Waste Type: Contact Handled and Remote Handled TRUW

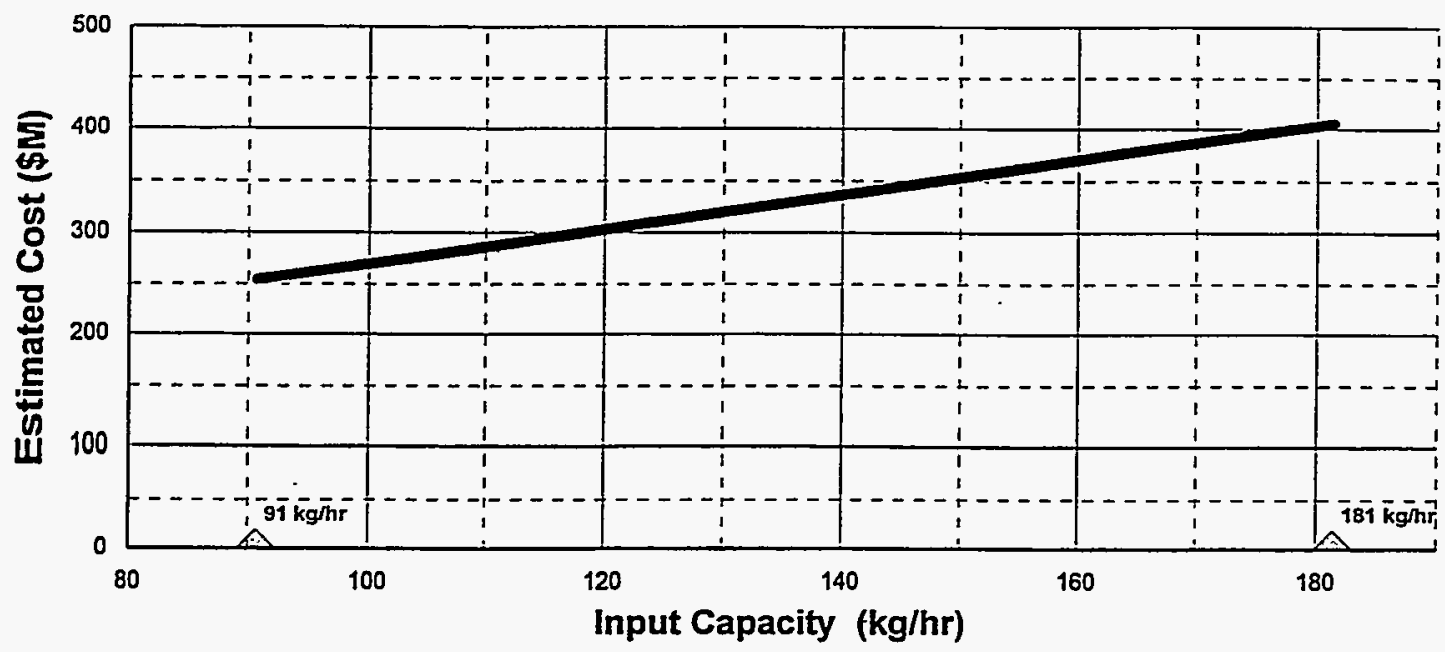

Contact Handled, Remote Handled

NOTE: Basis indudes 20 years O\&M

Triangles indicate capacities where detailed cost estimates were developed.

\section{WASTE CHARACTERIZATION}

Total Life Cycle Unit Costs

Module: WCHAR Waste Type: Contact Handled and Remote Handled TRUW

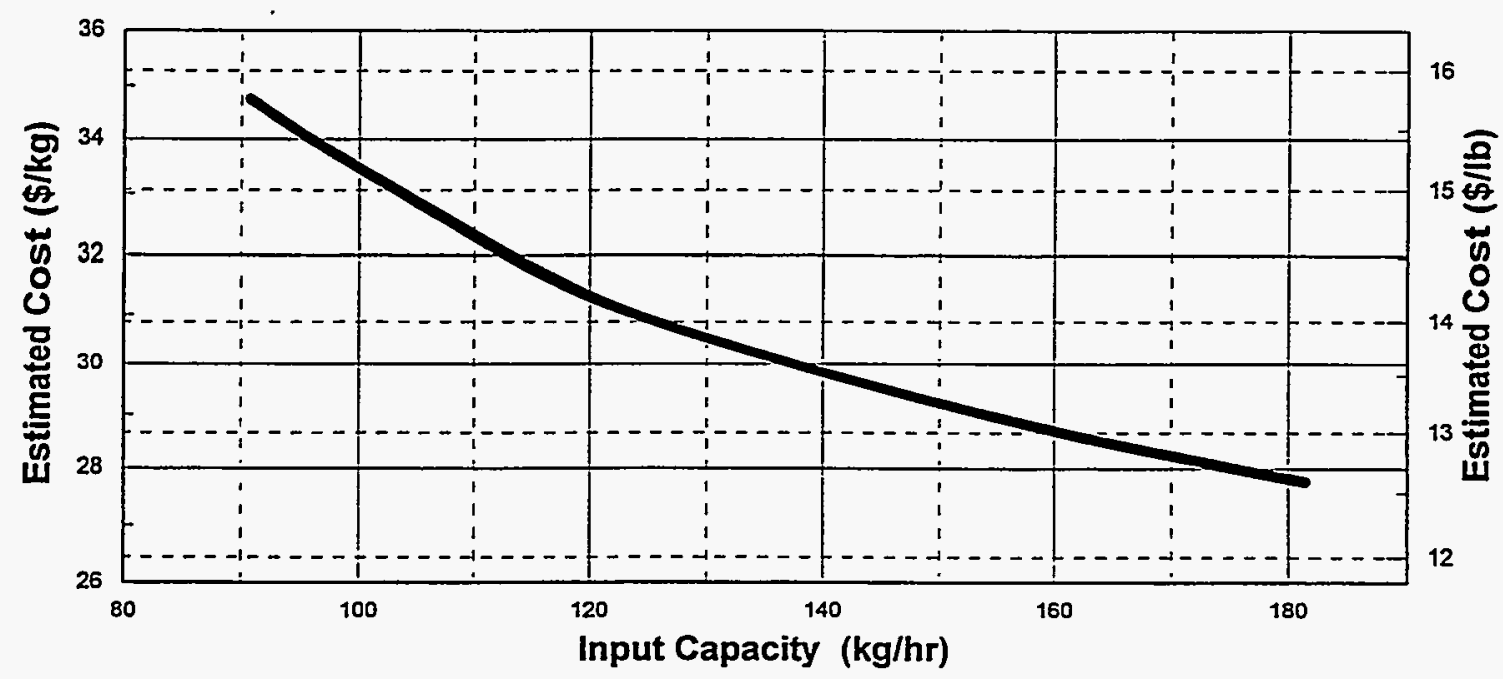

Contact Handled, Remote Handled

NOTE: Basis includes 20 years O\&M

Figure 3-5. Cost versus capacity including unit rates for the waste characterization (WCHAR) module. 


\section{TREATMENT ADMINISTRATION (MODULE TADMN)}

\subsection{Basic Information}

The treatment administration module includes all administrative and laboratory buildings required for waste management support functions. The treatment administration module is essentially the same for all treatment facilities regardless of their capacity. Module TADMN should be used whenever a new facility is planned.

\subsection{Technical Bases and Assumptions}

\subsubsection{Function and Operation of the Module}

The treatment administration module incorporates all technical and administrative support functions needed to manage the operation of a waste management facility. These functions include security, access control including personnel decontamination (radioactive and hazardous), maintenance of uncontaminated areas and equipment, health physics and radiation badges, facility access control, sanitary facilities, work control and personnel support, internal and external (public relations) communications, spill or emergency response provisions (hazardous and radioactive), analytical laboratory, environmental field sampling, environmental regulatory reporting, and records management.

\subsubsection{Integration of the Module}

The treatment administration module maintains general interfaces with all treatment modules. Operation and maintenance consumables include analytical supplies, office supplies, sanitary supplies, and personal protective equipment, which all must be purchased.

\subsection{Cost Bases, Assumptions, and Results}

Major equipment capital cost items are laboratory analytical equipment. A $\$ 1$ million allowance is made for analytical instruments and components needed for a mixed-waste laboratory. Table 4-1 lists the plan dimensions of the module. Estimated FTEs and cost versus capacity of this module are shown in Figures 4-1 through 4-3. 
Table 4-1. Plan dimensions of treatment administration module (TADMN).

\begin{tabular}{|c|c|c|c|c|}
\hline \multirow[b]{2}{*}{ Module size } & \multicolumn{2}{|c|}{$\begin{array}{c}\text { Dimensions } \\
(\mathrm{ft})\end{array}$} & \multicolumn{2}{|c|}{$\begin{array}{l}\text { Dimensions } \\
\text { (m) }\end{array}$} \\
\hline & $\begin{array}{l}\text { Module } \\
\text { length }\end{array}$ & $\begin{array}{l}\text { Module } \\
\text { width }\end{array}$ & $\begin{array}{l}\text { Module } \\
\text { length }\end{array}$ & $\begin{array}{c}\text { Module } \\
\text { width }\end{array}$ \\
\hline \multicolumn{5}{|l|}{ Large generator } \\
\hline Small & 100 & 92.5 & 30.5 & 28.2 \\
\hline Medium & 172.5 & 100 & 52.6 & 30.5 \\
\hline Large & 265 & 100 & 80.8 & 30.5 \\
\hline Small generator & - & - & - & - \\
\hline
\end{tabular}




\section{TREATMENT ADMINISTRATION}

FTE by Work Breakdown Structure Element

Module: TADMN Waste Type: Contact Handled and Remote Handled TRUW

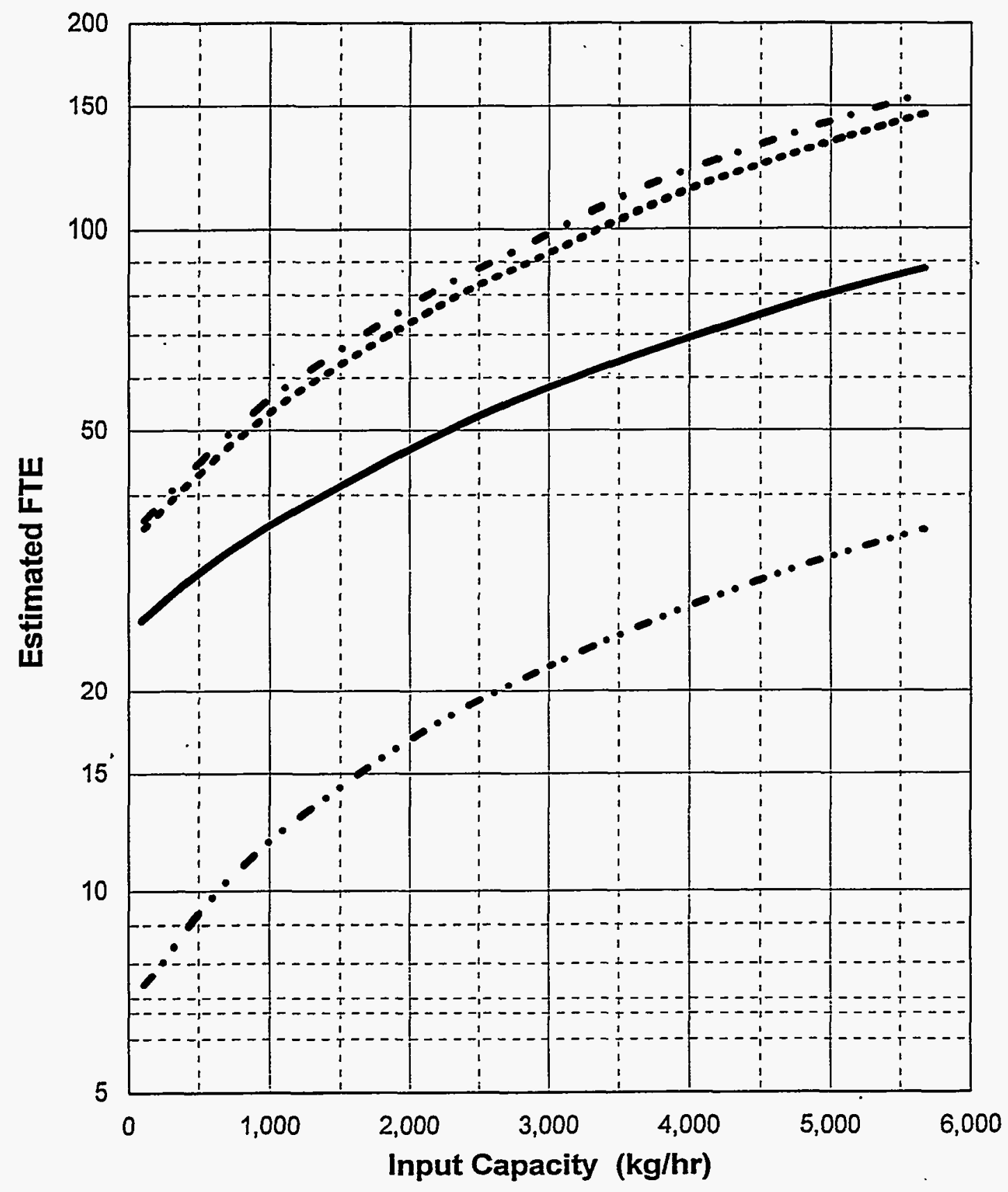

Pre-Operations Construction O\&M (1year) D\&D

Figure 4-1. FTE workers versus capacity for the treatment administration (TADMN) module. 


\section{TREATMENT ADMINISTRATION}

Costs by Work Breakdown Structure Element

Module: TADMN Waste Type: Contact Handled and Remote Handled TRUW

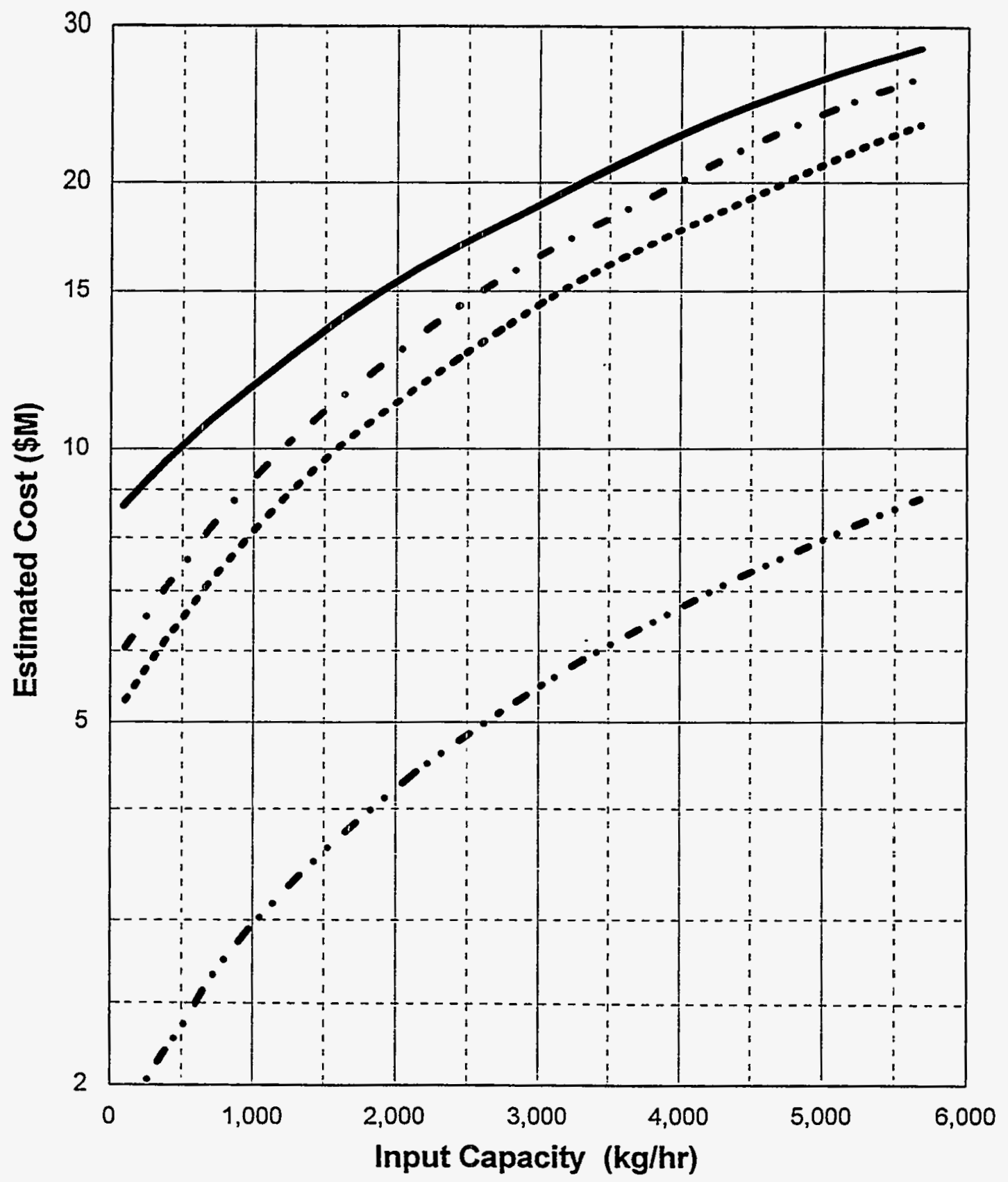

Pre-Operations Construction O\&M (1year) D\&D

Figure 4-2. PLCC versus capacity for the treatment administration (TADMN) module. 


\section{TREATMENT ADMINISTRATION}

Total Life Cycle Costs

Module: TADMN Waste Type: Contact Handled and Remote Handled TRUW

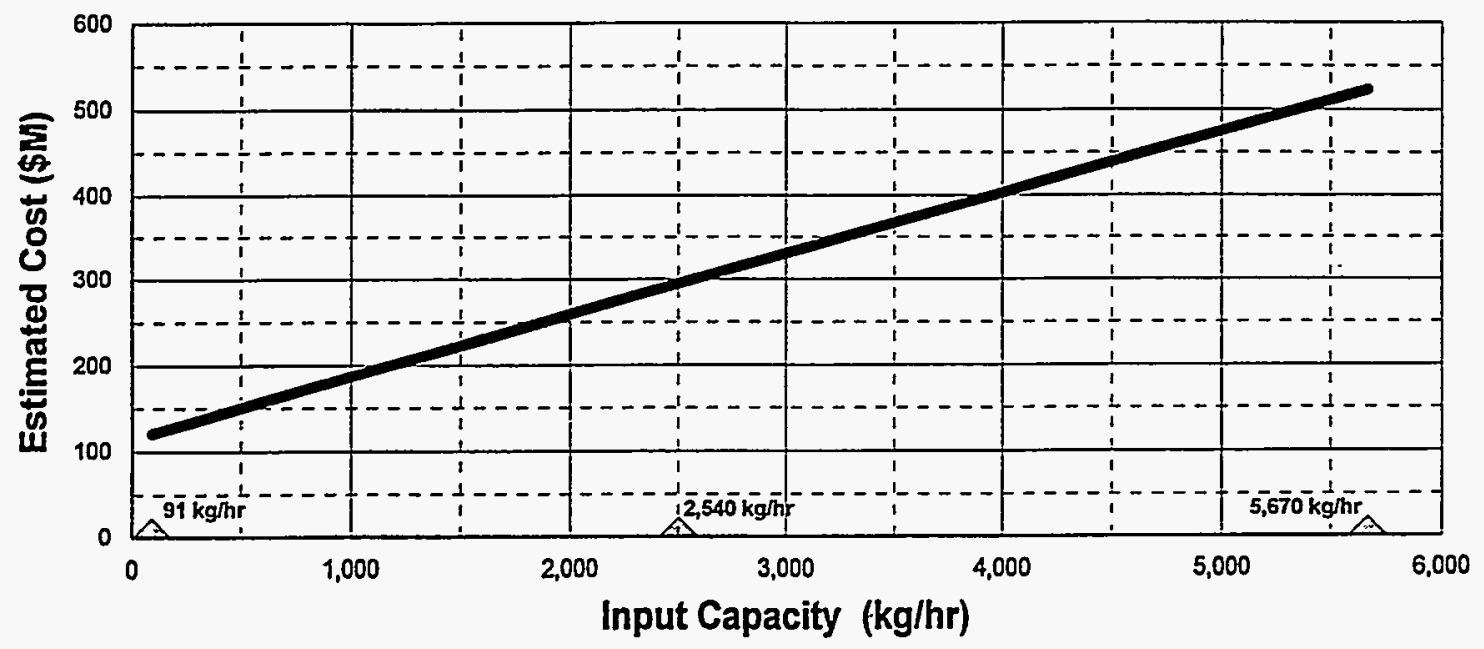

Contact Handled, Remote Handled

NOTE: Basis indudes 20 years O\&M

Triangles indicate capacities where detailed cost estimates were developed.

\section{TREATMENT ADMINISTRATION}

Total Life Cycle Unit Costs

Module: TADMN Waste Type: Contact Handled and Remote Handled TRUW

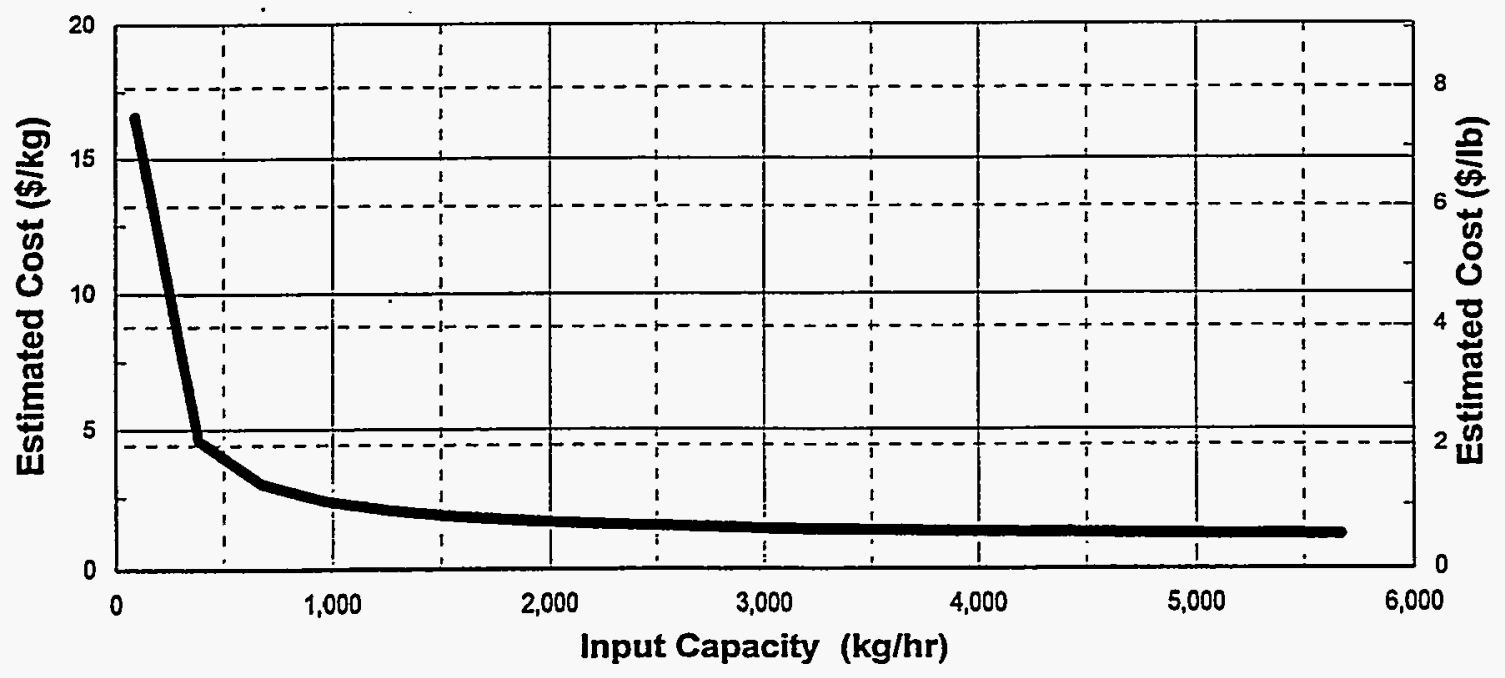

Contact Handled, Remote Handled

NOTE: Basis includes 20 years O\&M

Figure 4-3. PLCC versus capacity including unit rates for the treatment administration (TADMN) module. 


\section{RECEIVING AND INSPECTION (MODULE RCINS)}

\subsection{Basic Information}

The receiving and inspection module, shown in Figure 5-1, is intended to be contiguous with the open, dump, and sort and the waste treatment modules. It consists of two unit operations:

(a) unloading and stage, and (b) inspecting and assaying (NDE characterization). The containers of waste (in drums, boxes, and metal bins) arrive at the receiving and inspection module on a transport vehicle. Containers are removed from the transport vehicle and placed in a staging or storage area. The containers are visually examined, labeled, logged, recorded, and transported to inspection and assay. Unit operations are shown in the PFD in Figure 5-2.

The purpose of the inspect and assay unit operation is to physically and radiologically characterize the waste by NDE techniques to allow segregation of the containers. Based on the inspection and assay results, the waste containers are grouped according to their processing needs. The inspect and assay unit operation also identifies a special waste category that applies to any containerized waste requiring special processing operations.

The receiving and unloading area is equipped with a bridge crane and a forklift truck. It is designed to receive and unload containers from flat-bed trailers or van trucks. Containers brought in large overpacks, for example, transportation [transuranic package transporter-II (TRUPACT-II)] type containers, can also be unloaded.

\subsection{Technical Bases and Assumptions}

\subsubsection{Function and Operation of the Module}

Wheeled vehicles are used to ship the containers (in overpacks, if necessary) from the generators to the fixed receiving and inspection module. These vehicles are not included in the module. In the unloading and staging unit operation, the vehicles are unloaded and the containers are placed in the staging area. Surge storage is also provided. Containers may be moved within the unloading, staging, and surge storage areas and transported to and from the various interfacing unit operations.

Containers are unloaded in an enclosed truck bay and placed in an indoor staging area. The area is large enough to maneuver the containers and provide sufficient surge storage capacity to meet the desired operational reliability.

The inspect and assay unit operation determines the radioactivity, physical properties, and other parameters needed to categorize the containerized waste before processing and in accordance with the criteria established for the processing unit operations. Various devices, such as PAN counting instruments, may be used. Containers holding waste classified as other than TRUW are returned to the generator. 
Waste containers are also examined to allow classification by gamma radioactivity (in accordance with the criteria established for the processing unit operations) and to ensure that they are suitable for contact handling (less than 200 milliRem per hour on surface) and for treatment by the given process units. Various devices, such as SGS instruments, could be used. Containerized waste that does not meet the criteria is either handled as special waste or returned to the generator.

After the containers are examined, they are weighed and measured to determine waste density. Contents (categorized as metal, paper, glass, sludge, gas cylinders, and liquids) are determined by NDE. At a minimum, each container is examined using a nondestructive assay unit equipped with a RTR device. Ultrasonic devices are also used. After examination, each container is labeled, and the properties of its contents are logged and entered into a computerized database.

To allow year-round operations and to minimize the effects of a potential spill, it is assumed that the unloading and staging operations will take place indoors.

\subsubsection{Integration of the Module}

In addition to general interfaces typical for all modules, waste from generator facilities becomes input to the receiving and inspection module. Operation and maintenance consumables, including personal protective equipment, must be purchased. Module output consists of containers of TRUW which are moved to the open, dump, and sort module or to treatment modules.

\subsection{Cost Bases, Assumptions, and Results}

Major equipment capital cost items for the fixed module include alpha assay, gamma assay, 20-ton bridge crane, and RTR units. The crane cost is based on vendor quotations. The inspection and assay units are based on conceptual designs and cost estimates for a radiological and hazardous materials measurement system provided by EG\&G Idaho. Budget estimate for an inspection and assay system is $\$ 2$ million. Figures 5-3 through 5-5 show FTEs and costs versus capacity for this module. 


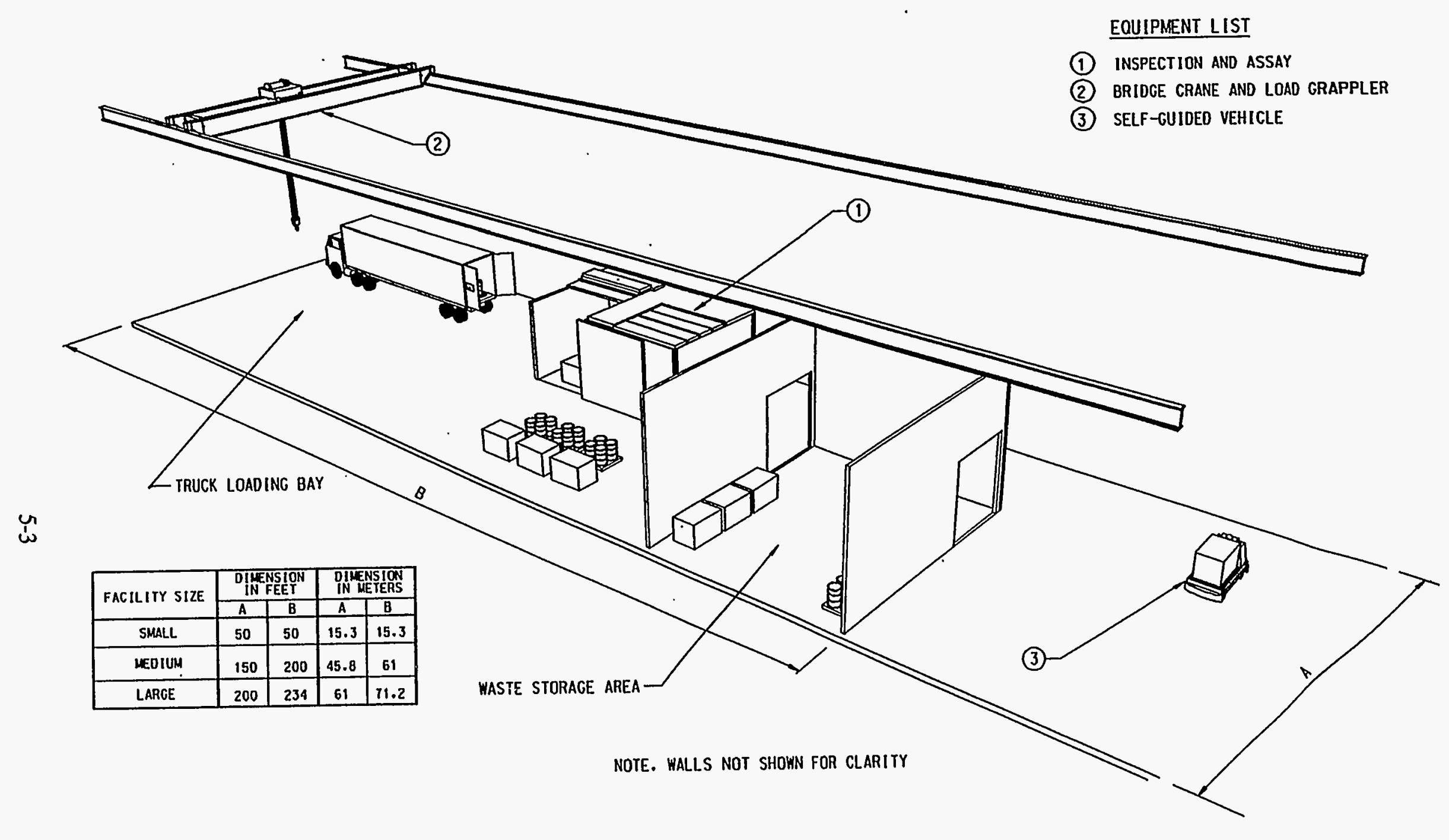

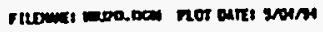

Figure 5-1. Equipment layout for the receiving and inspection (RCINS) module. 


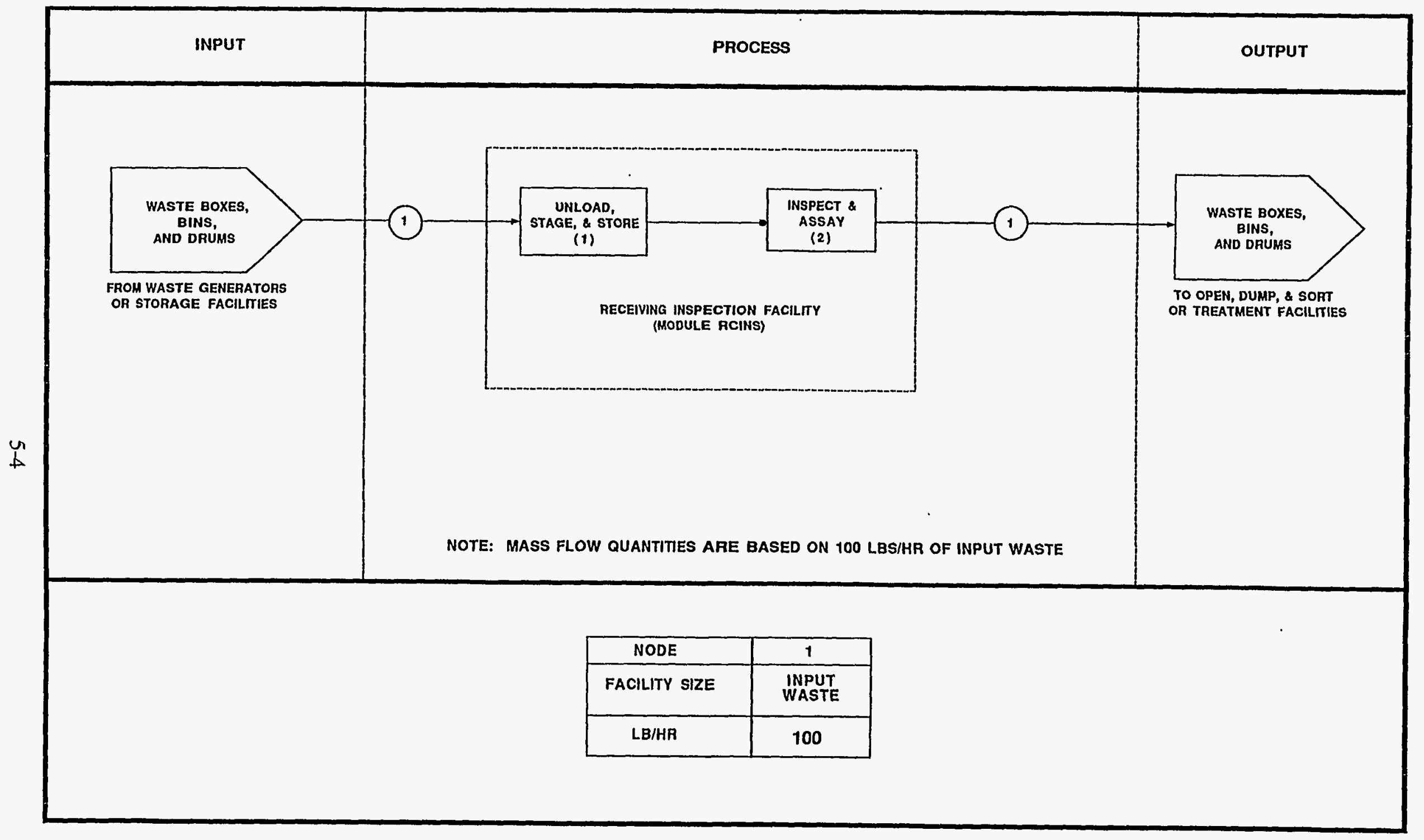

Figure 5-2. Process flow diagram for the receiving and inspection (RCINS) module. 


\section{RECEIVING AND INSPECTION}

FTE by Work Breakdown Structure Element

Module: RCINS Waste Type: Contact Handled and Remote Handled TRUW

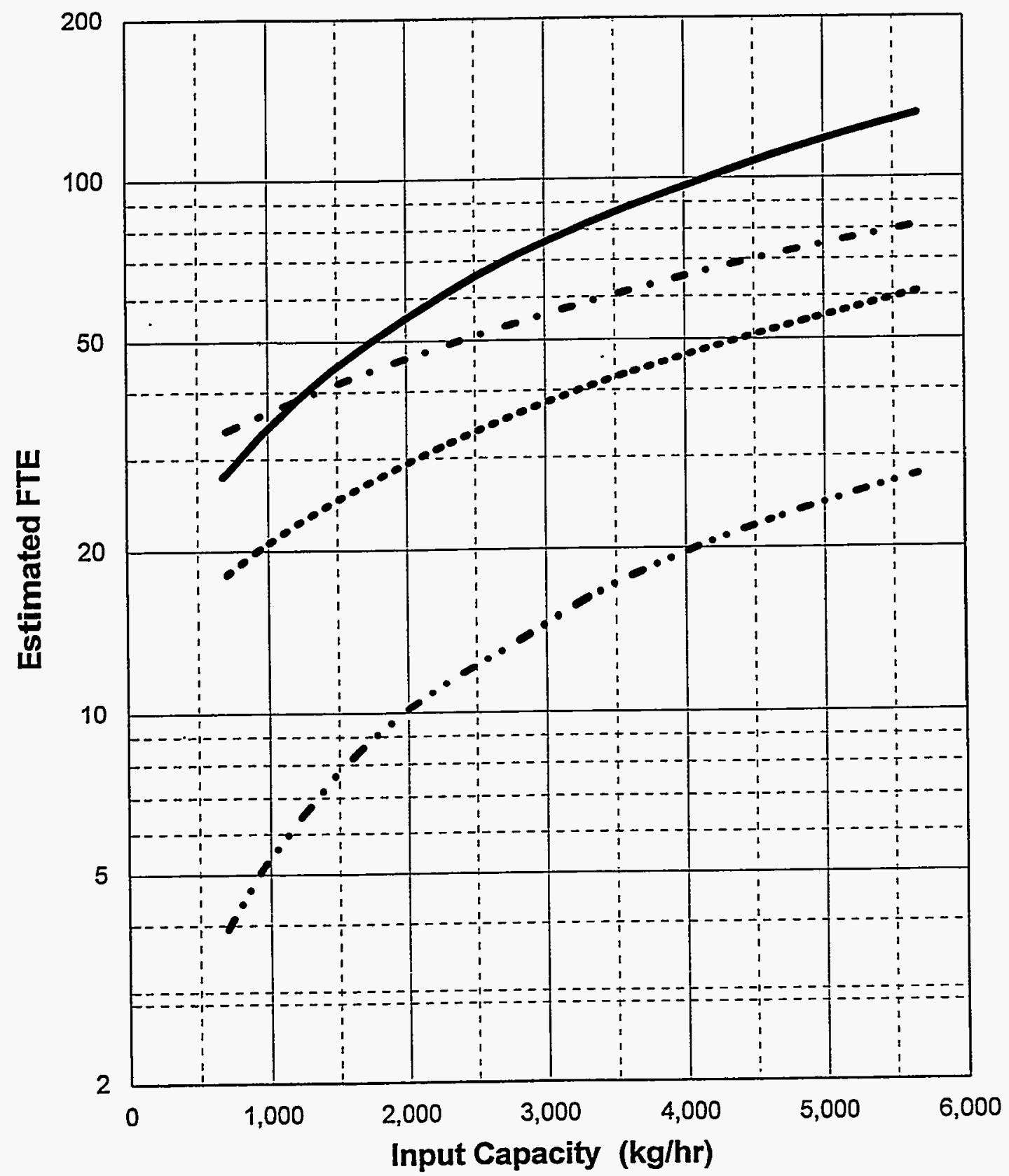

Pre-Operations Construction O\&M (1year) D\&D

Figure 5-3. FTE workers versus capacity for the receiving and inspection (RCINS) module. 


\section{RECEIVING AND INSPECTION}

Costs by Work Breakdown Structure Element

Module: RCINS Waste Type: Contact Handled and Remote Handled TRUW

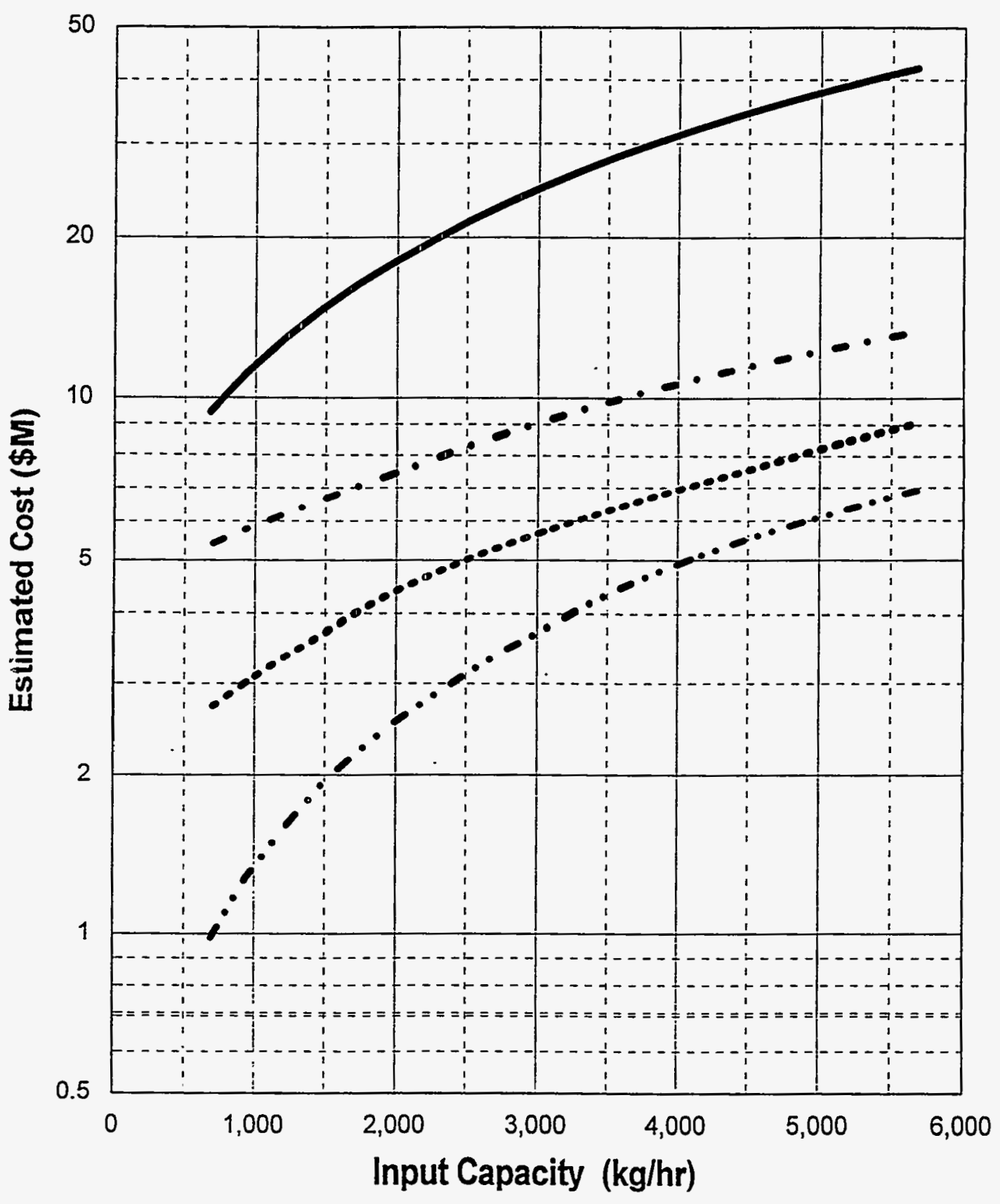

Pre-Operations Construction O\&M (1year) D\&D

Figure 5-4. PLCC versus capacity for the receiving and inspection (RCINS) module. 


\section{RECEIVING AND INSPECTION}

Total Life Cycle Costs

Module: RCINS Waste Type: Contact Handled and Remote Handled TRUW

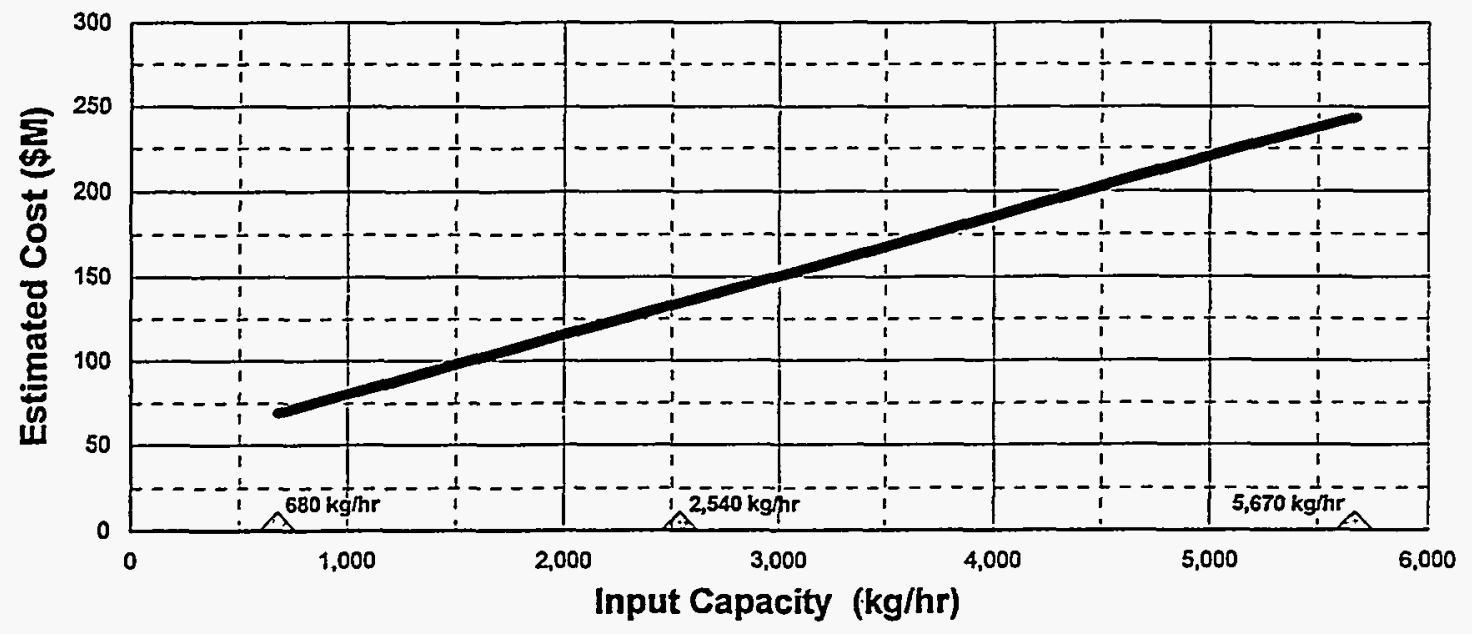

Contact Handled, Remote Handled

NOTE: Basis includes 20 years O\&M

Triangles indicate capacities where detailed cost estimates were developed.

\section{RECEIVING AND INSPECTION}

Total Life Cycle Unit Costs

Module: RCINS Waste Type: Contact Handled and Remote Handled

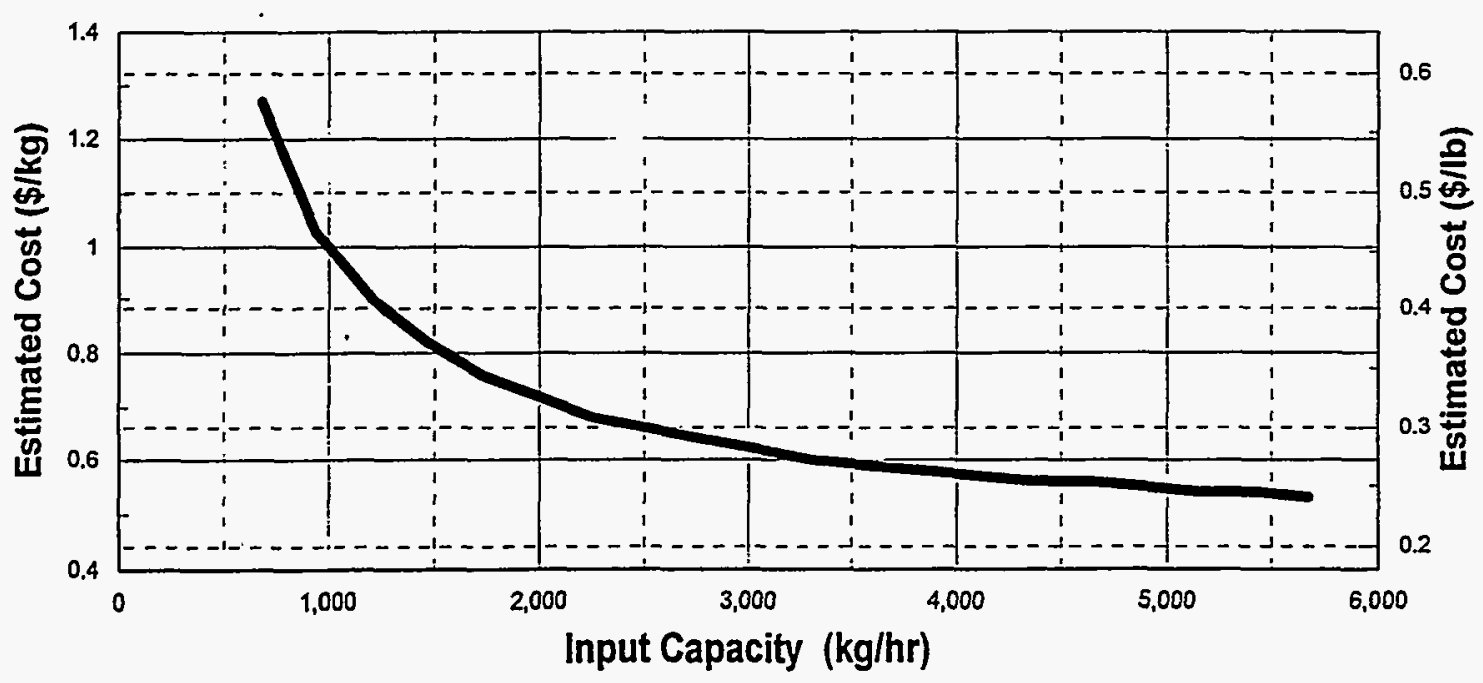

Contact Handled, Remote Handled

NOTE: Basis inciudes 20 years O\&M

Figure 5-5. PLCC versus capacity including unit rates for the receiving and inspection (RCINS) module. 


\section{OPEN, DUMP, AND SORT (MODULE OSORT)}

\subsection{Basic Information}

The open, dump, and sort module, shown in Figure 6-1, is designed to be contiguous with the treatment facilities and is ideal for use with an integrated waste management facility that handles multiple waste streams. The module opens and dumps the incoming waste containers and segregates the waste so it can be fed to a combination of treatment processes. The module handles the waste in drums, boxes, or metal bins that are assumed to be properly characterized before they are opened. The module may not be needed if the waste arrives presorted. Module T-OSORT is applicable to CH-TRUW, while module U-OSORT is intended for RH-TRUW. Unit operations are shown in the PFD in Figure 6-2.

The module also has the capability to reduce the size of empty nonmetal containers. Metal containers must be transported to other modules, such as a decontamination module, for washdown and reuse or to be prepared for disposal.

\subsection{Technical Bases and Assumptions}

\subsubsection{Function and Operation of the Module}

At the open, dump, and sort module the waste containers are decapped, and the waste is dumped either onto sorting devices or into transport bins that carry it to the treatment operations.

Containers of waste are opened by remote means, then dumped and sorted remotely by manipulators and robots housed in a cell. The cell has a controlled environment and multiple barriers. Adequate hoods and supporting ventilation are provided to minimize the spread of dust and contamination. Containers enter the cell through airlock doors. Equipment maintenance is accomplished in a controlled environment manually by personnel equipped with protective clothing. In addition, the equipment can be retrieved and decontaminated before maintenance is performed.

After the TRUW containers enter the controlled cubicle environment through airlock doors, they are grouped into two categories: homogeneous waste and heterogeneous waste. Containers of homogeneous waste are opened, dumped, placed in transport bins, and transported to treatment modules. Containers of heterogeneous waste are opened, dumped, robot sorted, placed in transport bins, and then transported to treatment modules. Waste meeting disposal requirements without any further treatment are packaged in this module.

The waste in containers that are designated for segregation is dumped onto a sorting station, which removes bulk metal, noncombustibles, partially combustibles, combustibles, special waste, ${ }^{f}$ and gas cylinders. Various sorting technologies, such as robotic assisted sort tables, vibratory screens, and air classifiers, may be used in the sorting station. Any spilled liquid is collected and transported

f. Special wastes are those materials that are incompatible with the treatment techniques provided in the facility (e.g., mercury). After identification and segregation, special wastes are treated by mobile units provided on a case-by-case basis. 
to other unit operations for treatment. The sorted waste material is placed in transfer bins and moved to the treatment modules. Nonmetallic containers are cut into smaller pieces as required for processing.

TRUW packages designated for direct disposal are distributed in multiple containers in such a way that eliminates criticality risks and does not exceed thermal heat generation criteria for individual containers.

To reduce gas generation rates in the disposal facility, TRUW designated for direct disposal may be repackaged in nickel drums in the open, dump, and sort module.

\subsubsection{Integration of the Module}

In addition to general interfaces for all modules, input interfaces to the open, dump, and sort module are waste containers from the receiving and inspection module. Operation and maintenance consumables including personal protective equipment are purchased. Output interfaces include sending solid sorted TRUW to treatment. Repackaged TRUW is transported for final inspection and certification. Reusable empty metal drums and boxes are transported to a decontamination module for cleaning and recycle. Other empty metal containers are transported to the metal decon or melting modules. Empty wood and fiberglass boxes are shredded and transported to treatment modules.

\subsection{Cost Bases, Assumptions, and Results}

Major equipment capital cost items for this module are container open, dump, and sort devices and robotics arms. The costs for these items are developed based on consultation with personnel from DOE contractors involved in the Office of Technology Development, Robotic Technology Development Program. Estimated FTE and cost versus capacity for this module is shown in Figures 6-3 through 6-5.

Input capacities for the open, dump, and sort modules should be based on the amount of uncharacterized waste to be treated. Presorted and newly generated wastes may already be sufficiently characterized to go directly to treatment. Uncharacterized and new "unknown" wastes would need to utilize this module. 


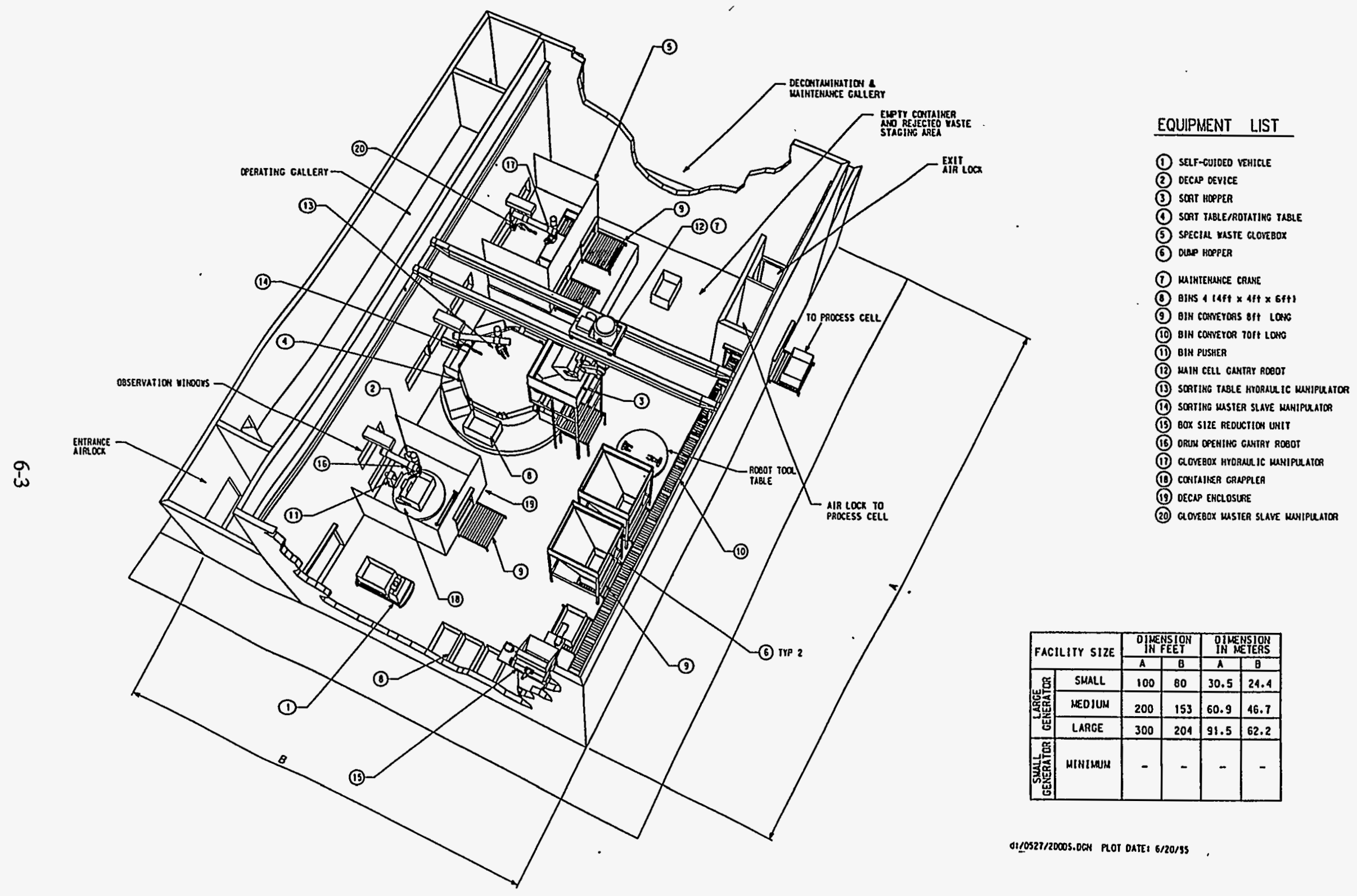

Figure 6-1. Equipment layout for the open, dump, and sort (OSORT) module. 


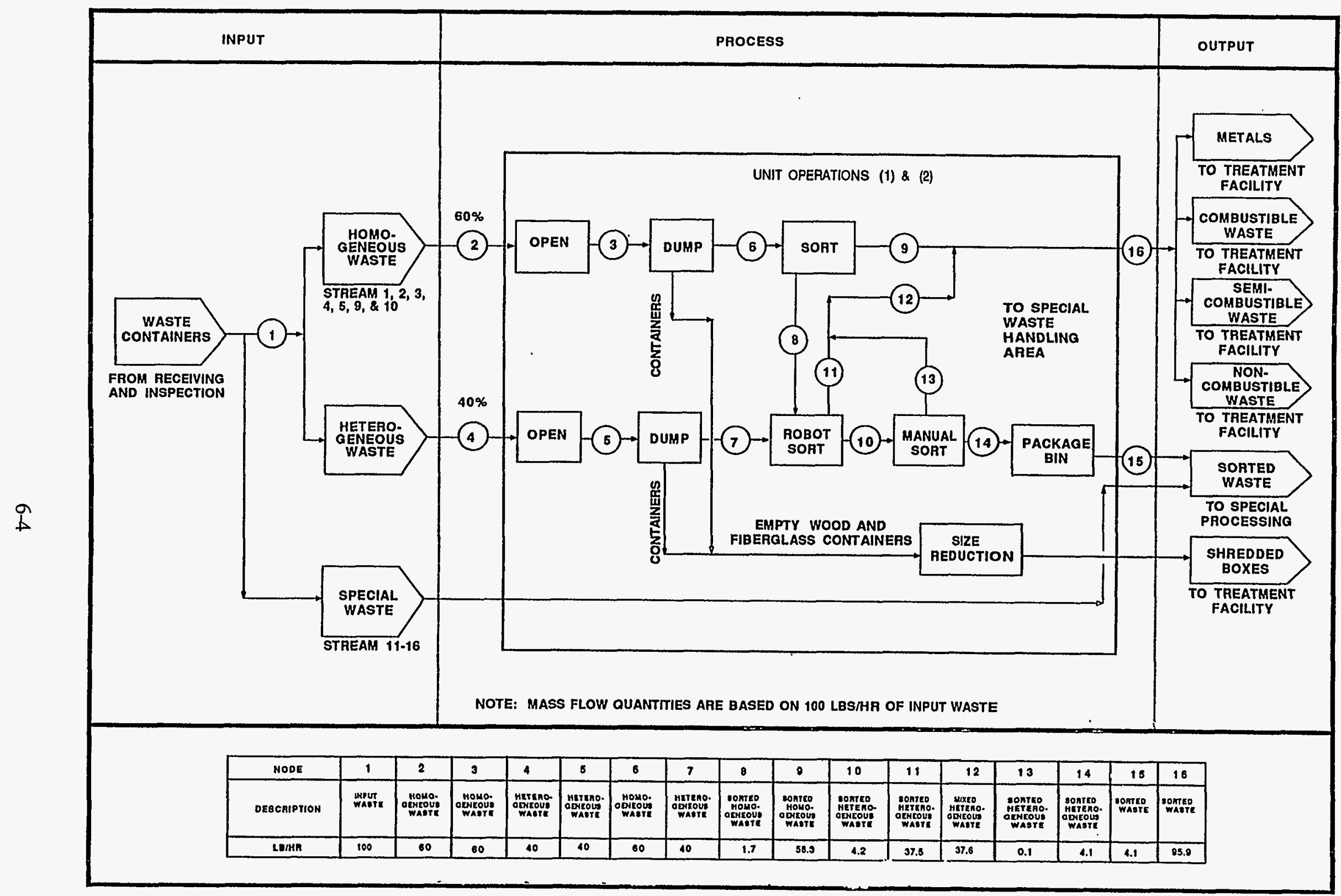

Figure 6-2. Process flow diagram for the open, dump, and sort (OSORT) module. 


\section{OPEN, DUMP, AND SORT}

FTE by Work Breakdown Structure Element Module: OSORT Waste Type: Contact Handled TRUW

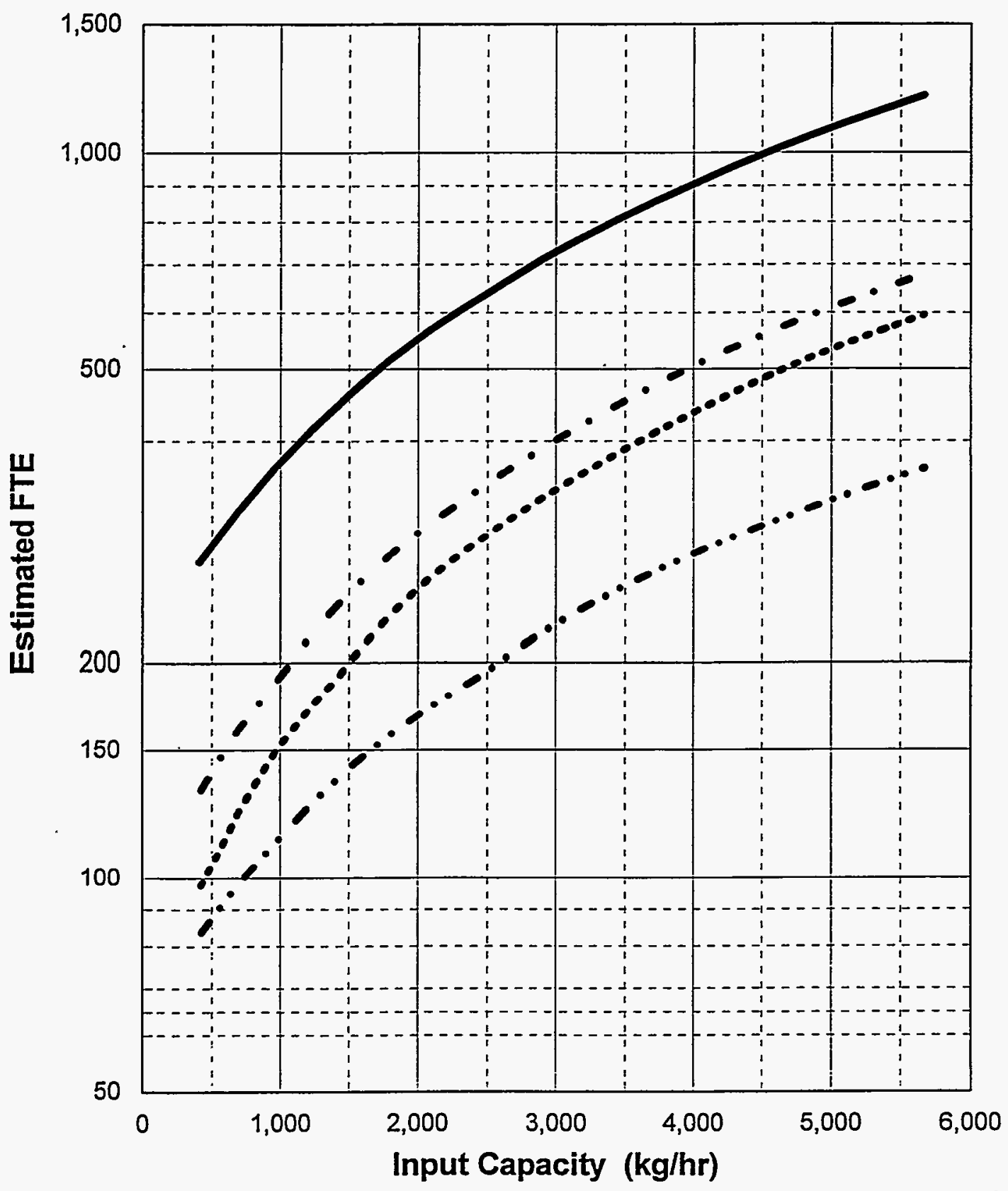

Pre-Operations Construction O\&M (1year) D\&D

Figure 6-3. FTE workers versus capacity for the CH open, dump, and sort (T-OSORT) module. 


\section{OPEN, DUMP, AND SORT}

FTE by Work Breakdown Structure Element

Module: OSORT Waste Type: Remote Handled TRUW

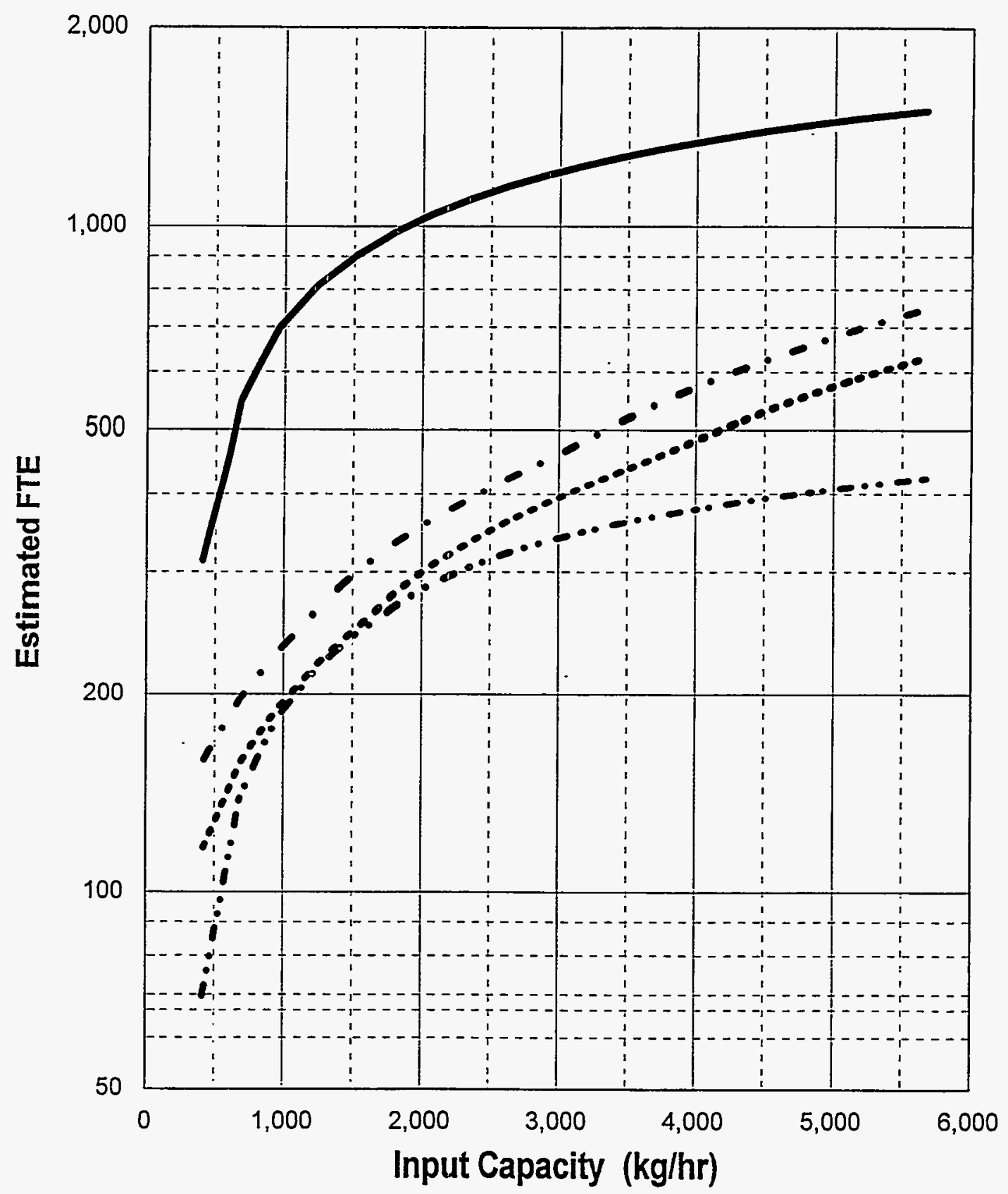

Pre-Operations Construction O\&M (1year) D\&D

Figure 6-4. FTE workers versus capacity for the RH open, dump, and sort (U-OSORT) module. 


\section{OPEN, DUMP, AND SORT}

\section{Costs by Work Breakdown Structure Element}

Module: OSORT Waste Type: Contact Handled TRUW

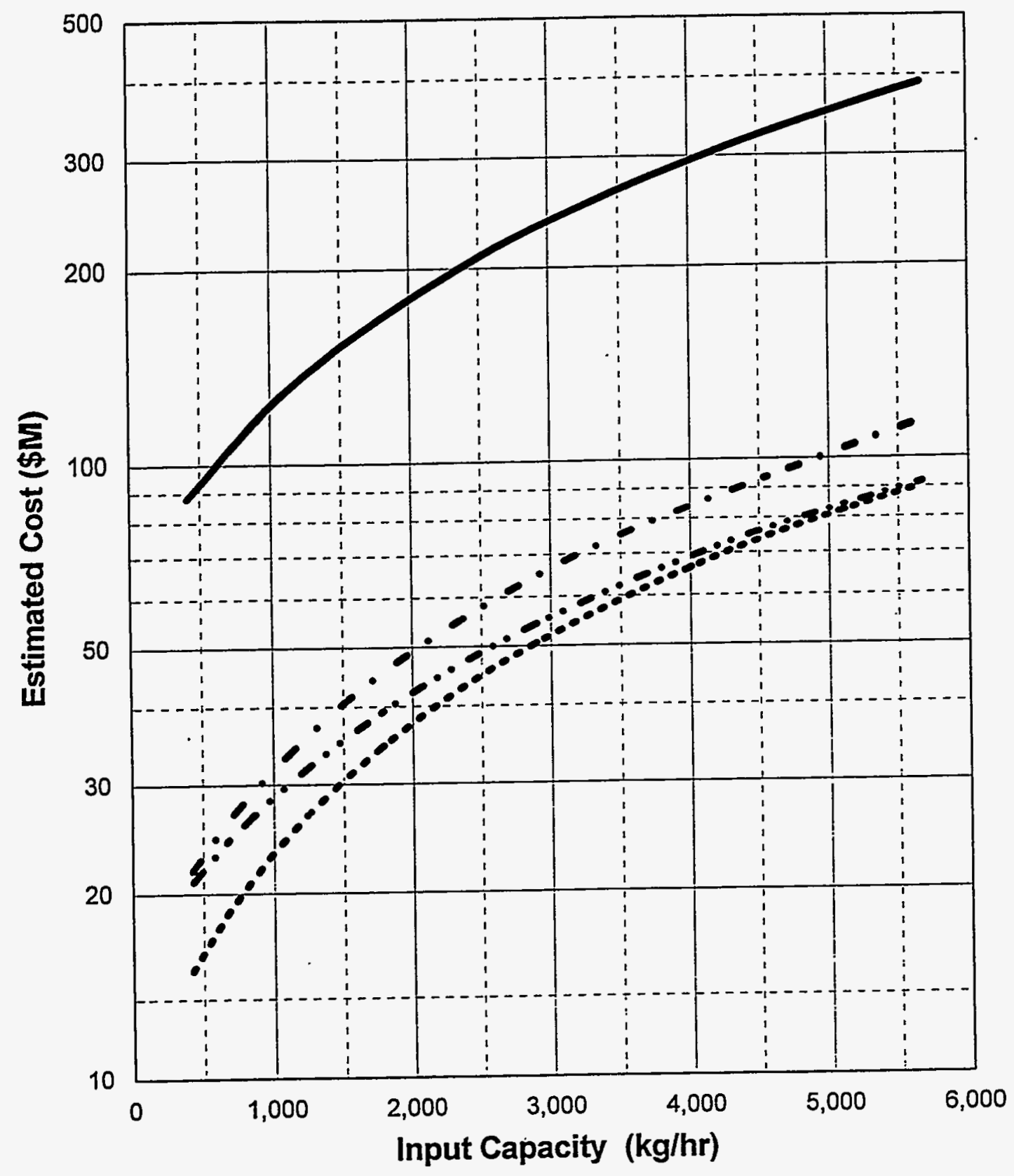

Pre-Operations Construction O\&M (1year) D\&D

Figure 6-5. PLCC versus capacity for the $\mathrm{CH}$ open, dump, and sort (T-OSORT) module. 


\section{OPEN, DUMP, AND SORT}

Costs by Work Breakdown Structure Element Module: OSORT Waste Type: Remote Handled TRUW

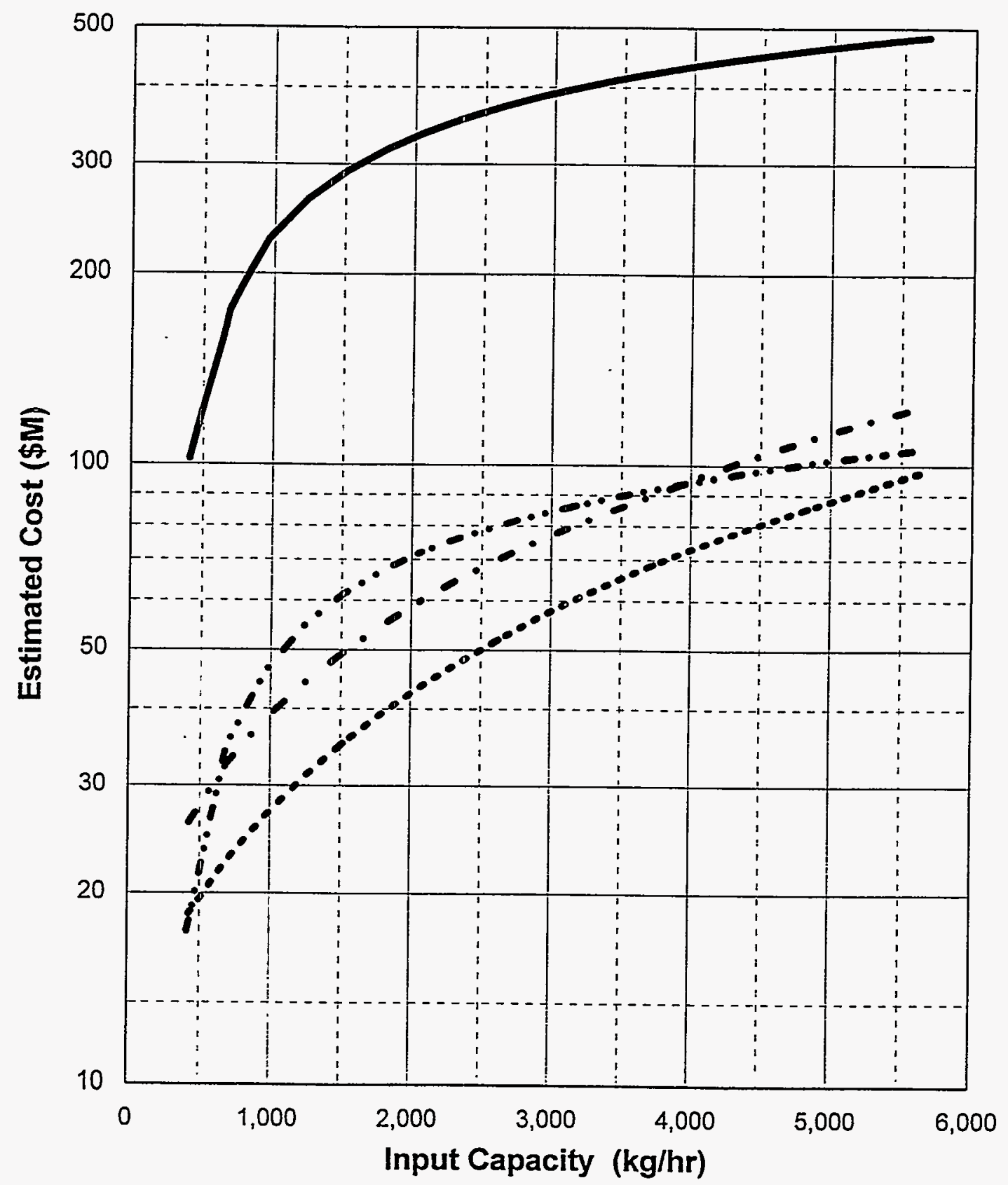

Pre-Operations Construction O\&M (1year) D\&D

Figure 6-6. PLCC versus capacity for the RH open, dump, and sort (U-OSORT) module. 


\section{OPEN, DUMP, AND SORT}

Total Life Cycle Costs

Module: OSORT Waste Type: Contact Handled and Remote Handled TRUW

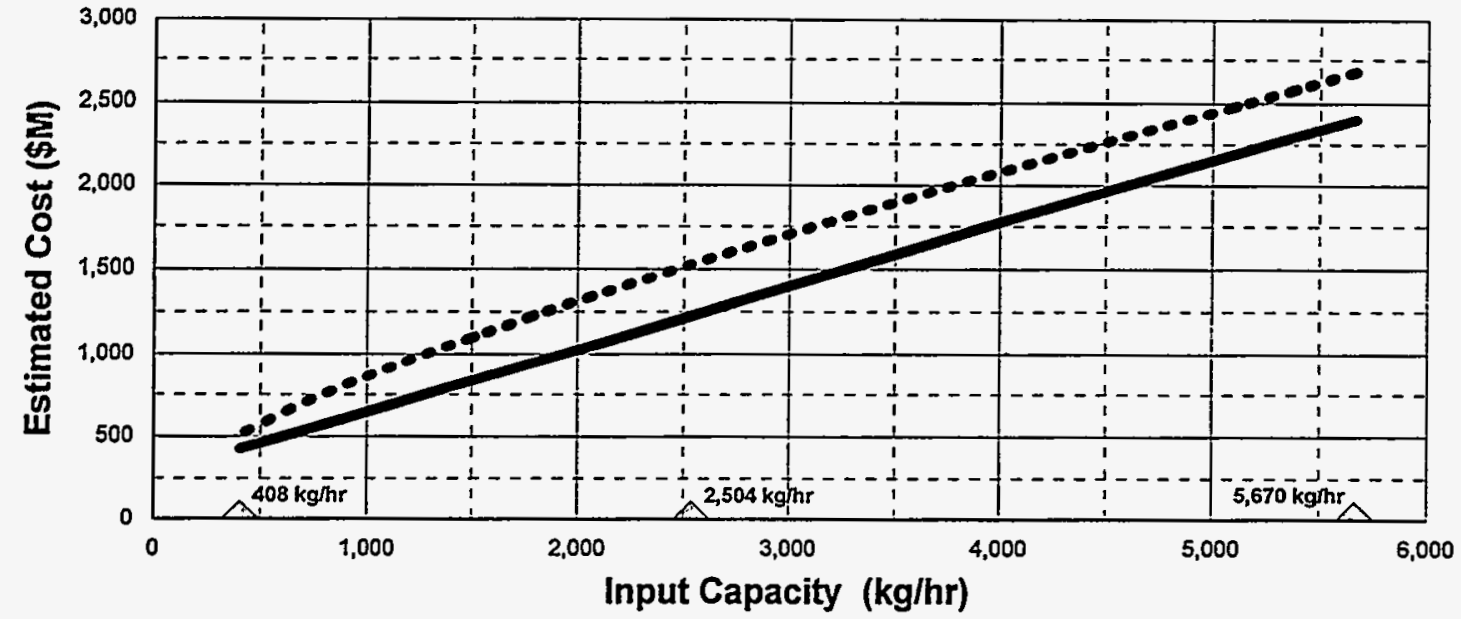

Contact Handled Remote Handled

NOTE: Basis indudes 20 years O\&M

Triangles indicate capacities where detailed cost estimates were developed.

\section{OPEN, DUMP, AND SORT}

Total Life Cycle Unit Costs

Module: OSORT Waste Type: Contact Handled and Remote Handled TRUW

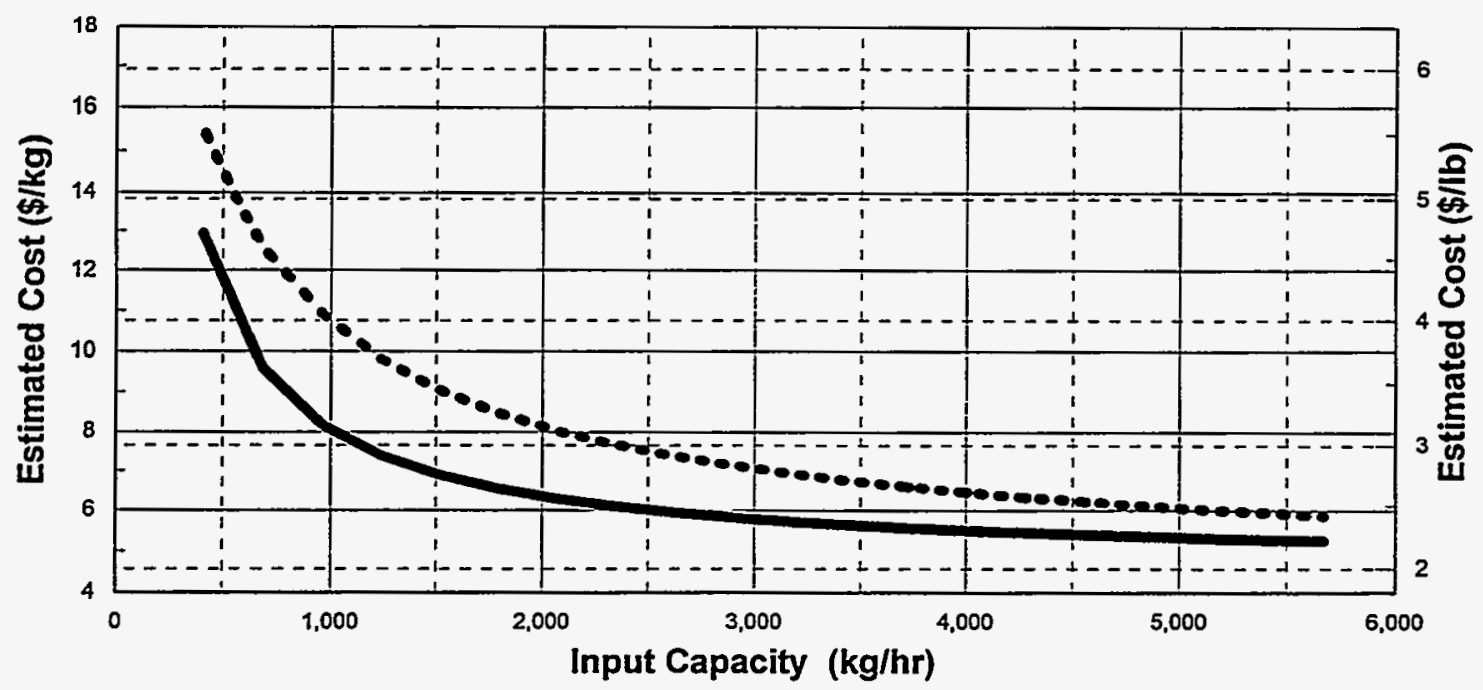

Contact Handled Remote Handled

Note: Basis includes 20 years O\&M

Figure 6-7. PLCC versus capacity including unit rates for the open, dump, and sort (OSORT) module. 


\section{MAINTENANCE (MODULE MAINT)}

\subsection{Basic Information}

The maintenance module is equipped with a building for receiving and repairing failed equipment. This module is used in conjunction with the treatment modules when such a function is not available at the existing facilities. The maintenance shop costs assume that the module will repair components contaminated with low-level radioactivity but not alpha emitters. Components contaminated with alpha particles must be decontaminated in the alpha maintenance galleries before they are brought into the maintenance shop.

\subsection{Technical Bases and Assumptions}

\subsubsection{Function and Operation of the Module}

Contaminated failed equipment and parts arrive at the shop in transfer carts. Parts are removed from the transport carts and are placed in a decontamination area where high-pressure spraying or other techniques are used to remove any loose contamination. After cleaning and decontamination, components are moved to maintenance tables. Maintenance machinery and tools are used as needed. The shop includes an overhead crane and a jib crane for material handling, and a paint booth.

\subsubsection{Integration of the Module}

The module receives failed equipment from the treatment module. The output is repaired equipment. The module has secondary waste containing decontamination solutions, spent oil, and solvent. Operation and maintenance material includes parts, materials, and consumables, which are assumed to be purchased items.

\subsection{Cost Bases, Assumptions, and Results}

Major equipment capital cost items are cranes, milling, sanding, drilling, and lathe machinery and tools. Costs for all machinery and equipment, including the cranes, are based on industrial (nonradioactive) applications. Table 7-1 lists plan dimensions of the module. Estimated FTE and costs versus capacity for this module are shown in Figures 7-1 through 7-3. 
Table 7-1. Plan dimensions of maintenance module (MAINT).

\begin{tabular}{|c|c|c|c|c|}
\hline \multirow[b]{2}{*}{ Module size } & \multicolumn{2}{|c|}{$\begin{array}{c}\text { Dimensions } \\
(\mathrm{ft})\end{array}$} & \multicolumn{2}{|c|}{$\begin{array}{c}\text { Dimensions } \\
\text { (m) }\end{array}$} \\
\hline & Length & Width & Length & Width \\
\hline \multicolumn{5}{|l|}{ Large generator } \\
\hline Small & 87 & 30 & 26.5 & 9.1 \\
\hline Medium & 250 & 30 & 76.2 & 9.1 \\
\hline Large & 334 & 30 & 101.8 & 9.1 \\
\hline
\end{tabular}




\section{MAINTENANCE}

FTE by Work Breakdown Structure Element Module: MAINT Waste Type: Contact Handled and Remote Handled TRUW

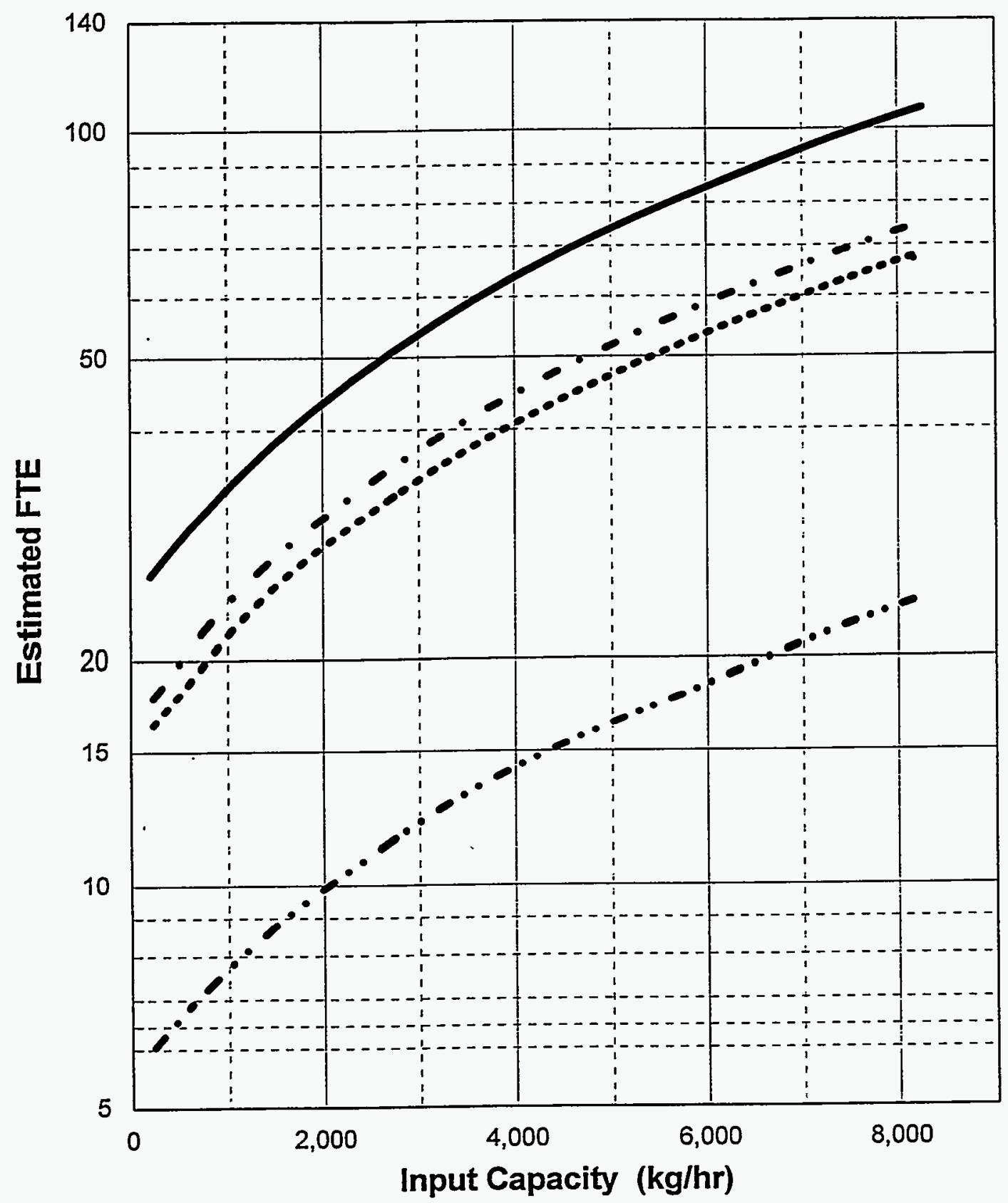

Pre-Operations Construction O\&M (1year) D\&D

Figure 7-1. FTE workers versus capacity for the maintenance (MAINT) module. 


\section{MAINTENANCE}

Costs by Work Breakdown Structure Element

Module: MAINT Waste Type: Contact Handled and Remote Handled TRUW

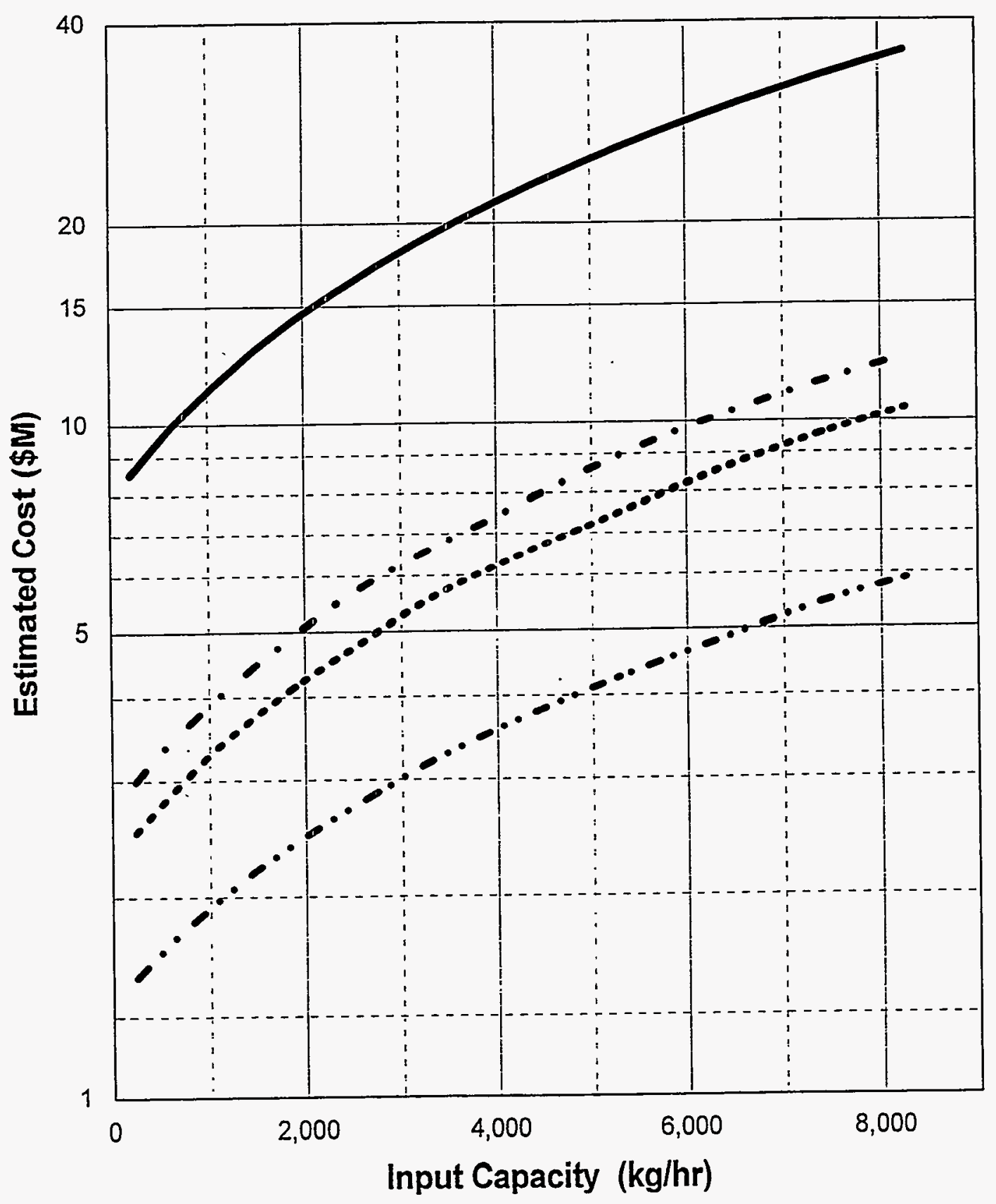

Pre-Operations Construction O\&M (1year) D\&D

Figure 7-2. PLCC versus capacity for the maintenance (MAINT) module. 
MAINTENANCE

Total Life Cycle Costs

Module: MAINT Waste Type: Contact Handled and Remote Handled TRUW

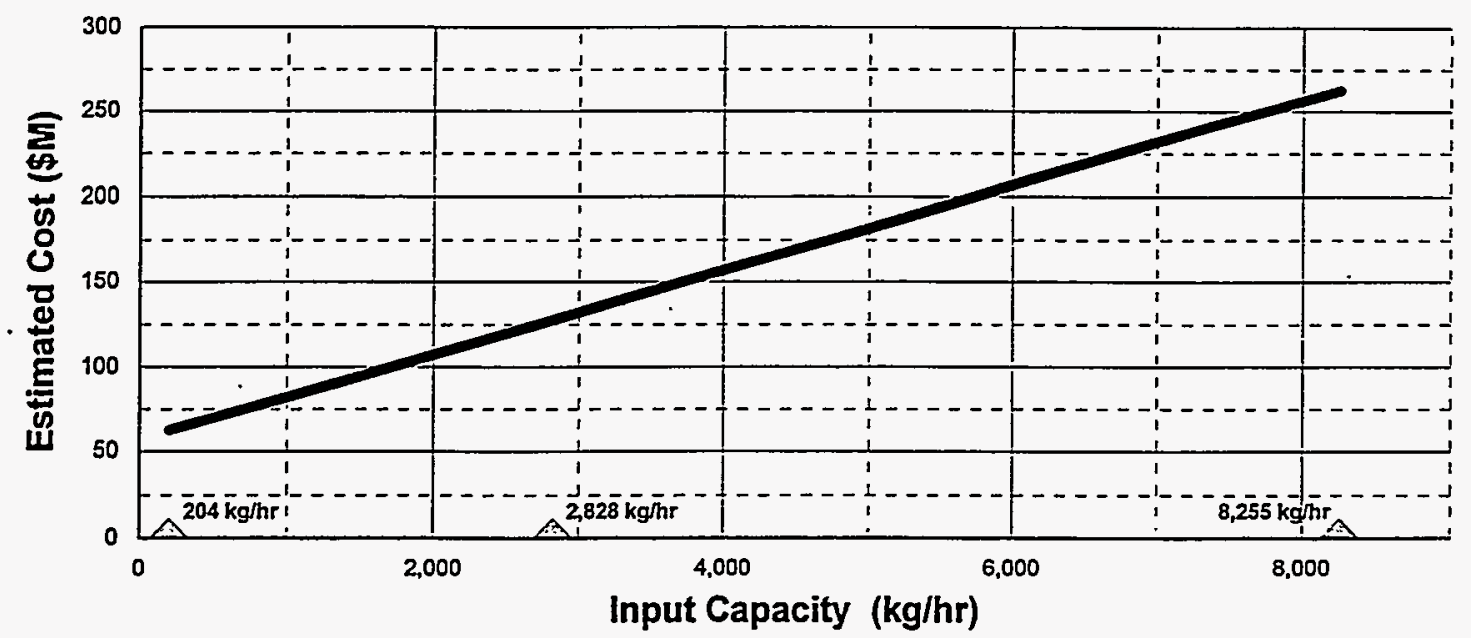

Contact Handled, Remote Handled

NOTE: Basis includes 20 years O\&M

Triangles indicate capacities where detailed cost estimates were developed.

\section{MAINTENANCE}

Total Life Cycle Unit Costs

Module: MAINT Waste Type: Contact Handled and Remote Handled TRUW

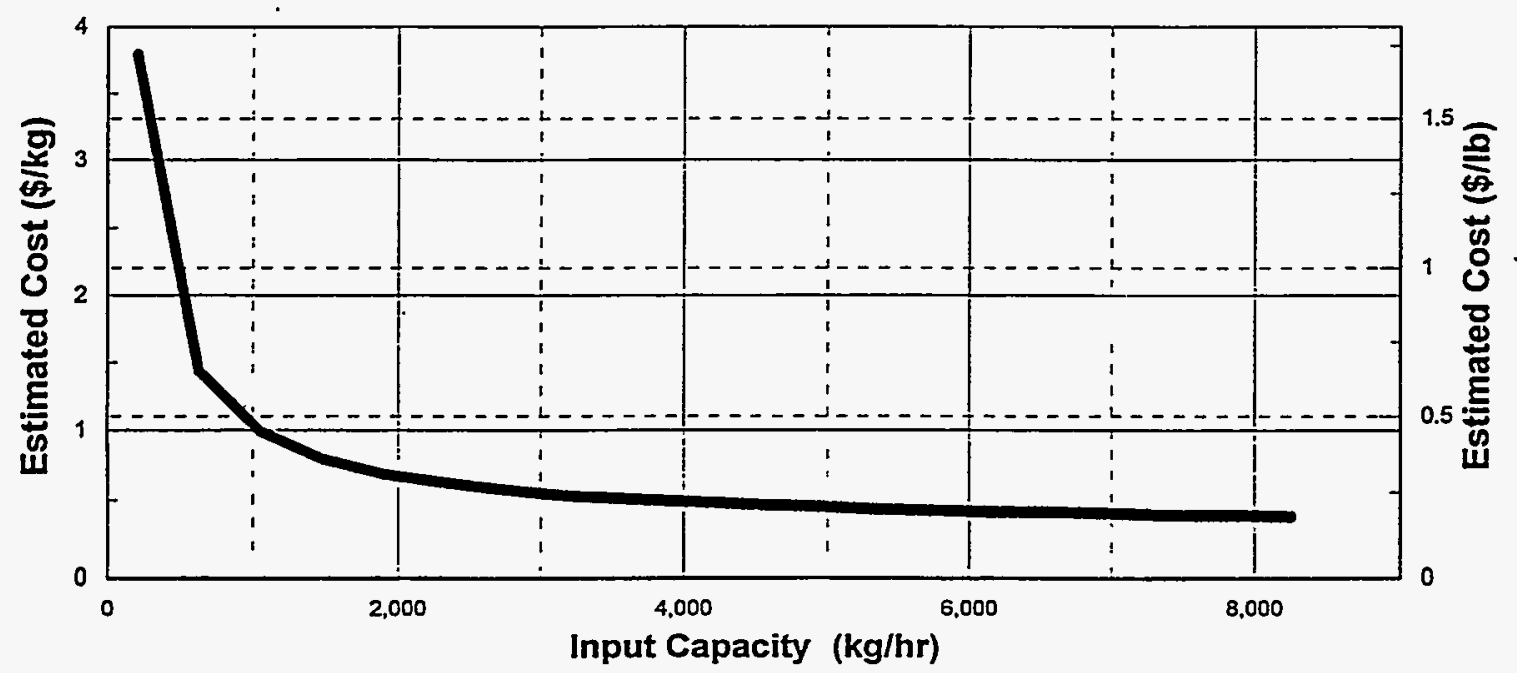

Contact Handled, Remote Handled

NOTE: Basis indudes 20 years O\&M

Figure 7-3. PLCC versus capacity including unit rates for the maintenance (MAINT) module. 


\section{INCINERATION (MODULE INCIN)}

\subsection{Basic Information}

This module is a thermal (flame) organic destruction unit. Module T-INCIN is applicable to CH-TRUW, while U-INCIN is intended for RH-TRUW. The CH-TRUW incineration module is shown in Figure 8-1. The INCIN module must be either used in conjunction with the receiving and inspection (RCINS) module and stabilization (VITRF or GROUT) modules or installed at a location where similar functions are available in existing facilities.

The incineration module receives and treats input organic solid waste, including process solid residues and organic and heterogeneous (i.e., combustibles commingled with noncombustibles) debris. Other material, such as organic liquids and lab packs, may also be processed by the incinerator. Extensive sorting of the organic and inorganic material is not necessary, as the incinerator can tolerate a high percentage of inorganic material in the feed. It is assumed that the input organic solids may contain up to $15 \%$ inorganic material.

The Controlled Air Incineration Facility at the Los Alamos National Laboratory has been used as the basis for the small TRUW incinerator module. The TSCA Incinerator at Oak Ridge National Laboratories and the Consolidated Incineration Facility at the Savannah River Site have been used as a basis for the large modules.

The waste is sorted at the receiving and inspection (RCINS) module and transferred to the incineration module in transport bins (or combustible boxes). The input waste generally consists of discarded paper, plastics, clothing (textile fabrics), wood, organic sludges, spent ion-exchange resins, spent activated carbon, and other solids produced by typical operations at DOE production or research and development installations.

Treatment units are provided assuming that the incoming waste contains radioactive constituents regulated under the Atomic Energy Act (AEA) and toxic metal and organics regulated under the Resource Conservation and Recovery Act (RCRA). In addition to the input waste, the incinerator module treats the secondary organic solid waste from other modules of the TRUW treatment facility. The module has a number of unit operations that accomplish the required functions. These unit operations are shown in the PFD in Figure 8-2.

\subsection{Technical Bases and Assumptions}

\subsubsection{Function and Operation of the Module}

The incineration module has all the unit operations needed for treating the incoming organic liquid and solid waste, which has a broad range of RCRA-regulated organic contaminants. Organic contaminants can include volatile organic compounds (VOCs), aromatics, alcohols, ketones, glycols, and petroleum compounds. The unit operations also have the capability to treat secondary waste, which consists of organic solids and organic liquids. The incoming solid waste is presorted before it is brought to the incineration module. 
The incoming waste is brought to the module in transfer bins (or cardboard boxes) mounted on transport devices. The contents are sorted and thoroughly characterized at the receiving and inspection module. Therefore, the function of the preparation and feed unit operation in the incineration module is merely to size reduce and convey the solid waste to the incineration chamber. The preparation and feed unit operation has a second feed device that batches and feeds organic liquids or slurries to the incinerator.

The incinerator oxidizes the organic and other combustible material contained in the feed. When sufficient solid waste is accumulated, the incinerator temperature is raised from the idle temperature (approximately $700-900^{\circ} \mathrm{F}$ ) to the combustion temperature (approximately

$\left.1,600-1,800^{\circ} \mathrm{F}\right)$. The process begins by gradually charging the incinerator chamber with input waste in solid form. Concentrated organic liquids are injected to the chamber as a fuel supplement, when needed. Low concentration organic liquids are added to cool the incinerator, when needed.

After oxidizing the organic liquids and solids, the resulting ash is discharged from the incinerator and placed in containers, which are transported to the stabilization module. The incinerator is designed to completely burn the feed and minimize the amount of carbon in the ash.

Gas generated during the incineration process is the module's first secondary waste stream. To ensure complete destruction of organic material, the gas is first heated in a secondary combustion chamber to a temperature of $2,000^{\circ} \mathrm{F}$ with a residence time of at least two seconds. This gas is then transported to an offgas treatment unit operation (or air pollution control unit) that cools and treats the gas to remove particulates, toxic metals, and acidic gases and other regulated elements and compounds before it is released to the atmosphere. This unit operation ensures that the offgas discharged to the atmosphere meets emission standards.

The offgas treatment unit operation has three major phases: dry filtration, wet scrubbing, and monitoring and discharge.

The dry filtration phase removes as much of the particulates (e.g., fly-ash and particulates of vaporized toxic metal compounds) as possible to minimize the amount of radioactive particles and toxic metal particles that pass to the wet scrubbing phase. This is done by first cooling the gas using a water quench and then dry filtering the gas using a bag or ceramic candle filters. The filtered gas is then transported to a filter of sulfur-impregnated activated carbon to remove mercury, lead, and other compounds. The final step in the dry phase consists of polishing the gas in a HEPA filter unit. Solid waste from this phase (fly ash, spent activated carbon, and spent HEPA filters) is transported to the stabilization module. If the incinerator input waste has a high mercury content, the spent activated carbon may be transported to a retort unit operation (to be included in the special waste module) for mercury recovery and amalgamation. ${ }^{\mathrm{g}}$

g. The overall fate of mercury in the system is as follows. Mercury vaporized during the incineration process is partially removed from the flue gas by the dry offgas filters and by carbon adsorption. The remainder is removed in the wet-gas primary scrubber using an aqueous acidic scrubbing medium. The mercury removed in the dry-gas filters accumulates in the ash and beds of activated carbon. This waste is eventually solidified by the stabilization module. The mercury removed during the wet scrubbing accumulates in the concentrated bottom sludge. This waste is also solidified by the stabilization module. 
The wet scrubbing phase further removes toxic metal, vapor, and acidic and alkaline gases (including hydrogen chloride and sulfur dioxide) and their salts. A series of wet scrubbing devices using caustic (or lime) solutions accomplishes this function. After scrubbing, the gas is transported to a moisture remover, a reheater, and to the emissions monitoring and discharge unit. Secondary waste from the scrubbing process, which consists of spent slurry, is neutralized and transported to a concentrator unit. The concentrator uses low-temperature evaporation to avoid revaporizing the captured mercury salts. Bottom sludge from the concentrator is transported to the polymer stabilization module. The concentrator distillate is treated and reused.

The monitoring and discharge phase continuously samples the gas and measures the concentration of the elements and compounds as specified by the facility emission control standards. The treated offgas meets the emissions standards as specified by the permit. The module minimizes as much as possible the volume of waste requiring disposal.

\subsubsection{Integration of the Module}

Input waste to the incineration module comes from the container open, dump, and sort; receiving and inspection; and aqueous waste treatment modules. Incinerator output consists of bottom ash and flyash, spent activated carbon, spent HEPA filters, and wet scrubber sludge, which are transported to the vitrification module or the grout stabilization module. Treated water is reused. Materials purchased for O\&M include such consumables as personal protective equipment, fuel, activated carbon, chemicals, and containers.

\subsection{Cost Bases, Assumptions, and Results}

The feed preparation, incinerator, secondary combustion chamber, dry offgas filtration, wet scrubber, stack monitors, and concentrator constitute the major equipment capital cost items.

The cost estimate for the incineration package is based on quotations by Joy Energy Systems of Charlotte, North Carolina, and ABB Raymond, Inc. of Lisle, Illinois. The cost estimate for the dry offgas filters is based on the use of a ceramic candle unit as quoted by Pall Advances Separation Systems of Cortland, New York. The cost estimate for the wet scrubbing unit is based on the use of a quencher and scrubbing unit as quoted by Croll-Reynolds Company of Westfield, New Jersey. The cost estimate for the concentrator unit is based on the use of a thin-film evaporator unit as quoted by LCI Corporation of Charlotte, North Carolina. The cost estimate for the air- and area-monitoring unit is based on a quote by Eberline Corporation of Santa Fe, New Mexico. The estimate for the stack-monitoring unit is also based on information received from Eberline. Estimated FTEs and costs versus capacity for this module are shown in Figures 8-3 through 8-7. 


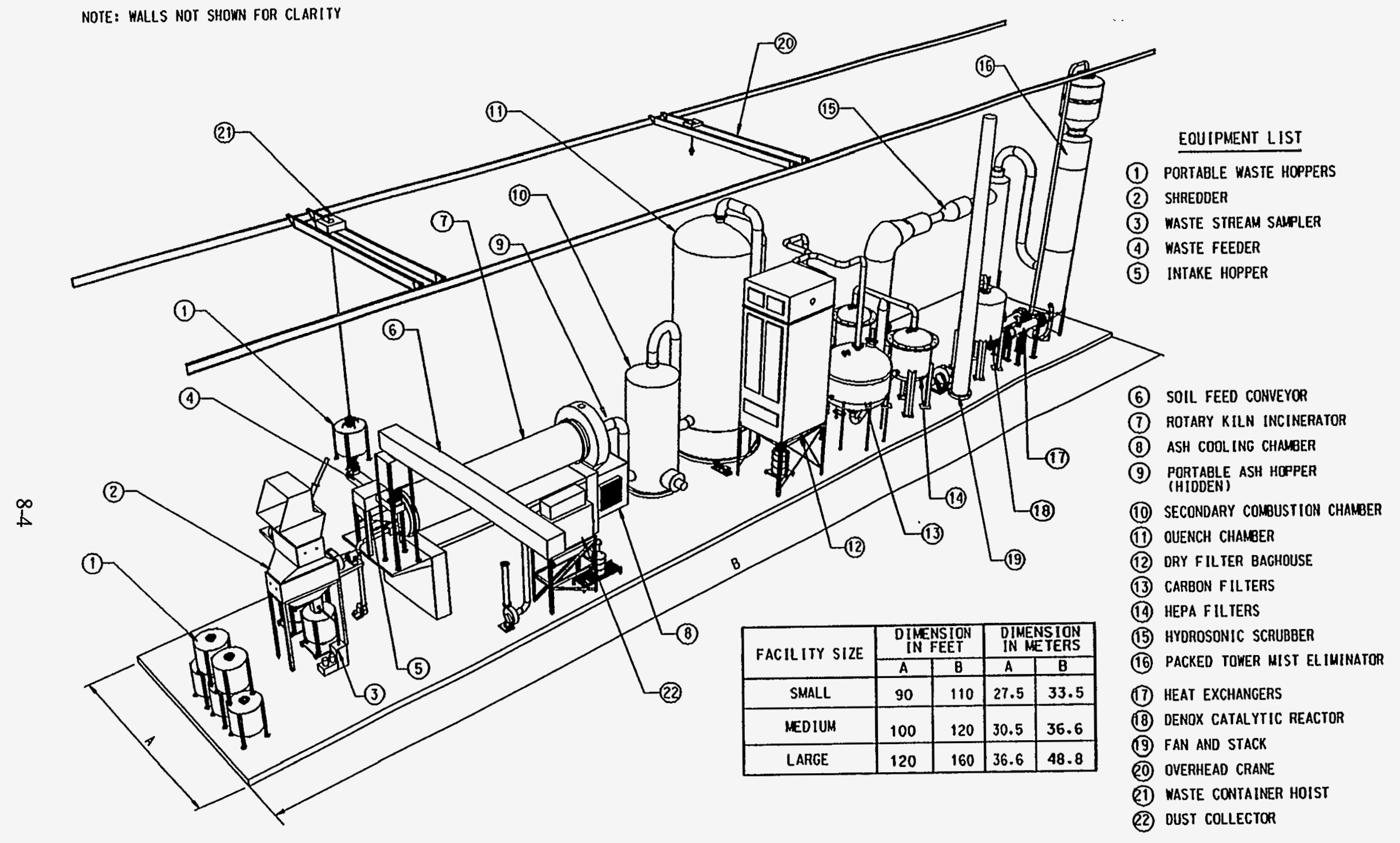

Figure 8-1. Equipment layout for the incineration (INCIN) module. 


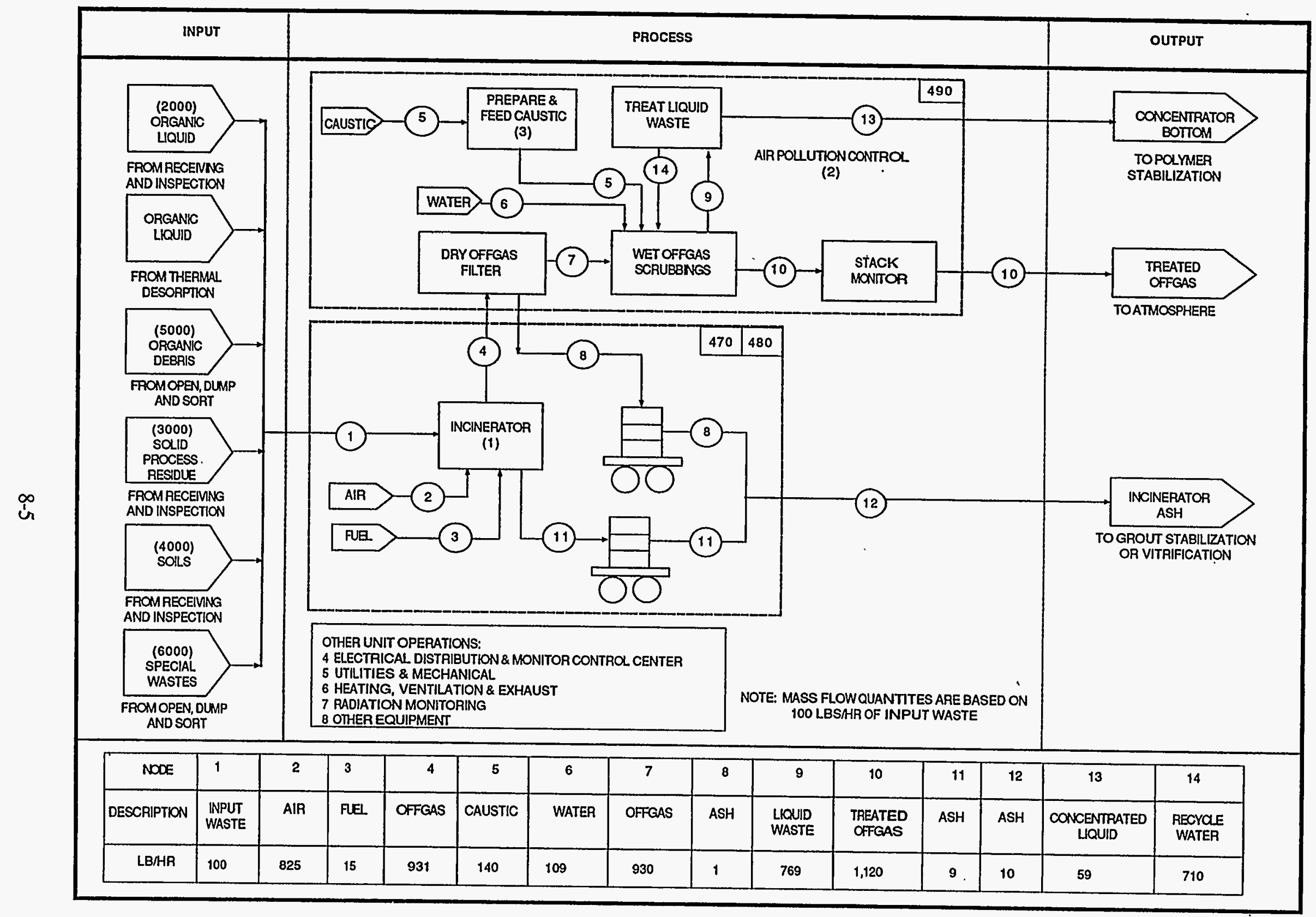

Figure 8-2. Process flow diagram for the incineration (INCIN) module. 


\section{INCINERATION}

FTE by Work Breakdown Structure Element Module: INCIN Waste Type: Contact Handled TRUW

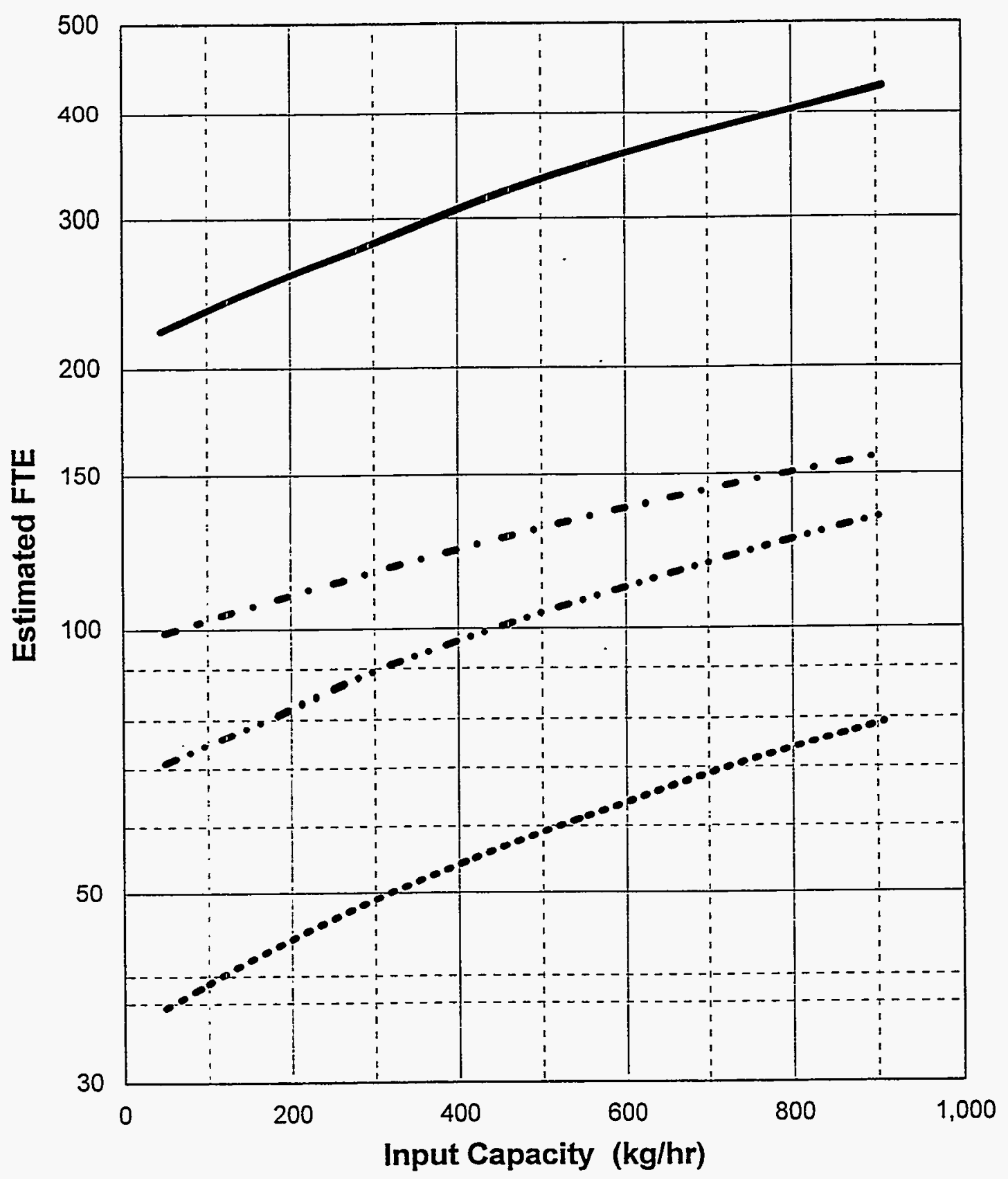

Pre-Operations Construction O\&M (1year) D\&D

Figure 8-3. FTE workers versus capacity for the $\mathrm{CH}$ incineration (T-INCIN) module. 


\section{INCINERATION}

FTE by Work Breakdown Structure Element Module: INCIN Waste Type: Remote Handled TRUW

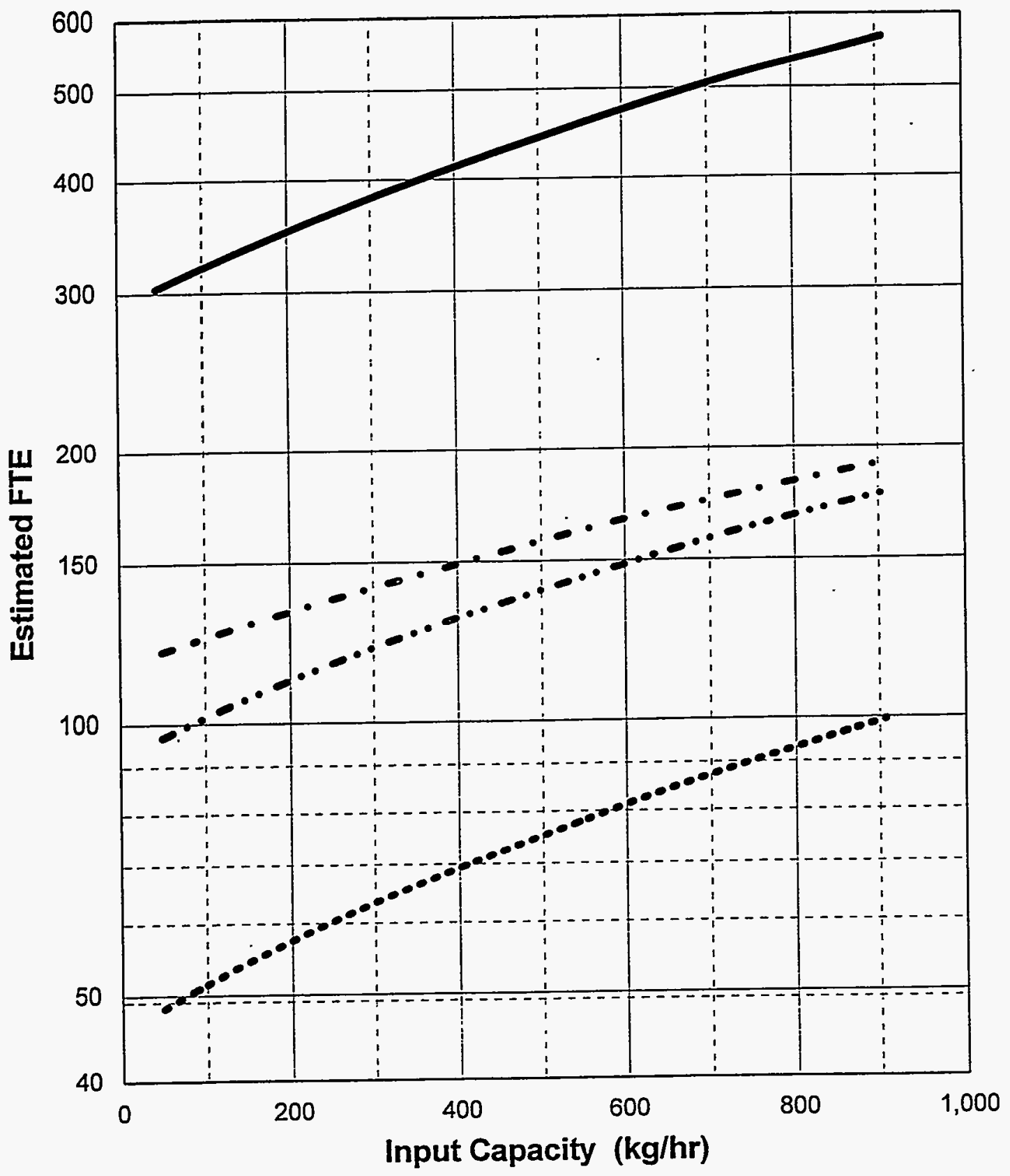

Pre-Operations Construction O\&M (1year) D\&D

Figure 8-4. FTE workers versus capacity for the RH incineration (U-INCIN) module. 


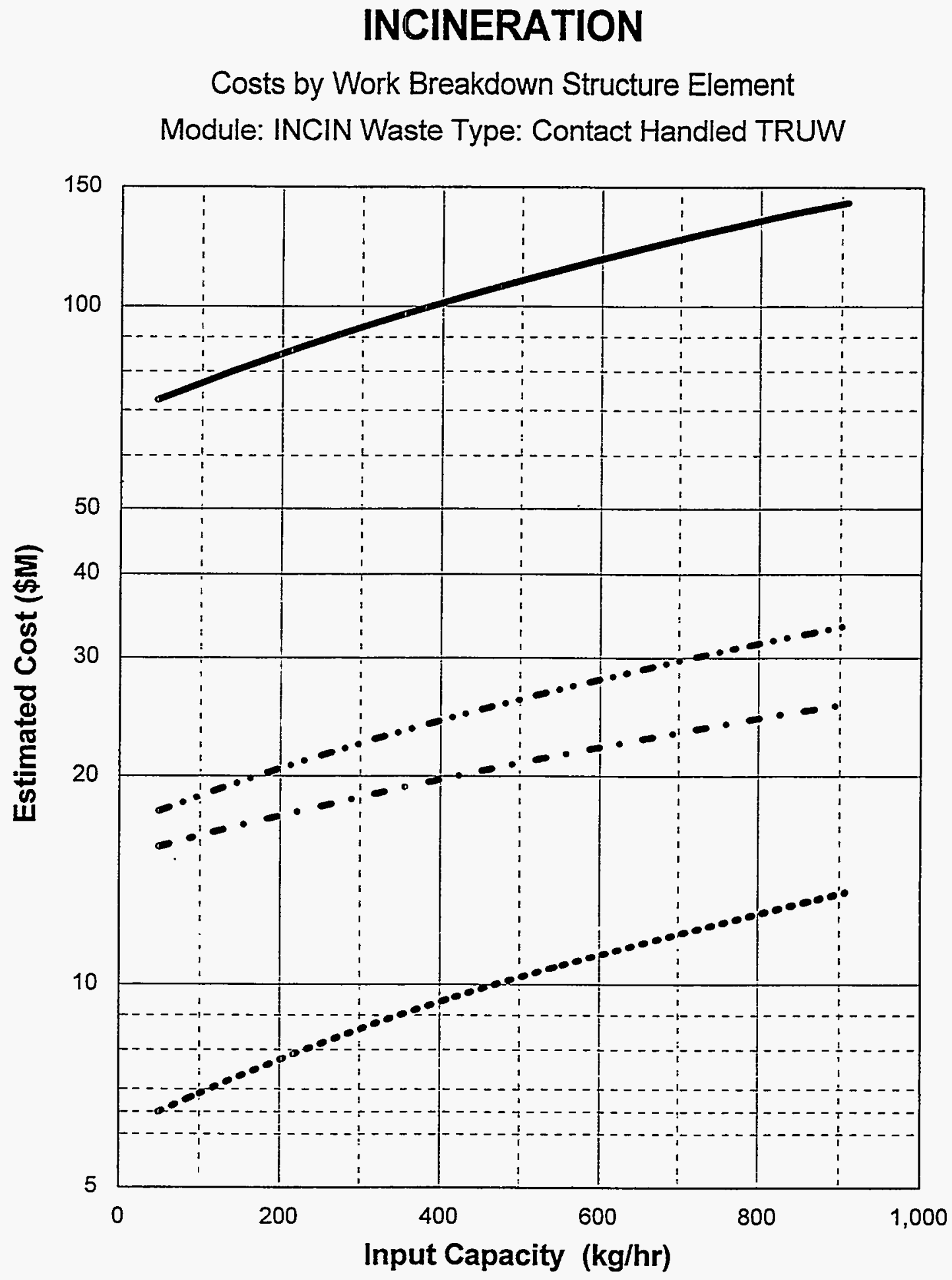

Pre-Operations Construction O\&M (1year) D\&D

Figure 8-5. PLCC versus capacity for the $\mathrm{CH}$ incineration (T-INCIN) module. 


\section{INCINERATION}

Costs by Work Breakdown Structure Element Module: INCIN Waste Type: Remote Handled TRUW

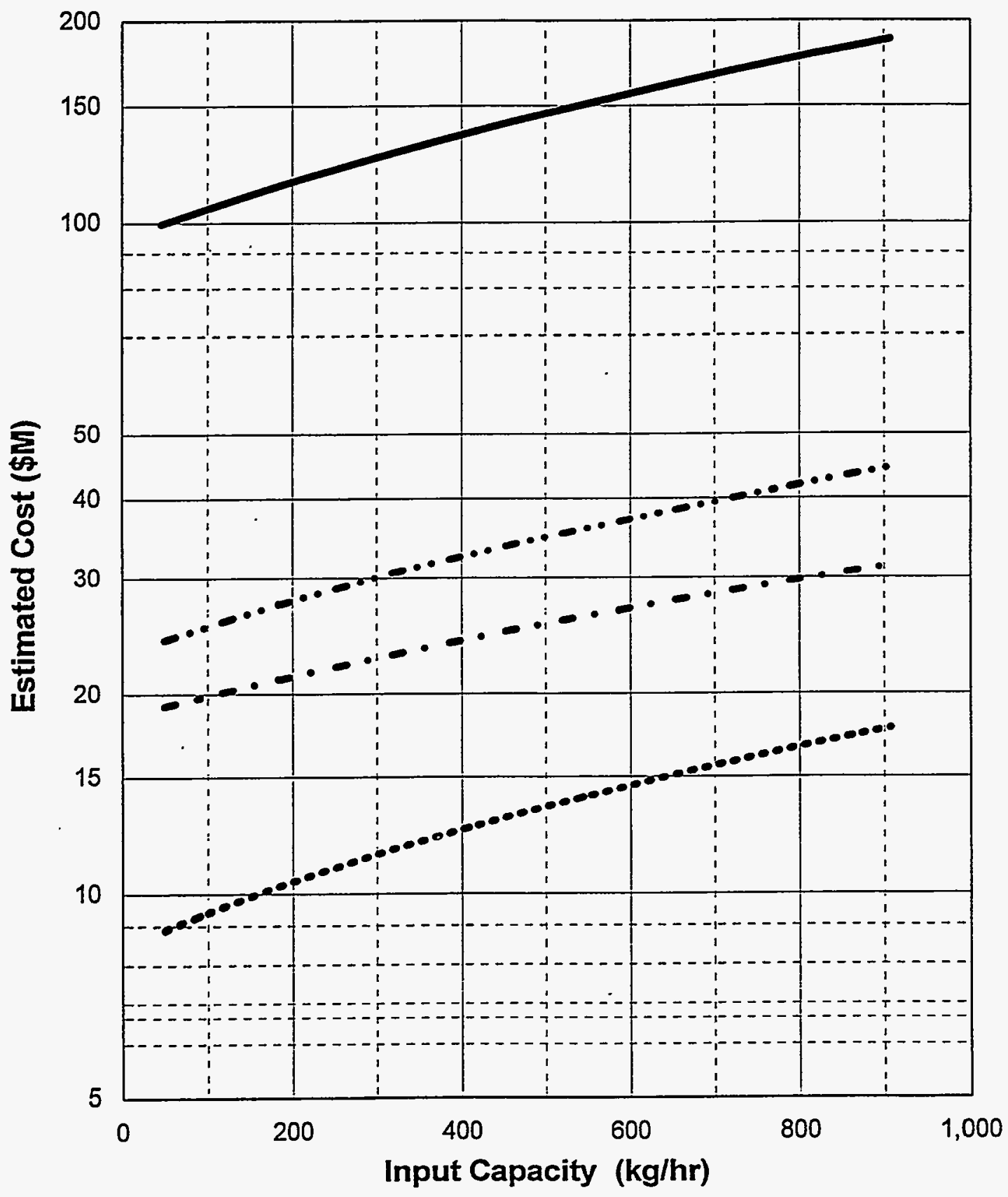

Pre-Operations Construction O\&M (1year) D\&D

Figure 8-6. PLCC versus capacity for the RH incineration (U-INCIN) module. 


\section{INCINERATION}

\section{Total Life Cycle Costs}

Module: INCIN Waste Type: Contact Handled and Remote Handled TRUW

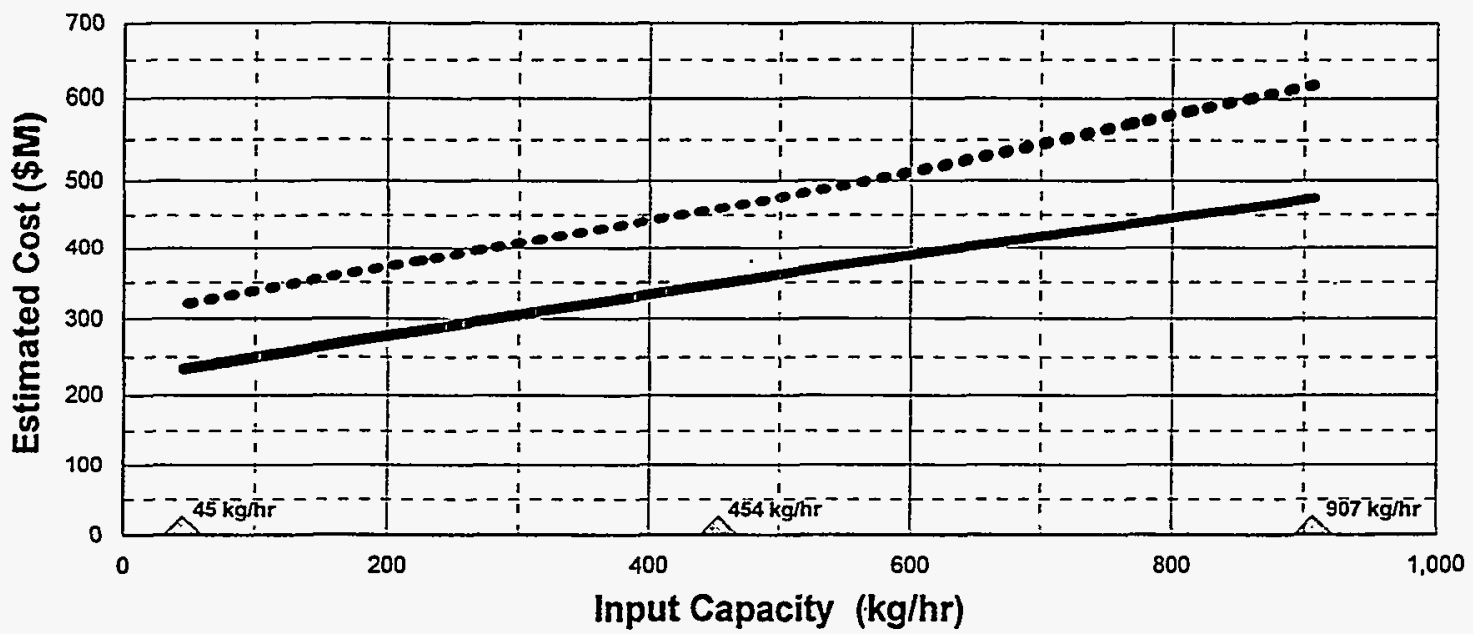

Contact Handled Remote Handled

NOTE: Basis includes 20 years of O\&M

Triangles indicate capacities where detailed cost estimates were developed.

\section{INCINERATION}

Total Life Cycle Unit Costs

Module: INCIN Waste Type: Contact Handled and Remote Handled TRUW

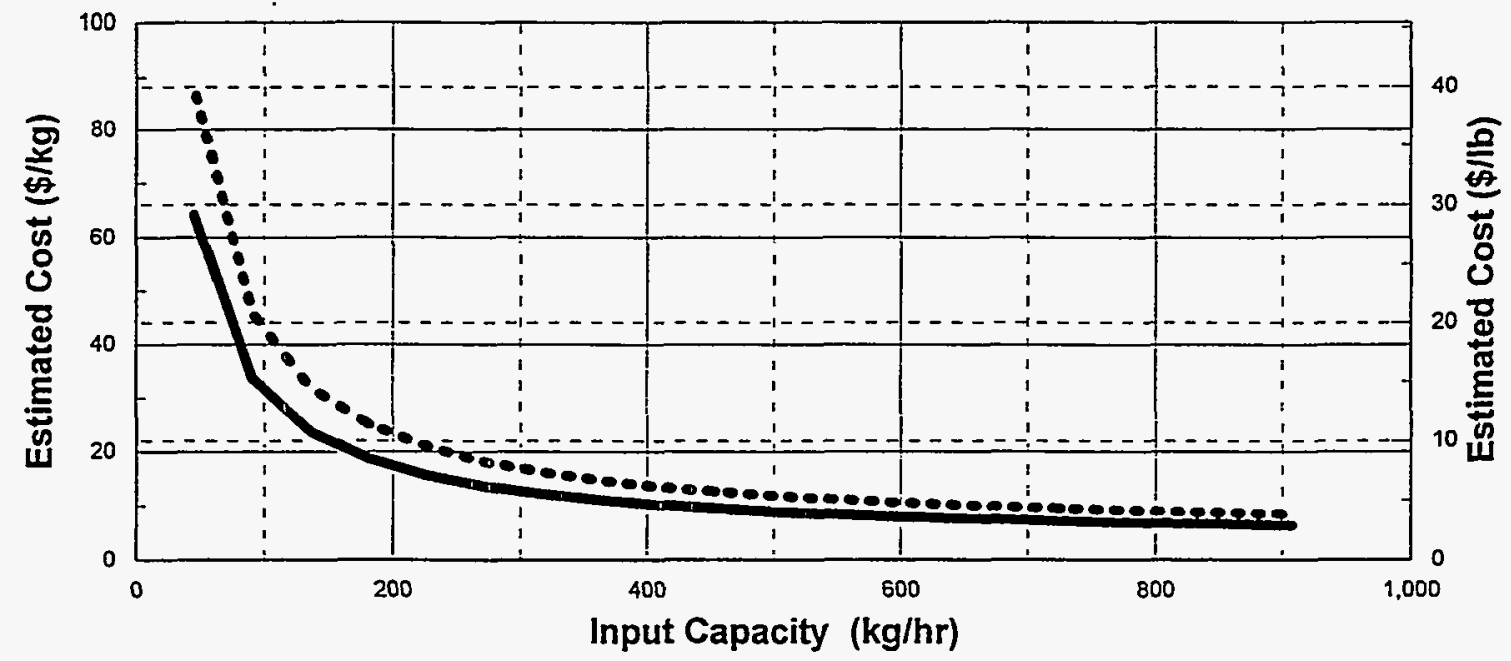

Contact Handled Remote Handled

NOTE: Basis indudes 20 years O\&M

Figure 8-7. PLCC versus capacity including unit rates for the incineration (INCIN) module. 


\section{DEACTIVATION (MODULE DEACT)}

\subsection{Basic Information}

The deactivation module, shown in Figure 9-1, must be used in conjunction with the open, dump, and sort (OSORT) module; or the stabilization (GROUT or ORGSB) modules and aqueous waste treatment (AQWTR) module; or installed at a location where similar functions are available in existing facilities.

The deactivation module collects and treats reactive metals present in the input as either solids or as liquid solutions. The metal waste is shipped to the module in cans, drums, and special transport containers having several different capacities. Treatment units are provided based on the assumption that the incoming waste contains radioactive constituents regulated under AEA and toxic metal regulated under RCRA. The module has a number of unit operations that accomplish the required functions. Unit operations are shown in the PFD in Figure 9-2.

\subsection{Technical Bases and Assumptions}

\subsubsection{Function and Operation of the Module}

The deactivation module has all the unit operations needed for treating incoming solid and liquid waste having reactive characteristics with a broad range of RCRA-controlled toxic, heavy-metal contaminants. Toxic metal contaminants can include arsenic, barium, beryllium, cadmium, chromium, cyanide, selenium, sodium, and uranium.

The incoming metal waste is segregated into solids and liquids before it is brought to the treatment module. Solids are brought to a metal preparation area for radioassay and sorting before treatment in the chemical treatment area as in the case of sodium and uranium, or in the metal classification area for recovery. Liquids are brought to a chemical treatment area.

The deactivation unit operations have maximum flexibility for batch operation. The waste is transferred from the incoming containers to the appropriate treatment operation.

Typical steps for treating bulk quantities of the liquid and solid waste categories are as follows (refer to PFD in this section):

Solid metal waste. Solid metal waste is processed through a metal preparation area where the waste is sorted into the various metal types and radioactivity categories. Sodium and uranium metal is segregated and transported to the sodium destruction and uranium removal areas, respectively. All other metal is washed to remove tramp particles, then is dried and is again radioassayed. Large pieces are reduced in size by cutting before packaging. Metal determined not to be radioactively contaminated is transported to recycle. Radioactive metal is transported to the stabilization module. Metal particles collected by a filter in the washing operation, and dust particles collected by a HEPA filter in the air exhaust hood over the cutting operation, are eventually transported to the stabilization module. Liquids from the washing step are transported to the aqueous waste module. 
Sodium waste. Metallic sodium (from the sorting step in the metal preparation area) is transported to the sodium destruction area and placed in the reactor. Here it reacts with water to form sodium hydroxide. Small amounts of hydrogen from the reaction are destroyed in the offgas treatment step. Before the resultant sodium hydroxide solution is transported to the aqueous waste module, it can be neutralized by adding acid to the reactor.

Uranium waste. Metallic uranium from the sorting step in the metal preparation area is transported to the uranium removal area and placed in a reactor, where it is dissolved with nitric acid. The resulting liquid can be reacted with a solution of lime that-precipitates most of the metal as a hydroxide, which is allowed to settle. Liquid in the reactor is decanted to the aqueous waste treatment module. Hydroxide sludge is transported to the solids removal area where it passes through a filter press to remove large particles and through a pressure filter to remove fine particles. The sludge could also be transported to the chemical treatment area for additional processing in the precipitation unit. The liquid from filtration is then processed by ion exchange to remove trace amounts of uranium.

Liquid waste. Waste that contains a toxic metal in solution is transported to the chemical treatment area. Uranium solutions are transported to a reactor and processed with the solutions generated as described above. In the chemical treatment area, a single unit allows for pretreatment with hydrogen peroxide and sodium hypochlorite to oxidize the metal, and treatment with ferric sulfate, lime, and a polymer to coprecipitate metal in a hydroxide floc. The floc settles in a clarifier, which is part of the same unit, and is processed by the filter press in the solids removal area as described in the uranium waste section above. Clarifier liquid is again filtered in a pressure filter to remove fines and then goes to the ion-exchange system to remove traces of dissolved metal.

The unit operations remove radioactivity and RCRA-regulated metal to a level that permits the treated water to be either recycled for reuse or discharged if allowed by the site discharge permits. Before release, the treated water from the ion-exchange system is sampled and assayed for discharge or for further treatment in the aqueous waste module.

\subsubsection{Integration of the Module}

Input waste to the deactivation module comes from the open, sort, and dump module. Output includes radioactive metal, spent resin, spent filter material, and concentrated sludge, which are transported to the stabilization modules. Secondary aqueous waste is transported to aqueous waste treatment. Materials purchased for O\&M, such as personal protective equipment, ion-exchange resin, filter material, chemicals, and containers, are assumed to be consumable supplies and their costs are estimated accordingly.

\subsection{Cost Bases, Assumptions, and Results}

The mass balance summary presented in this section is based on the assumption that input waste consists of $75 \%$ solids by weight and $25 \%$ liquids. The solids are assumed to be $5 \%$ barium, $10 \%$ beryllium, $50 \%$ cadmium, $10 \%$ chromium, $10 \%$ selenium, $10 \%$ sodium, and $5 \%$ uranium. The liquids are assumed to be $25 \%$ arsenic, $20 \%$ barium, $25 \%$ cyanide, $20 \%$ selenium, and $10 \%$ uranium. For purposes of sizing equipment, each element in solution was assumed to be $500 \mathrm{mg} / \mathrm{L}$. The 
pretreatment and precipitation unit, filter press and pressure filter, ion exchange system, sodium and uranium reactors, chemical and holding tanks and pumps, metal washing and sorting hoods or glove boxes, and offgas treatment equipment constitute the major equipment capital cost items. Their costs are based on prices submitted by various vendors. The small generator module PLCC and operating manpower staffing is based on an approximate metal waste treatment rate of five and $20 \mathrm{lb} / \mathrm{hr}$.

Estimated FTE and cost versus capacity for this module are shown in Tables 9-1 and 9-2.

Table 9-1. DEACT FTEs (for both contact- and remote-handled transuranic waste).

\begin{tabular}{lc}
\hline & $\begin{array}{c}9.1 \mathrm{~kg} / \mathrm{hr} \\
(\mathrm{FTEs})\end{array}$ \\
\hline Preoperations & 8 \\
Construction & 48 \\
O\&M (20 years) & 138 \\
D\&D & 9 \\
Total life-cycle (20́ years O\&M) & 203 \\
\hline
\end{tabular}

Table 9-2. DEACT costs (for both contact- and remote-handled transuranic waste).

\section{$9.1 \mathrm{~kg} / \mathrm{hr}$}

(\$ million)

\begin{tabular}{|c|c|}
\hline Preoperations & 1.4 \\
\hline Construction & 11.6 \\
\hline O\&M (20 years) & 19.8 \\
\hline $\mathrm{D} \& \mathrm{D}$ & 2.2 \\
\hline Total life-cycle ( 20 years O\&M) & 35.0 \\
\hline Unit cost $(\$ / \mathrm{kg})$ & 47.7 \\
\hline
\end{tabular}


NOTE: AREAS ALLOCATED TO SUPPORT UNIT OPERATIONS ARE NOT SHOWN ON THE PLAN.

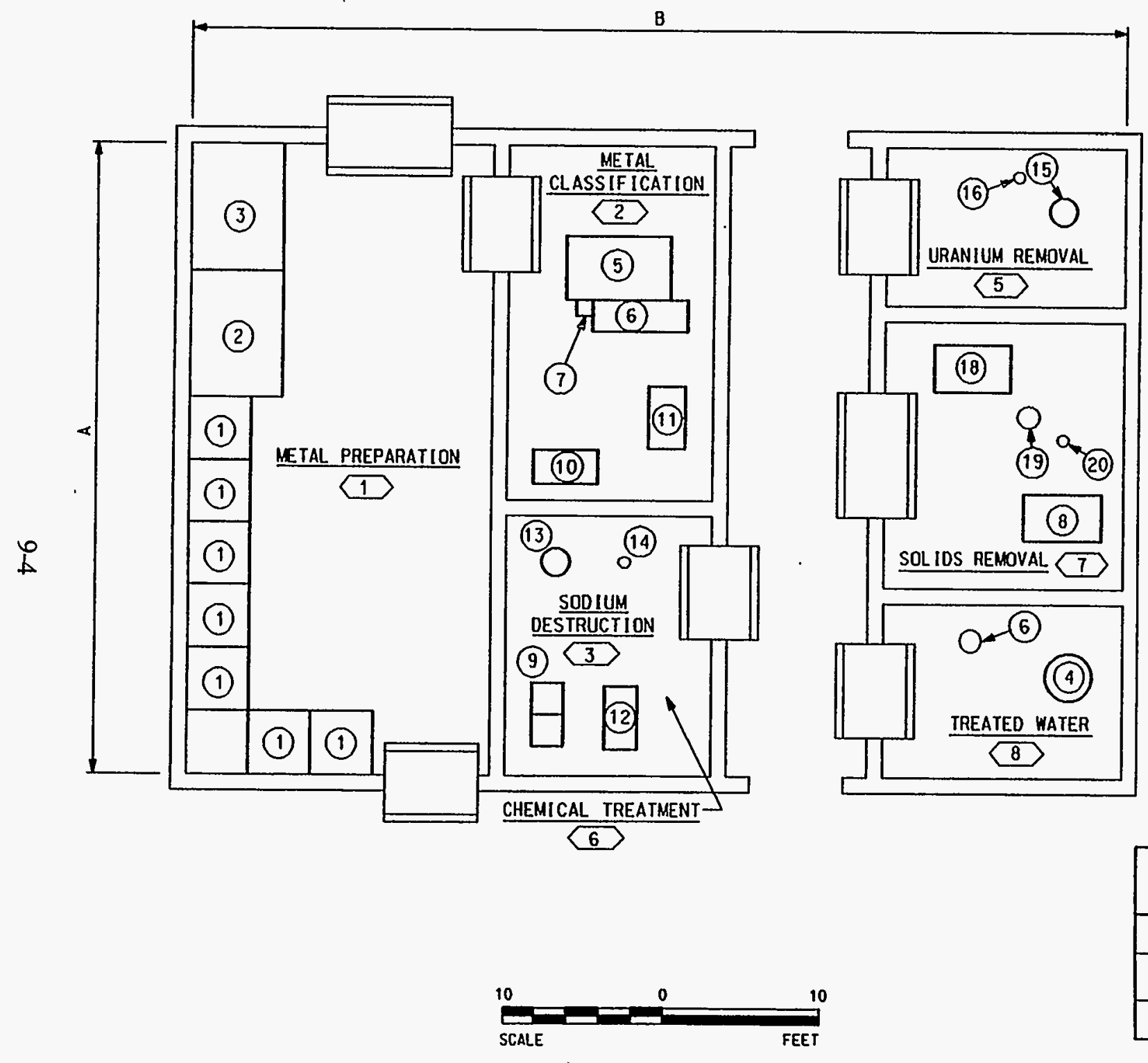

Figure 9-1. Equipment layout for the deactivation (DEACT) module.

\section{EQUIPMENT LIST}

(1) METAL SORT STATION

(2) MEtal wash STATION

(3) METAL DRYING STATION

(4) AQUEOUS WASTE TANK \& PUMPS

(5) CUT/SAW STATION

(6) TREATED WATER TANK \& PUMPS

(7) ROLLING BIN

(8) ION EXCHANGE SKID

(9) PRE-TREATMENT \& PRECIPITATION

(10) UNLOAD TABLE

(11) ROLLOUT PALLET

(12) CHEMICAL SOLUTIONS FEED TANKS AND PUMPS

(13) SODIUM REACTOR

(14) ACIO TANK \& PUMP

(15) URANIUM REACTOR

(16) ACID TANK \& PUMP

(17) Lime PREParation tank

(18) FILTER PRESS (FP)

(19) FP LIQUID HOLDING TANK \& PUMP

(20) BAG F ILTER

\begin{tabular}{|c|c|c|c|c|}
\hline \multirow{2}{*}{ FACILITY SIZE } & \multicolumn{2}{|c|}{$\begin{array}{l}\text { DIMENSION } \\
\text { IN FEET }\end{array}$} & \multicolumn{2}{|c|}{$\begin{array}{l}\text { DINENSION } \\
\text { IN METERS }\end{array}$} \\
\hline & A & $\mathbf{B}$ & $\bar{A}$ & 8 \\
\hline SMALL & 110 & 60 & 33.5 & 18.3 \\
\hline MEDIUM & - & - & _ & - \\
\hline LARGE & - & - & - & - \\
\hline
\end{tabular}




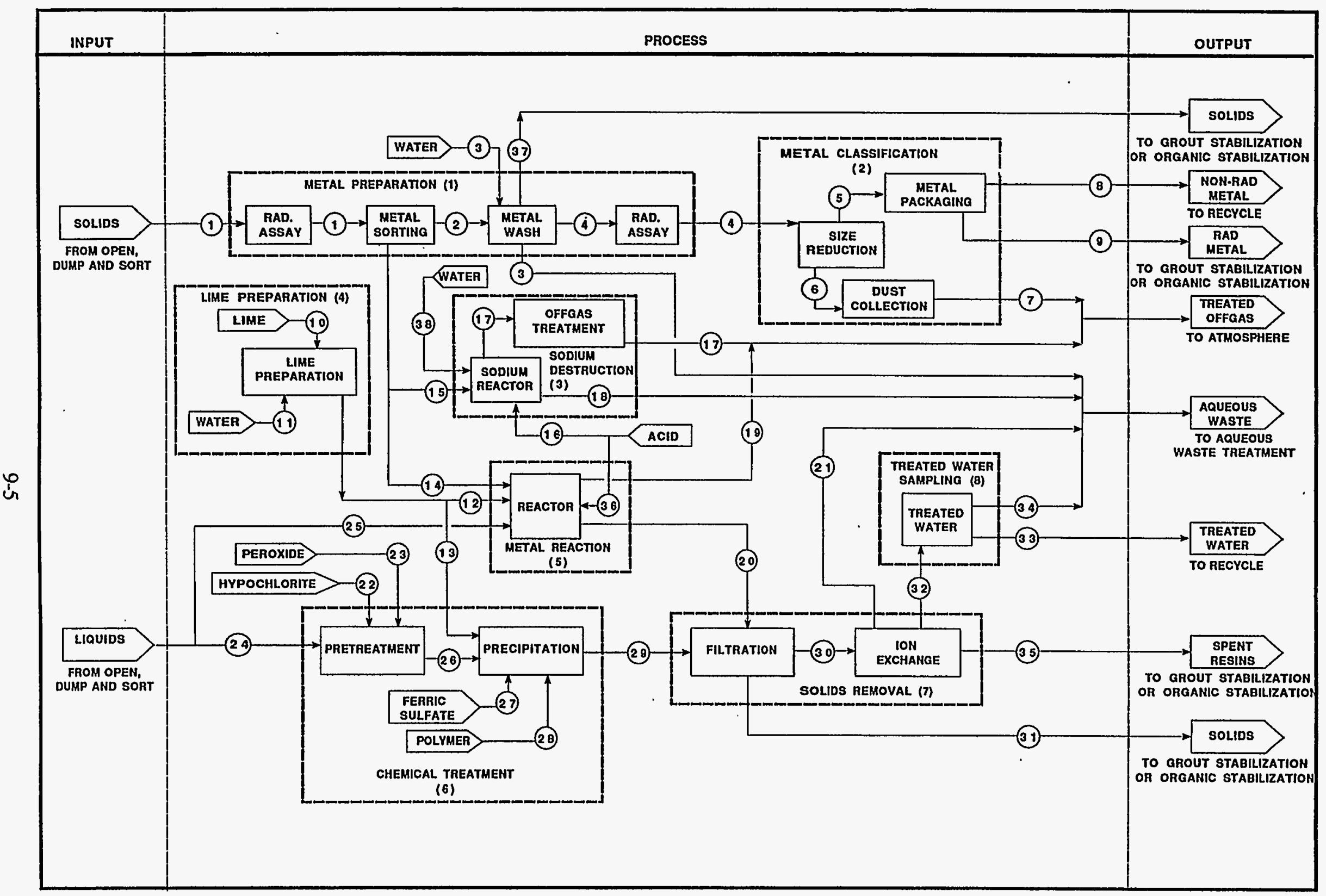

Figure 9-2. Process flow diagram for the deactivation (DEACT) module. 
'(pənựuos) ' ¿-6 aมn6!ฺ

\begin{tabular}{|c|c|c|c|c|c|c|c|c|c|c|c|c|c|c|c|c|c|c|c|}
\hline 0 & 0 & 6.9 & $\overline{g^{\prime} 0}$ & 90 & 5.811 & $\varepsilon \cdot \angle z ।$ & 61 & 8.092 & $\nabla^{\prime} \cdot 86$ & 6.0 & $7 \cdot 9$ & 8.06 & 01 & 06 & $L^{\prime} 0$ & $1 \cdot 0$ & $\varepsilon \varepsilon 1$ & b.081 & $8 H / 87$ \\
\hline$\left|9 \varepsilon^{\prime}\right|$ & $\nabla 0$ & $L^{\prime} L$ & s.0 & $8 \% 0$ & ozl & 8.02। & $\varepsilon 1$ & 9 9tz & 0 & 0 & 0 & 0 & 0 & 0 & 0 & 0 & $\nabla 21$ & 9.892 & YH/87 \\
\hline y3IVM & 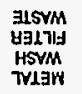 & ODY & $\begin{array}{l}\text { SNNS3Y } \\
\text { NN3dS }\end{array}$ & $\begin{array}{l}\text { IIsYM } \\
\text { ghcorror }\end{array}$ & $\begin{array}{l}\text { YyivM } \\
\text { OaIVset }\end{array}$ & 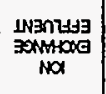 & 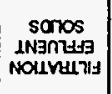 & 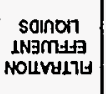 & 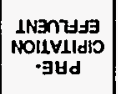 & yaruาod & 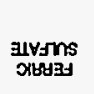 & 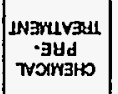 & 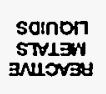 & 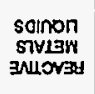 & $300 \times 043 d$ & 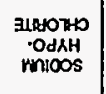 & $\begin{array}{l}\text { בlsvyM } \\
\text { siogroy }\end{array}$ & $\begin{array}{l}\text { soinon } \\
\text { youpryt }\end{array}$ & NOLLIYOSBO \\
\hline $8 \varepsilon$ & $\angle \varepsilon$ & $9 \varepsilon$ & $9 \varepsilon$ & $p \varepsilon$ & ce & $z \varepsilon$ & $1 \varepsilon$ & $O \varepsilon$ & 62 & 82 & $\angle 2$ & 82 & sz & $\forall z$ & $\varepsilon z$ & 22 & 12 & 02 & $300 \mathrm{~N}$ \\
\hline
\end{tabular}

\begin{tabular}{|c|c|c|c|c|c|c|c|c|c|c|c|c|c|c|c|c|c|c|c|}
\hline 1.0 & 0 & 0 & 0 & 0 & 0 & $\theta^{\prime} z$ & 981 & 2.091 & s $\angle 2$ & 0 & 0 & o & o & 0 & 0 & 0 & 0 & 0 & 甘H/Q7 \\
\hline 1.0 & $g \cdot s \mid t^{\prime} t$ & Y'o & st & 01 & 67 & 0 & $9 r z$ & เฉz & $9 z$ & $g \cdot p t$ & ot & 1.0 & $1 \cdot 0$ & $\theta^{\prime}+8$ & $\angle \cdot b 8$ & $\angle \| \nabla^{\prime} t$ & $1 \cdot 98$ & 001 & ४н/87 \\
\hline סעדנו & $\begin{array}{l}\text { glovM } \\
\text { snosioy }\end{array}$ & $\sin 20$ & abr & רW & new & 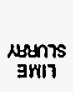 & $\begin{array}{c}\text { Leanns } \\
\text { JW1I }\end{array}$ & yatrm & 3N17 & 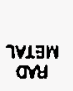 & $\begin{array}{c}7130 \\
\text { ant }\end{array}$ & $\begin{array}{c}\text { houtosm } \\
\text { Isno }\end{array}$ & 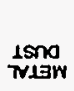 & 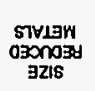 & 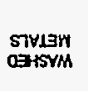 & 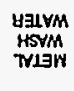 & 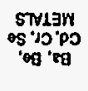 & 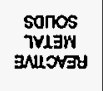 & | NOILAlitosza \\
\hline 61 & 81 & 41 & 91 & st & 71 & 81 & $z_{1}$ & 11 & 01 & $B$ & 8 & 2 & 9 & 9 & $\nabla$ & $\varepsilon$ & $z$ & 1 & $300 \mathrm{~N}$ \\
\hline
\end{tabular}

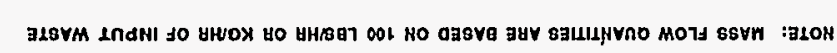




\section{NEUTRALIZATION (MODULE NEUTR)}

\subsection{Basic Information}

The neutralization module, shown in Figure 10-1, must be either used in conjunction with the receiving and inspection (module RCINS) and the grout stabilization (GROUT) module, or installed at a location where similar functions are available.

The neutralization module collects and treats input aqueous waste that is corrosive (pH below 2.0 or above 10.0 ) or contains inorganic compounds requiring destruction. The corrosive aqueous waste is received at the module in cans, drums, or special transport containers having several different capacities. In addition to treating input aqueous waste, this module treats the secondary aqueous waste (floor drains, equipment drains, and chemical wastes) for the TRUW treatment facility. The module has a number of unit operations that accomplish the required functions. Module T-NEUTR is intended for CH-TRUW, while module U-NEUTR is intended for RH-TRUW. Unit operations are shown in the PFD in Figure 10-2.

\subsection{Technical Bases and Assumptions}

\subsubsection{Function and Operation of the Module}

The neutralization module has all the unit operations needed for treating an incoming liquid waste having a range of RCRA-controlled toxic, heavy metal and inorganic contaminants. Toxic metal contaminants can include mercury, cadmium, chromium, and lead. The unit operations also have the capability to treat secondary liquid waste generated by the TRUW treatment facility, such as distillate from air pollution control (module INCIN), rinse water container washdown operations (modules RCINS and GROUT), and liquids collected from the module equipment and floor drains.

The incoming liquid waste is precharacterized before it is brought to the treatment modules. For bulk operations, the incoming waste is segregated into different groups: liquids with a low $\mathrm{pH}$, liquids with a high $\mathrm{pH}$, and liquids that require destruction of various inorganic compounds.

The neutralization unit operations have maximum flexibility and can be used in series, in parallel, or as stand-alone units. Flexible piping connectors are provided at the inlet and outlet of each treatment device. The waste is transferred from the transport container to appropriate batch tanks or directly to a desired treatment unit operation.

Typical steps for treating bulk quantities of the three waste categories are as follows (refer to Figure 10-2):

Low-pH waste. Waste having a low $\mathrm{pH}$ and requiring no treatment other than neutralization is treated with a basic neutralizer compound and transported to the stabilization module. No further processing is performed in order to minimize concentration and potentially increase the criticality of the treated stream. 
High-pH waste. Waste high in $\mathrm{pH}$ is processed through the neutralization module by the addition of acidic neutralizer compounds. The final treatment $\mathrm{pH}$ selected is dependent on the quantity of suspended solids that the stream would produce. This amount is minimized in order to reduce the criticality of the stream. Any sludge generated from the neutralization process is removed and transported to stabilization. Supernate from the neutralization is also transported to stabilization.

Inorganic wastes. Waste containing only inorganic compounds that require destruction are treated by reacting these compounds with various compounds that will convert the toxic compounds into non- or lesser-toxic compounds. The resulting treated stream is transported to stabilization.

\subsubsection{Integration of the Module}

Input waste to the neutralization module comes from the receiving and inspection module or from onsite waste generators. This input waste has been precharacterized. Other input includes secondary waste from incineration, decontamination, and stabilization modules. Output from the neutralization module to the stabilization module includes spent resins, spent carbon, slight amounts of sludge, and the neutral aqueous stream. Materials purchased for O\&M, such as personal protective equipment, ion exchange resins, activated carbon, chemicals, and containers are assumed to be consumable supplies and their costs are estimated accordingly.

\subsection{Cost Bases, Assumptions, and Results}

Input wastes are assumed to be properly characterized to allow a trained operator to anticipate the critical nature of an input, treated, or output stream. The neutralization unit, ion exchange, spent carbon units, filters, and radiation monitors constitute the major equipment capital items. Their costs are based on prices submitted by various vendors. Operating manpower for the module is based on a batch operation with close monitoring of the treatment process at all times.

Estimated FTE and cost versus capacity for this module are shown in Figures 10-3 through 10-7. 
NOTE: AREAS ALLOCATEO TO SUPPORT UNIT OPERATIONS ARE NOT SHOWN ON THE PLAN

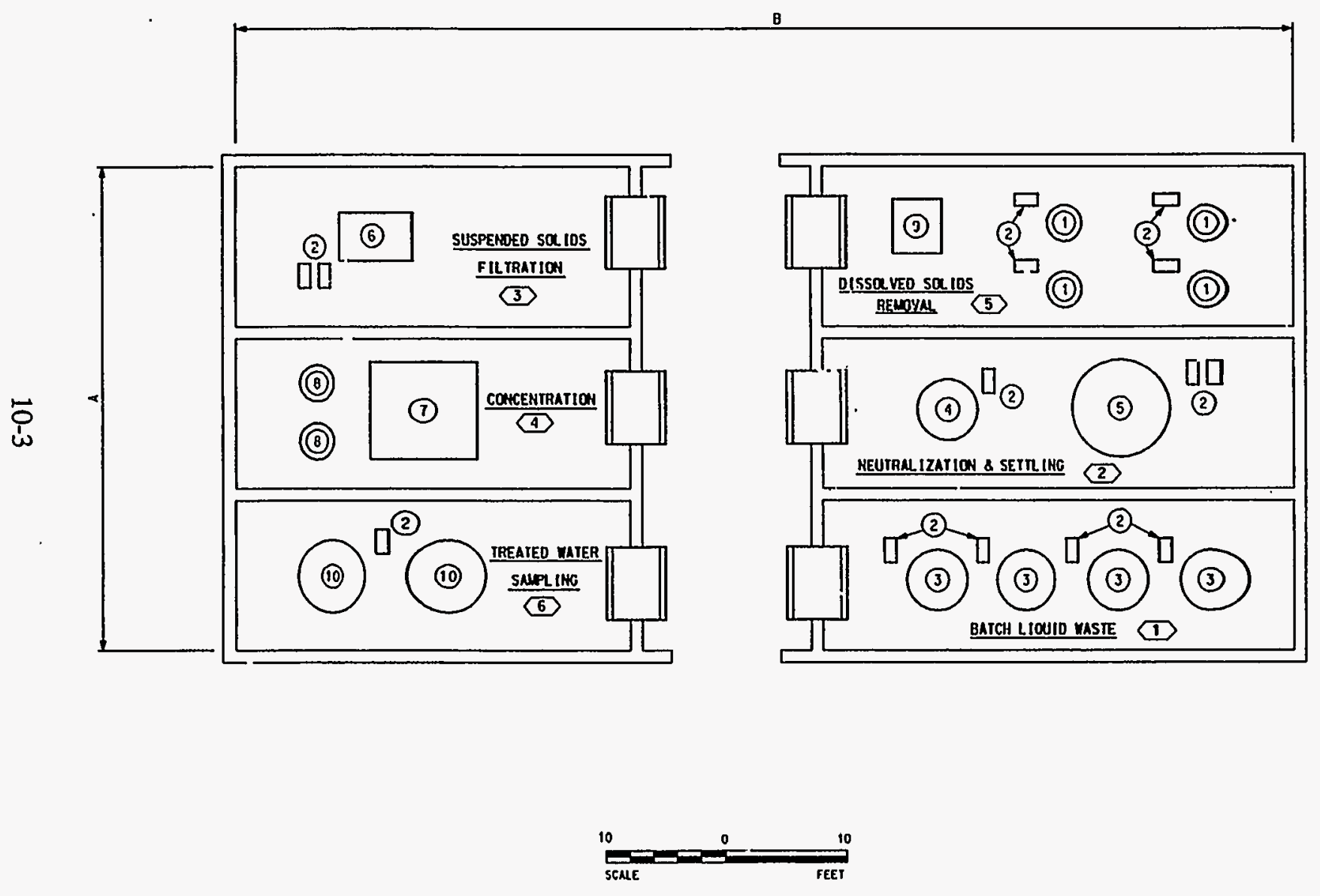

\section{EOUIPMENT LIST}
(1) CHEMICaL ADOITION TANK
(2) PUip
(3) Batch HOLO taNkS
(4) Meutralizer
(5) SETTLER
(6) Filtation Unit
(7) EVAPORATION UNIT
(B) carbon units
(9) Ion exchange unit
(10) treated maten tank

\begin{tabular}{|c|c|c|c|c|}
\hline \multirow{2}{*}{ FACILITY SIZE } & \multicolumn{2}{|c|}{$\begin{array}{l}\text { OILESION } \\
\text { OFFET }\end{array}$} & \multicolumn{2}{|c|}{$\begin{array}{l}\text { OIINENSIN } \\
\text { INIETRS }\end{array}$} \\
\hline & & 8 & & B \\
\hline SWALL & 110 & |86.5 & |33.6 & 26.4 \\
\hline LEOIUM & 120 & 94 & 36.7 & 28.7 \\
\hline LARGE & 130 & 111. & 39.7 & 34 \\
\hline
\end{tabular}

Figure 10-1. Equipment layout for the neutralization (NEUTR) module. 


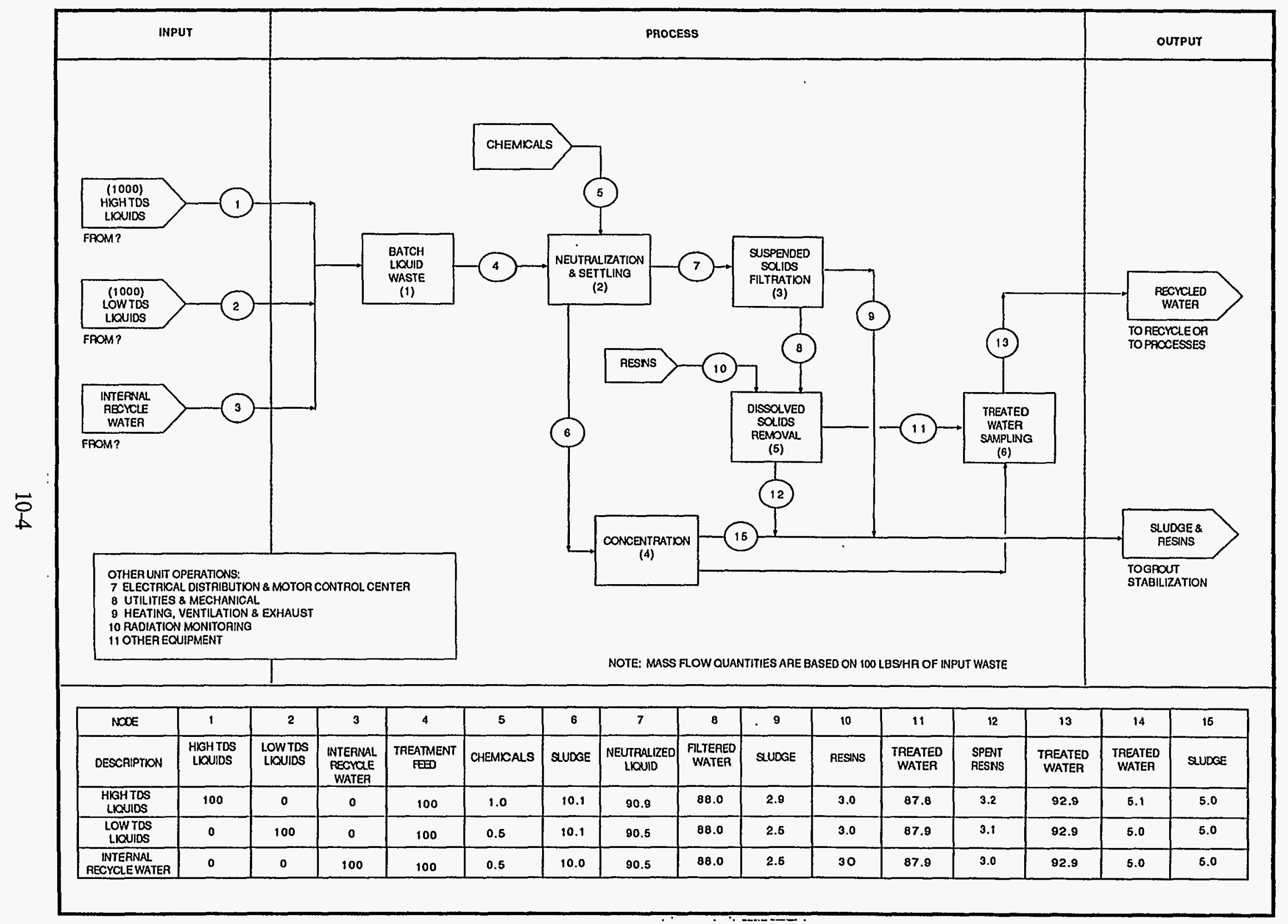

Figure 10-2. Process flow diagram for the neutralization (NEUTR) module. 


\section{NEUTRALIZATION}

FTE by Work Breakdown Structure Element Module: NEUTR Waste Type: Contact Handled TRUW

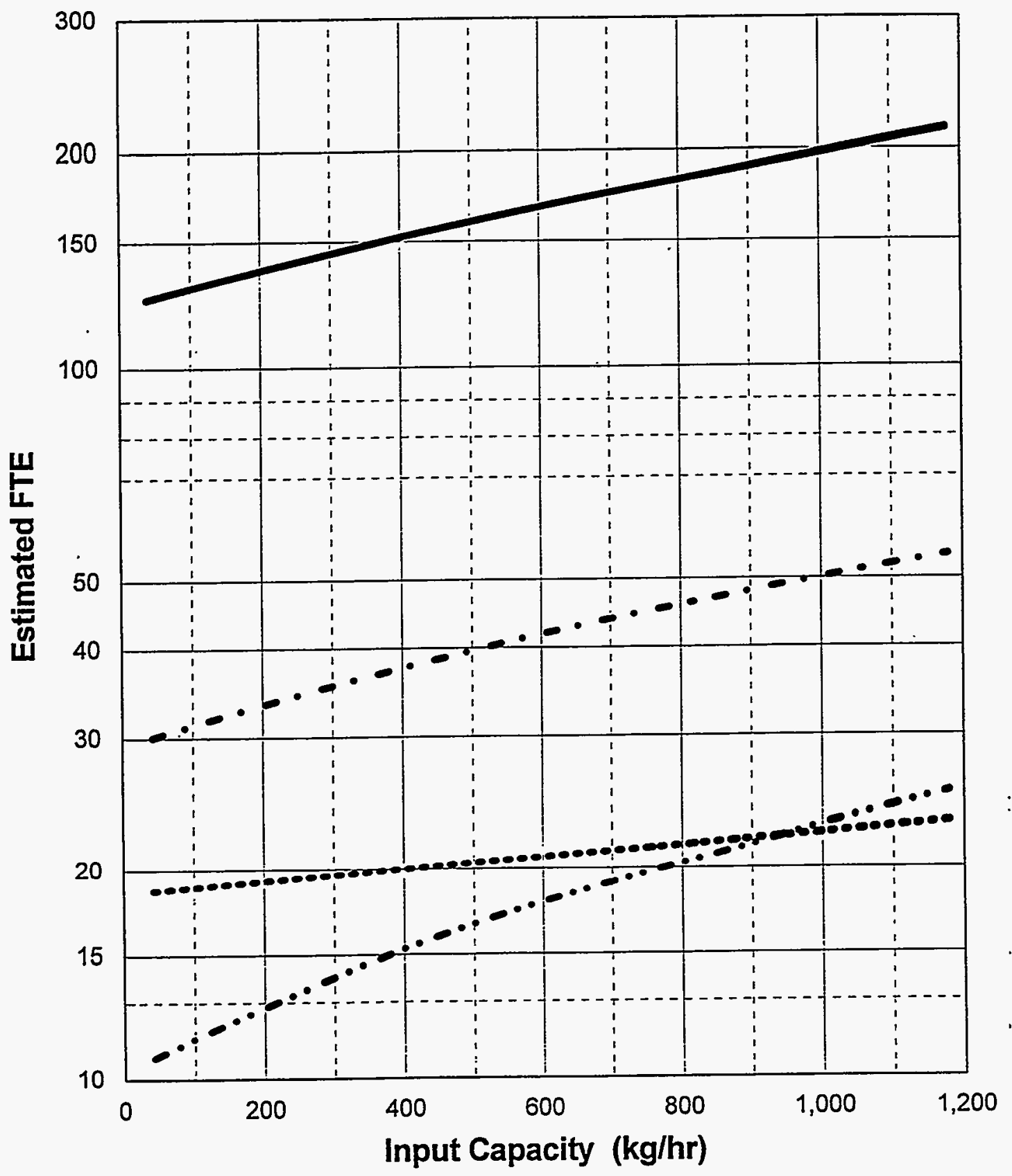

Pre-Operations Construction O\&M (1year) D\&D

Figure 10-3. FTE workers versus capacity for the $\mathrm{CH}$ neutralization (T-NEUTR) module. 


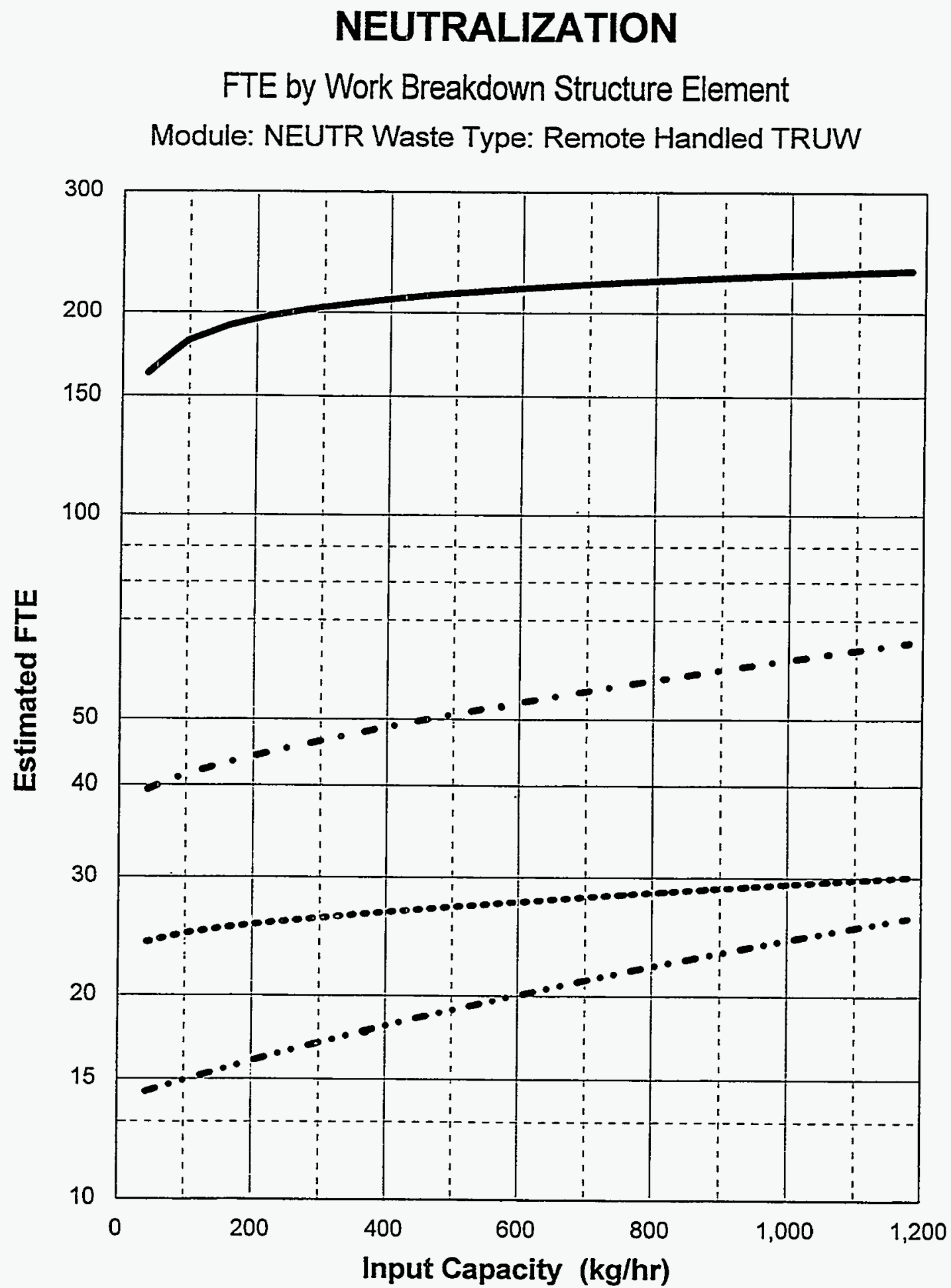

Pre-Operations Construction O\&M (1year) D\&D

Figure 10-4. FTE workers versus capacity for the RH neutralization (U-NEUTR) module. 


\section{NEUTRALIZATION}

Costs by Work Breakdown Structure Element Module: NEUTR Waste Type: Contact Handled TRUW

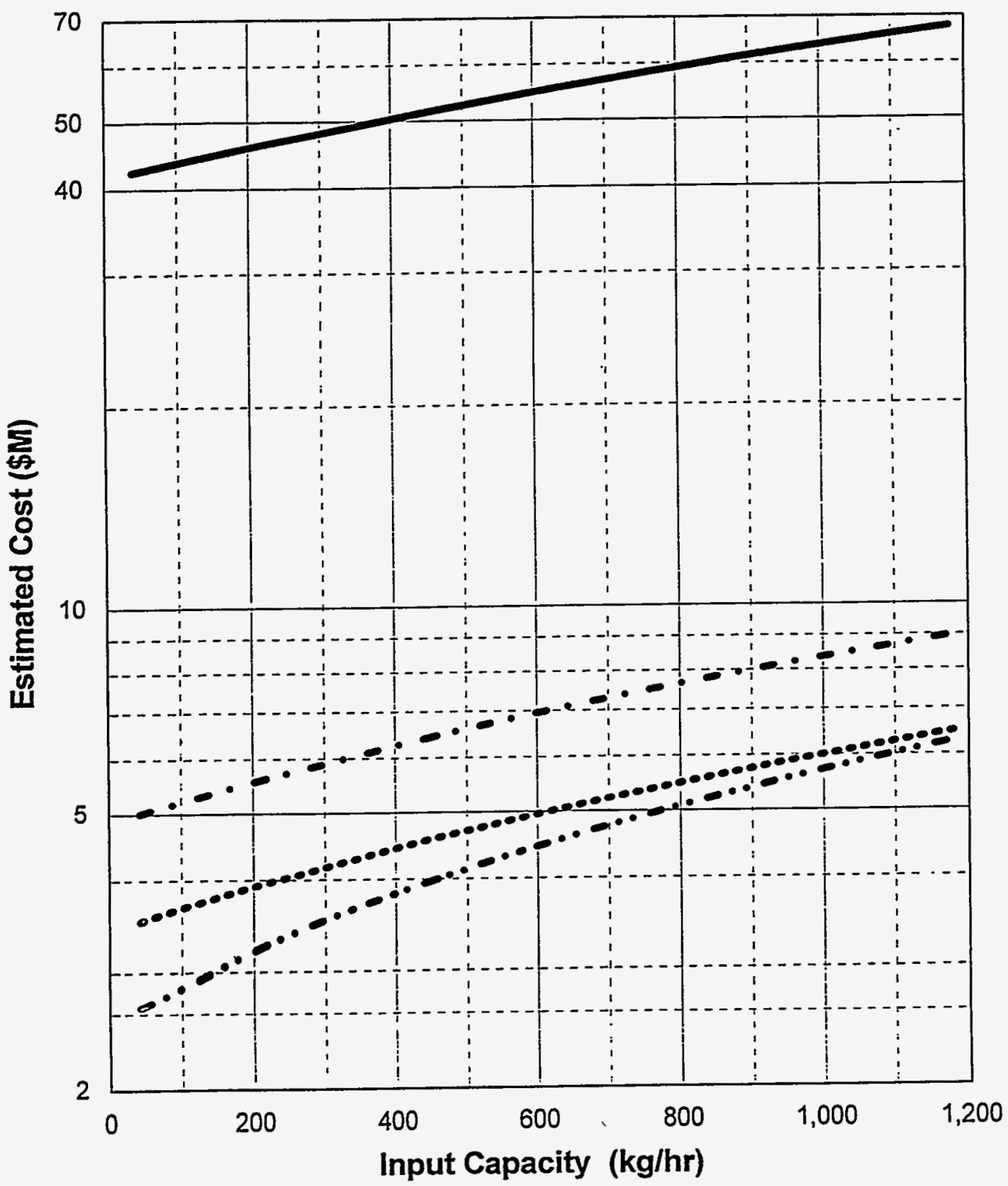

Pre-Operations Construction O\&M (1year) D\&D - -

Figure 10-5. PLCC versus capacity for the $\mathrm{CH}$ neutralization (T-NEUTR) module. 


\section{NEUTRALIZATION}

Costs by Work Breakdown Structure Element Module: NEUTR Waste Type: Remote Handled TRUW

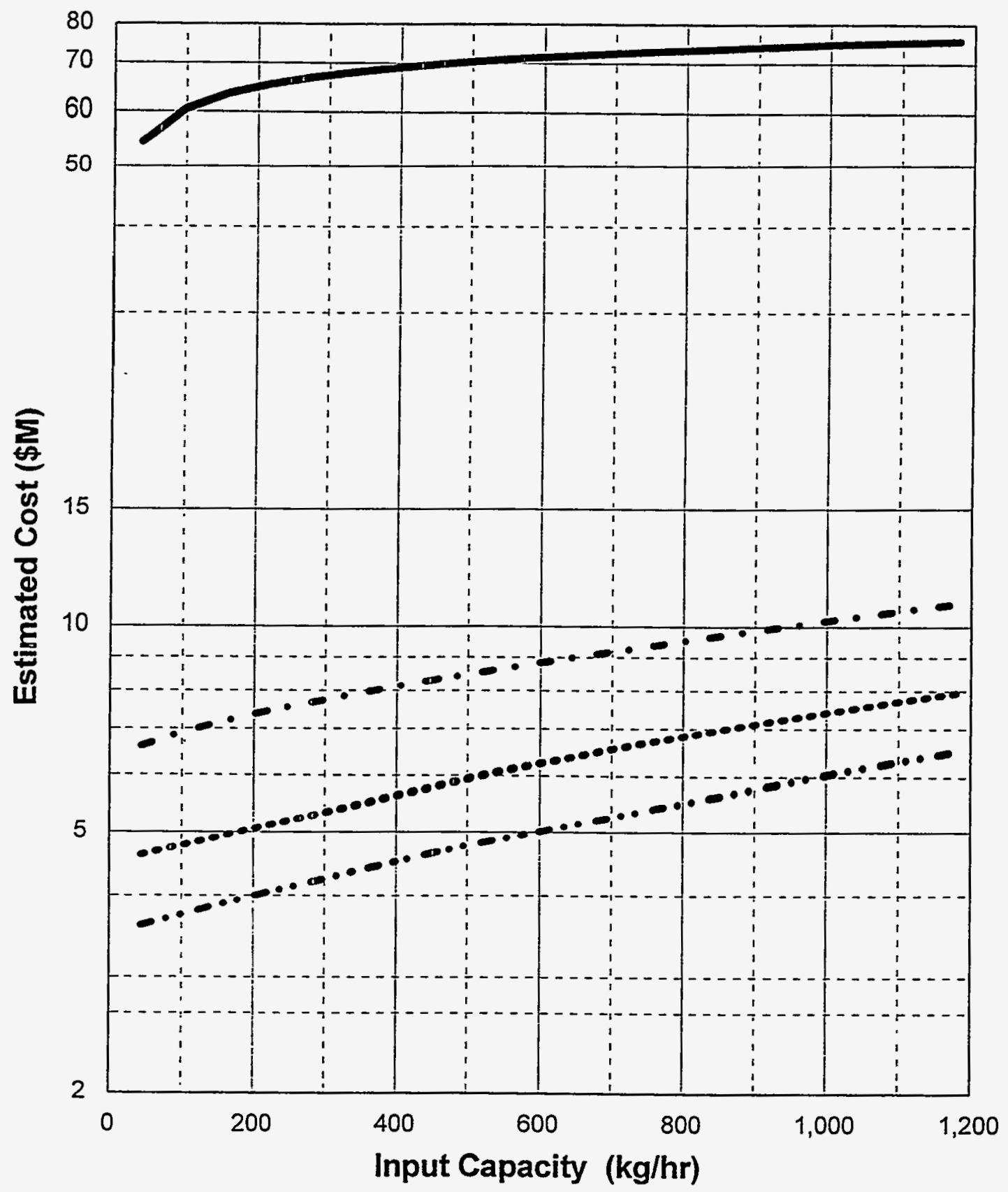

Pre-Operations Construction O\&M (1year) D\&D

Figure 10-6. PLCC versus capacity for the RH neutralization (U-NEUTR) module. 


\section{NEUTRALIZATION}

Total Life Cycle Costs

Module: NEUTR Waste Type: Contact Handled and Remote Handled TRUW

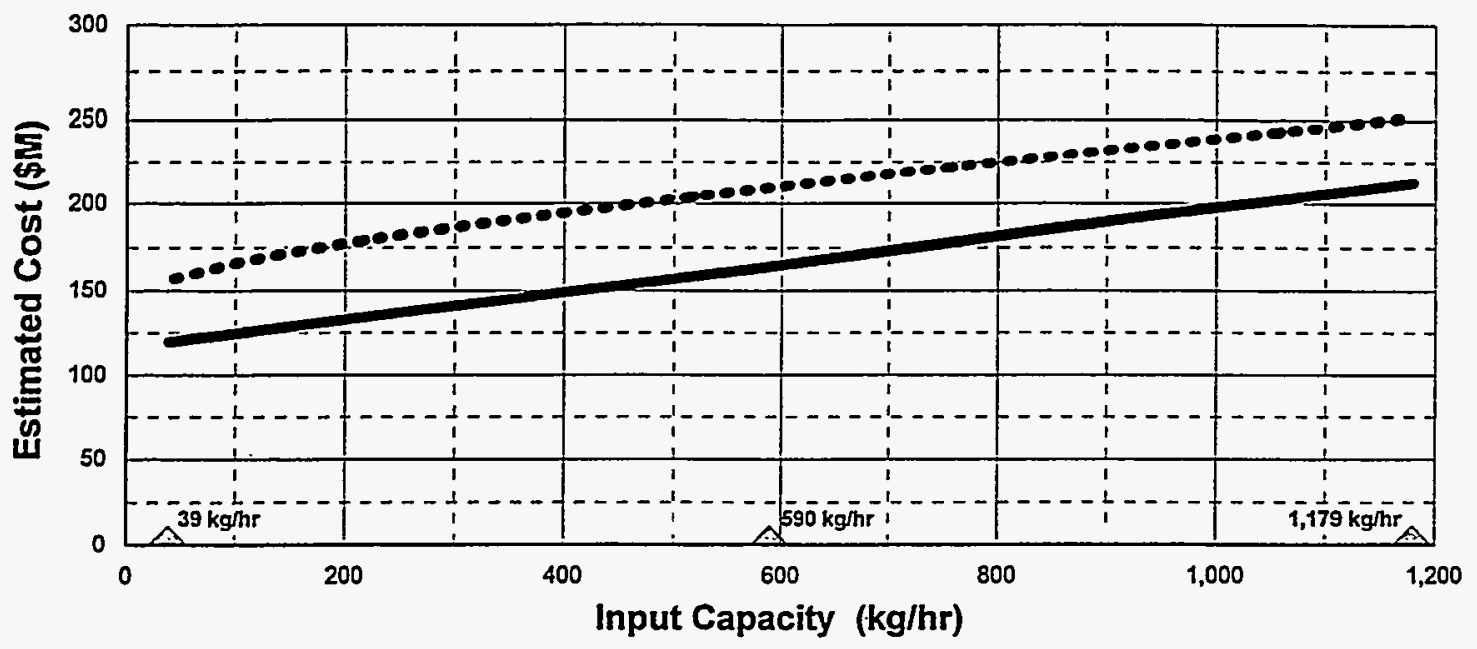

Contact Handled Remote Handled

NOTE: Basis includes 20 years O\&M

Triangles indicate capacities where detailed cost estimates were developed.

\section{NEUTRALIZATION}

Total Life Cycle Unit Costs

Module: NEUTR Waste Type: Contact Handled and Remote Handled TRUW

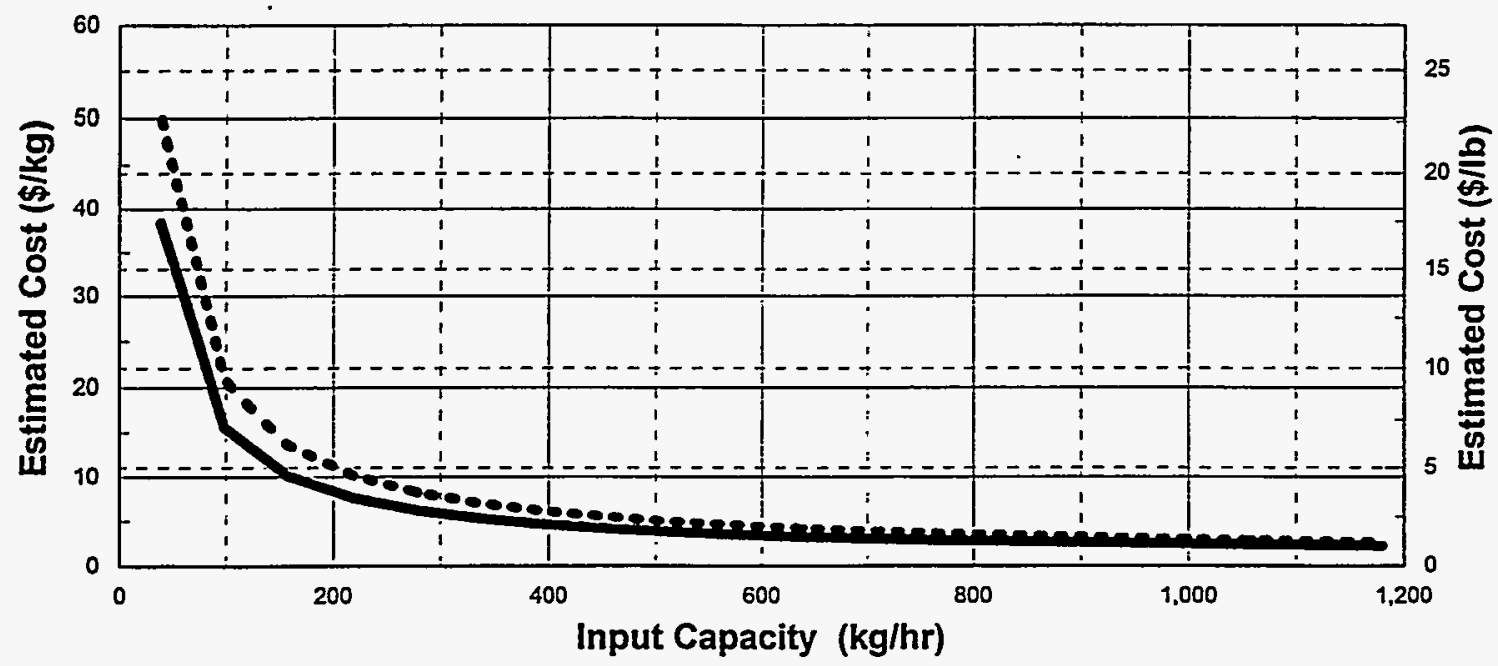

Contact Handled Remote Handled

NOTE: Basis inciudes 20 years O\&M

Figure 10-7. PLCC versus capacity including unit rates for the neutralization (NEUTR) module. 


\section{LEAD RECOVERY (MODULE PBRCR)}

\subsection{Basic Information}

The lead recovery module, shown in Figure 11-1, is used as an addition to an existing facility where similar functions are already installed or in conjunction with treatment front-end and back-end support (TADMN, RCINS, OSORT, MAINT, and CSHIP) modules.

The module involves nine major process unit operations that decontaminate solid lead waste material by wet abrasive blasting or by melting. Lead acid batteries are treated by neutralization and solidification. Products from this module are lead bricks and shielding, which can be recycled, and neutralized acidity, which must be stabilized. Slag containing radioactive particles from the melting process will also be cast into ingots and macroencapsulated for land disposal. Liquid effluent is recovered and processed in the aqueous waste treatment module. Module T-PBRCR is intended for CH-TRUW, while module U-PBRCR is intended for RH-TRUW. Unit operations are shown in the PFD in Figure 11-2.

\subsection{Technical Bases and Assumptions}

\subsubsection{Function and Operation of the Module}

Presorted incoming waste will be received at the module in drums. These enter the processing building and will be opened for inspection. Each drum will be routed to decontamination or to lead melting, depending on which type of waste the drum contains. Lead bricks and shielding material will be processed in the decontamination line. This process line will consist of a decontamination booth, where fixed contamination is removed using a liquid abrasive solution. In this process, it was assumed that a $1 / 16$-in. layer of lead material will be removed from the object being blasted.

Drums containing the waste material will be moved to the decontamination booth by powered roller conveyor. The material will be removed from the drum by a hydraulic drum dumper. Waste bricks or shielding will be manually placed onto the cleaning table by means of a glove box and will be moved into the booth for cleaning. After cleaning and drying, the table will be moved out of the opposite side of the booth for assaying. Articles proving to be decontaminated will be deposited into a clean drum. Articles not passing assay are placed in another drum and returned to the processing line. Drums containing cleaned material are taken by crane to the drum washer before exiting the building through an airlock.

Material such as lead blankets, lead shot, and leaded gloves are processed in the lead melter. This material, loaded in 55-gal drums, is dumped by the drum dumper onto a sorting table. The sorted material is transported to the melter. The lead battery is also disassembled on this table. The lead battery shell is cut off by a small stationary circular saw. Sulfuric acid is collected in a 55-gal tank. Lead internal parts are collected in a stainless-steel 55-gal drum. The full drum containing 91 $\mathrm{kg}(200 \mathrm{lb})$ of lead is then dumped into a shredder and reduced in size to minus $1 / 8 \mathrm{in}$. Sodium carbonate is fed into the shredder during the shredding operation. Lead paste is collected under the shredder and dumped by drum dumper into the stirrer. The reaction for transforming lead sulfate 
(main paste component) into lead carbonate under vigorous stirring takes about one hour. The paste is then dumped into the melter, where the melting occurs at a temperature less than $1,000^{\circ} \mathrm{C}$.

The lead is melted in an induction melting furnace. Electric current penetrates the metal causing a stirring force in the melted lead separating the slag from the lead. Radioactive impurities in the form of slag are then separated from the surface of the melted lead before the lead is poured into a casting machine. The casting machine produces lead ingots measuring $4 \times 4 \times 12 \mathrm{in}$. These ingots are collected in containers for cooling and moving them into the inspection area by overhead crane.

Smelter emissions are collected by overhead hood and treated in an offgas treatment facility. A secondary combustor is used followed by quench elbow dry filters and a high efficiency $\mathrm{SO}_{2}$ absorption tower. The dry treatment train consists of high-temperature HEPA filtration units with secondary combustion capabilities (such as ceramic filters). In this train, any combustible constituents are thermally destroyed, and particulates are removed from the offgas stream. An induced air blower moves the conditioned effluent through the wet treatment train that is designed to remove $\mathrm{SO}_{2}, \mathrm{HCl}$, and NOx.

The unit operations produce three secondary waste streams: filter elements, liquid from abrasive blasting solution, and offgas. Filters in the abrasive blasting operation will be changed monthly. These waste elements will be placed in drums for disposal. Secondary liquid waste including acids from battery disposal and bleed from abrasive blasting will be treated in the aqueous waste treatment unit.

\subsubsection{Integration of the Module}

Input consists mainly of contaminated lead bricks, shielding material, and lead acid batteries received in drums or bins from open, dump, and sort (OSORT) module. Major O\&M purchased materials such as personal protective equipment, filter elements, abrasive media, flux, and disposable containers are assumed to be consumable supplies, and their respective costs are estimated accordingly.

Output consists mainly of lead bricks, shielding, and ingots for recycling. Drums are cleaned and recycled. Slag is cast into ingots, which are macroencapsulated and placed in drums. Waste products from the abrasive blasting process are also placed in drums. These outputs are moved to the certification and shipping module or to stabilization. Waste acids and water are transported to aqueous waste treatment. Treated offgas is discharged to the atmosphere.

\subsection{Cost Bases, Assumptions, and Results}

Lead waste is received in drums. Lead bricks and sheets that can be decontaminated are separated from lead waste to be melted. The maximum size of any piece to be decontaminated or shredded is $12 \times 12 \times 12 \mathrm{in}$.

Since the quantities of lead waste to be decontaminated versus lead waste to be melted might not be consistent, each of the two lead recovery processes are designed for $75 \%$ of total feed rate capacity. 
Estimated FTE and cost versus capacity for this module are shown in Figures 11-3 through 11-7. 


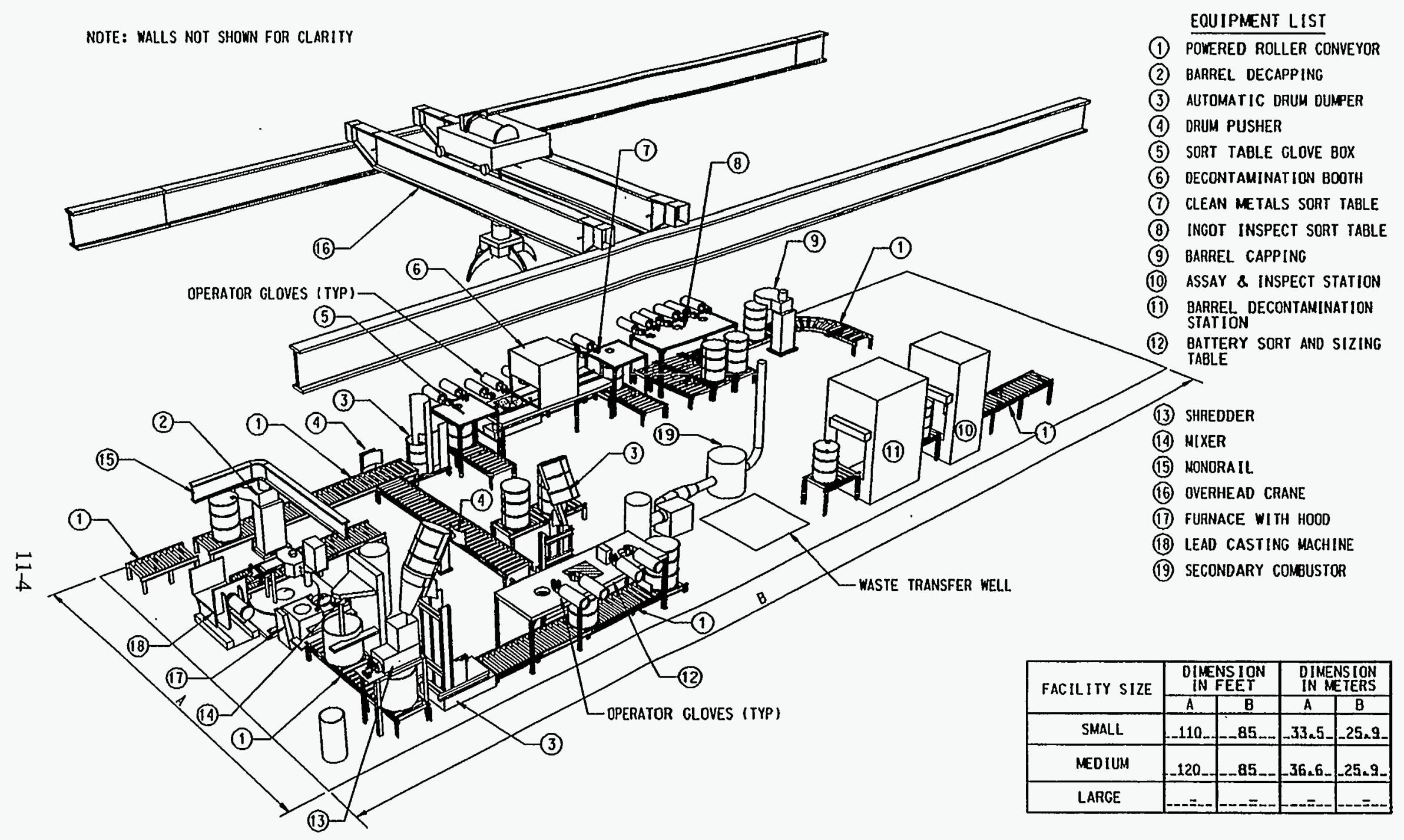

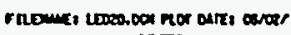

Figure 11-1. Equipment layout for the lead recovery (PBRCR) module. 


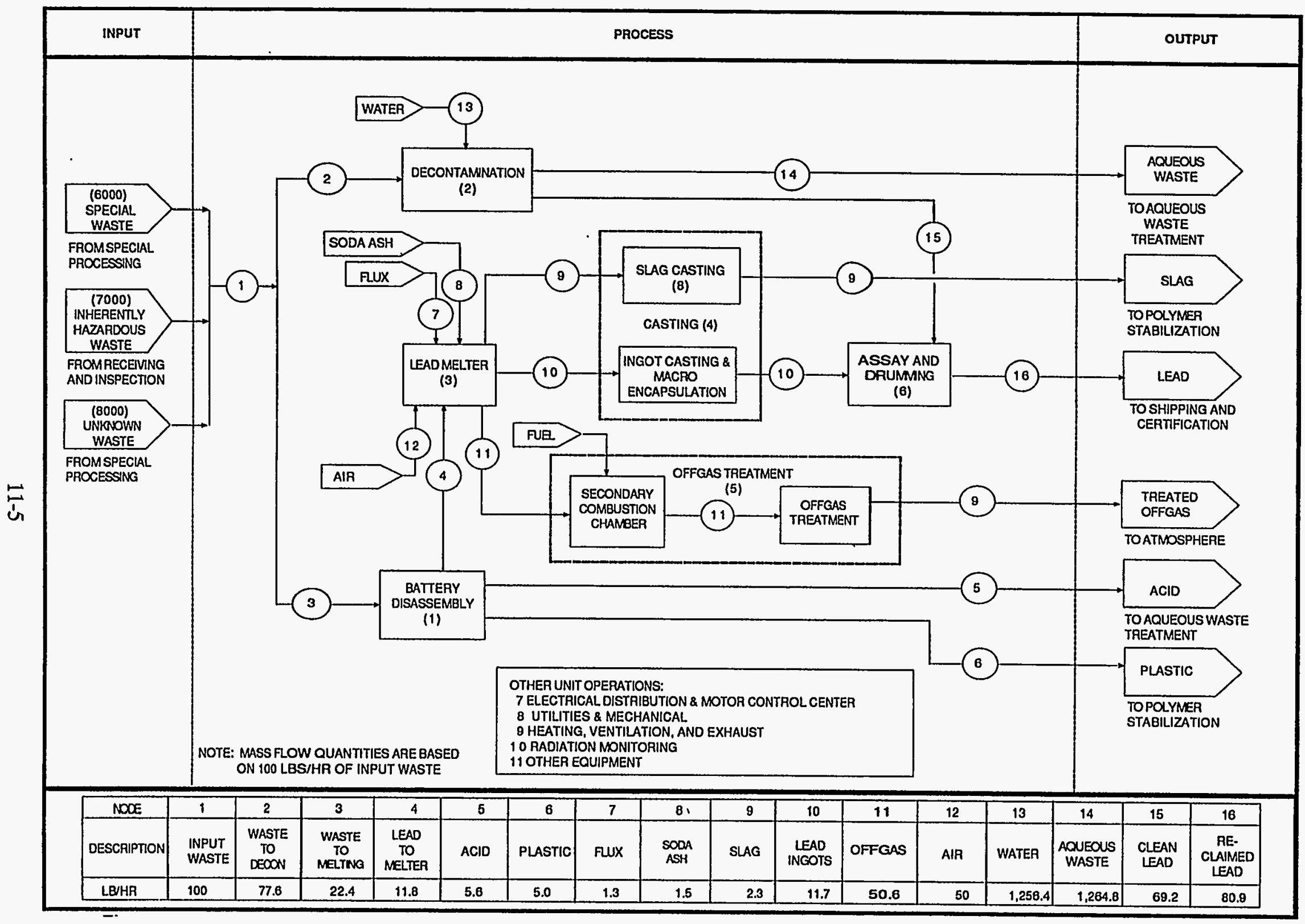

Figure 11-2. Process flow diagram for the lead recovery (PBRCR) module. 


\section{LEAD RECOVERY}

FTE by Work Breakdown Structure Element Module: PBRCR Waste Type: Contact Handled TRUW

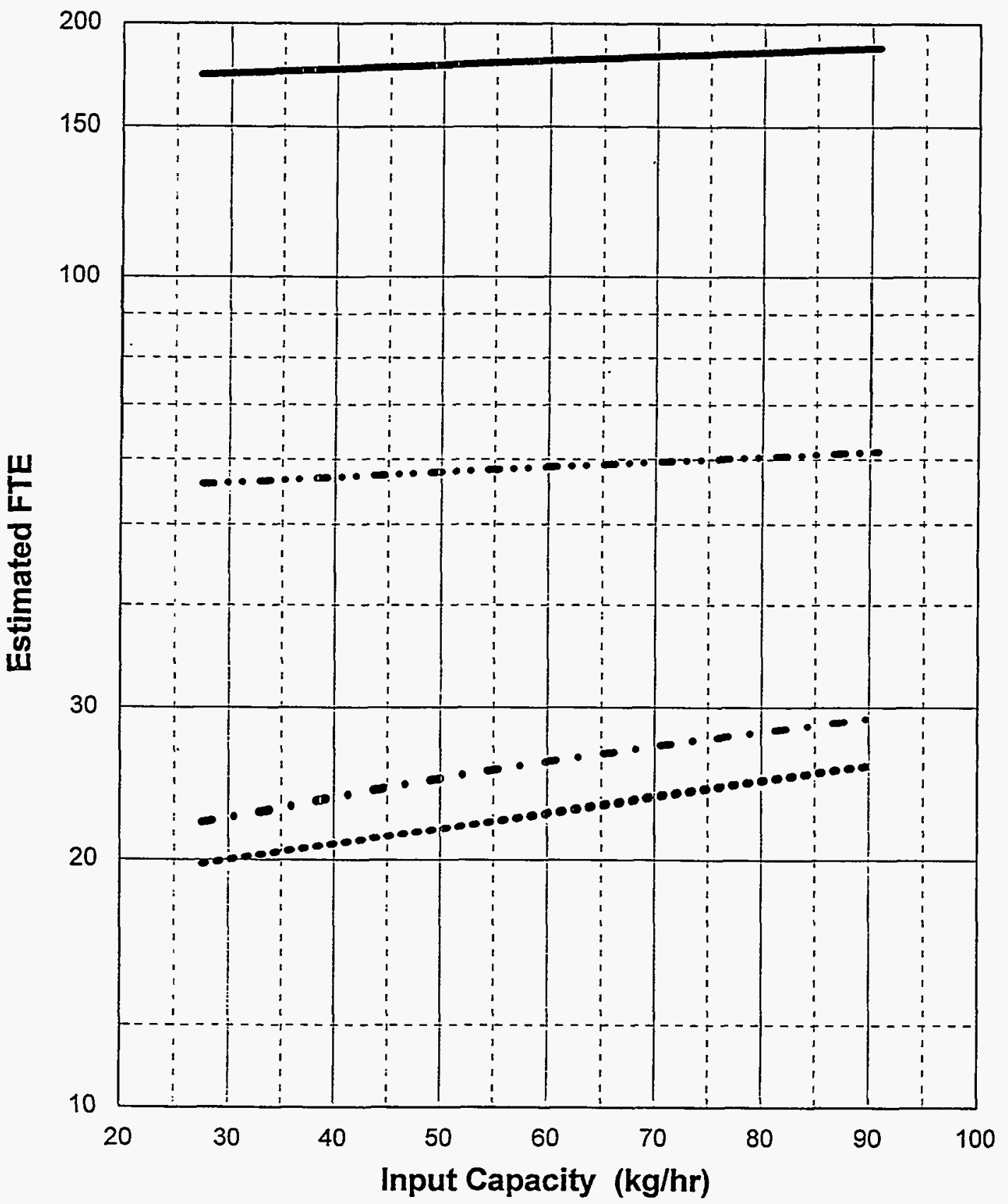

Pre-Operations Construction O\&M (1year) D\&D $\cdots$

Figure 11-3. FTE workers versus capacity for the $\mathrm{CH}$ lead recovery (T-PBRCR) module. 


\section{LEAD RECOVERY}

FTE by Work Breakdown Structure Element Module: PBRCR Waste Type: Remote Handled TRUW

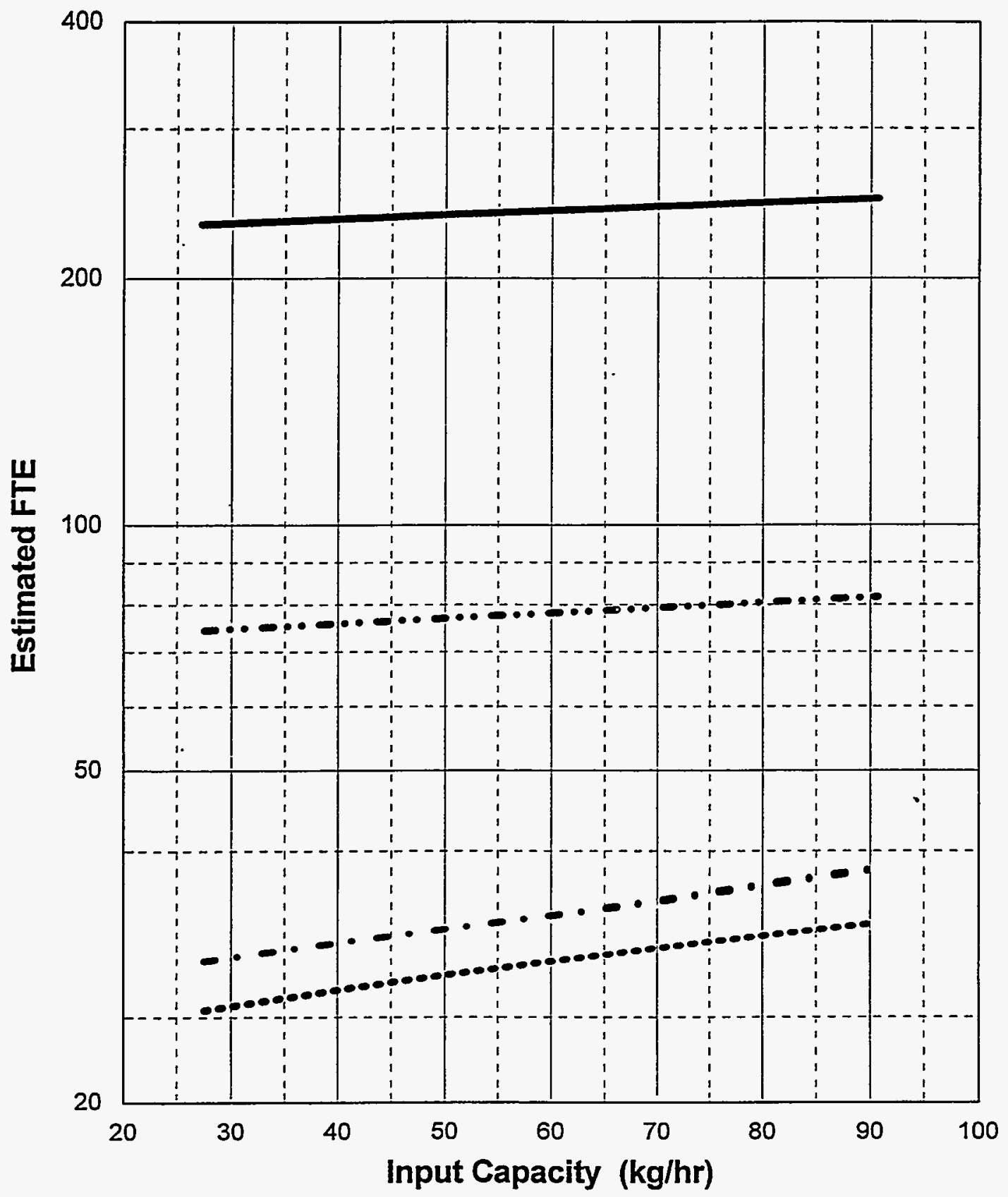

Pre-Operations Construction O\&M (1year) D\&D - -

Figure 11-4. FTE workers versus capacity for the RH lead recovery (U-PBRCR) module. 


\section{LEAD RECOVERY}

Costs by Work Breakdown Structure Element Module: PBRCR Waste Type: Contact Handled TRUW

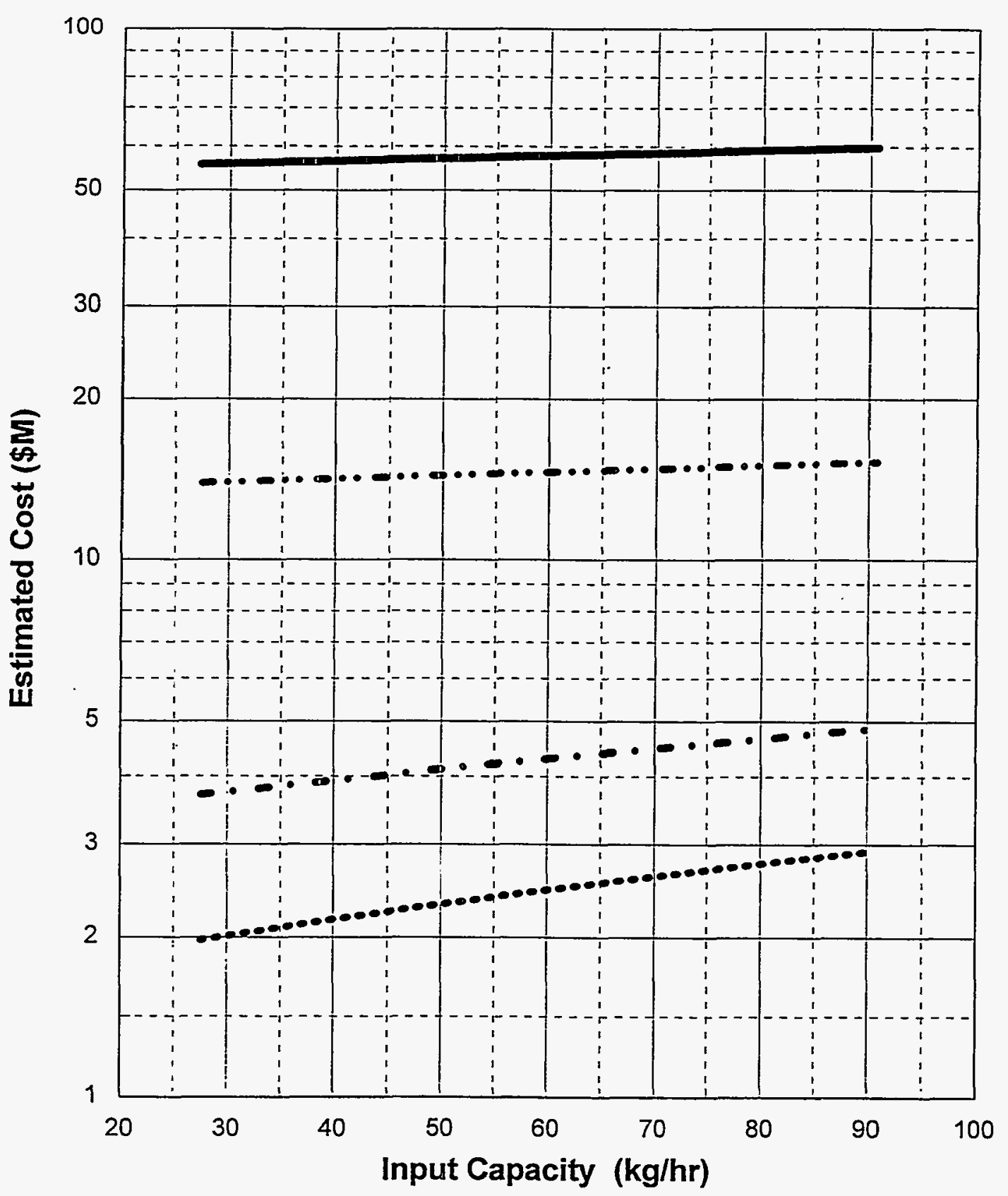

Pre-Operations Construction O\&M (1year) D\&D

Figure 11-5. PLCC versus capacity for the $\mathrm{CH}$ lead recovery (T-PBRCR) module. 


\section{LEAD RECOVERY}

Costs by Work Breakdown Structure Element Module: PBRCR Waste Type: Remote Handled TRUW

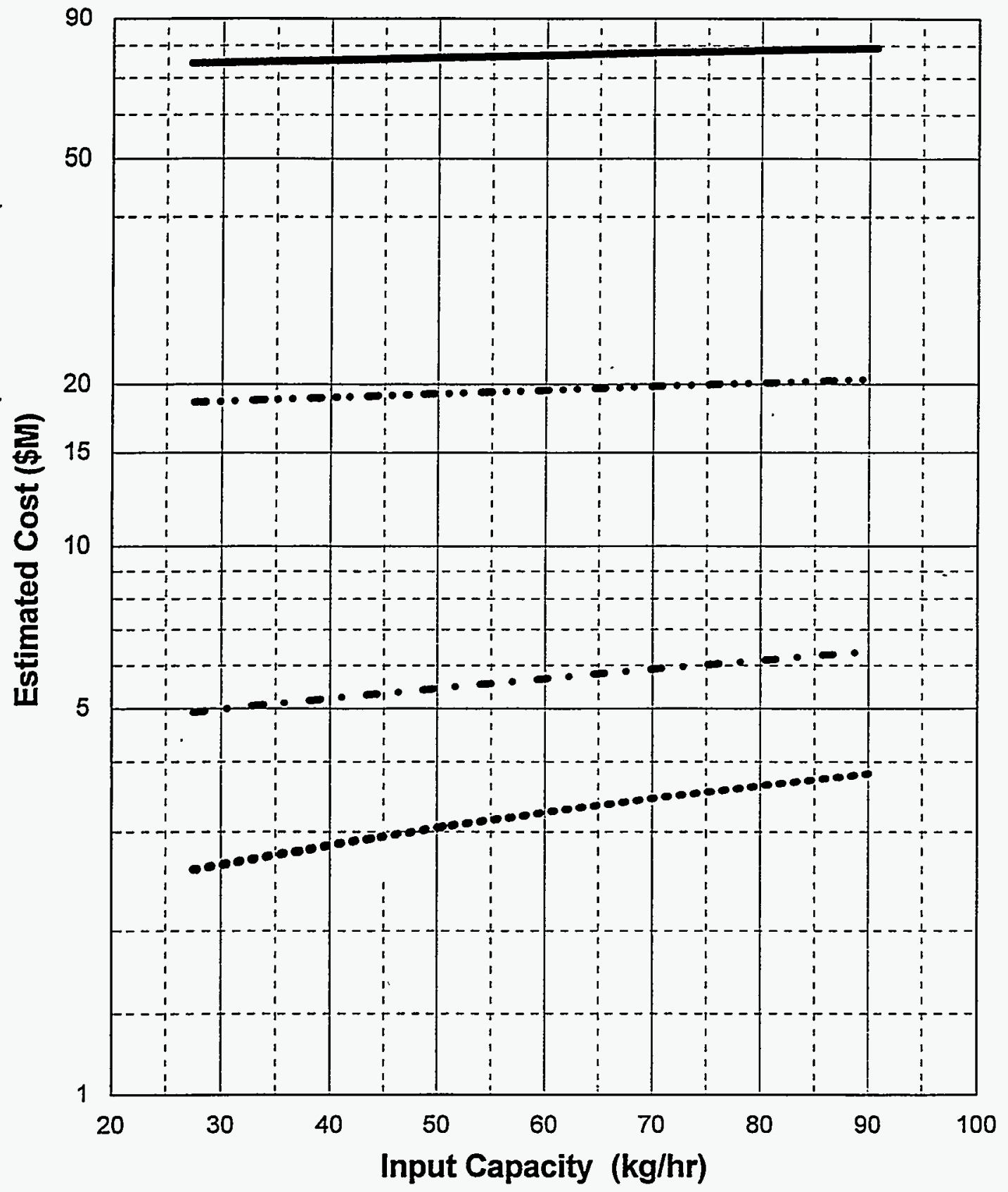

Pre-Operations Construction O\&M (1year) D\&D

Figure 11-6. PLCC versus capacity for the RH lead recovery (U-PBRCR) module. 


\section{LEAD RECOVERY}

Total Life Cycle Costs

Module: PBRCR Waste Type: Contact Handled and Remote Handled TRUW

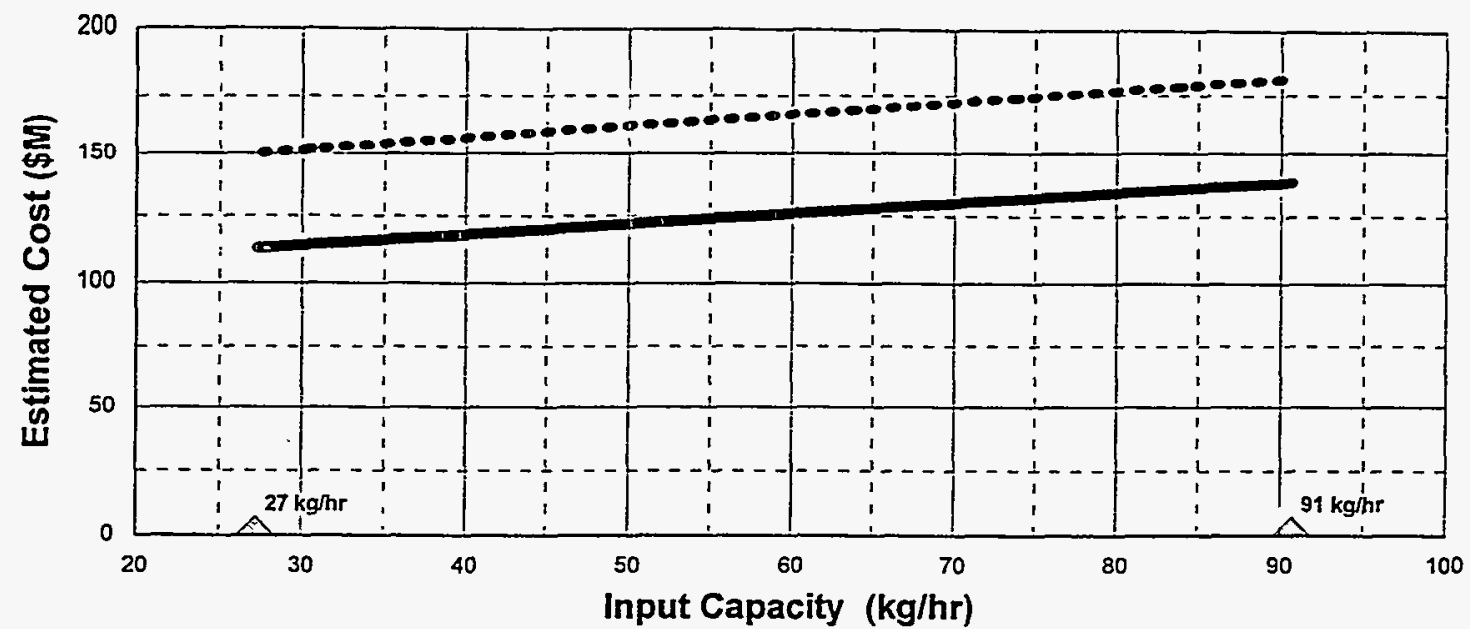

Contact Handled Remote Handled

NOTE: Basis includes 20 years $O \& M$

Triangles indicate capacities where detailed cost estimates were developed.

\section{LEAD RECOVERY}

Total Life Cycle Unit Costs

Module: PBRCR Waste Type: Contact Handled and Remote Handled TRUW

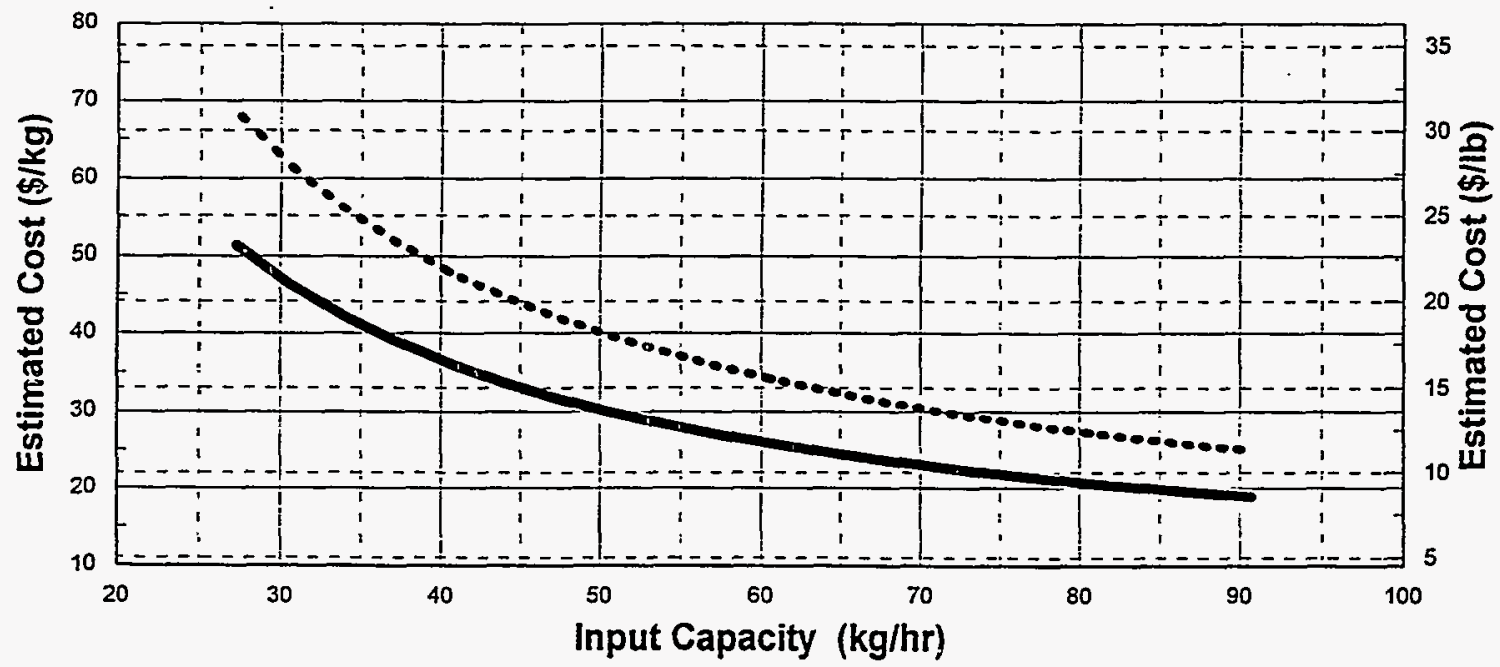

Contact Handled Remote Handled

NOTE: Basis indudes 20 years O\&M

Figure 11-7. PLCC versus capacity including unit rates for the lead recovery (PBRCR) module. 


\section{MERCURY SEPARATION (MODULE RMERC)}

\subsection{Basic Information}

The mercury separation module, shown in Figure 12-1, is used for the removal of mercury from sludges as well as solids. ${ }^{\mathrm{h}}$ The module can also accept elemental (liquid) mercury for stabilization by amalgamation techniques. Aqueous waste contaminated with mercury and its salts would be processed by the aqueous waste treatment (AQWTR) module. Module T-RMERC is intended for CH-TRUW, while module U-RMERC is intended for RH-TRUW.

The module can be installed in the same building and used in conjunction with the open, dump, and sort (OSORT) module; the aqueous waste treatment (AQWTR) module; and the stabilization (VITRF or GROUT) modules; or the packaging (PACKG) module, or installed in a new building with similar functions available in existing facilities.

The input waste is sorted at the receiving and inspection (RCINS) module, where waste containing mercury is segregated from other incoming waste. Treatment units are provided assuming that the incoming waste contains radioactive constituents regulated under AEA, and toxic metal and organics regulated under RCRA. In addition to the input waste, the mercury separation module could treat mercury contaminated ash or solids generated by other modules of the treatment facility. The module has a number of unit operations that accomplish the required functions. These unit operations are shown in the PFD in Figure 12-2.

\subsection{Technical Bases and Assumptions}

\subsubsection{Function and Operation of the Module}

The mercury separation module has all the operations needed for treating and stabilizing liquid mercury, and sludge and solids containing or contaminated with elemental mercury or mercury compounds.

Incoming waste is transported to the module in transfer bins mounted on transfer devices. Elemental liquid mercury is separated from other mercury-contaminated waste. The elemental mercury is transferred to a liquid-mercury storage bottle, and other mercury waste is transferred to a waste preparation and feed bin. From the feed bin, the solid material is shredded, combined with sludges requiring no feed preparation, and transferred to an electrically heated vacuum retort. The retort thermally volatilizes (at approximately $1,000^{\circ} \mathrm{F}$ ) the low-boiling point constituents, including mercury and mercury compounds, under high vacuum conditions. A small amount of nitrogen is admitted to the retort as an inert sweep gas. The retort is maintained at operating temperature for a predetermined heat soak period and then cooled. The solid residue, essentially inorganics and char,

h. Detailed composition of the input waste is not available. However, it is assumed that organic sludges may include cutting and lubrication oils and mercuric acetates. Inorganic sludges may include those generated from acid leaching, thermal treatment, and mercury sulfide precipitates. Solids may include mercury-specific ionexchange resin (e.g., Ionac SR-5), rags, wipes, and personal protective equipment. 
are removed from the retort, assayed, and delivered either to a thermal treatment or to a stabilization module.

The vapors from the retort pass through a heat exchanger, which reduces the vapor temperature enough to condense the mercury while allowing the other low-boiling point constituents to remain volatilized. These remaining volatilized vapors (mainly water and organics) are burned in a secondary combustion chamber at a temperature of approximately $2,000^{\circ} \mathrm{F}$. This gas is then transported to an offgas treatment unit operation that cools and treats the gas by quenching, dry filtration, carbon adsorption, and high efficiency filtration to remove regulated elements and compounds before the treated gas is released to the atmosphere. The unit operation ensures that the offgas discharged to the atmosphere meets the given emission standards.

The condensed mercury is separated from the uncondensed offgas and transported to the elemental mercury storage bottle. The liquid mercury is transferred to an amalgamation operation where the mercury is combined with copper (or zinc) powder, steel shot (for proper mixing), and nitric acid. This combination is mixed to form a copper-mercury amalgam, eliminating free mercury. The amalgam is packaged for assay and inspection to ensure that the amalgam meets toxicity characteristic leaching procedure (TCLP) standards.

\subsubsection{Integration of the Module}

Input waste comes from the receiving and inspection module. Secondary waste received from other modules could include offgas mercury separation beds in the incineration module and mercury separation sludges in the aqueous waste treatment modules.

Output from mercury separation consists of packaged copper-mercury amalgam which is transported to certification and shipping. Spent HEPA filters, spent activated carbon, and solid debris are transported either to an incineration or to a stabilization module, and wet scrubber sludges are transported to the aqueous waste treatment module. Materials purchased for O\&M include such consumables as personal protective equipment, fuel, activated carbon, copper powder, steel shot, and nitric acid.

\subsection{Cost Bases, Assumptions, and Results}

It is assumed that the module feed stream contains 5\% elemental (liquid) mercury and 95\% other solid waste. Liquid elemental mercury can be readily segregated from the remaining solid waste. Mercury contaminated solid waste composition is approximately $5 \%$ mercury, $32 \%$ inorganics, $42 \%$ volatile organics, $4 \%$ nonvolatile organics, and $17 \%$ moisture. One retort batch can be completed per 8-hour shift.

Cost estimates are based upon prices submitted by various vendors. The cost estimate for the feeder/shredder is based on a quote from System Service Solutions of Wilsonville, Ohio. The cost estimate for the retort is a quote from Denver Mineral Engineers, Inc. of Littleton, Colorado. The cost estimate for the amalgam mixer is based on a quote from Miracle Paint Rejuvenator of St. Paul, Minnesota. The cost estimate for the offgas treatment is based on the use of a dry filter as quoted by Pall Advanced Separation Systems of Cortland, New York, and a quencher and scrubbing unit as quoted by Croll-Reynolds Company of Westland, New Jersey. 
Estimated FTE and cost versus capacity for this module are shown in Figures 12-3 through 12-7. 


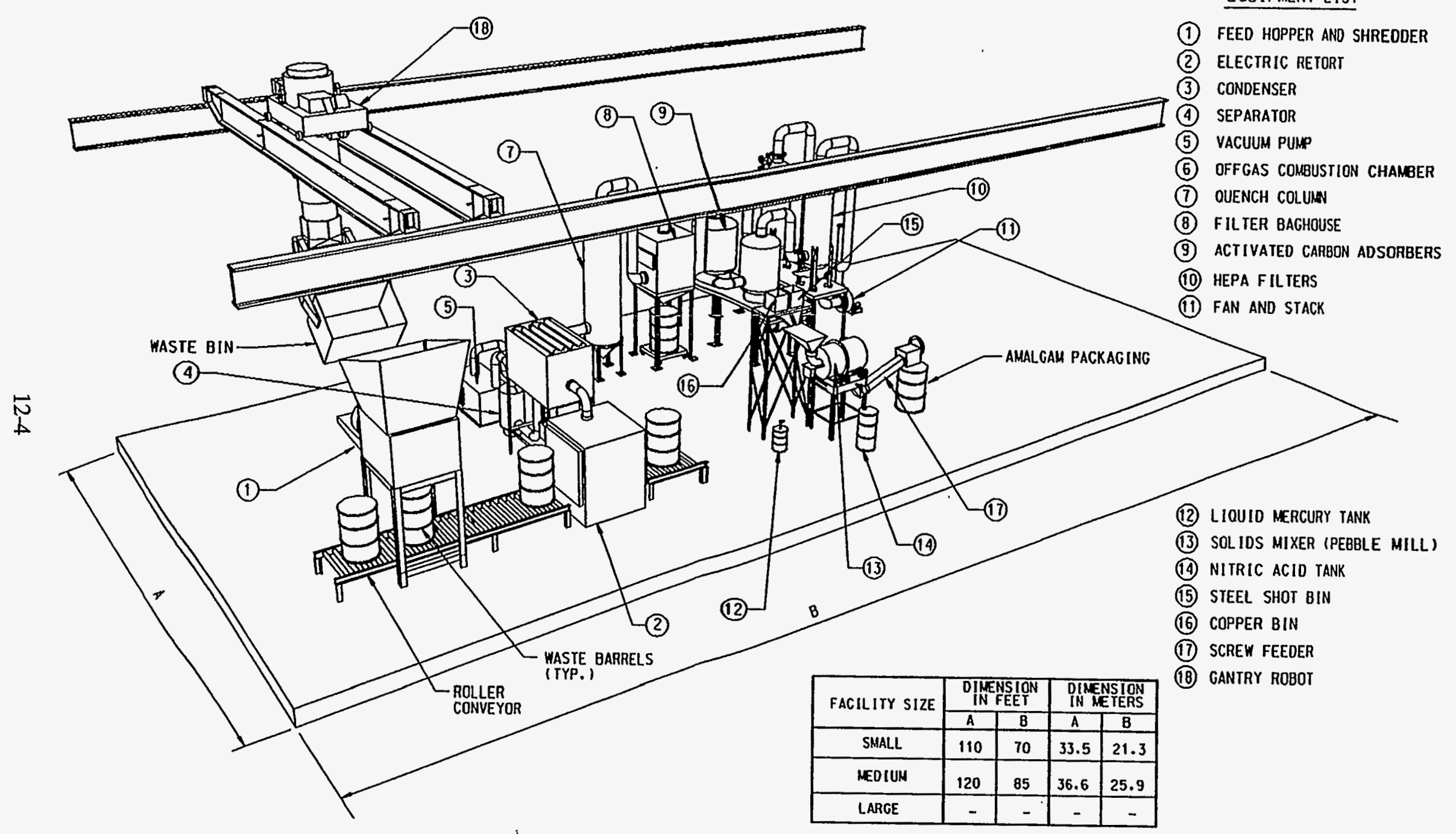

Figure 12-1. Equipment layout for the mercury separation (RMERC) module. 


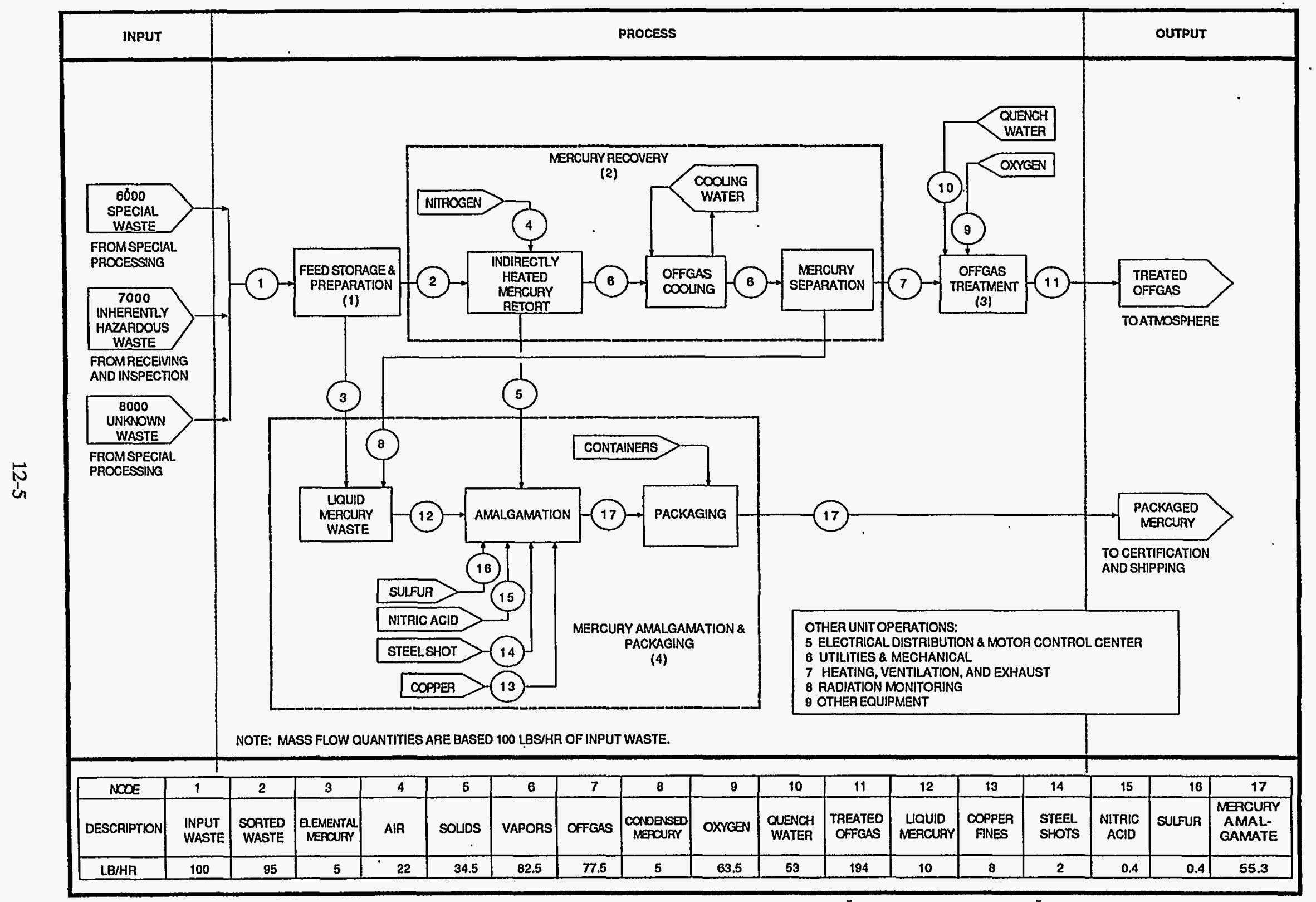

Figure 12-2. Process flow diagram for the mercury separation (RMERC) module. 


\section{MERCURY SEPARATION}

FTE by Work Breakdown Structure Element Module: RMERC Waste Type: Contact Handled TRUW

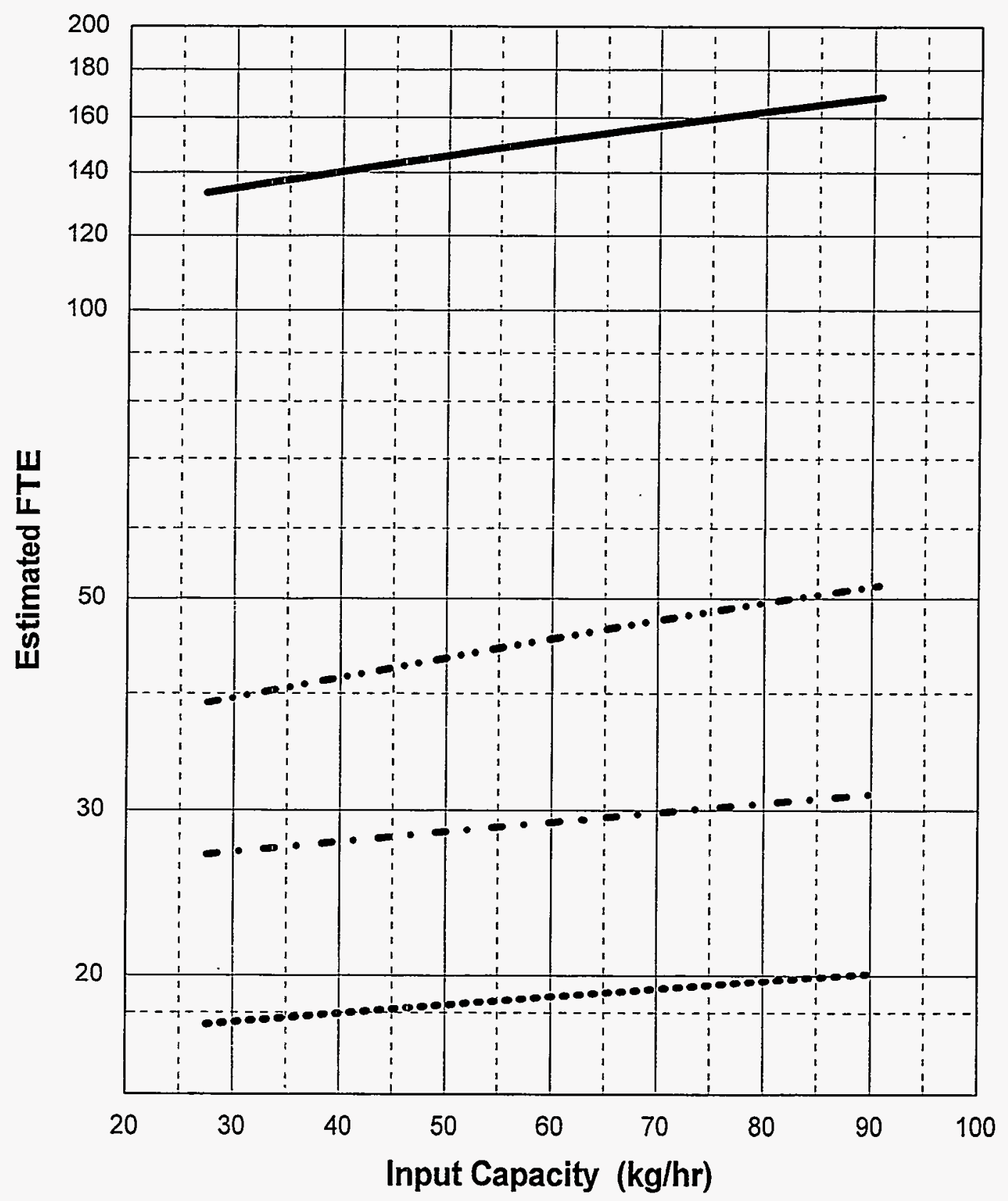

Pre-Operations Construction O\&M (1year) D\&D

Figure 12-3. FTE workers versus capacity for the $\mathrm{CH}$ mercury separation (T-RMERC) module. 


\section{MERCURY SEPARATION}

FTE by Work Breakdown Structure Element Module: RMERC Waste Type: Remote Handled TRUW

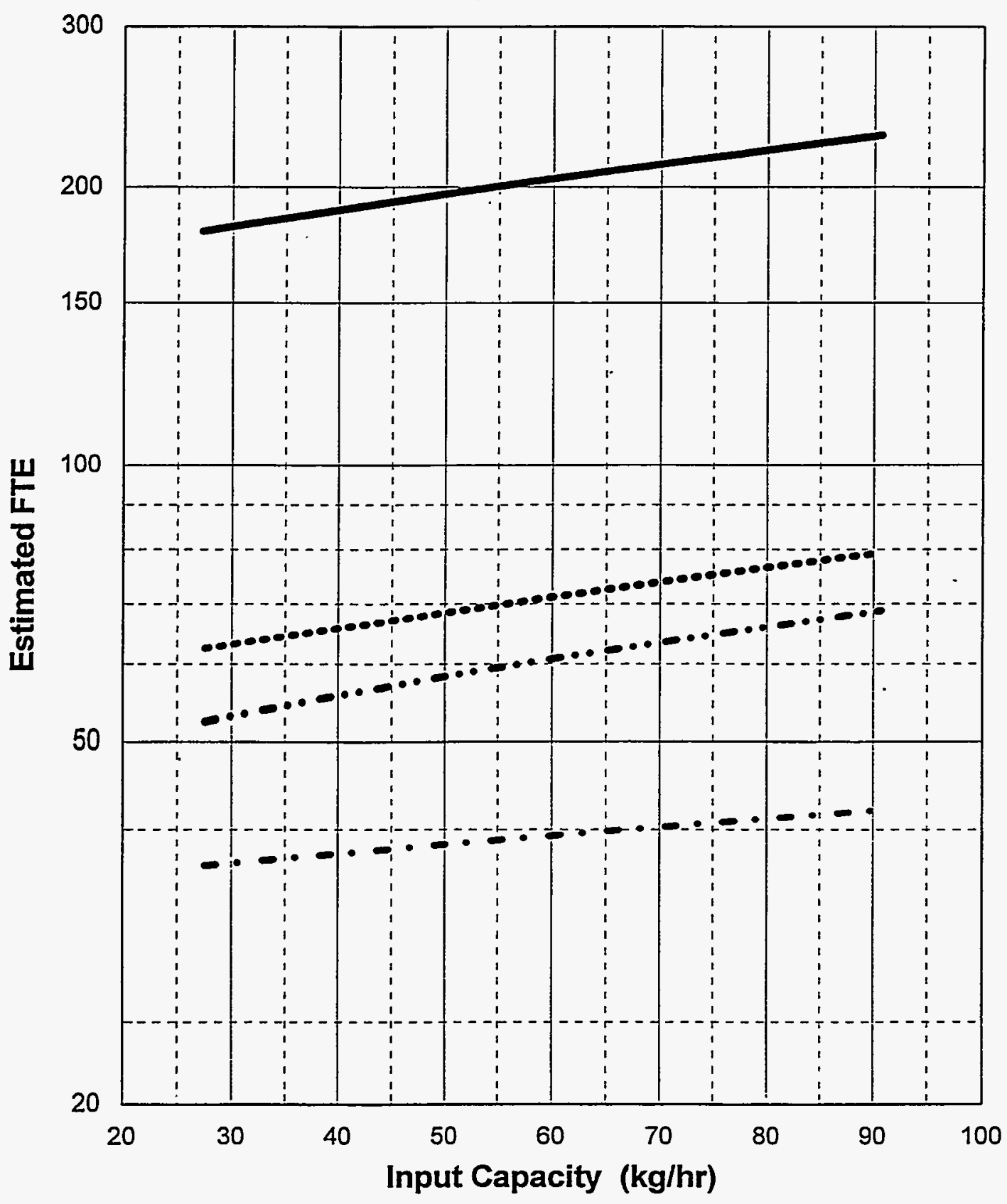

Pre-Operations Construction O\&M (1year) D\&D

Figure 12-4. FTE workers versus capacity for the RH mercury separation (U-RMERC) module. 


\section{MERCURY SEPARATION}

Costs by Work Breakdown Structure Element Module: RMERC Waste Type: Contact Handled TRUW

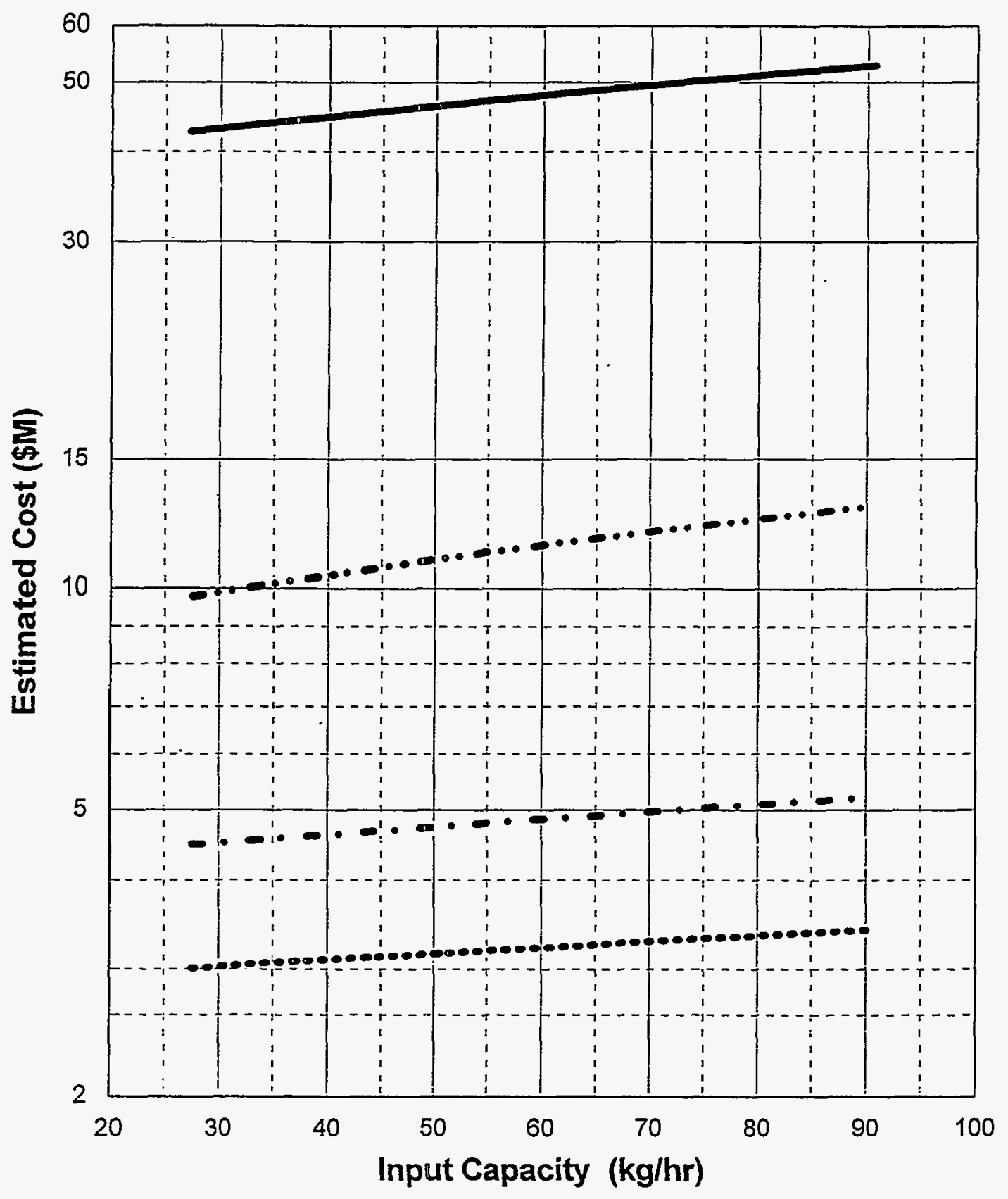

Pre-Operations Construction O\&M (1year) D\&D

Figure 12-5. PLCC versus capacity for the $\mathrm{CH}$ mercury separation (T-RMERC) module. 


\section{MERCURY SEPARATION}

Costs by Work Breakdown Structure Element Module: RMERC Waste Type: Remote Handled TRUW

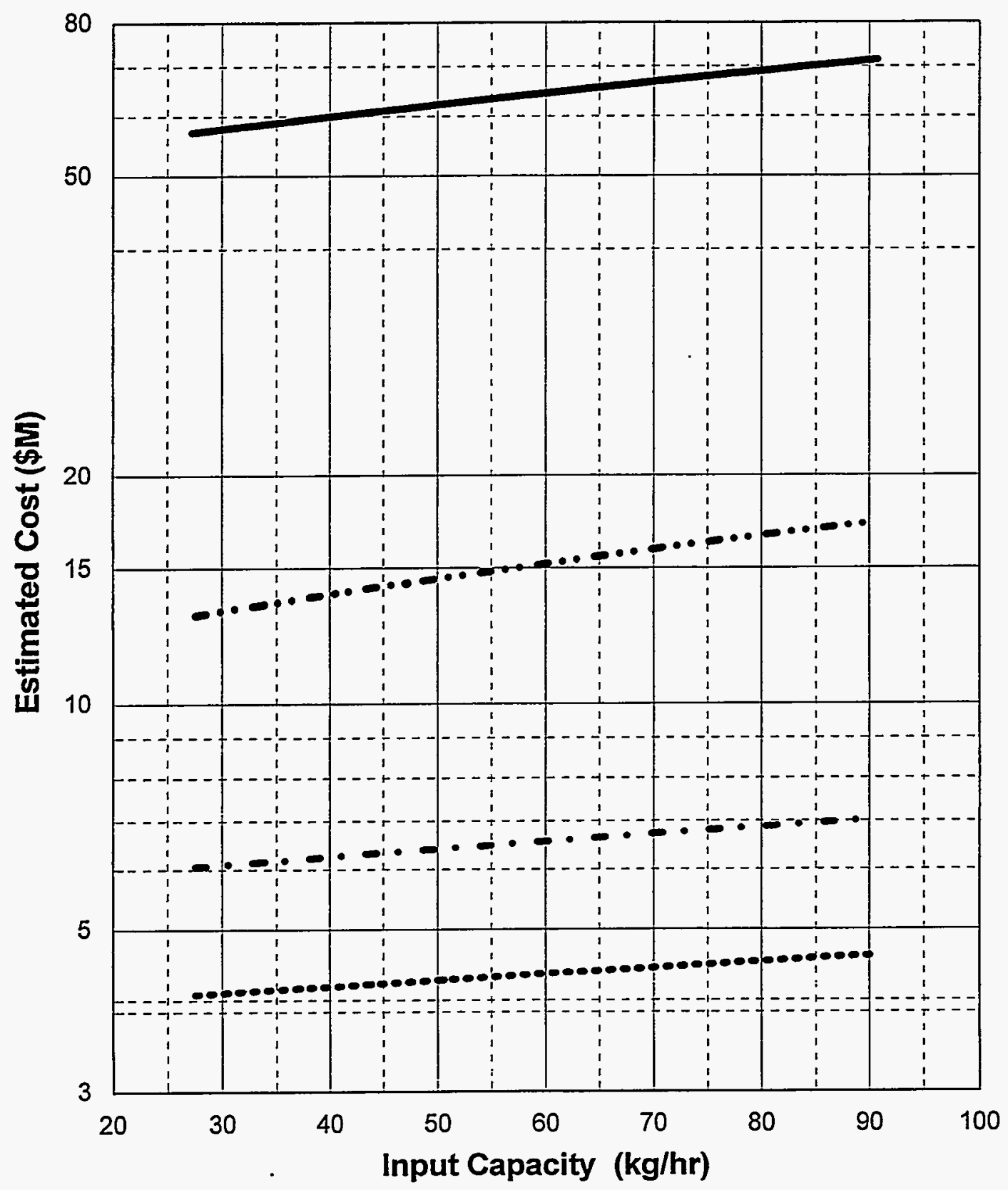

Pre-Operations Construction O\&M (1year) D\&D

Figure 12-6. PLCC versus capacity for the RH mercury separation (U-RMERC) module. 


\section{MERCURY SEPARATION}

Total Life Cycle Costs

Module: RMERC Waste Type: Contact Handled and Remote Handled TRUW

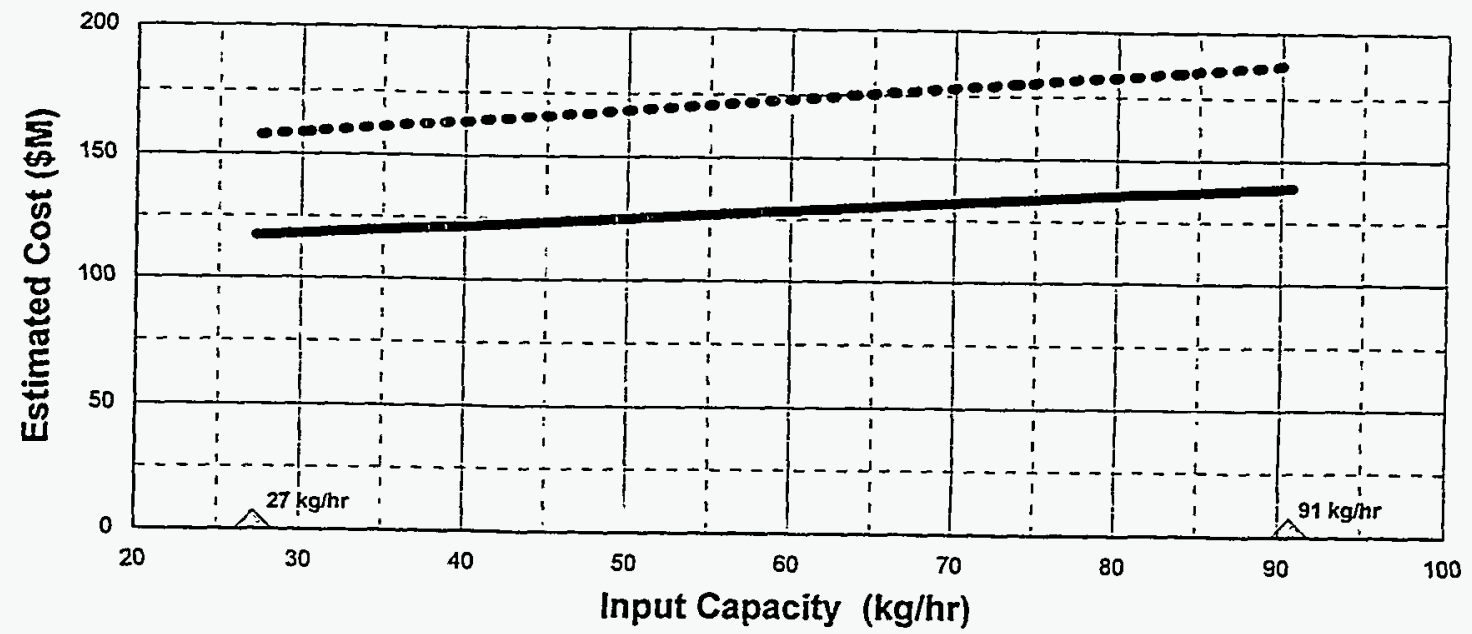

Contact Handled Remote Handled

NOTE: Basis includes 20 years O\&M

Triangles indicate capacities where detailed cost estimates were developed.

\section{MERCURY SEPARATION}

Total Life Cycle Unit Costs

Module: RMERC Waste Type: Contact Handled and Remote Handled TRUW

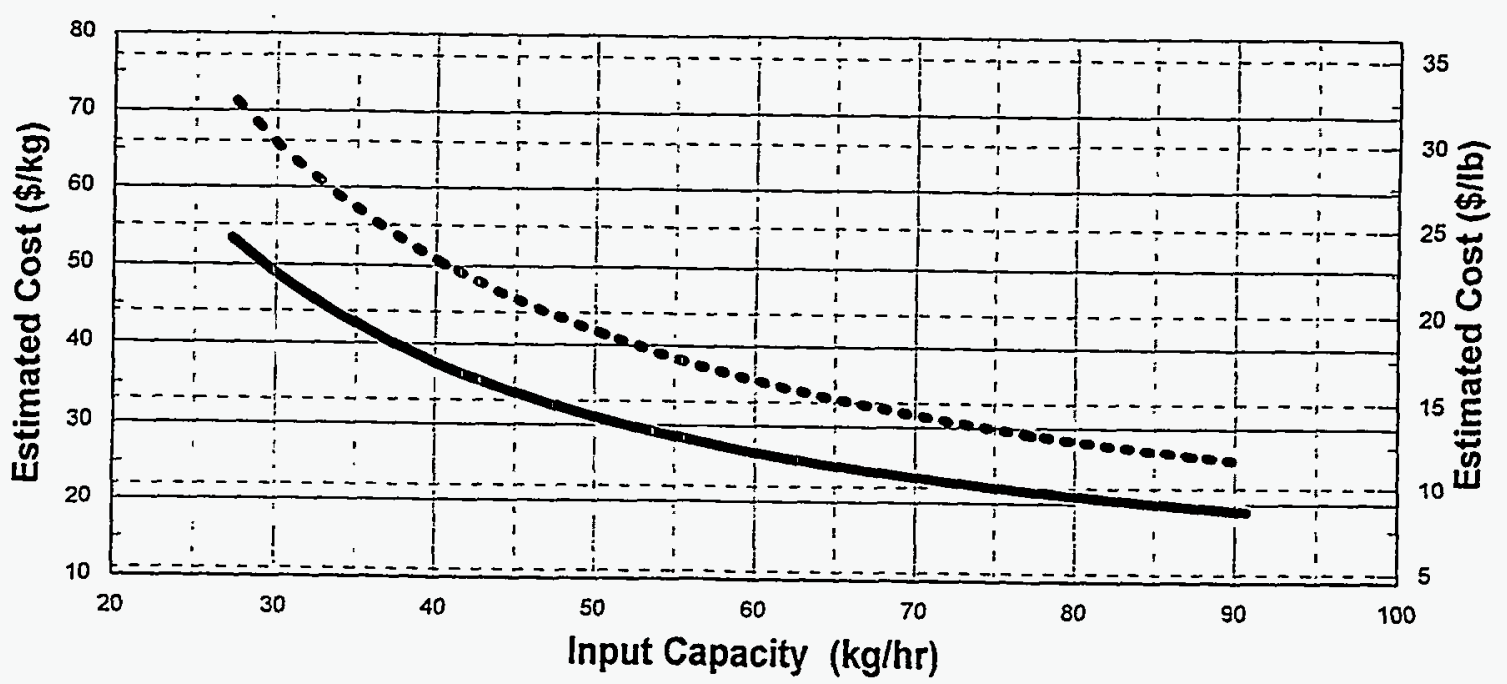

Contact Handled Remote Handled

NOTE: Basis inciudes 20 years O\&M

Figure 12-7. PLCC versus capacity including unit rates for the mercury separation (RMERC) module. 


\section{SHREDDING AND COMPACTION (MODULE CMPCT)}

\subsection{Basic Information}

The shredding and compaction module, shown in Figure 13-1, is used either in conjunction with the treatment front-end and back-end support modules (see modules TADMN, RCINS, OSORT, MAINT, and CSHIP) or as an addition to existing facilities where similar functions are already available. Module T-CMPCT is intended for CH-TRUW, while module U-CMPCT is intended for RH-TRUW. The shredding and compaction module functions either (a) as an up-front process unit for feeding size-reduced waste to a given process train or $(b)$ as a self-contained process unit where solids are size-reduced, compacted in drums, and transported to the certification and shipping module. Unit operations are shown in the PFD in Figure 13-2.

\subsection{Technical Bases and Assumptions}

\subsubsection{Function and Operation of the Module}

The module is designed to shred incoming solid waste and package it in 55-gal drums, compact the drums and repackage them in 85-gal overpacks. This module is capable of shredding, compaction, and repackaging. A dust collection and filtration unit is provided to treat air containing fugitive dust from the shredding operations.

After shredding, drums containing shredded waste are transported to the supercompactor unit operation where a lift device places the filled drums onto press conveyors. The operator selects a drum from one of the conveyors and feeds it to the press through an airlock. A device pierces the drum to release gasses that may be trapped. A high-pressure compactor (supercompactor) compresses the drum and transfers it from the press to a staging conveyor (or turntable). A lift device picks up the compressed drum and places it into one of several overpacks located on an adjacent conveyor. After each overpack is filled, the operator feeds it to the grout station where grout is added to fill void spaces in the overpack. The overpack is then transported to the sorting machine where it is capped and scaled. The operator moves the sealed overpack to a drum washing unit where a high-pressure water spray jet is used to remove any loose contamination on the outside surface of the overpacks. The overpacks are then inspected prior to being released from the treatment module.

\subsubsection{Integration of the Module}

Primary module inputs are bulk waste from the open, dump, and sort (OSORT) module and treated debris from the thermal desorption module (THDRB). Major O\&M purchased materials, such as personal protective equipment, laboratory material, and overpacks, are assumed to be consumable supplies and their costs are estimated accordingly.

Major module outputs are drums containing shredded TRUW, which are transferred either to other process units or to a back-end support (CSHIP) module. Treated offgas is discharged into the atmosphere. 


\subsection{Cost Bases, Assumptions, and Results}

Costs for the preparation and feed unit are based on vendor quotes for shredders, conveyors, and dust collection equipment. The compactor and the solidification unit costs are based on estimates provided by Stock Equipment Company of Chagrin Falls, Ohio. Estimated FTE and cost versus capacity for this module are shown in Figures 13-3 to 13-7.

The costs were compared to costs reported for the existing supercompaction facility at Rocky Flats. The capital and operating costs generated in this estimate were found to be within $12 \%$ of the capital and operating costs reported for the Rocky Flats facility. 


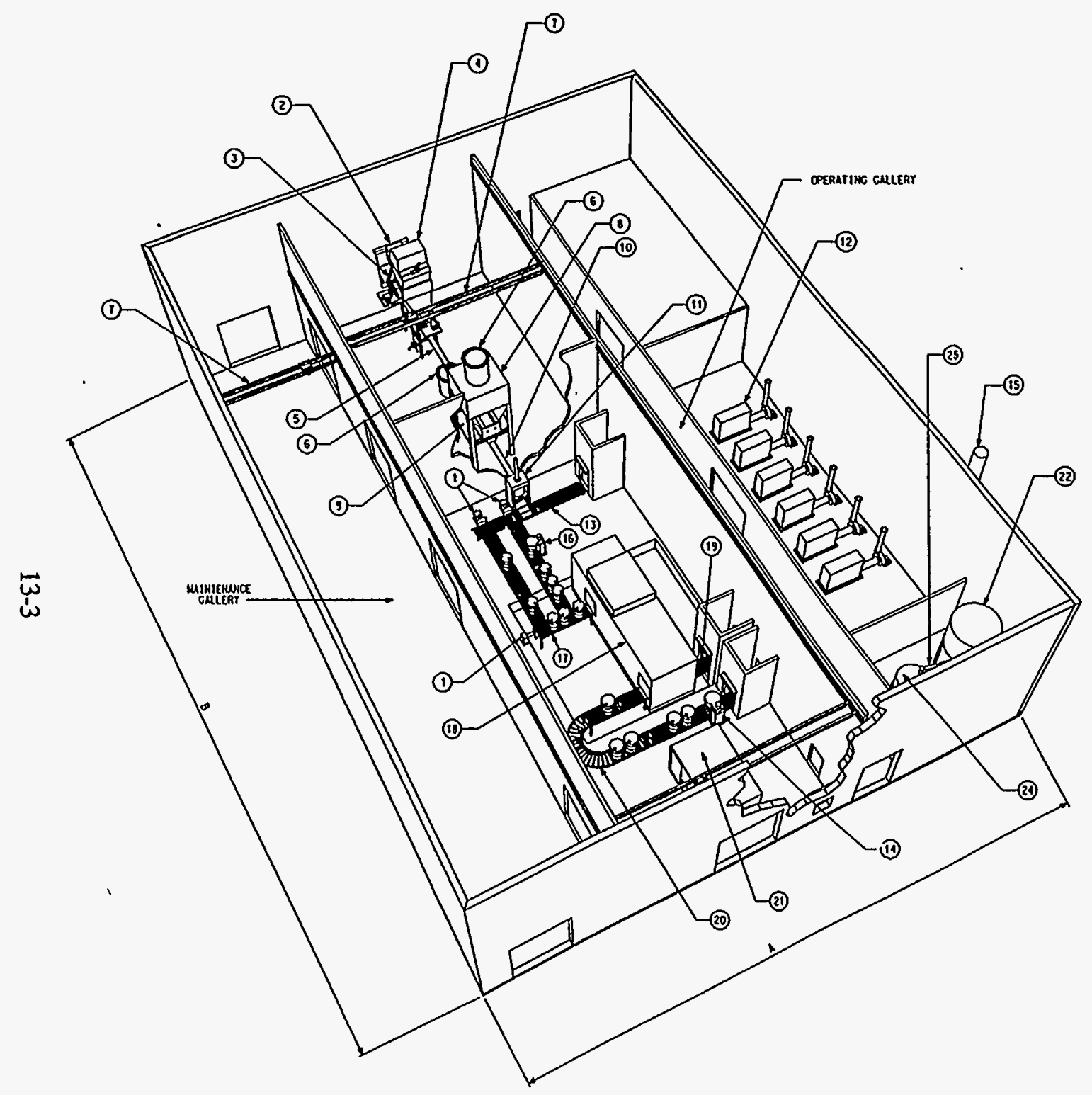

\section{EQUIPMENT LIST}

(1) ORM PUSAER

(3) $5 \times 1 P$

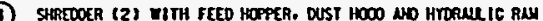

(5) ANCER FEEDER

(5) WLSTE TRMUSFER BIM

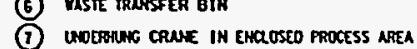

(7) Live Botron BuK STORACE Hopper

(9) TeFtiar SHREDOEA

(10) NUCER FEEOCR

(ii) SHREDOEO YASTE COAPACTOR (30 tons

(18) hePA FILTER ANO FAH

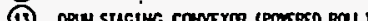

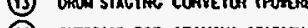

(11) orkentar ros semino station

(i) stace

(ib) DRUS rop seauing Station

(ii) SUPERCOPACTOR FEED COMEYTR (POTRREO RRLL)

(ii) LOUUNR SUPERCORACTOR INIT

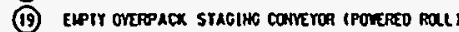

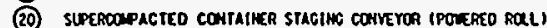

(21) HOUNR HTORMU IC POERR LAII

(22) SToRuce Bin

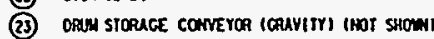

(24) OAY BIS

(23) PHEUHitic COWMERoR

\begin{tabular}{|c|c|c|c|c|}
\hline \multirow{2}{*}{ FACILITY SIZE } & \multicolumn{2}{|c|}{$\begin{array}{l}\text { OHENSION } \\
\text { HFEET }\end{array}$} & \multicolumn{2}{|c|}{$\begin{array}{l}\text { DIMENSION } \\
\text { IN LEIEAS }\end{array}$} \\
\hline & $A$ & B & A & 8 \\
\hline SMALL. & 45 & 200 & 13.8 & 61 \\
\hline LEOIUM & 45 & 200 & 13.8 & 61 \\
\hline LARGE & 80 & 200 & 24.4 & 61 \\
\hline
\end{tabular}

Figure 13-1. Equipment layout for the shredding and compaction (CMPCT) module. 


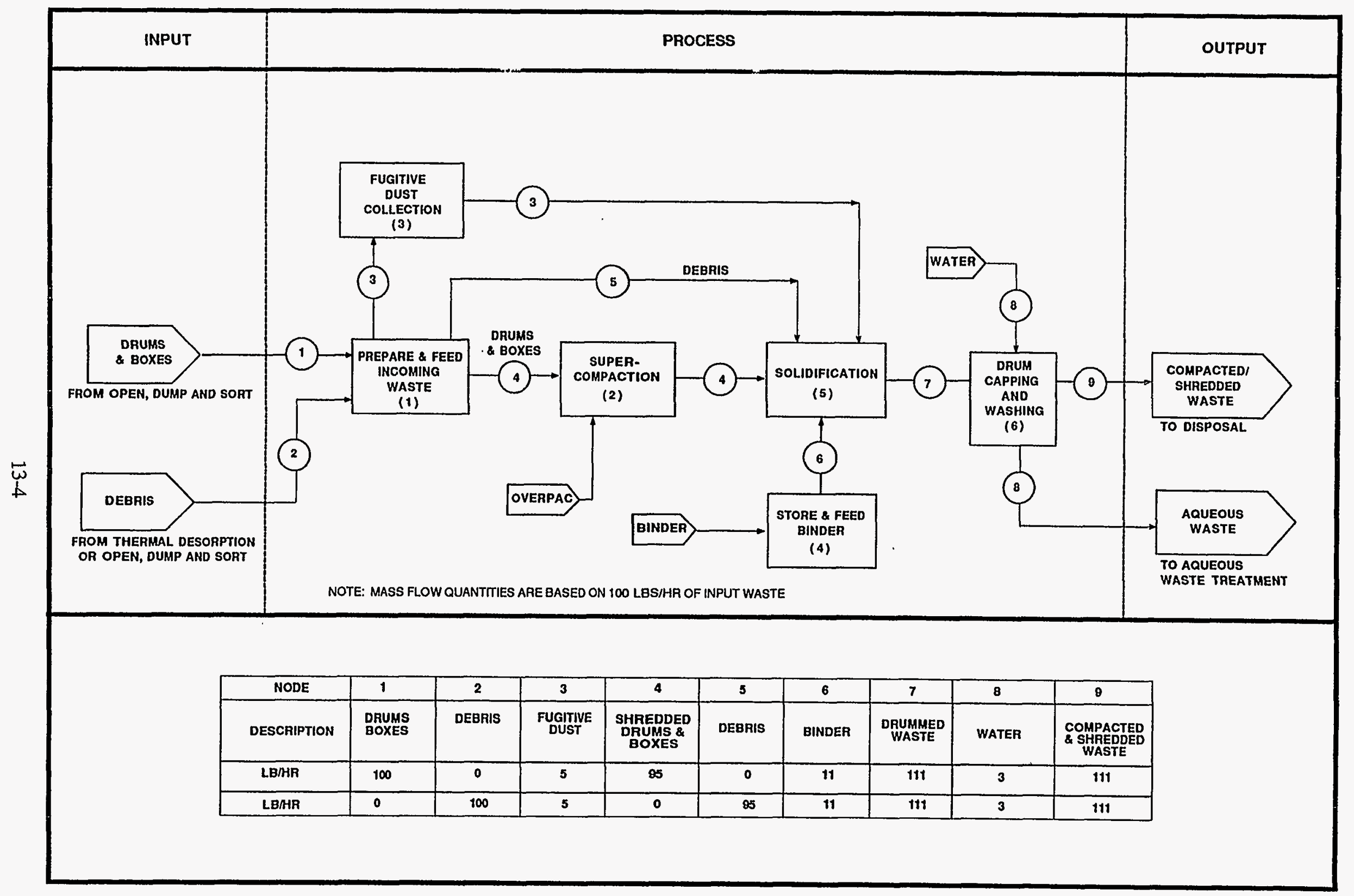

Figure 13-2. Process flow diagram for the shredding and compaction (CMPCT) module. 


\section{SHREDDING AND COMPACTION}

FTE by:Work Breakdown Structure Element Module: CMPCT Waste Type: Contact Handled TRUW

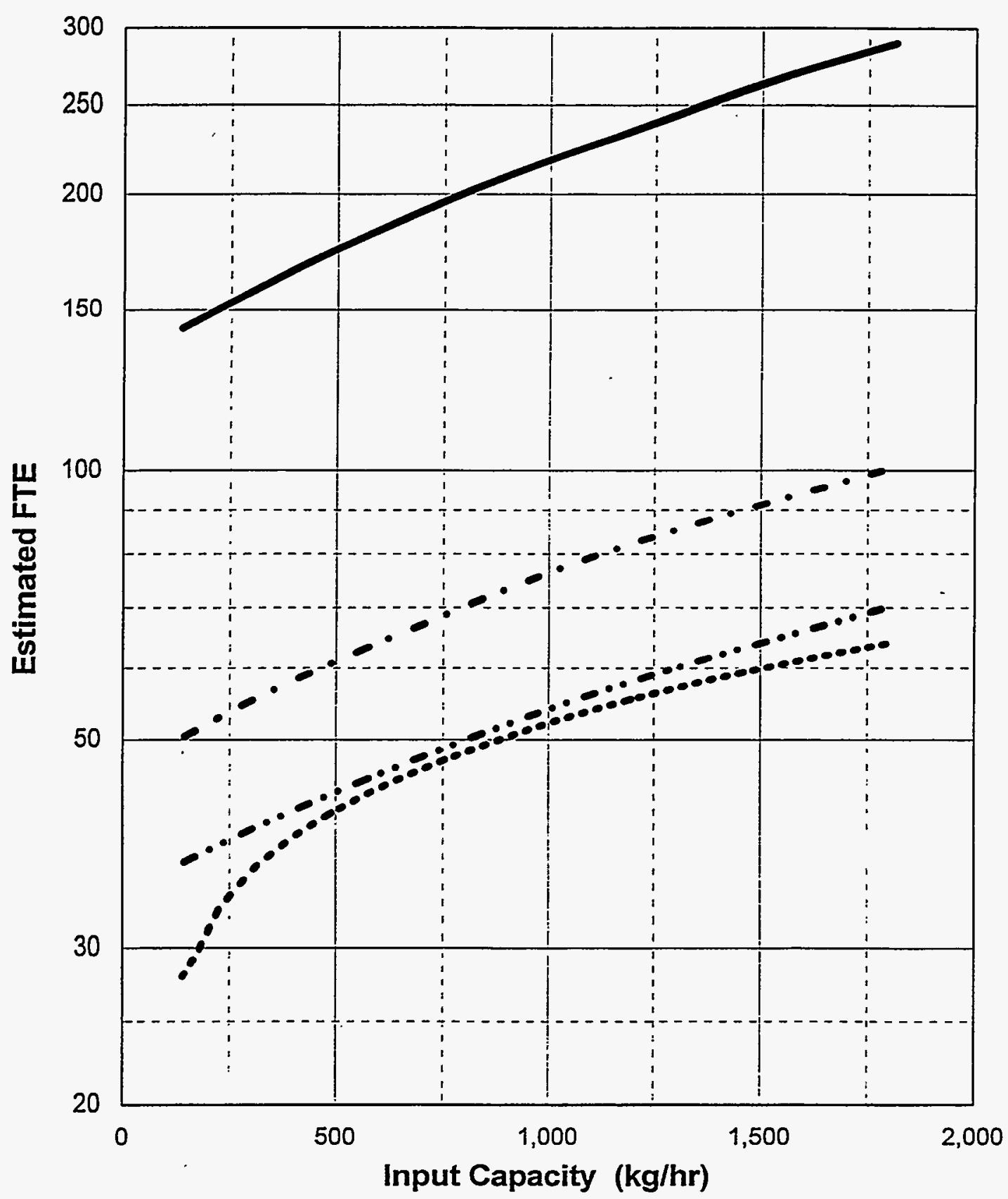

Pre-Operations Construction O\&M (1year) D\&D

Figure 13-3. FTE workers versus capacity for the $\mathrm{CH}$ shredding and compaction (T-CMPCT) module. 


\section{SHREDDING AND COMPACTION}

FTE by Work Breakdown Structure Element

Module: CMPCT Waste Type: Remote Handled TRUW

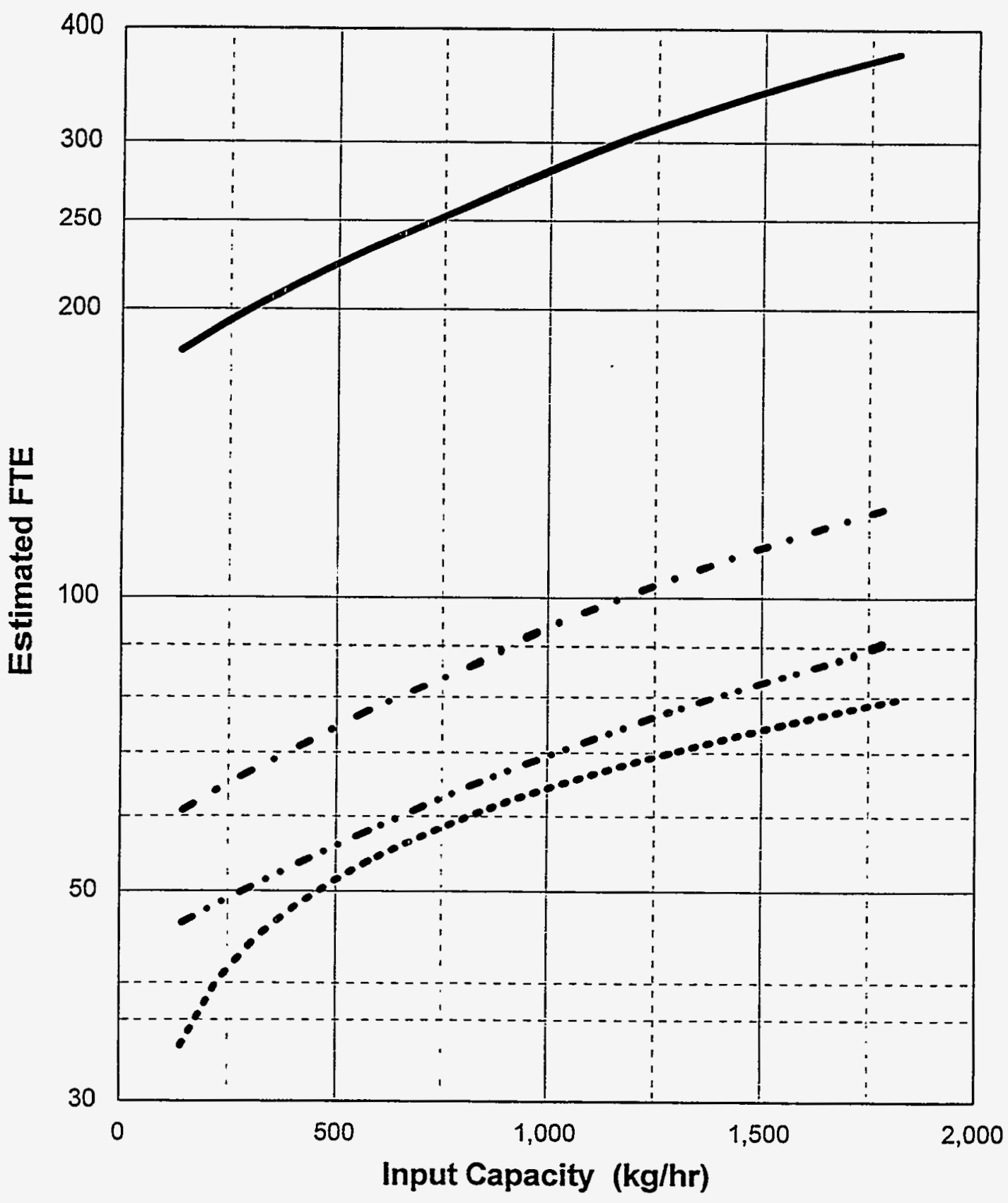

Pre-Operations Construction O\&M (1year) D\&D

Figure 13-4. FTE workers versus capacity for the RH shredding and compaction (U-CMPCT) module. 


\section{SHREDDING AND COMPACTION}

Costs by Work Breakdown Structure Element Module: CMPCT Waste Type: Contact Handled TRUW

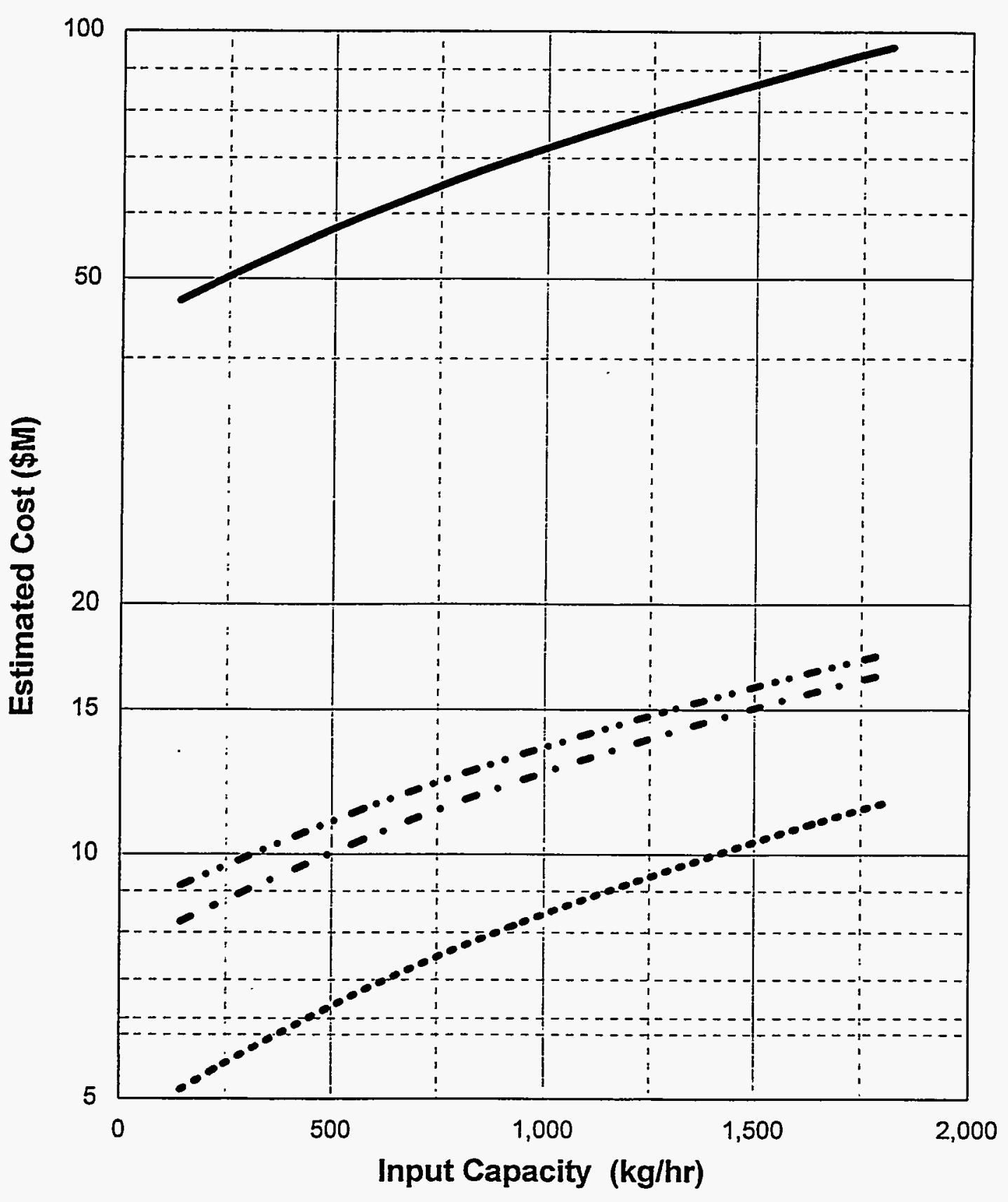

Pre-Operations Construction O\&M (1year) D\&D

Figure 13-5. PLCC versus capacity for the $\mathrm{CH}$ shredding and compaction (T-CMPCT) module. 


\section{SHREDDING AND COMPACTION}

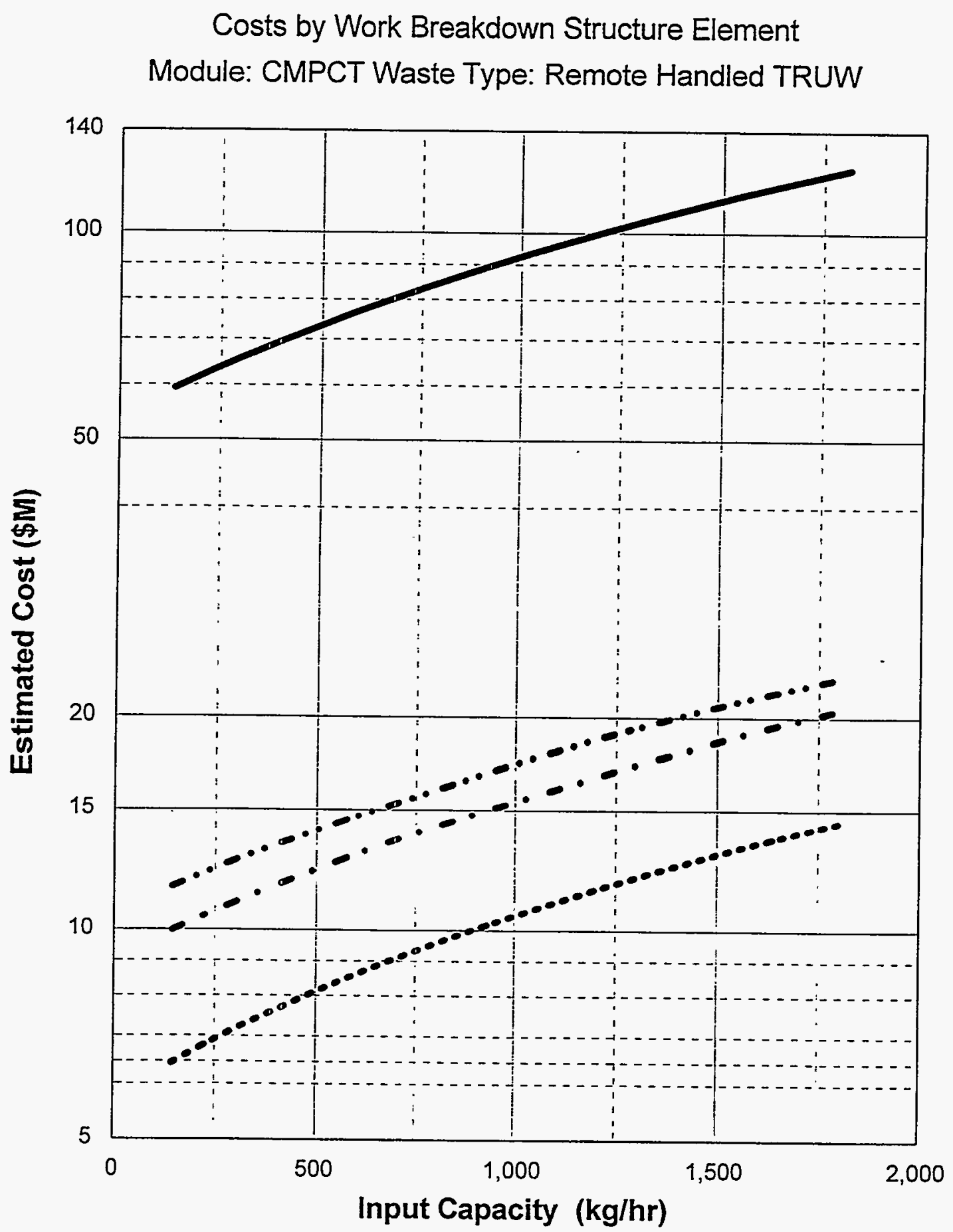

Pre-Operations Construction O\&M (1year) D\&D $\cdots$

Figure 13-6. PLCC versus capacity for the RH shredding and compaction (U-CMPCT) module. 


\section{SHREDDING AND COMPACTION}

Total Life Cycle Costs

Module: CMPCT Waste Type: Contact Handled and Remote Handled TRUW

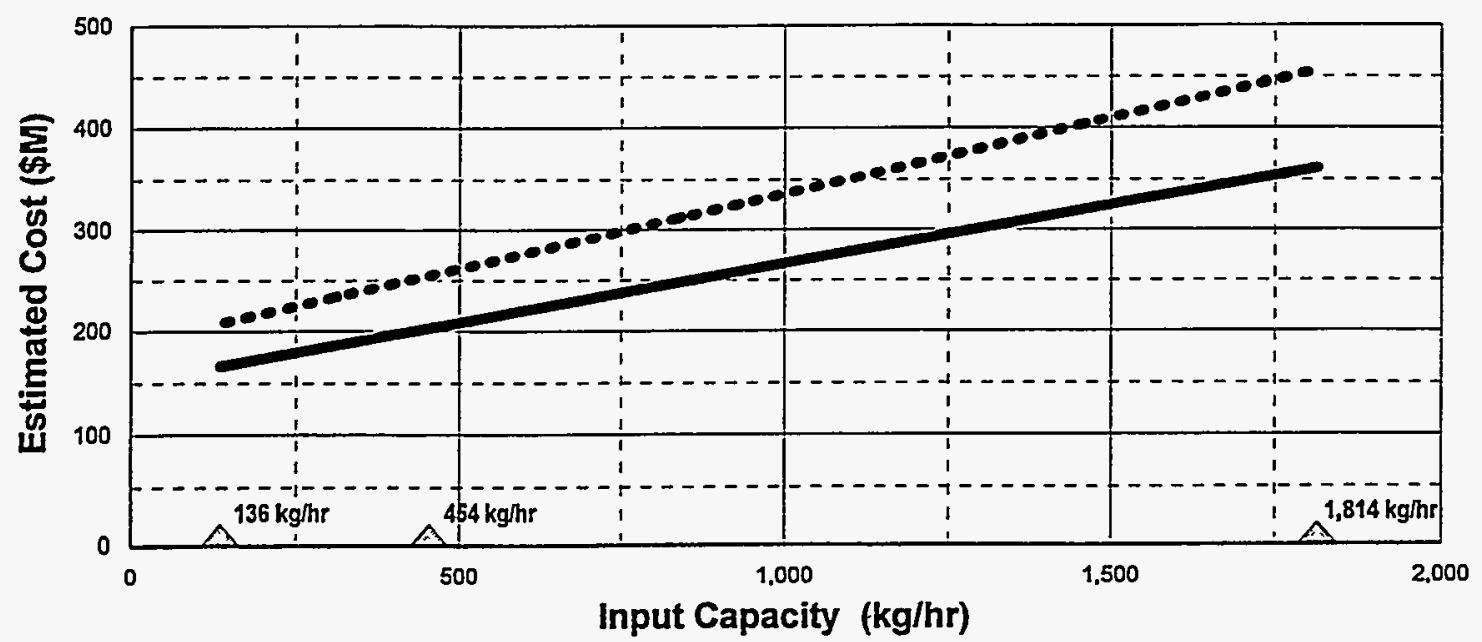

Contact Handled Remote Handled

NOTE: Basis inciudes 20 years O\&M

Triangles indicate capacities where detailed cost estimates were developed.

\section{SHREDDING AND COMPACTION}

Total Life Cycle Unit Costs

Module: CMPCT Waste Type: Contact Handled and Remote Handled TRUW

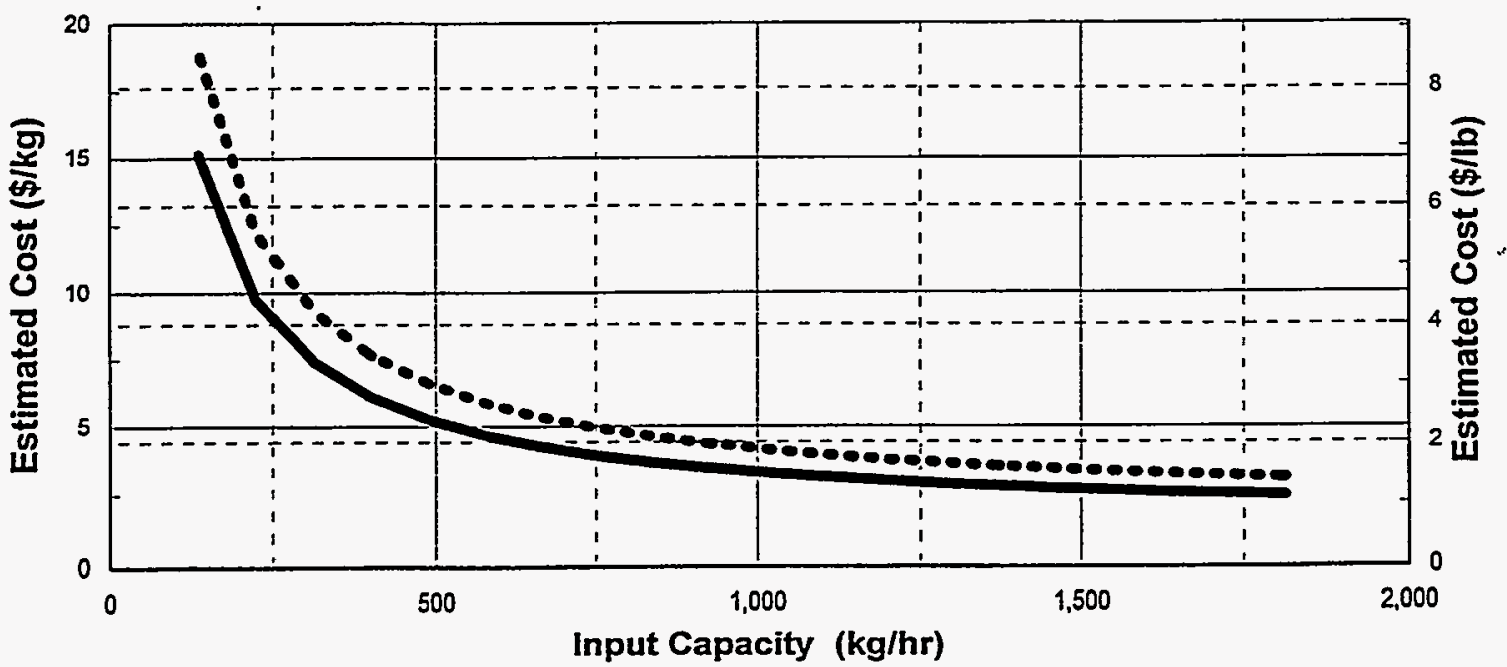

Contact Handled Remote Handled

NOTE: Basis includes 20 years O\&M

Figure 13-7. PLCC versus capacity including unit rates for the shredding and compaction (CMPCT) module. 


\section{AQUEOUS WASTE TREATMENT (MODULE AQWTR)}

\subsection{Basic Information}

The aqueous waste treatment module, shown in Figure 14-1, must be either used in conjunction with the receiving and inspection (RCINS) and stabilization (GROUT) modules, or installed at a location where similar functions are available in existing facilities. Module T-AQWTR is intended for CH-TRUW, while module U-AQWTR is intended for RH-TRUW.

The aqueous waste treatment module collects and treats input aqueous waste, which is generally assumed to contain less than $1 \%$ total organic carbon (TOC). The aqueous waste is received at the module in cans, drums, special transport containers having several different capacities, or by pipeline. In addition to the input waste, the aqueous waste treatment module treats the secondary waste (floor drains, equipment drains, and chemical wastes) from the integrated waste treatment facility. This module also contains a wet-air oxidation unit operation, which is used for organic destruction. The module has a number of unit operations that accomplish the required functions. These unit operations are shown in the PFD in Figure 14-2.

\subsection{Technical Bases and Assumptions}

\subsubsection{Function and Operation of the Module}

The aqueous waste treatment module has all the unit operations needed for treating an incoming liquid waste having a broad range of RCRA-controlled toxic, heavy-metal, and organic contaminants. Toxic metal contaminants can include mercury, cadmium, chromium, and lead. Organic contaminants can include VOCs, such as carbon tetrachloride, chloroform, methylene chloride, tetrachloroethylene, trichlorethylene, and trichloroethane; aromatics, such as benzene, toluene, and xylene; alcohols; glycols; ketones, such as methyl ethyl ketone and methyl isobutyl ketone; phenols; and petroleum compounds. The unit operations also have the capability to treat secondary liquid waste generated by the TRUW treatment facility, such as distillate from air pollution control (module INCIN), rinse water from container washdown operations (modules RCINS, ORGSB, and GROUT), and liquids collected from the module equipment and floor drains.

The incoming liquid waste is precharacterized before it is brought to the treatment module. For bulk operations, the incoming waste is segregated into four different groups: high TOC liquid [between 1 and 10,000 parts per million (ppm)], liquid with a low concentration of total dissolved solids (TDS) (less than $100 \mathrm{ppm}$ ), liquid with a high concentration of TDS (greater than $100 \mathrm{ppm}$ ), and mercury contaminated liquid.

The aqueous waste treatment unit operations have maximum flexibility and can be used in series, in parallel, or as stand alone units. Flexible piping connectors are provided at the inlet and outlet of each treatment device. The waste is transferred from the transport containers to appropriate batch tanks or directly to a desired treatment unit operation.

Typical steps for treating bulk quantities of the various waste categories are as follows (refer to Figure 14-2): 
High TOC waste. Waste high in TOC is first processed through a gross-organic removal unit. Typical treatment techniques used in this unit operation could include flotation thickeners or coalescing devices. The organics from the gross-organic removal unit are collected and transported to an incineration module. The aqueous phase is transported to a suspended-solids filtration unit utilizing typical techniques including superfine filtration or backflushable filters. Solids captured by the filtration unit are transported as a slurry to a concentration unit that further concentrates the sludge. The sludge phase is transported to the stabilization module while the liquid phase is transported for final polishing by a dissolved-solids removal unit, which could use a combination of cation, anion, and mixed-bed ion exchange resins. The aqueous phase from the suspended-solids filtration unit is transported to a dissolved-organic removal unit that, typically, could use an activated carbon unit for removing VOCs and aromatics. This is followed by a combination of stripping and chemical oxidation for removing alcohols, ketones, phenols, and glycols. Organics removed by the dissolved-organic removal unit are oxidized and discharged or are captured using activated carbon. The aqueous effluent from the dissolved-organic removal unit is transported to the dissolved-solids removal unit for final polishing. The treated water is then transported to a sampling unit before recycling and reuse. If the high TOC input waste also has a high TDS content, it is further processed through an intermediate step involving a neutralization and settling unit, as appropriate.

Low TDS waste. Waste low in TDS is processed through the suspended-solids filtration unit followed by the dissolved-solids removal unit. The treated water is then transported to a sampling unit before recycling and reuse. If the input waste has organic contamination, it is processed through intermediate steps involving gross organic removal and dissolved organic removal, as appropriate. Inorganic solids and organic liquids removed during treatment of low TDS waste are handled in the same manner as described for high TOC waste.

High TDS waste. Waste high in TDS is processed through the neutralization and settling unit, where chemicals are added to neutralize, precipitate, and enhance settling of solids as sludge. The sludge is transported to the concentration unit, where the water is removed and the resulting concentrated siudge is transported to the stabilization module. Supernate from the neutralization and settling unit is transported to the suspended-solids filtration unit, followed by a final polishing by the dissolved-solids removal unit. The treated water is then transported to a sampling unit before recycling and reuse. Solids and organic liquids removed during treatment of low TDS waste treatment steps are handled in the same manner as described for high TOC waste.

Mercury contaminated waste. Waste that contains mercury (or other toxic metals) is transported to the neutralization and settling unit operation, where precipitating chemicals are added to force settling of the heavy metal as an insoluble salt and concentrate them as a bottom sludge. The bottom sludge is transported to the concentration unit, where the water is removed. The resulting concentrated sludge is transported to the stabilization module. The aqueous waste from the precipitation and neutralization unit is transported to the suspended-solids removal unit, followed by the dissolved-solids removal unit. This latter unit has absorbent and ion-exchange media (e.g., thiol ion-exchange resin media, such as Duolite GT-83 or Ionac SR-4, designed to remove trace quantities of mercury). The treated water is transported to a sampling tank before recycling and reuse. Solids and organic liquids removed during the treatment of low TDS waste are handled in the same manner as described for high TOC waste. 
The unit operations remove radioactivity and RCRA-regulated metal and organics to a level that allows the treated water to be either recycled for reuse or discharged, if allowed by the site discharge permits.

\subsubsection{Integration of the Module}

Input waste to the aqueous waste treatment module comes from the receiving and inspection module or from onsite waste generators that have been precharacterized. Other input includes secondary waste from the incineration and stabilization modules. Output from the aqueous waste treatment module to the stabilization module includes spent resins, spent carbon, and concentrated sludge. Treated water output is transported to various modules for reuse. Recovered liquid organics are transported to the incineration module. Materials purchased for O\&M, such as personal protective equipment, ion-exchange resins, activated carbon, chemicals, and containers, are assumed to be consumable supplies, and their costs are estimated accordingly.

\subsection{Cost Bases, Assumptions, and Results}

Input waste is assumed to consist of (see mass flow rates in Figure 14-2) 33\% high TOC liquid, 25\% low TDS liquid, 38\% high TDS liquid, and 4\% mercury contaminated waste. The precipitation and neutralization unit, gross-organic removal filter, backflushable filters, ion exchanger, organic distillation unit, charcoal filter, and evaporator constitute the major equipment capital cost items; their costs are based on prices submitted by various vendors. The cost estimate for the gross-organic removal unit is based on a quotation by McTighe Industries, Inc. of Mitchell, South Dakota. The cost estimate for the organic stripper unit is based on a quotation by APV Crepaco, Inc. of Tonawanda, New York. The cost estimate for the evaporation unit is based on a quotation by LCI Processing, Inc. of Charlotte, North Carolina. The cost estimate for the chemical oxidation using a combination of hydrogen peroxide and ultraviolet light is based on a quotation by Peroxidation System, Inc. of Tucson, Arizona. The cost estimate for the suspended-solids filtration unit is based on using a membrane filtration system called Memberalox, whose price was quoted by U.S. Filter Corporation of Warrendale, Pennsylvania.

Estimated FTE and cost versus capacity for this module are shown in Figures 14-3 through 14-7. 


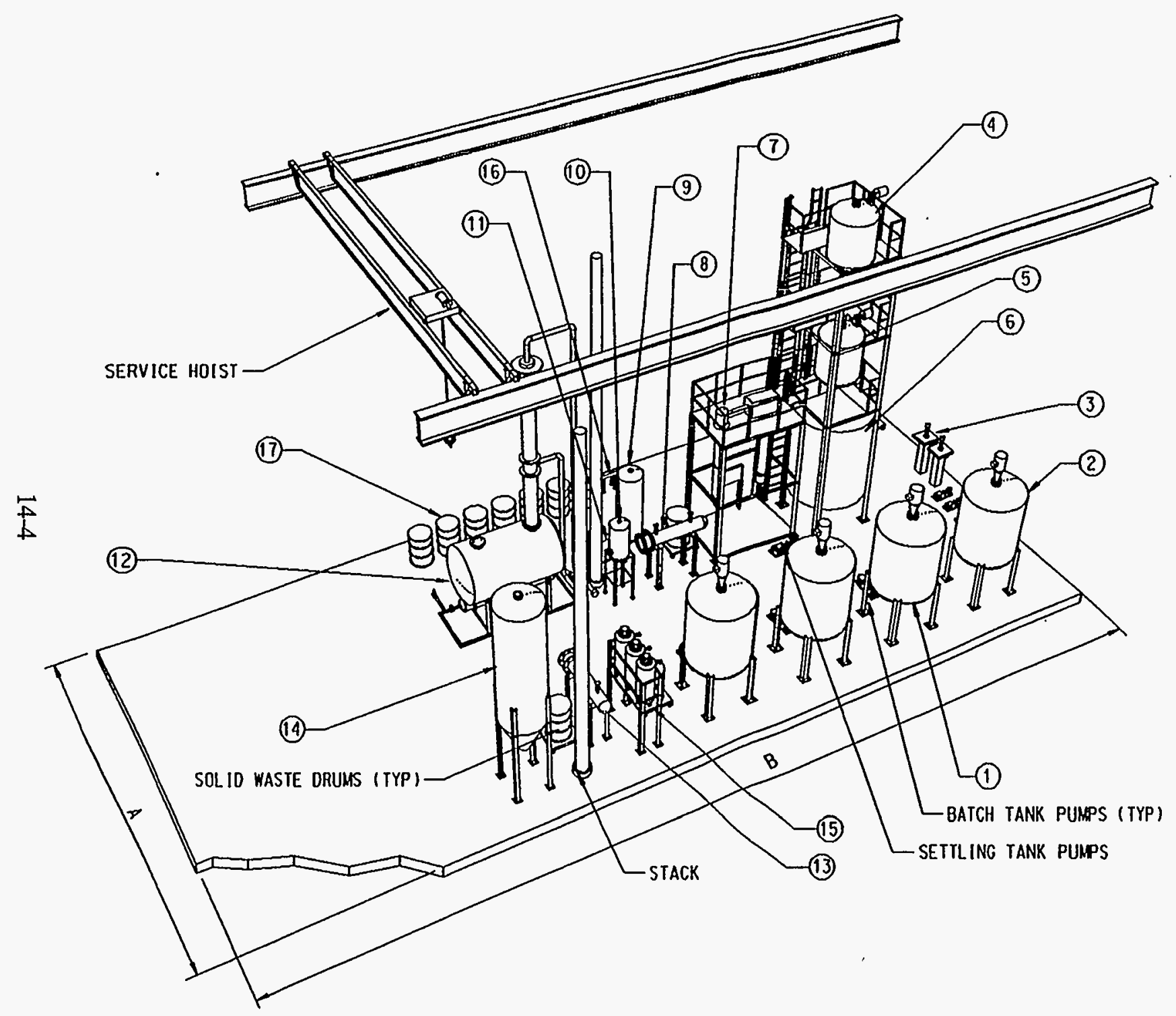

EQUIPMENT LIST

(1) BATCH TANKS WITH ACITATOR (TYP 4)

(2) OIL AND WATER SEPARATOR

(3) SOLIDS FILTER

(4) NEUTRALIZER TANK WITH AGITATOR

(5) REACTOR TANK WITH AGITATOR

(6) SETtLING TANK

(7) eVaporator UNIT

(8) CONDENSER

(9) CONDENSED WATER tANK

(10) VAPOR PHASE CARBON FILTER

(11) VACUUM PUMP

(12) BATCH STILL

(13) STILL CONDENSER

(14) VAPOR PHASE CARBON FILTER

(15) ION EXCHANGE UNIT

(16) UV AND PEROXIDE UNIT

(17) CARBON FILTER DRUMS

NOTE: WALLS NOT SHOWN FOR CLARITY

\begin{tabular}{|c|c|c|c|c|}
\hline \multirow{2}{*}{ FACILITY SIZE } & \multicolumn{2}{|c|}{$\begin{array}{c}\text { DIMENSION } \\
\text { INFEET }\end{array}$} & \multicolumn{2}{|c|}{$\begin{array}{l}\text { DINENSION } \\
\text { IN METERS }\end{array}$} \\
\hline & $A$ & 8 & $A$ & $\mathrm{~B}$ \\
\hline SMALL & 110 & 60 & 33.5 & 18.3 \\
\hline HED IUU & 120 & 85 & 36.6 & 25.9 \\
\hline LARGE & 130 & 100 & 39.7 & 30.5 \\
\hline
\end{tabular}

Figure 14-1. Equipment layout for the aqueous waste treatment (AQWTR) module. 


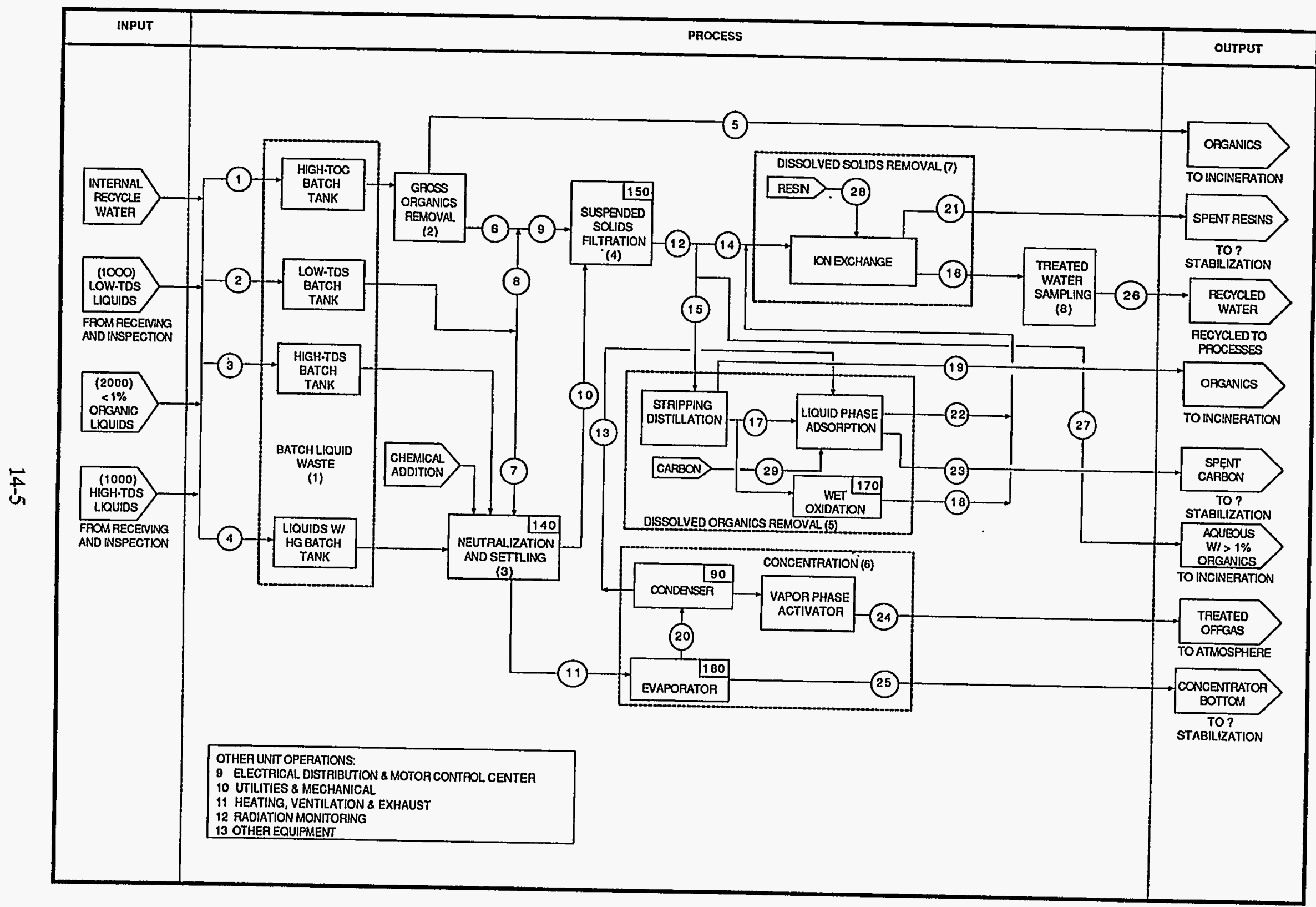

Figure 14-2. Process flow diagram for the aqueous waste treatment (AQWTR) module. 


\begin{tabular}{|c|c|c|c|c|c|c|c|c|c|c|c|c|c|c|c|}
\hline NDOE & 1 & 2 & 3 & 4 & 5 & 6 & 7 & 8 & 9 & 10 & 11 & 12 & 13 & 14 & 15 \\
\hline DESCRIPTION & $\begin{array}{l}\text { HKGH-TOC } \\
\text { LRQUIDS }\end{array}$ & $\begin{array}{l}\text { LKUUIDS } \\
\text { WITHLOW } \\
\text { DISSOLVED } \\
\text { SOLIDS }\end{array}$ & $\begin{array}{l}\text { LKQUIDS } \\
\text { WITH HIGH } \\
\text { OISSOLVED } \\
\text { SOLIDS }\end{array}$ & $\begin{array}{l}\text { MERAURY } \\
\text { CONTAINING } \\
\text { LIQUIDS }\end{array}$ & ORGANICS & $\begin{array}{l}\text { AOUEOUS } \\
\text { WASTE }\end{array}$ & $\begin{array}{l}\text { LOW } \\
\text { DISSOLVEO } \\
\text { SOLIDS }\end{array}$ & $\begin{array}{l}\text { LOW } \\
\text { DISSOLVED } \\
\text { SOLIDS }\end{array}$ & $\begin{array}{l}\text { AQUEOUS } \\
\text { WASTE }\end{array}$ & $\begin{array}{l}\text { CLAAIFIED } \\
\text { WASTE }\end{array}$ & SLUDGE & $\begin{array}{l}\text { AQUEOLS } \\
\text { WASTE }\end{array}$ & DONDENSATE & $\begin{array}{l}\text { AOUEOUS } \\
\text { WASTE }\end{array}$ & $\begin{array}{l}\text { AQUEOUS } \\
\text { CONTAINING } \\
\text { DISSOLVED } \\
\text { OFGANICS }\end{array}$ \\
\hline LB/HA & 100 & 0 & 0 & 0 & 1.7 & 98.3 & 0 & 0 & 88.3 & 0 & 0 & 98.3 & 0 & 78.6 & 16.7 \\
\hline LE/HR & 0 & 100 & 0 & 0 & 0 & 0 & 16 & 84 & 84 & 14.4 & 1.6 & 98.4 & 1.3 & 78.7 & 16.7 \\
\hline LB/HR & 0 & 0 & 100 & 0 & 0 & 0 & 0 & 0 & 0 & 80 & 10 & 90 & 8.1 & 72 & 15.3 \\
\hline LB/HR & 0 & 0 & 0 & 100 & 0 & 0 & 0 & 0 & 0 & 90 & 10 & 90 & 8.1 & 72 & 15.3 \\
\hline
\end{tabular}

\begin{tabular}{|c|c|c|c|c|c|c|c|c|c|c|c|c|c|c|}
\hline NOOE & 16 & 17 & 18 & 19 & 20 & 21 & 22 & 23 & 24 & 25 & 26 & 27 & 28 & 29 \\
\hline DESGRIPTKON & $\begin{array}{l}\text { TREATEO } \\
\text { WATER }\end{array}$ & $\begin{array}{l}\text { STRIPPED } \\
\text { AQUEOUS } \\
\text { WASTE }\end{array}$ & $\begin{array}{l}\text { TREATED } \\
\text { WATEF }\end{array}$ & $\begin{array}{l}\text { REOONERED } \\
\text { OAGANICS }\end{array}$ & $\begin{array}{l}\text { CONOERSER } \\
\text { CONCENTTATE }\end{array}$ & $\begin{array}{l}\text { SPENT } \\
\text { RESAN }\end{array}$ & $\begin{array}{l}\text { TAEATED } \\
\text { WATER }\end{array}$ & $\begin{array}{l}\text { SPENT } \\
\text { CAROON }\end{array}$ & $\begin{array}{l}\text { TREATED } \\
\text { OFFGAS }\end{array}$ & $\begin{array}{l}\text { EVAPORATOR } \\
\text { CONCENTRATE }\end{array}$ & $\begin{array}{l}\text { RECYCLEO } \\
\text { WATER }\end{array}$ & $\begin{array}{c}1 \% \\
\text { ORGANICS }\end{array}$ & RESINS & CAPBON \\
\hline LB/HR & 84.4 & 5,7 & 10 & 1 & 0 & 3 & 5.7 & 3 & 0 & 0 & 94.4 & 2.9 & 3 & 3 \\
\hline LB/HR & 95.7 & 5.7 & 10 & 1 & 1.4 & 3 & 7 & 3 & 0.1 & 0.2 & 95.7 & 3 & 3 & 3 \\
\hline LB/HR & 94.4 & 4.3 & 10 & 1 & 8.5 & 3 & 12.4 & 3 & 0.4 & 1.5 & 94.4 & 2.7 & 3 & 3 \\
\hline LE/HR & 94.4 & 4.3 & 10 & 1 & 8.5 & 3 & 12.4 & 3 & 0.4 & $\$ .5$ & 94.4 & 2.7 & 3 & 3 \\
\hline
\end{tabular}

NOTE: MASS FLOW QUANTMIES ARE BASED ON 100 LBSHR OF INPUT WASTE

Figure 14-2. (continued). 


\section{AQUEOUS WASTE TREATMENT}

FTE by Work Breakdown Structure Element

Module: AQWTR Waste Type: Contact Handled TRUW

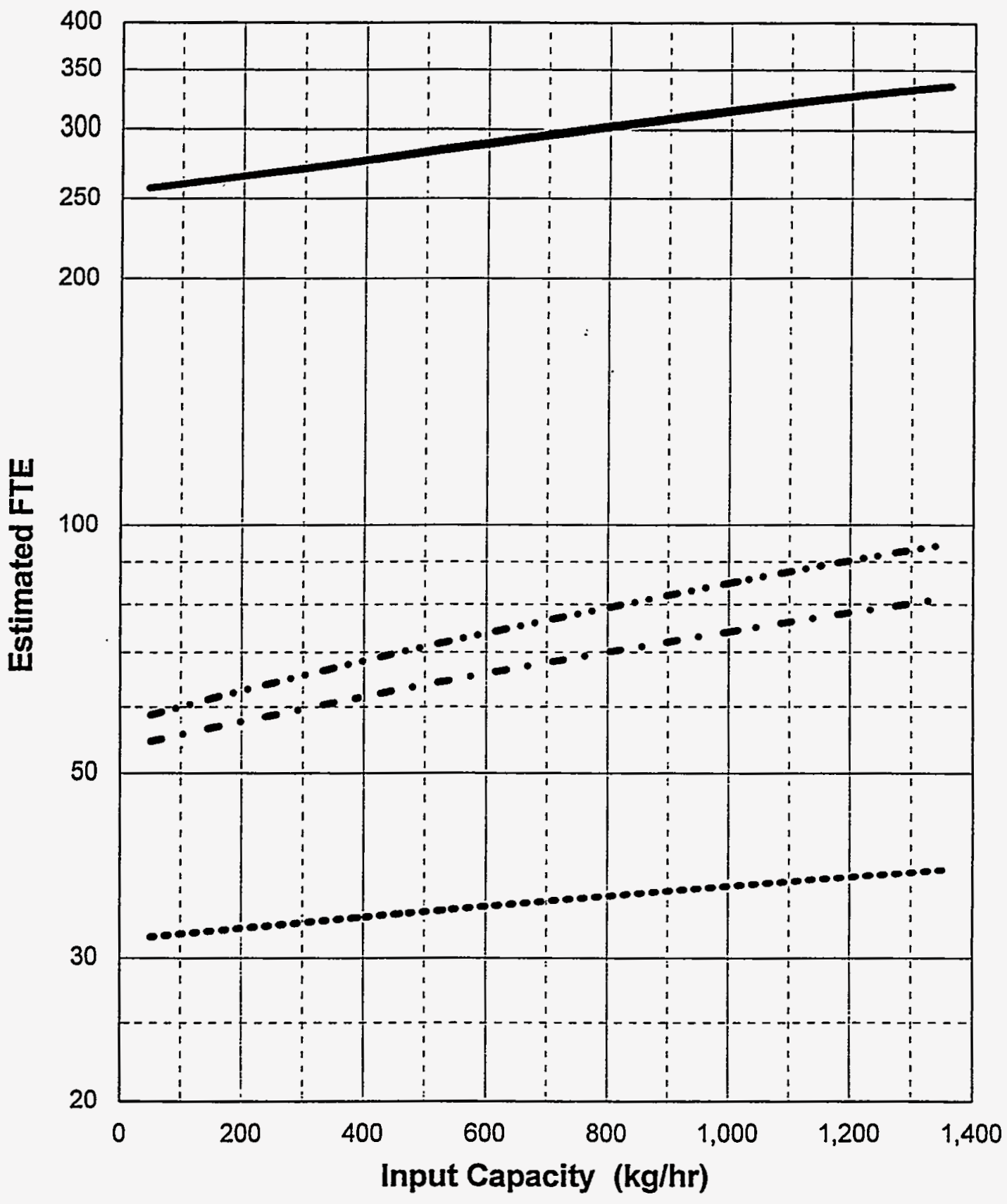

Pre-Operations Construction O\&M (1year) D\&D

Figure 14-3. FTE workers versus capacity for the $\mathrm{CH}$ aqueous waste treatment (T-AQWTR) module. 


\section{AQUEOUS WASTE TREATMENT}

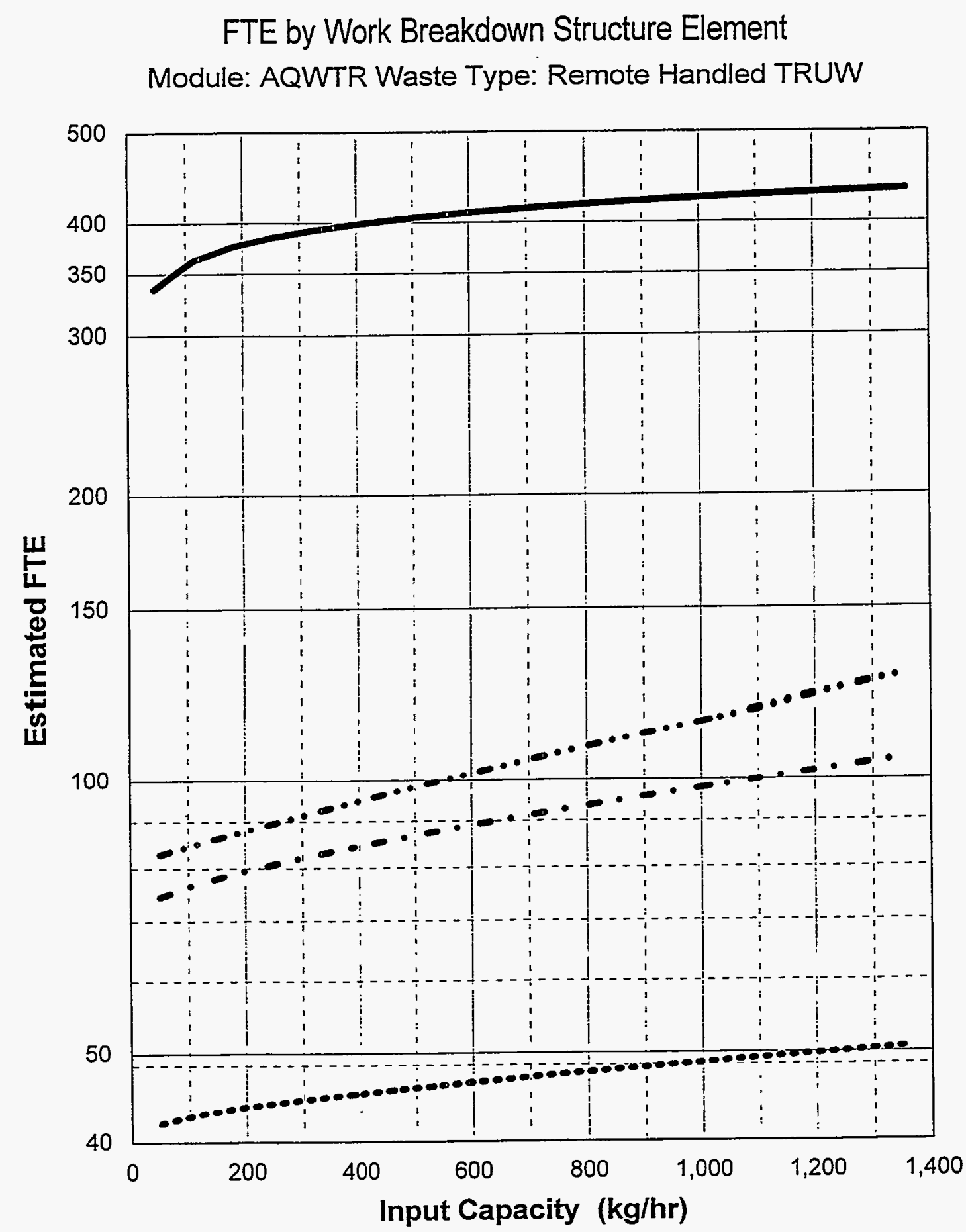

Pre-Operations Construction O\&M (1year) D\&D

Figure 14-4. FTE workers versus capacity for the RH aqueous waste treatment (U-AQWTR) module. 


\section{AQUEOUS WASTE TREATMENT}

Costs by Work Breakdown Structure Element

Module: AQWTR Waste Type: Contact Handled TRUW

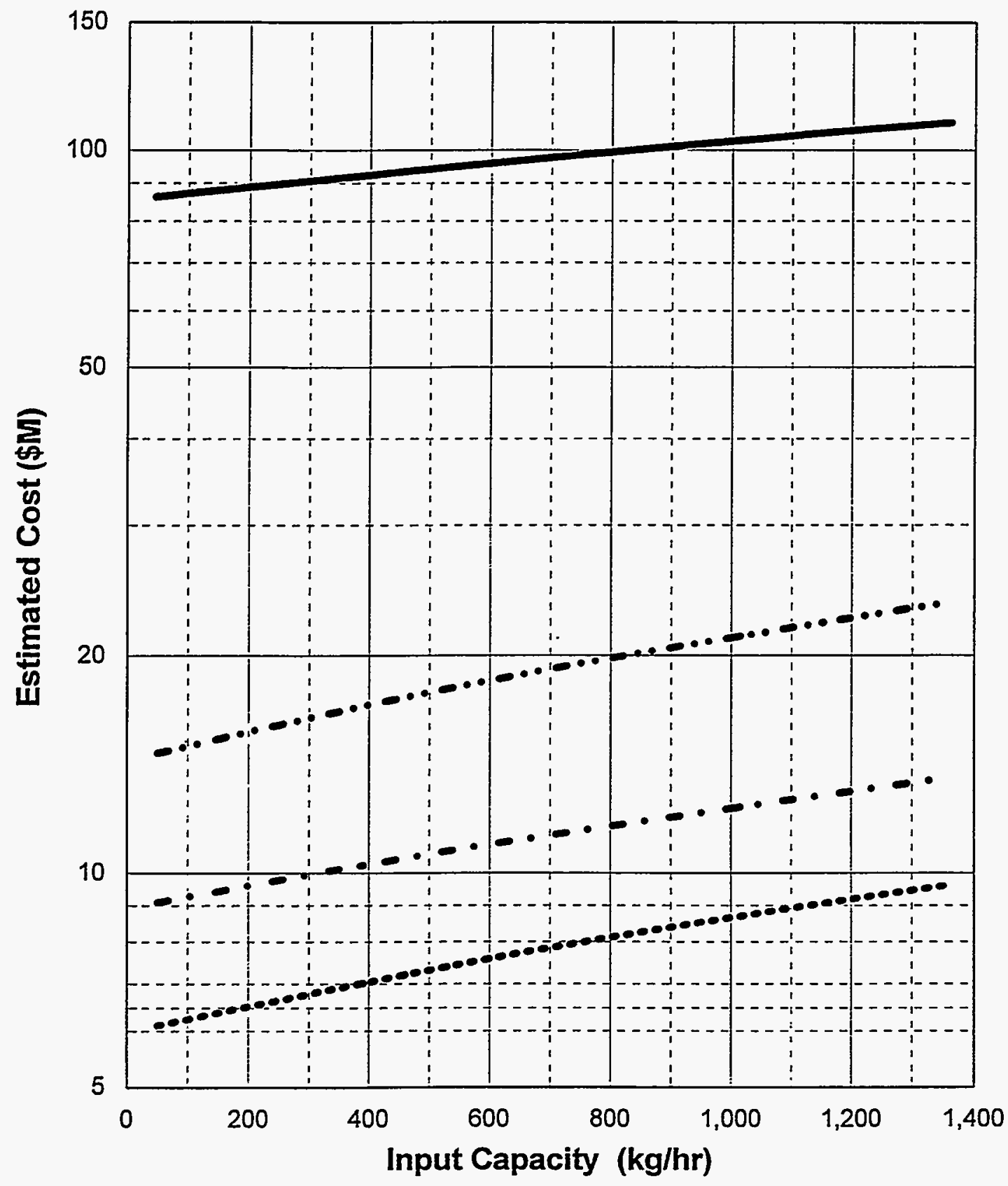

Pre-Operations Construction O\&M (1year) D\&D

Figure 14-5. PLCC versus capacity for the $\mathrm{CH}$ aqueous waste treatment (T-AQWTR) module. 


\section{AQUEOUS WASTE TREATMENT}

Costs by Work Breakdown Structure Element

Module: AQWTR Waste Type: Remote Handled TRUW

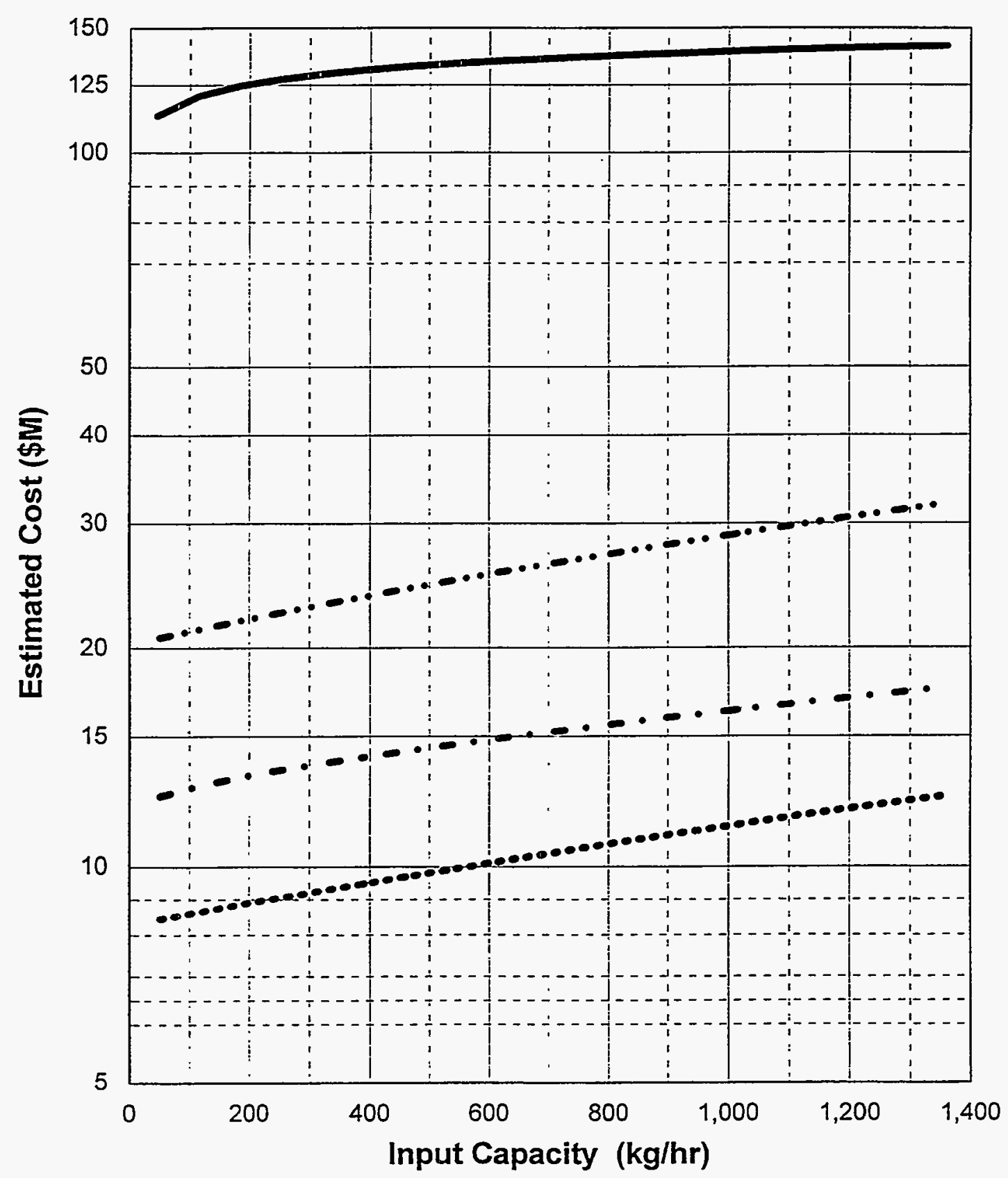

Pre-Operations Construction O\&M (1year) D\&D

Figure 14-6. PLCC versus capacity for the RH aqueous waste treatment (U-AQWTR) module. 


\section{AQUEOUS WASTE TREATMENT}

Total Life Cycle Costs

Module: AQWTR Waste Type: Contact Handled and Remote Handled TRUW

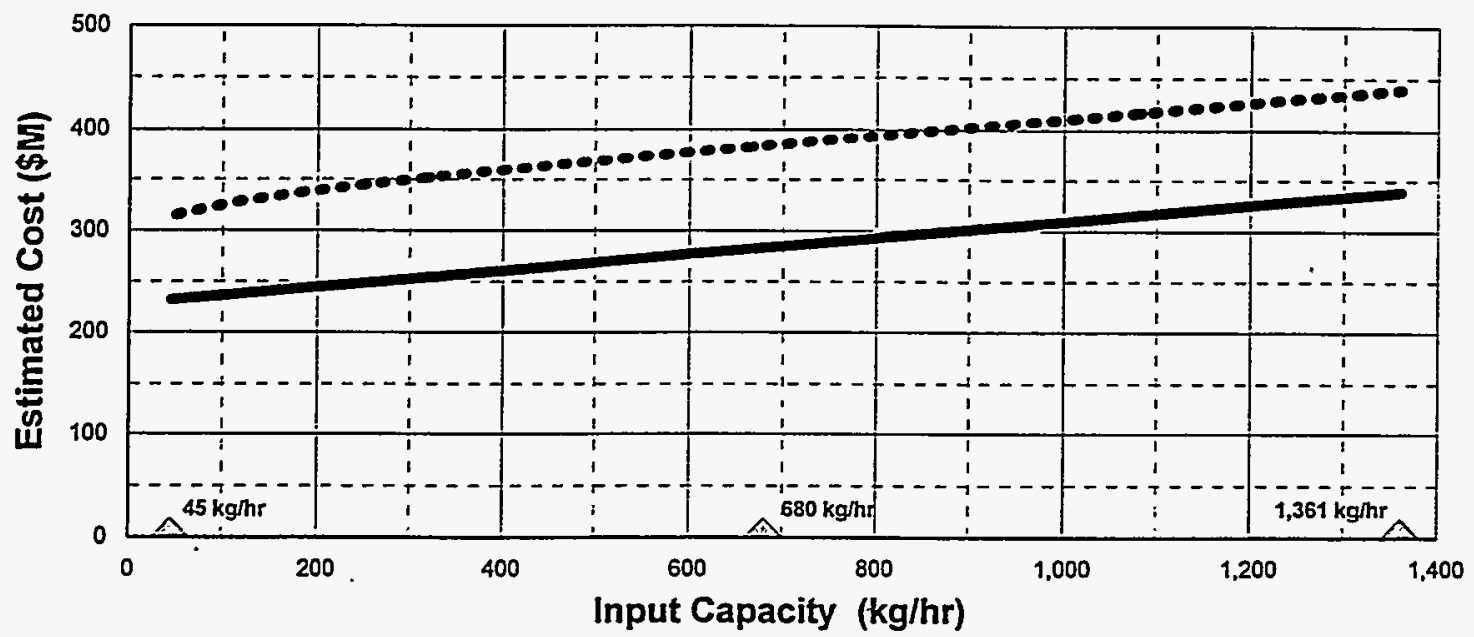

Contact Handled Remote Handled

NOTE: Basis includes 20 years O\&M

Triangles indicate capacities where detailed cost estimates were developed.

\section{AQUEOUS WASTE TREATMENT}

Total Life Cycle Unit Costs

Module: AQWTR Waste Type: Contact Handled and Remote Handled TRUW

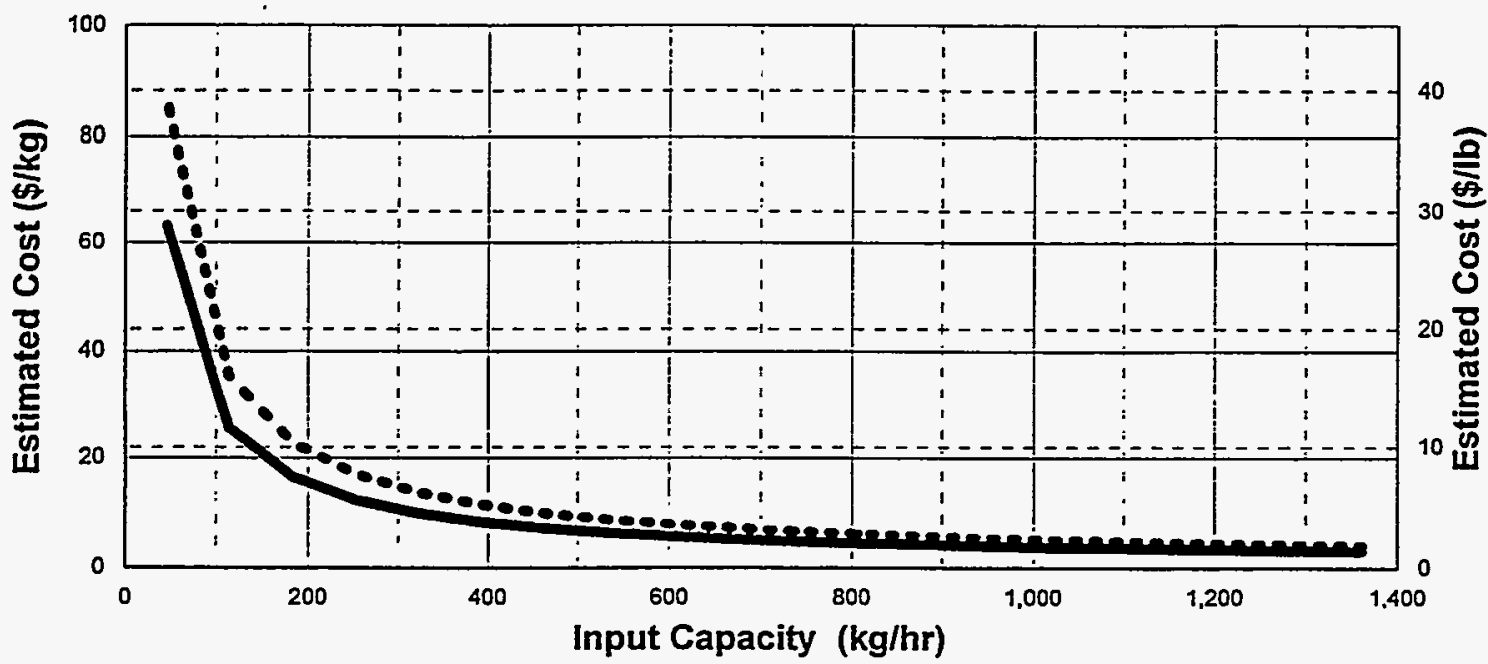

Contact Handled Remote Handled

NOTE: Basis includes 20 years O\&M

Figure 14-7. PLCC versus capacity including unit rates for the aqueous waste treatment (AQWTR) module. 


\section{GROUT STABILIZATION (MODULE GROUT)}

\subsection{Basic Information}

The grout stabilization module, shown in Figure 15-1, provides secondary waste treatment capability and is used at the end of the treatment modules. The module output is transported to the certification and shipping (CSHIP) module. The primary function of this module is to solidify solid and liquid waste and sludge that arrive from treatment modules, storage facilities, or the generators. Module T-GROUT is applicable to CH-TRUW and module U-GROUT is for RH-TRUW. Unit operations are shown in the PFD in Figure 15-2.

The module consists of five main process unit operations that incorporate all buildings, systems, processes, equipment, devices, controls, and accessories required to prepare the incoming waste and stabilize it either by macro or microencapsulation techniques.

\subsection{Technical Bases and Assumptions}

\subsubsection{Function and Operation of the Module}

The module receives concentrated liquid waste and sludge via a pipeline or by special containers. A chemical addition unit is used to adjust the chemistry of the feed before it is fed to the solidification unit operation. A preparation and feed unit crushes and shreds incoming solid waste. The shredded waste is then collected in a storage hopper.

The microencapsulation unit operation solidifies concentrated liquid waste, sludge, or a combination of the two. The unit has a remotely operated in-drum solidification assembly equipped with intake tanks and hoppers for sludge, liquid waste, and grout. To accomplish the solidification process, a drum is placed onto a transfer cart. The cart moves the drum to various fill stations where feeders place sludge and liquid waste and binder in the drum. Next, the cart moves the filled drum to a mixing station where the drum is capped and tumbled to achieve the required mixture. The cart moves the drum for a repeat of the filling and mixing steps to maximize the fill efficiency.

The macroencapsulation unit operation solidifies bulkier solids such as spent filters, shredded solids, and pelletized debris. Macroencapsulation is accomplished by placing the solids in a drum, adding grout, and mixing the two components. In large generator modules, a pugmill accomplishes this function.

After encapsulation, the operator remotely moves the filled container to a capping and washing unit. This unit operation provides for sample collection, capping of the container, and removal of loose contamination from the container surface by high-pressure spray water jets. The containerized waste is ready for processing through radioassay and final certification, which are included in the back-end (CSHIP) module. 


\subsubsection{Integration of the Module}

Input to the module consists of concentrator bottom from the aqueous waste treatment (AQWTR) module; process residues from the open, dump, and sort (OSORT) module; ash from the incineration (INCIN) module; filtration solids from the deactivation (DEACT) module; spent filters from treatment modules; and drums, containers, and inorganic debris from the shredding and compaction (CMPCT) module. Major O\&M purchased materials, such as personal protective equipment, laboratory material, binder, and containers are assumed to be consumable supplies and their costs are estimated accordingly.

Output consists mainly of drummed, solidified $\mathrm{CH}$ - and RH-TRUW, which is moved to a backend (CSHIP) module. Waste water from drum washing is transported to the aqueous waste treatment (AQWTR) module. Treated offgas is discharged to the atmosphere.

\subsection{Cost Bases, Assumptions, and Results}

Incoming waste size reduction and preparation units (shredders) and solidification mixers are the major equipment capital cost items. Costs for the preparation and feed unit are based on vendor quotes for shredders, conveyors, and dust collection equipment. Solidification module assembly prices are based on quotes by Stock Equipment Company of Chagrin Falls, Ohio. Estimated FTEs and cost versus capacity for this module are shown in Figures 15-3 to 15-7. 


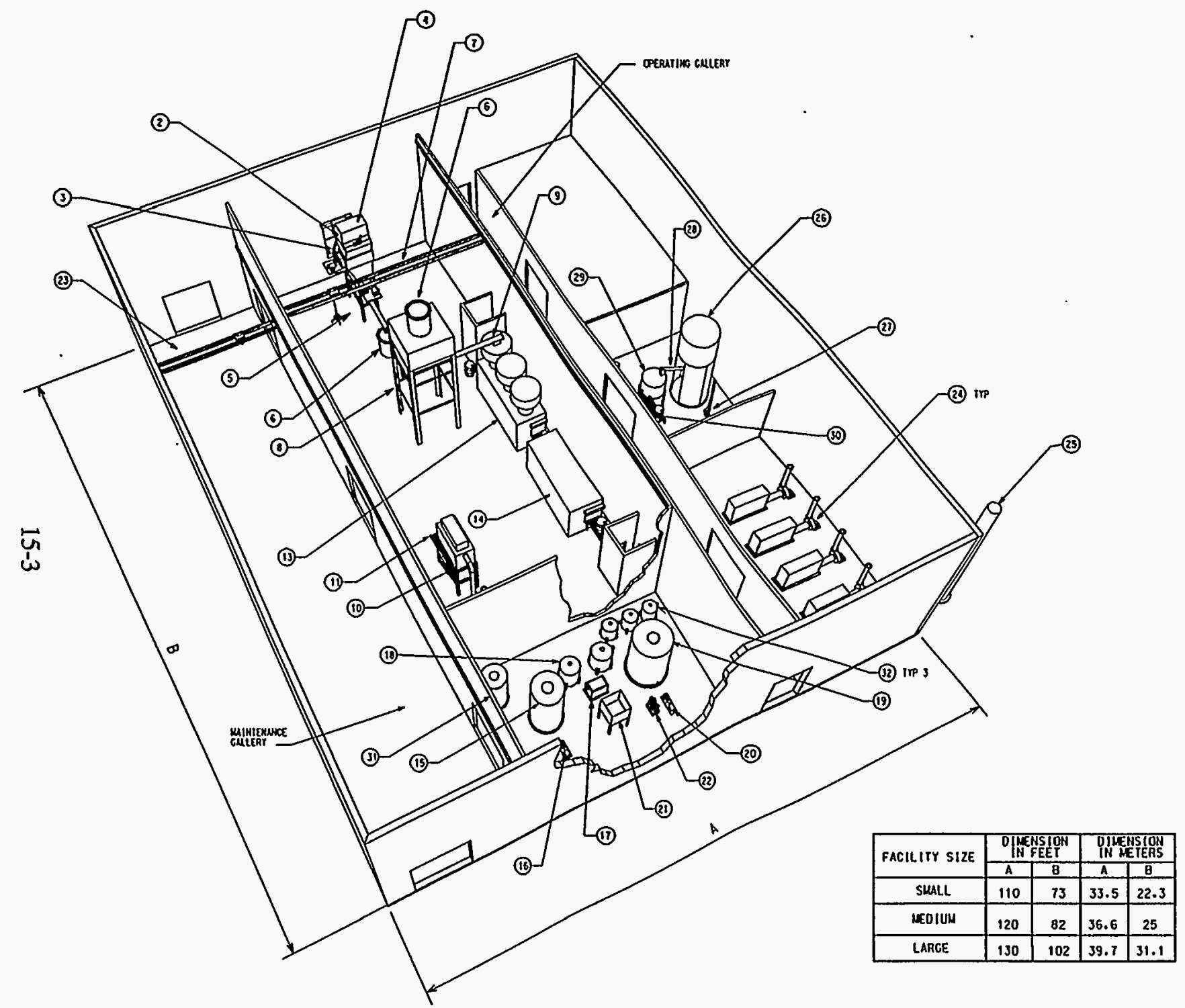

(1) DRUN PUSHER

(2) INCOUIHG VASTE BIH

(3) BIN HOLST

(4) SHREDOER (2) YITH FEEO HOPPER. OUST HOOO NHO HYORAUU IC RAH

(5) AUCER FEEDER

(6) WASIE transfer BIM

(7) UHoERANG CRME IN ENCLOSEO PROCESS AREA

(8) LIVE BOTION BURK STORAGE HOPPER

(9) nuGer FEEOER

(10) OUSY COLECTOR. FN NHO HEPA FILTER

(ii) DRIN STAGIHG COWNEYOR (POXERED ROLL)

(12) ORLW STAGIHG CONVEYOR IPOTEREO ROLL)

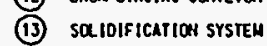

(14) ORUM CAPPING NYO VASHING SYSTEM

(15) RECEIVIHG TAHK

(16) Pup

(ii) FILTER

(18) ION EXchunge VESSELS

(19) TREAIEO MASTE TNKK

(20) Plas

(21) SLUDOE TANX

(22) PUA

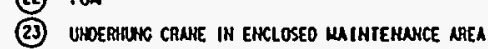

(24) HEPA FILTER AHO FAN

(25) stack

(26) BthoER STORAGE SILO

(2i) घhOKER

(20) PHeumaric converos

(29) DAY BIH

(30) ORLU STAGIHE CONEEYOR ICRAVITY

(II) PRECIPITATION TASK

(32) OREANIC RENOULL FILTER VESSELS

Figure 15-1. Equipment layout for the grout stabilization (GROUT) module. 


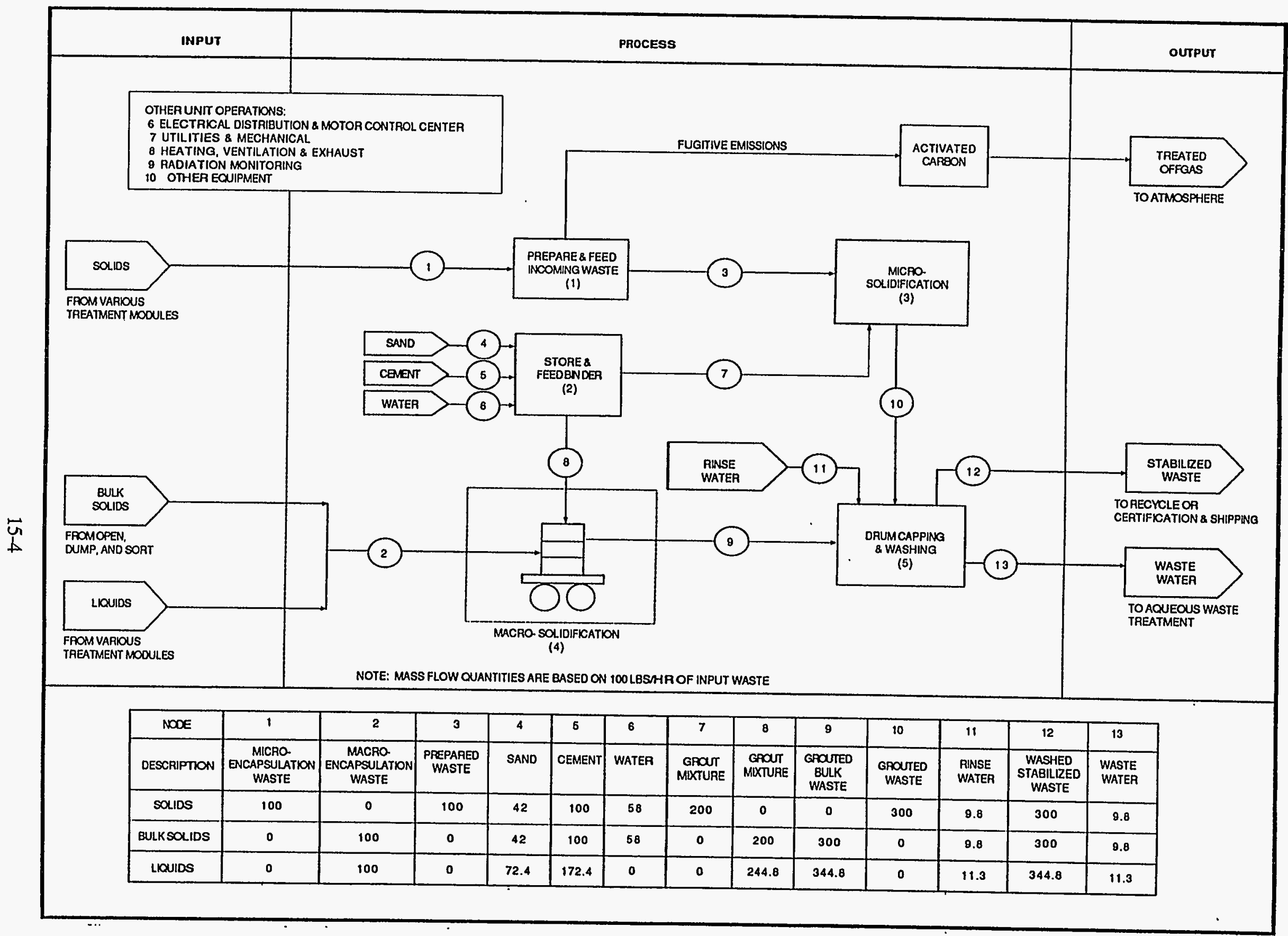

Figure 15-2. Process flow diagram for the grout stabilization (GROUT) module. 


\section{GROUT STABILIZATION}

\section{FTE by Work Breakdown Structure Element}

Module: GROUT Waste Type: Contact Handled TRUW

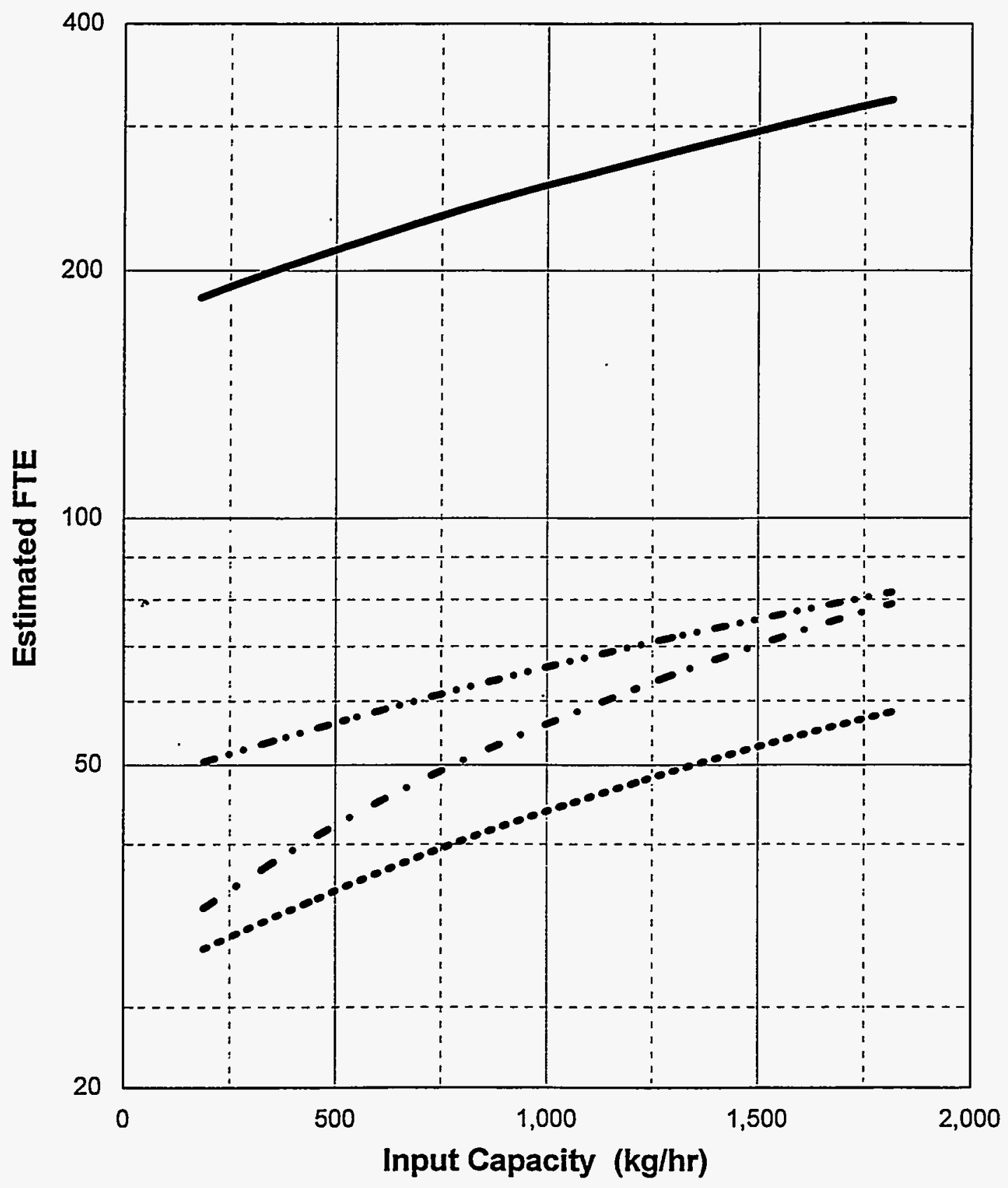

Pre-Operations Construction O\&M (1year) D\&D

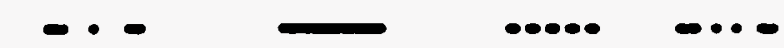

Figure 15-3. FTE workers versus capacity for the $\mathrm{CH}$ grout stabilization (T-GROUT) module. 


\section{GROUT STABILIZATION}

FTE by Work Breakdown Structure Element Module: GROUT Waste Type: Remote Handled TRUW

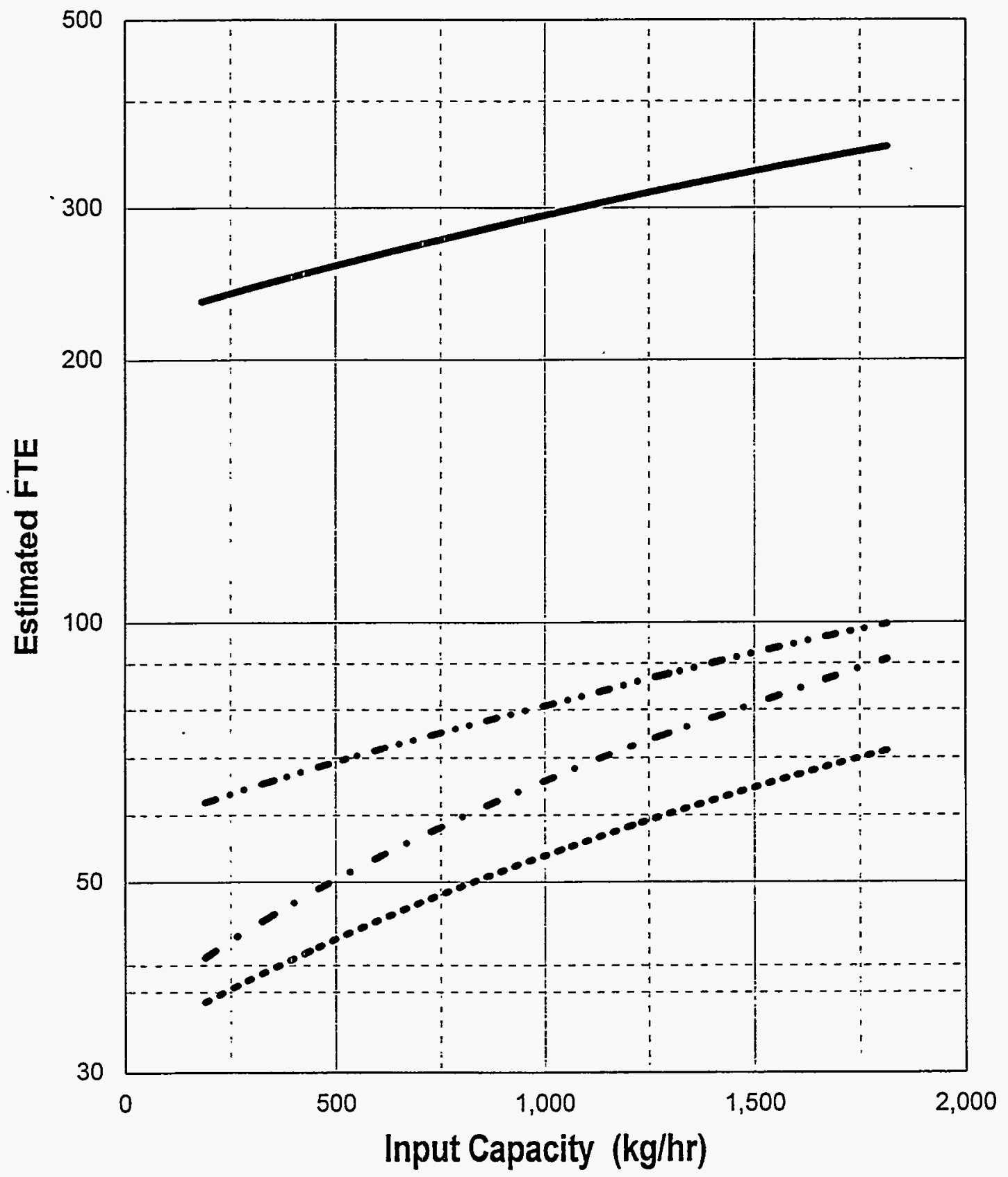

Pre-Operations Construction O\&M (1year) D\&D

Figure 15-4. FTE workers versus capacity for the RH grout stabilization (U-GROUT) module. 


\section{GROUT STABILIZATION}

Costs by Work Breakdown Structure Element

Module: GROUT Waste Type: Contact Handled TRUW

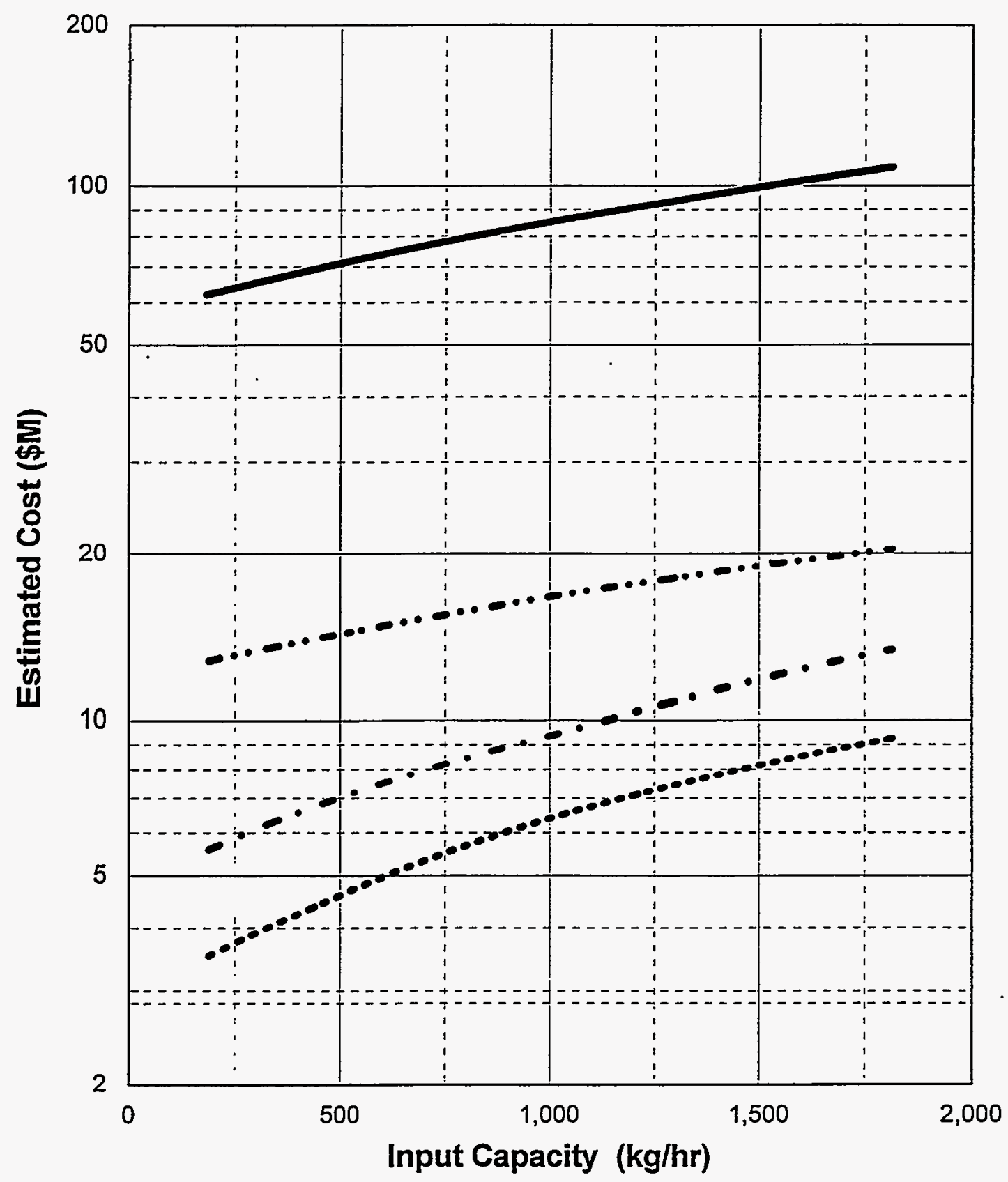

Pre-Operations Construction O\&M (1year) D\&D

Figure 15-5. PLCC versus capacity for the $\mathrm{CH}$ grout stabilization (T-GROUT) module. 


\section{GROUT STABILIZATION}

Costs by Work Breakdown Structure Element Module: GROUT Waste Type: Remote Handled TRUW

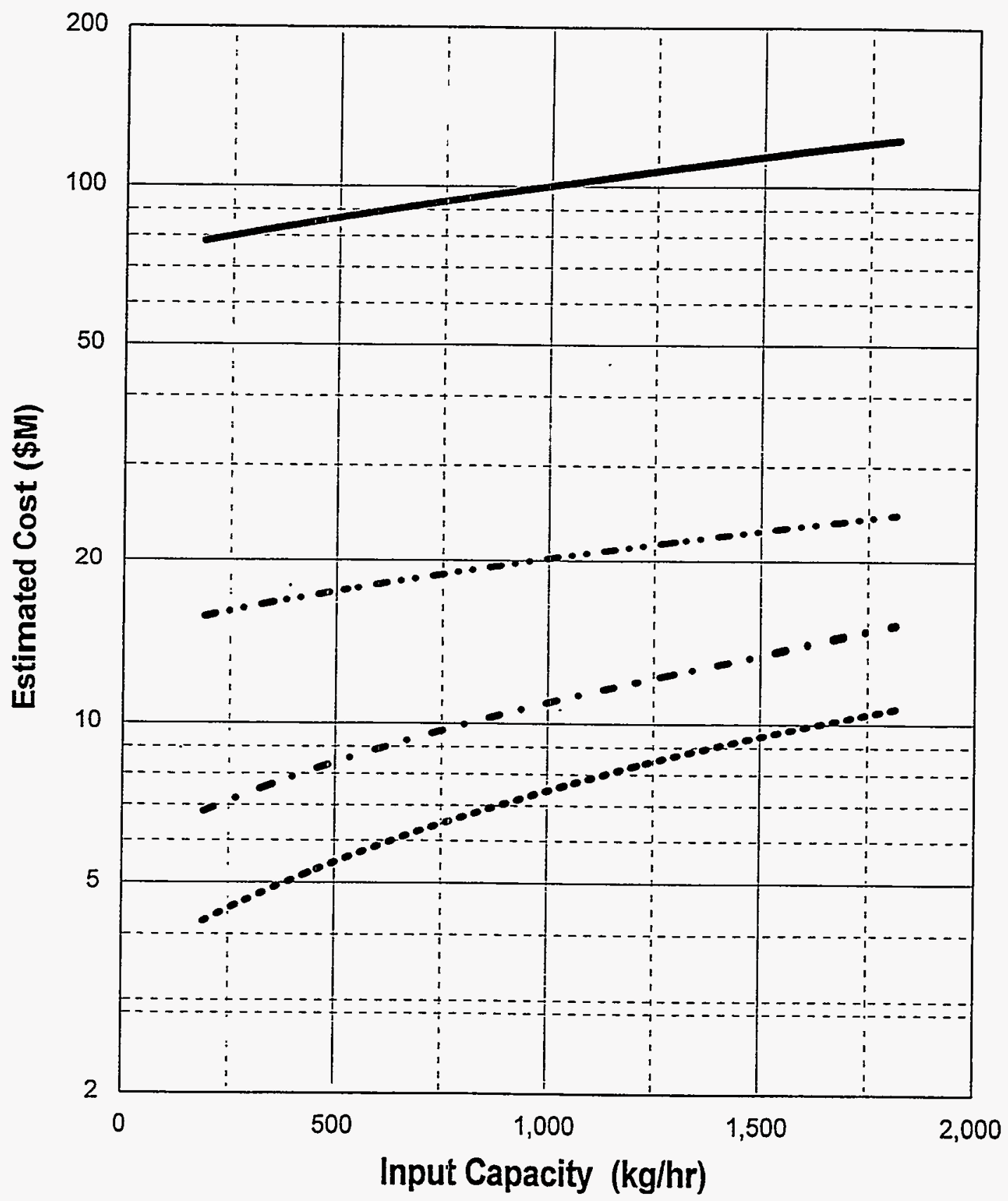

Pre-Operations Construction O\&M (1year) D\&D

Figure 15-6. PLCC versus capacity for the RH grout stabilization (U-GROUT) module. 


\section{GROUT STABILIZATION}

Total Life Cycle Costs

Module: GROUT Waste Type: Contact Handled and Remote Handled TRUW

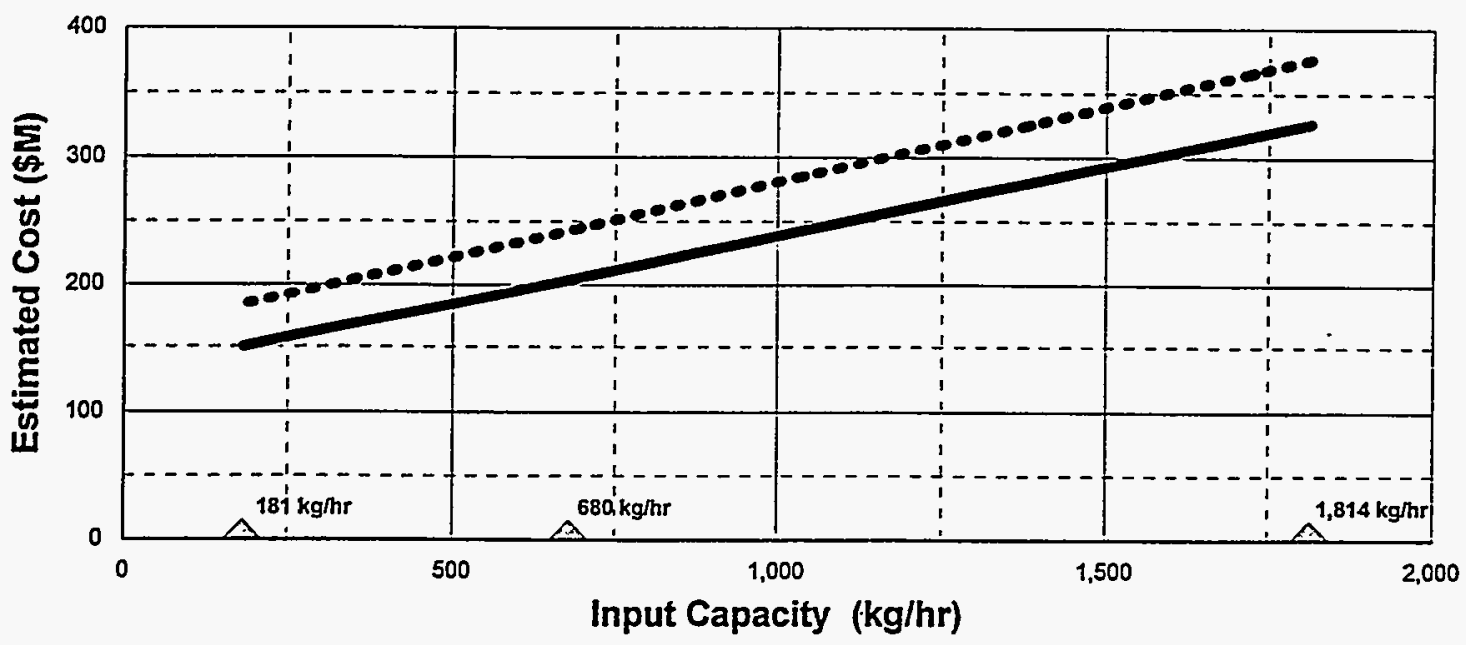

Contact Handled Remote Handled

NOTE: Basis includes 20 years of O\&M

Triangles indicate capacities where detailed cost estimates were developed.

\section{GROUT STABILIZATION}

Total Life Cycle Unit Costs

Module: GROUT Waste Type: Contact Handled and Remote Handled TRUW

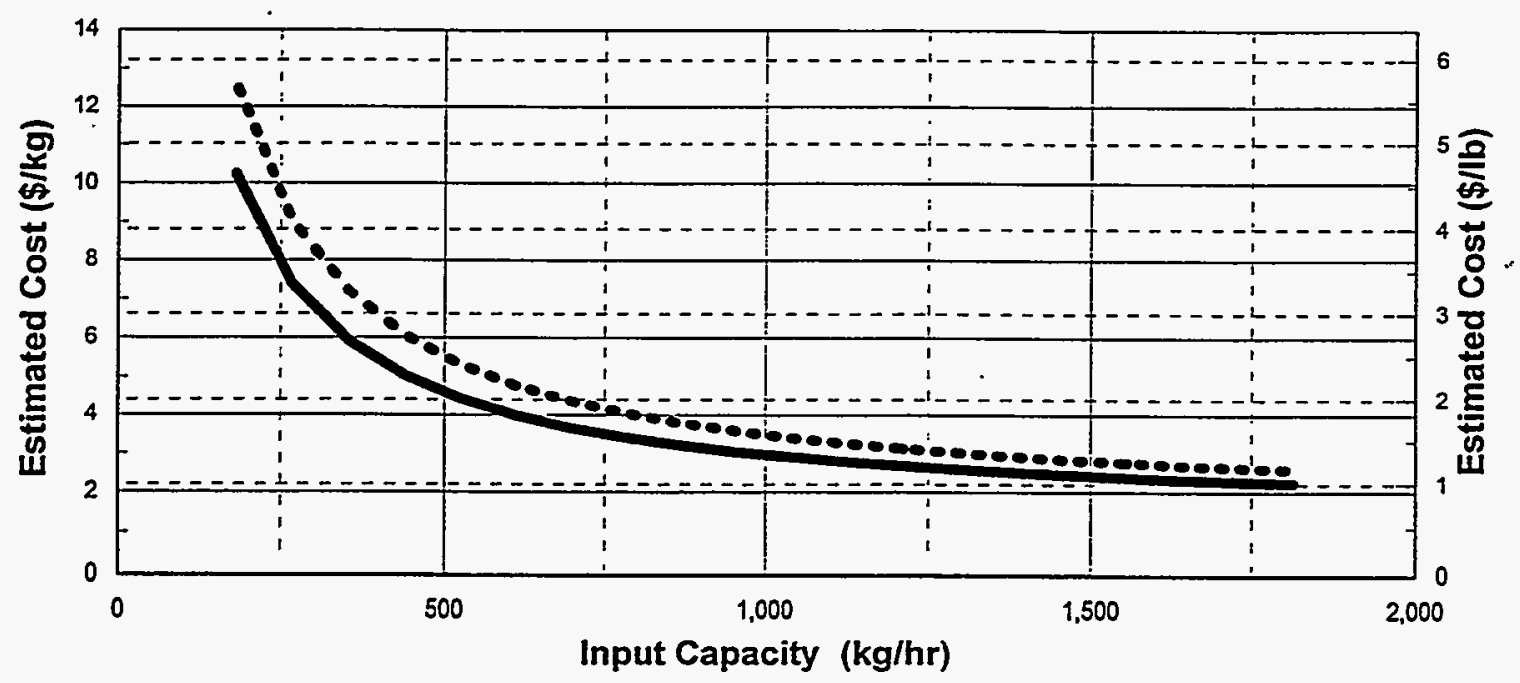

Contact Handled Remote Handled

NOTE: Basis includes 20 years O\&M

Figure 15-7. PLCC versus capacity including unit rates for the grout stabilization (GROUT) module. 


\section{VITRIFICATION (MODULE VITRF)}

\subsection{Basic Information}

The vitrification module, shown in Figure 16-1, consists of 12 operations designed to convert the incoming waste into a leach-resistant, rock-like or glass-like material. Vitrified waste that is similar in composition to iron-enriched basalt should meet both land disposal restrictions and DOE disposal requirements (Roads 1992). Secondary liquid is transported to the aqueous waste treatment (AQWTR) module. Offgas is transported to the offgas treatment unit operation. Secondary waste treatment by-products, such as offgas scrubber sludge, are sent to the grout stabilization treatment (GROUT) module. Module T-VITRF is intended for CH-TRUW, while module U-VITRF is intended for RH-TRUW. Unit operations are shown in the PFD in Figure 16-2.

The vitrification module processes noncombustible waste such as inorganic sludge, ash, soil, brick, concrete, and similar materials. The module can process solid waste of various shapes and forms. The size limitation imposed by the crusher/shredder is approximately $.09 \mathrm{~m}^{3}\left(1 \mathrm{ft}^{3}\right)$ and the incoming waste can contain as much as $10 \%$ combustibles. The module is equipped with a predryer for processing wet sludge and solids.

\subsection{Technical Bases and Assumptions}

\subsubsection{Function and Operation of the Module}

Specific operations include an input waste preparation and feed unit that crushes and shreds the incoming waste and transfers it to a melter unit operation. At the melter unit operation, a predryer, operating at approximately $300-400^{\circ} \mathrm{F}$, receives, dries, and feeds shredded waste and any sludge that must be vitrified to a vitrification furnace (or melter). Soil is added to the melter through a soil storage and feed unit operation. The furnace melts the soil and waste to form a molten slag. A slag cooling and packaging unit is used to receive the molten slag from the melter and cast it into containers. Containers are then sealed and washed by high-pressure water to remove loose contamination from the container surface. Containers are then transported out of this module to the certification and shipping (CSHIP) module.

The melter is equipped with a secondary combustion unit that completes the volatile gas destruction. An induced air blower moves the secondary combustor effluent through the air pollution control device that is designed to remove particulates. A surge tank retains offgas for reprocessing in the event of a process upset. Secondary liquid waste is transported to the aqueous waste treatment module.

\subsubsection{Integration of the Module}

Major module inputs include waste from the shredding, aqueous waste treatment, deactivation, and incineration modules, and soil. Major O\&M purchased materials are consumables, such as personal protective equipment, laboratory material, binder, soil, and disposable containers. 
Major module outputs are containerized and vitrified. Vitrified waste is moved to the certification and shipping (CSHIP) module. Treated offgas is discharged into the atmosphere. Secondary liquid waste is transported to the aqueous waste treatment module.

\subsection{Cost Bases, Assumptions, and Results}

Incoming waste sizing and preparation (shredders), meiter, and its offgas unit are the major equipment capital cost items. Cost for the preparation and feed unit are based on vendor quotes for shredders, conveyors, and dust collection equipment. Melter prices are based on price quotes received from two vendors, Callidus Technologies and Retec. Callidus Technologies provided price quotes for the various offgas units. Estimated FTEs and cost versus capacity for this module are shown in Figures 16-3 to 16-7. 


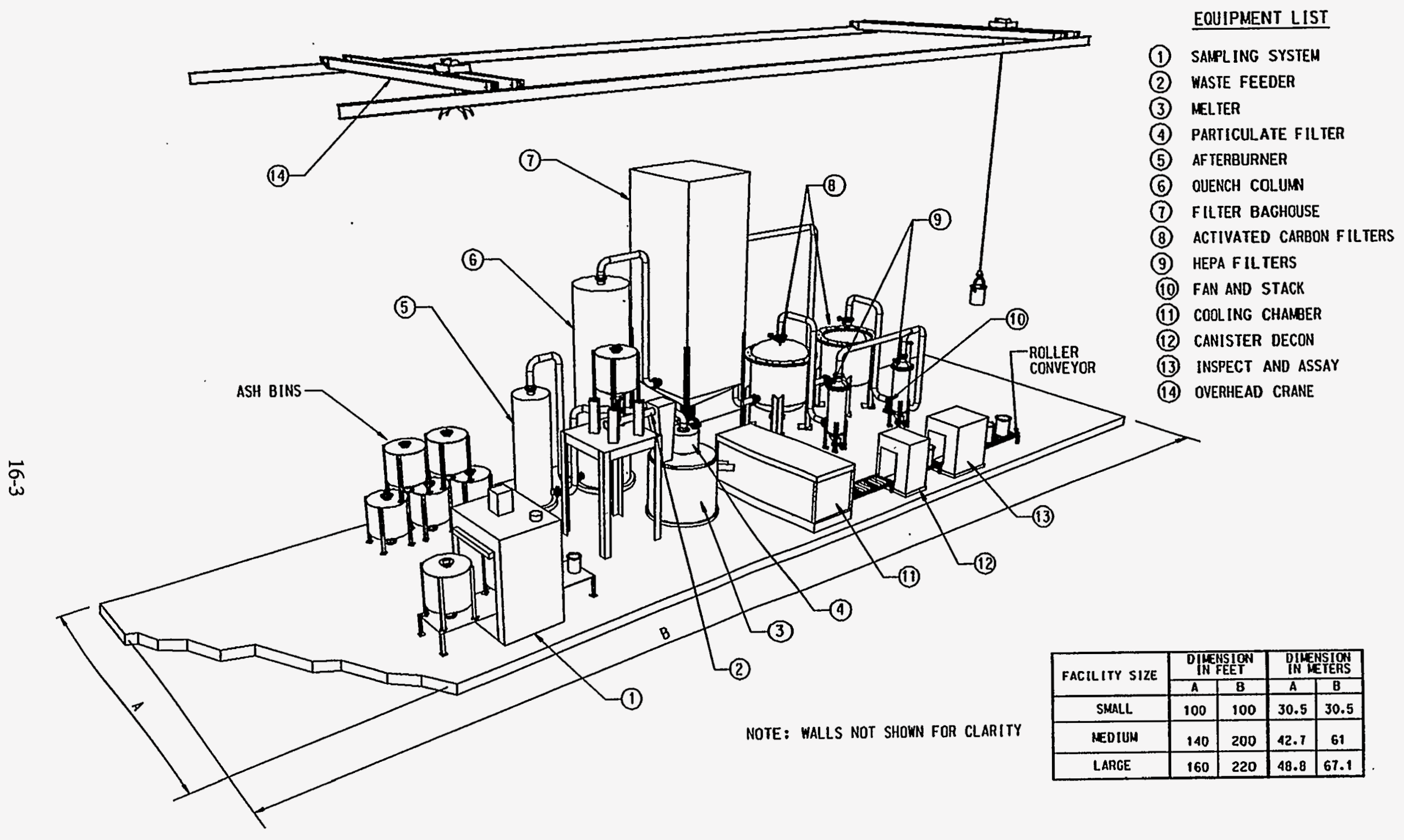

Figure 16-1. Equipment layout for the vitrification (VITRF) module. 


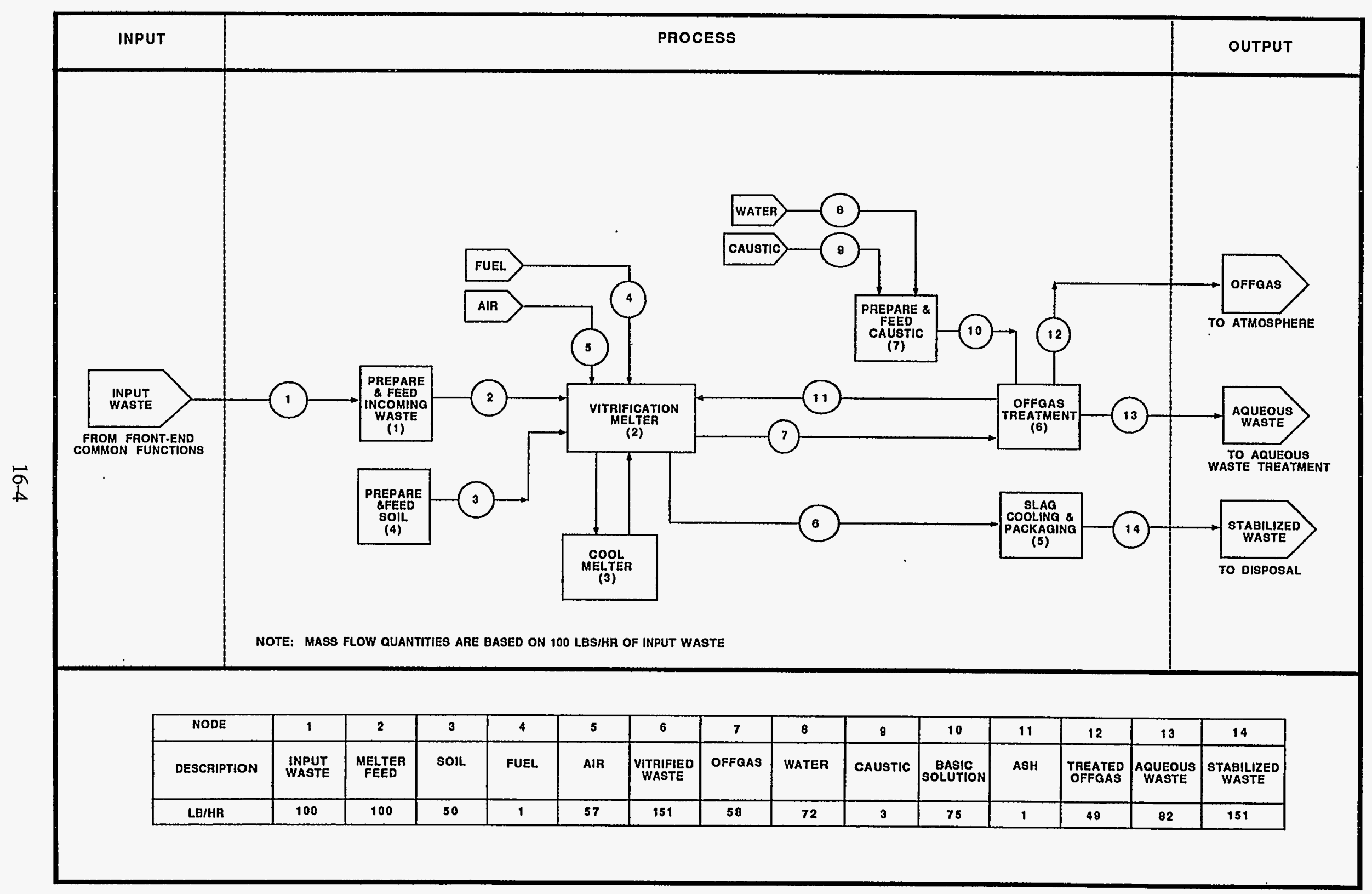

Figure 16-2. Process flow diagram for the vitrification (VITRF) module. 


\section{VITRIFICATION}

FTE by Work Breakdown Structure Element Module: VITRF Waste Type: Contact Handled TRUW

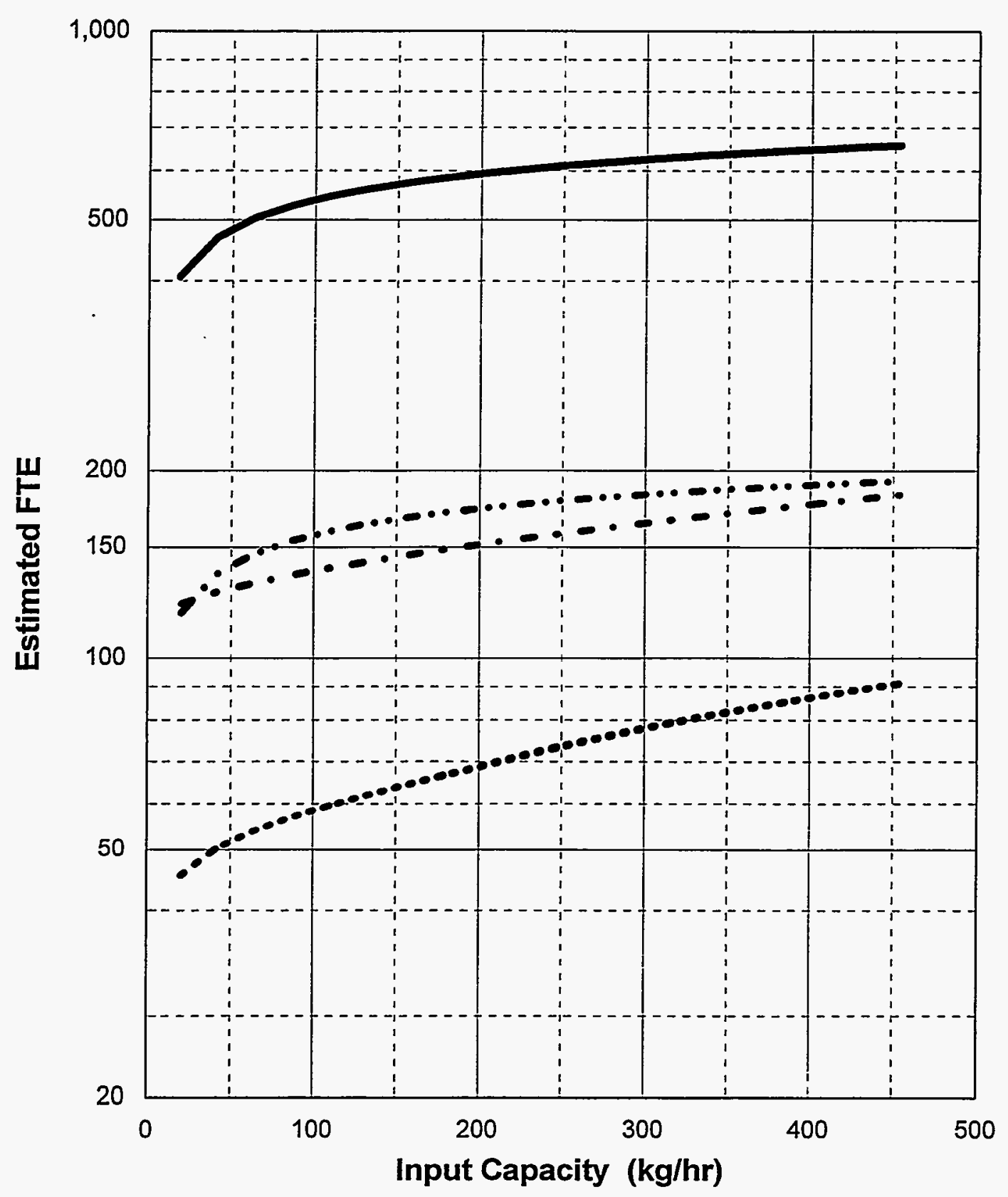

Pre-Operations Construction O\&M (1year) D\&D

Figure 16-3. FTE workers versus capacity for the $\mathrm{CH}$ vitrification (T-VITRF) module. 


\section{VITRIFICATION}

FTE by Work Breakdown Structure Element Module: VITRF Waste Type: Remote Handled TRUW

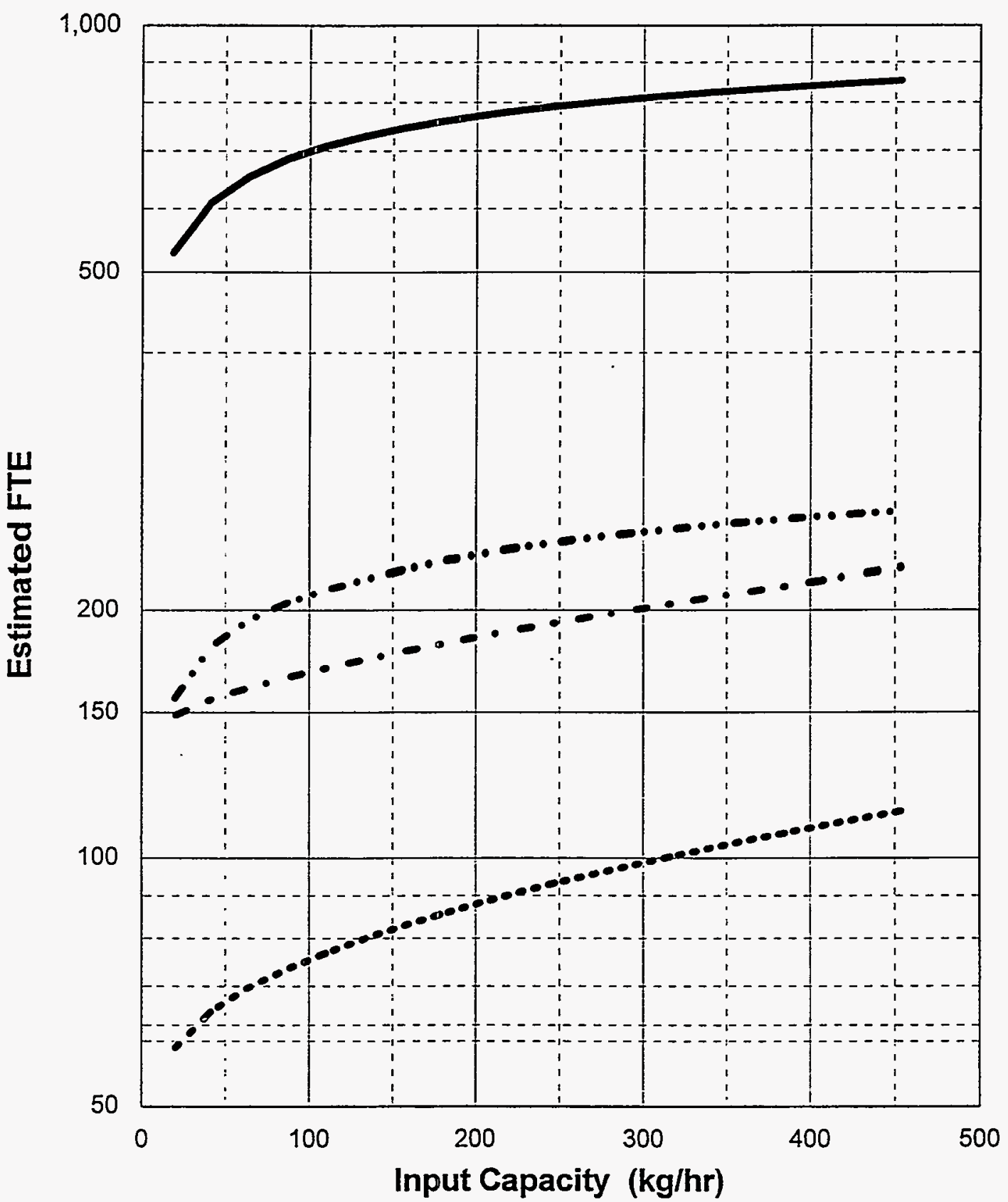

Pre-Operations Construction O\&M (1year) D\&D

Figure 16-4. FTE workers versus capacity for the RH vitrification (U-VITRF) module. 


\section{VITRIFICATION}

Costs by Work Breakdown Structure Element Module: VITRF Waste Type: Contact Handled TRUW

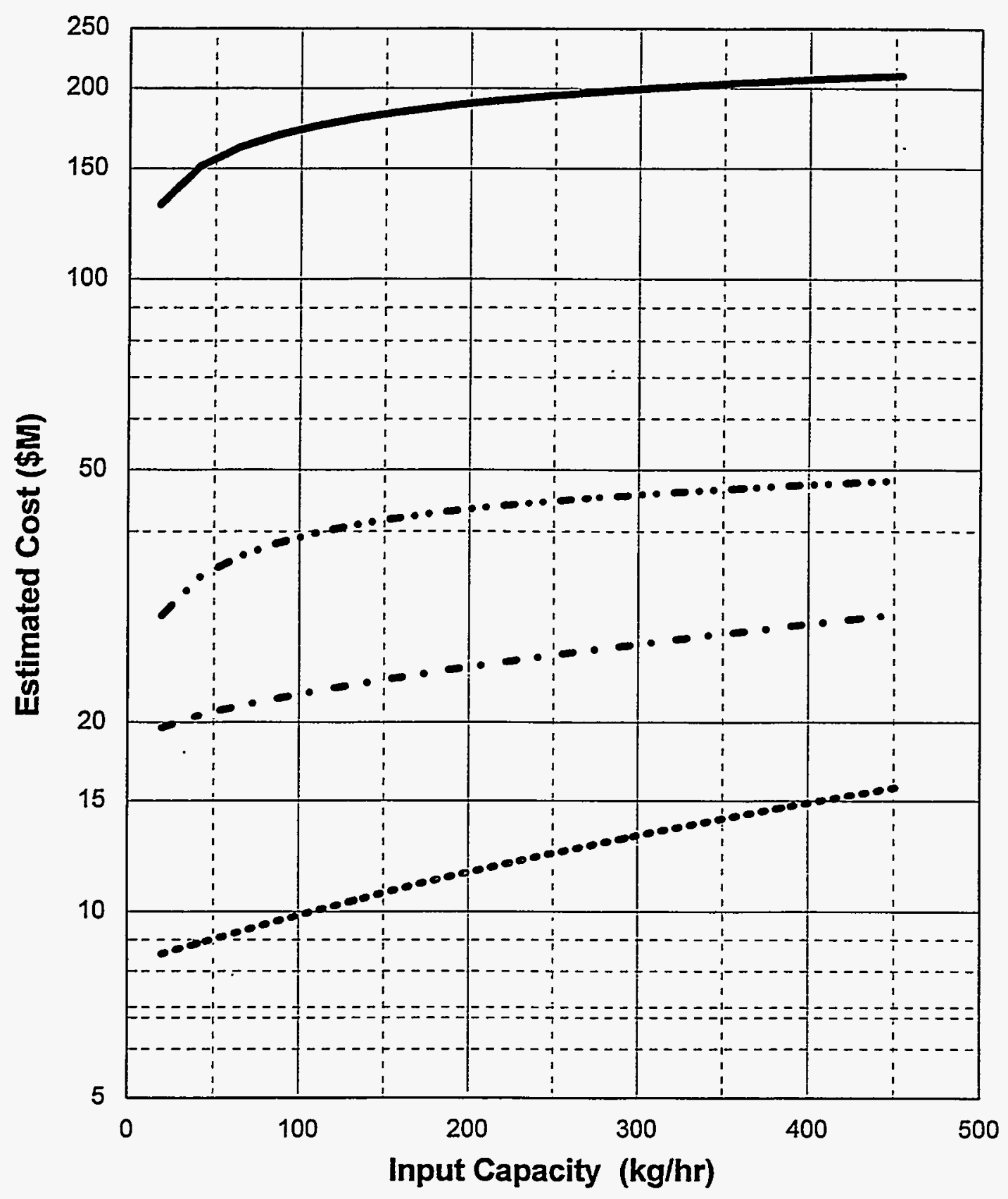

Pre-Operations Construction O\&M (1year) D\&D

Figure 16-5. PLCC versus capacity for the $\mathrm{CH}$ vitrification (T-VITRF) module. 


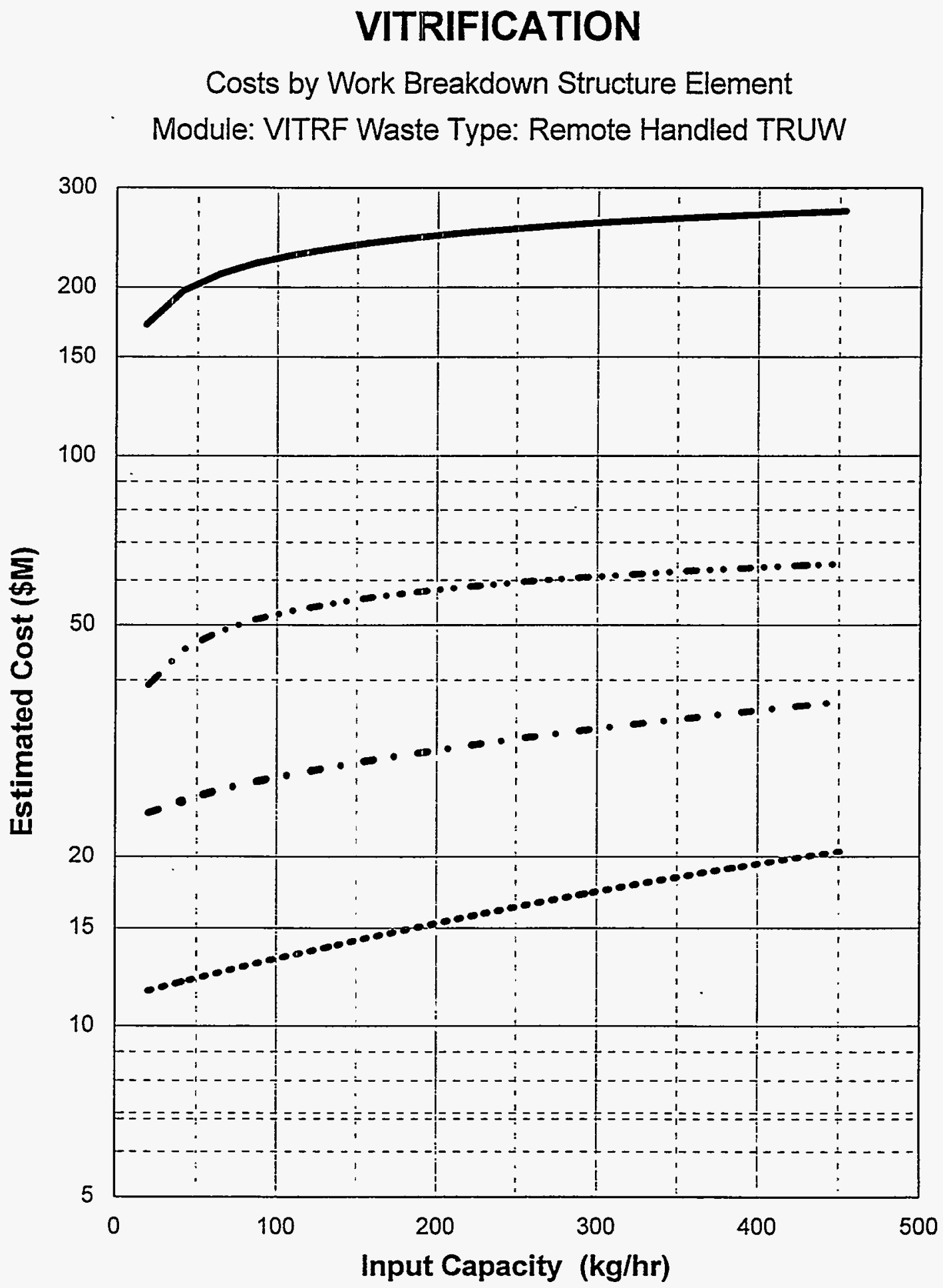

Pre-Operations Construction O\&M (1year) D\&D
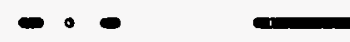

$\bullet \bullet \bullet \bullet \bullet \bullet$

Figure 16-6. PLCC versus capacity for the RH vitrification (U-VITRF) module. 


\section{VITRIFICATION}

Total Life Cycle Costs

Module: VITRF Waste Type: Contact Handled and Remote Handled TRUW

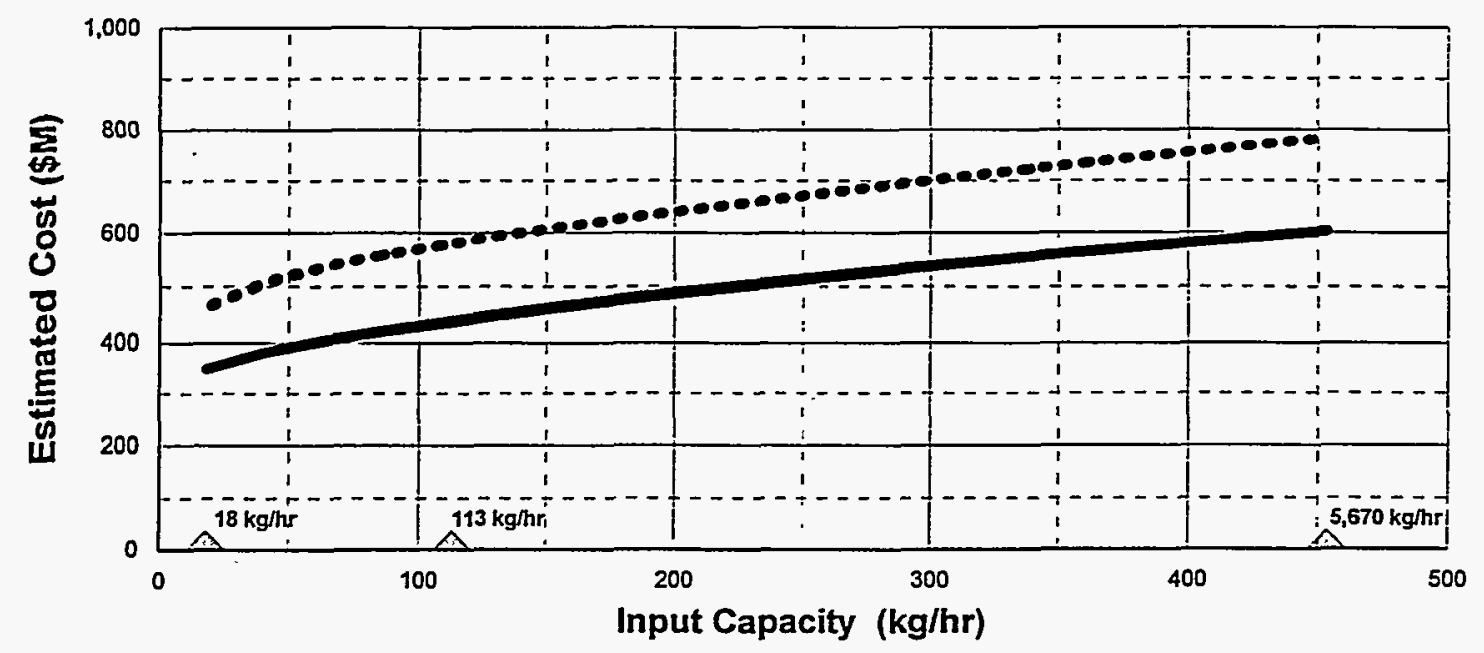

Contact Handled Remote Handled

NOTE: Basis includes 20 years O\&M

Triangles indicate capacities where detailed cost estimates were developed.

\section{VITRIFICATION}

Total Life Cycle Unit Costs

Module: VITRF Waste Type: Contact Handled and Remote Handled

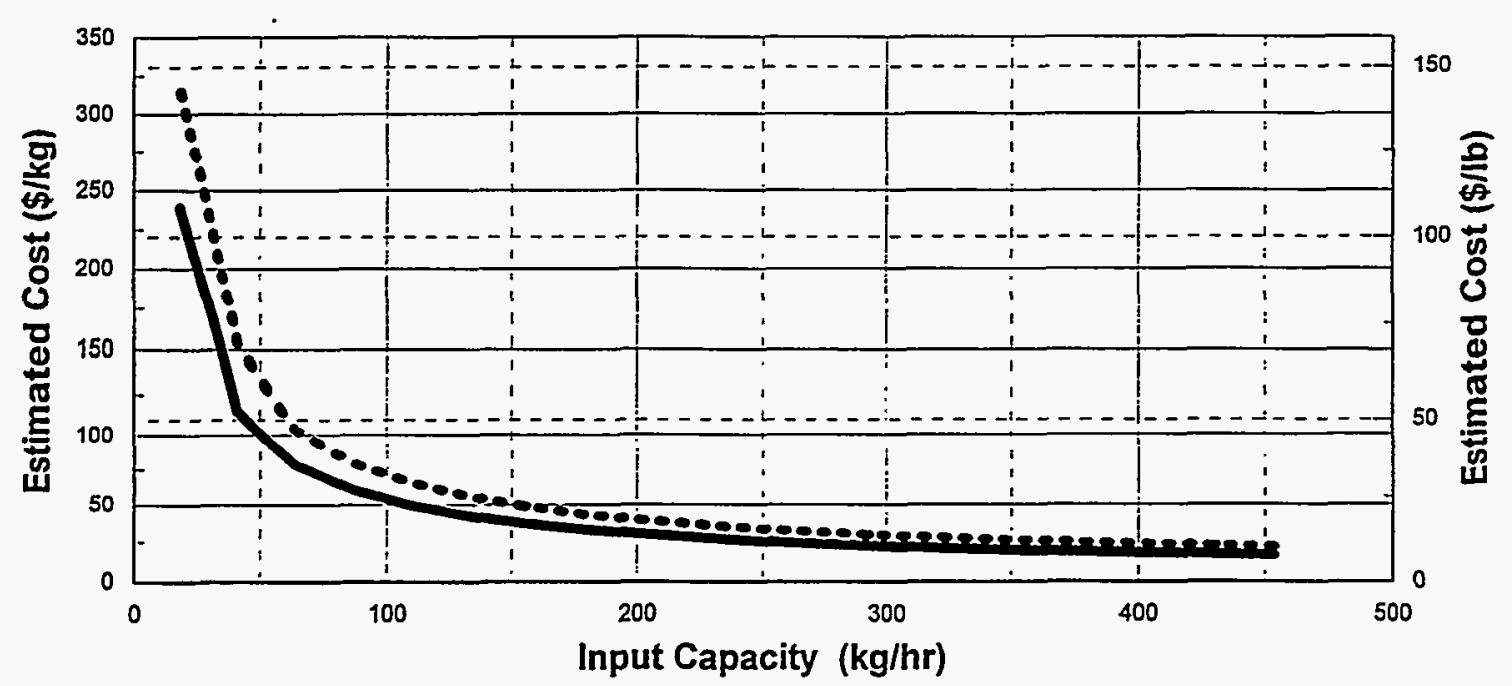

Contact Handled Remote Handled

NOTE: Basis includes 20 years of O\&M

Figure 16-7. PLCC versus capacity including unit rates for the vitrification (VITRF) module. 


\section{ORGANIC STABILIZATION (MODULE ORGSB)}

\subsection{Basic Information}

The organic stabilization module, shown in Figure 17-1, provides primary and secondary waste treatment of organic liquids. The module output is transported to the certification and shipping (CSHIP) module. The main purpose of this module is to solidify organic liquids that arrive from treatment modules, storage facilities, or the waste generators. Unit operations are shown in the PFD in Figure 17-2.

The module consists of two main process unit operations that incorporate all buildings, systems, processes, equipment, devices, controls, and accessories required to prepare and stabilize the incoming waste.

\subsection{Technical Bases and Assumptions}

\subsubsection{Function and Operation of the Module}

The module receives organic liquid waste in drums, or receives the waste via a pipeline and meters it into drums. A chemical binder, calcium silicate, is added directly into the incoming drums and blended with a mixer. This mixing operation can be accomplished manually or remotely.

After mixing, the operator will manually or remotely transfer the filled container to a capping and washing unit. This unit operation provides for sample collection, capping of the container, and removal of loose contamination from the container surface by high-pressure spray water jets. The containerized waste is ready for processing through radioassay and final certification, which are included in the back-end (CSHIP) module.

\subsubsection{Integration of the Module}

Input to the module consists of organic liquids from the receiving and inspection (RCDNS) module and various treatment modules. Major O\&M purchased materials, such as personal protective equipment, laboratory material, binder, and containers, are assumed to be consumable supplies, and their costs are estimated accordingly.

Output consists mainly of drummed, solidified CH- and RH-TRUW, all of which are moved to a back-end (CSHIP) module. Waste water from drum washing is transported to the aqueous waste treatment (AQWTR) module.

\subsection{Cost Bases, Assumptions, and Results}

The mixing unit and drum capping and washing unit are the major equipment capital cost items. Costs for the mixer and support equipment are based on quotes from vendors. The drum capping and washing assembly price is based on quotes by the Stock Equipment Company of Chagrin Falls, Ohio. Estimated FTEs and cost versus capacity for this module are shown in Figures 17-3 to 17-5. 


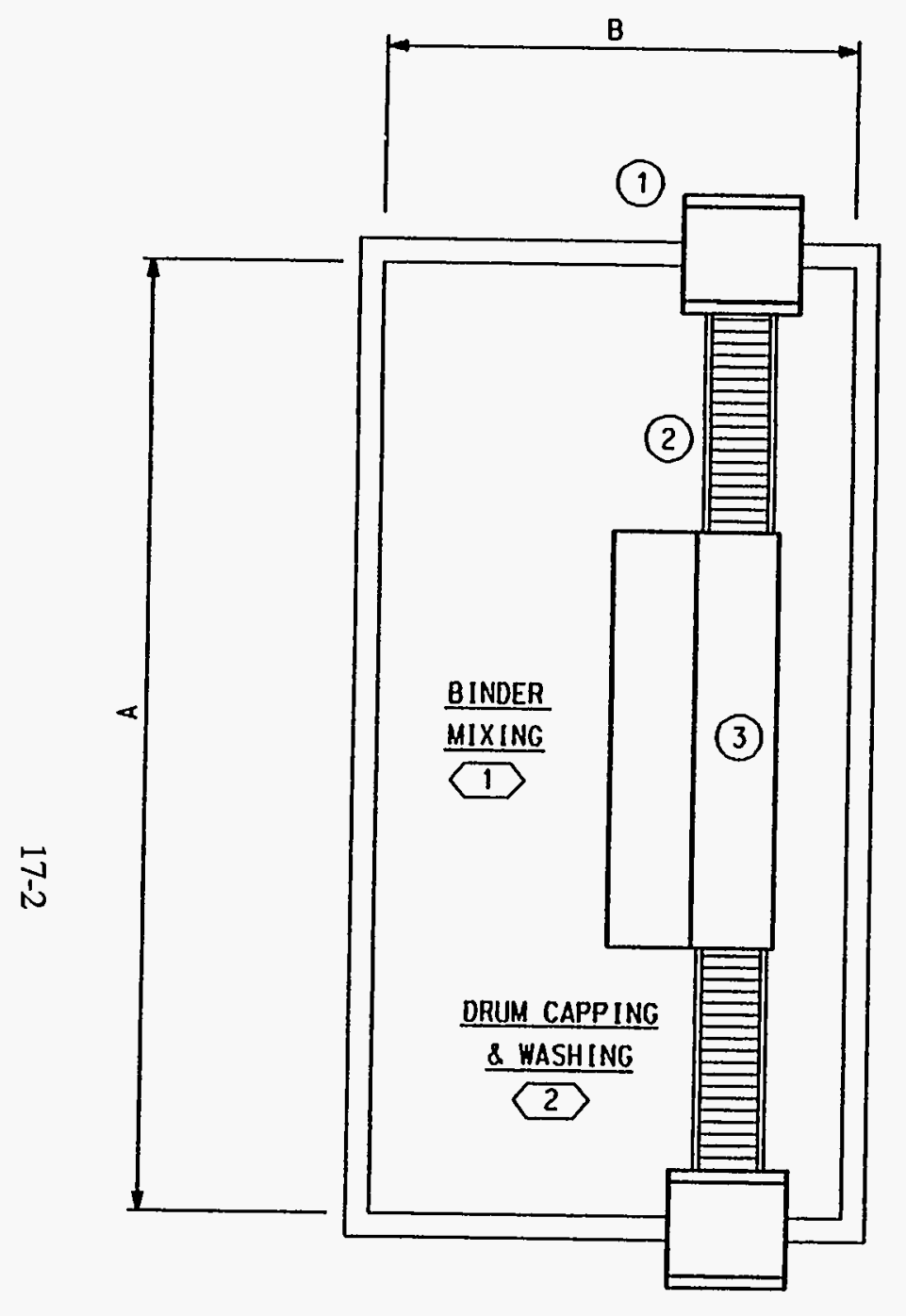

NOTE: AREAS ALLOCATED TO SUPPORT UNIT OPERATIONS ARE NOT SHOWN ON THE PLAN

\section{EQUIPMENT LIST}
(1) AIRLDCK (TYP.)
(2) ROLLER CONVEYOR
(3) DRUM CAPPING \& WASHING UNIT

\begin{tabular}{|c|c|c|c|c|}
\hline \multirow{2}{*}{ FACILITY SIZE } & \multicolumn{2}{|c|}{ DIMENSION } & \multicolumn{2}{c|}{ DINENSION } \\
\cline { 2 - 5 } & INEET & \multicolumn{2}{c|}{ IN METERS } \\
\hline SMALL & 110 & 20 & 33.5 & 6.1 \\
\hline MEDIUM & 110 & 20 & 33.5 & 6.1 \\
\hline LARGE & - & - & - & - \\
\hline
\end{tabular}

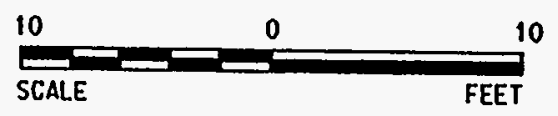

Figure 17-1. Equipment layout for the organic stabilization (ORGSB) module. 


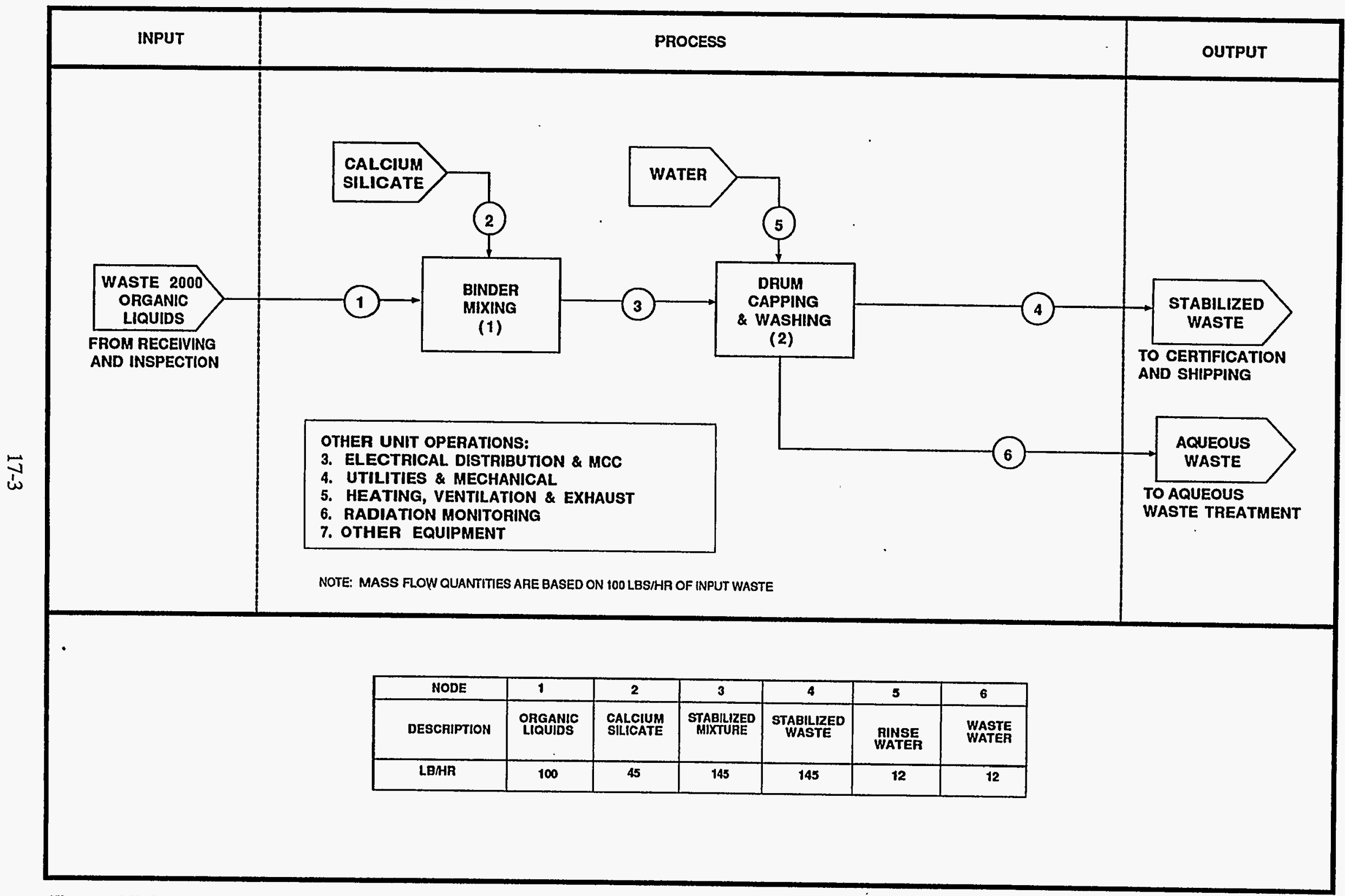

Figure 17-2. Process flow diagram for the organic stabilization (ORGSB) module. 


\section{ORGANIC STABILIZATION}

FTE by Work Breakdown Structure Element

Module: ORGSB Waste Type: Contact Handled and Remote Handled TRUW

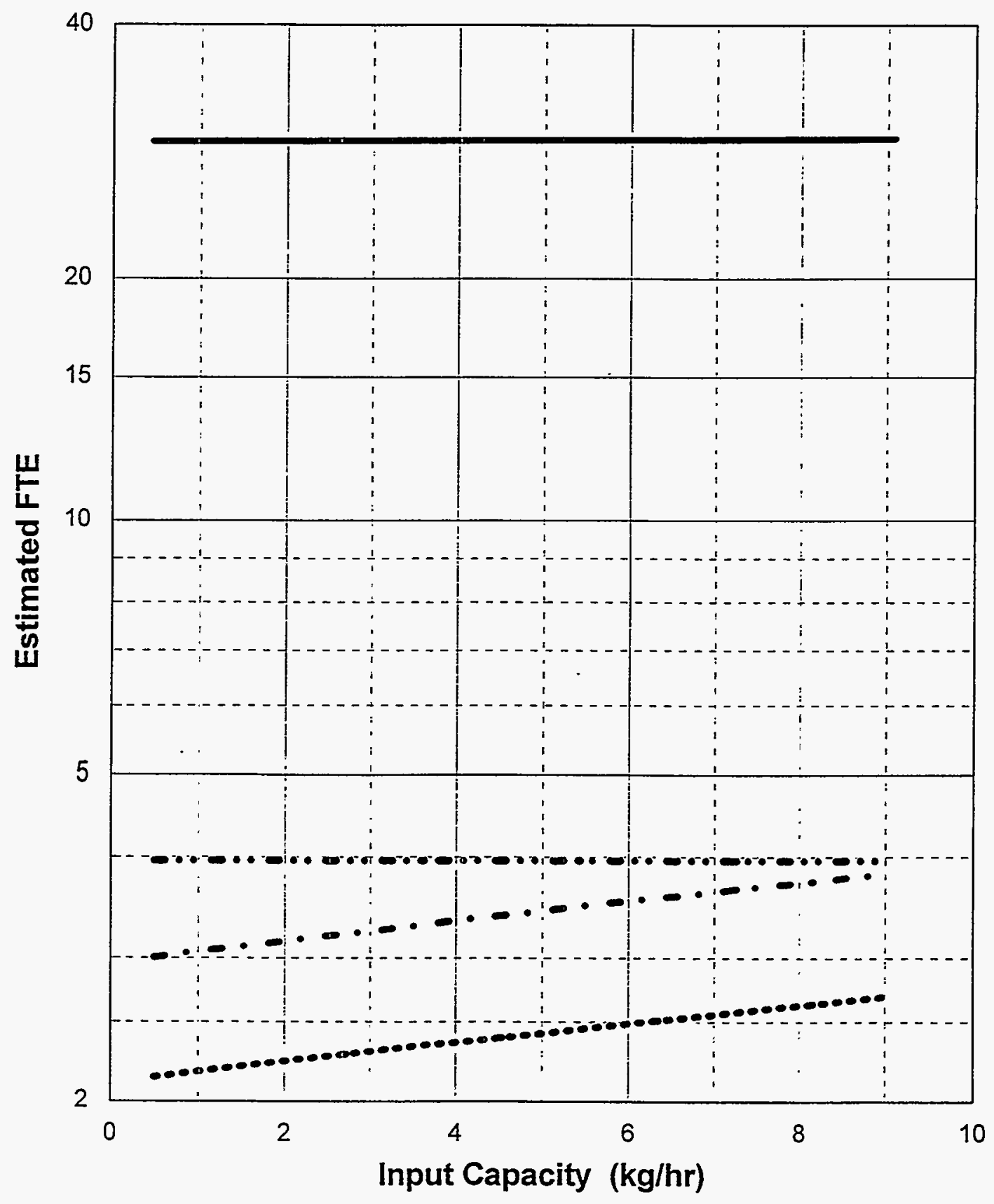

Pre-Operations Construction O\&M (1year) D\&D

Figure 17-3. FTE versus workers capacity for the organic stabilization (ORGSB) module. 


\section{ORGANIC STABILIZATION}

Costs by Work Breakdown Structure Element

Module: ORGSB Waste Type: Contact Handled and Remote Handled TRUW

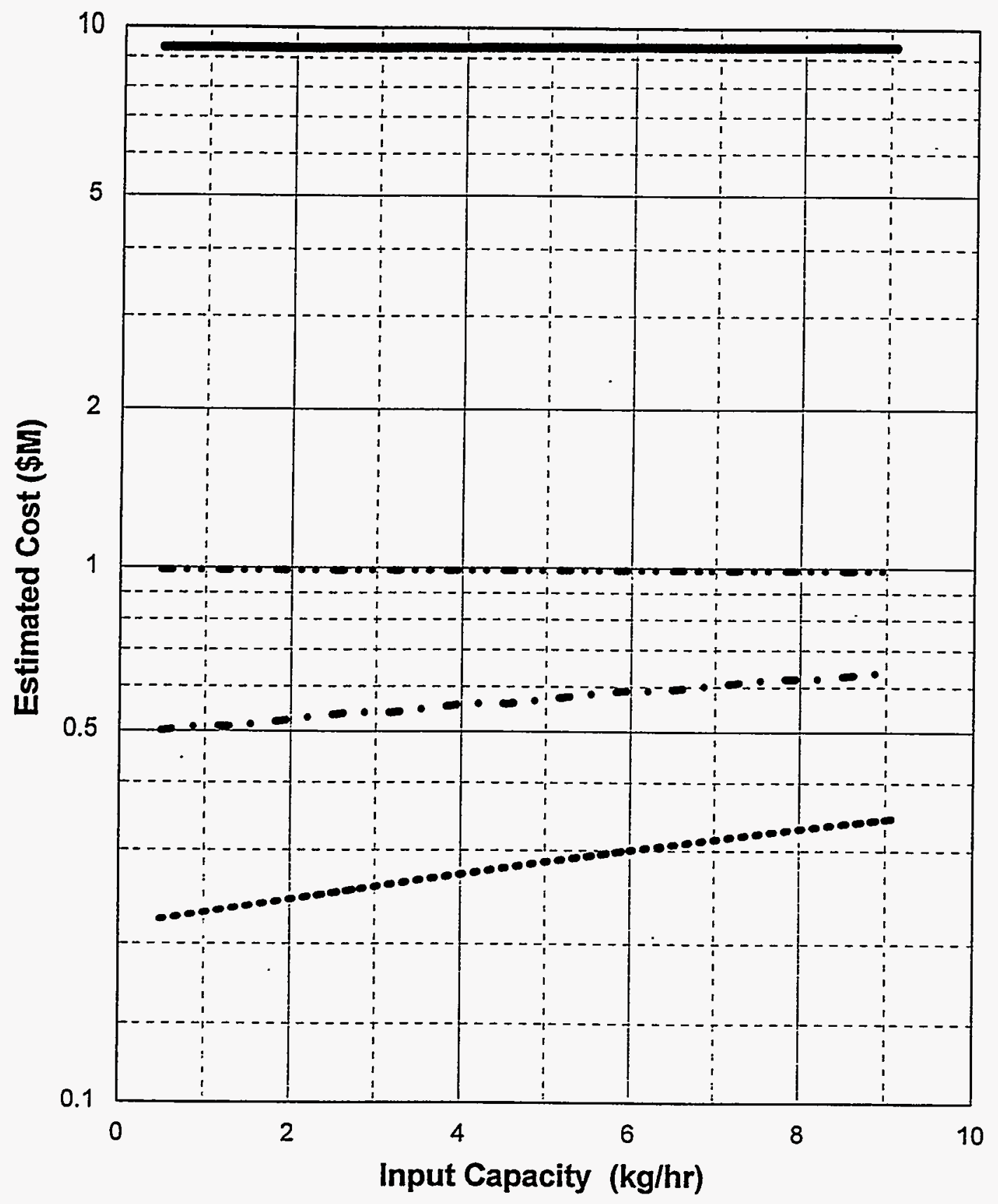

Pre-Operations Construction O\&M (1year) D\&D

Figure 17-4. PLCC versus capacity for the organic stabilization (ORGSB) module. 


\section{ORGANIC STABILIZATION}

Total Life Cycle Costs

Module: ORGSB Waste Type: Contact Handled and Remote Handled TRUW

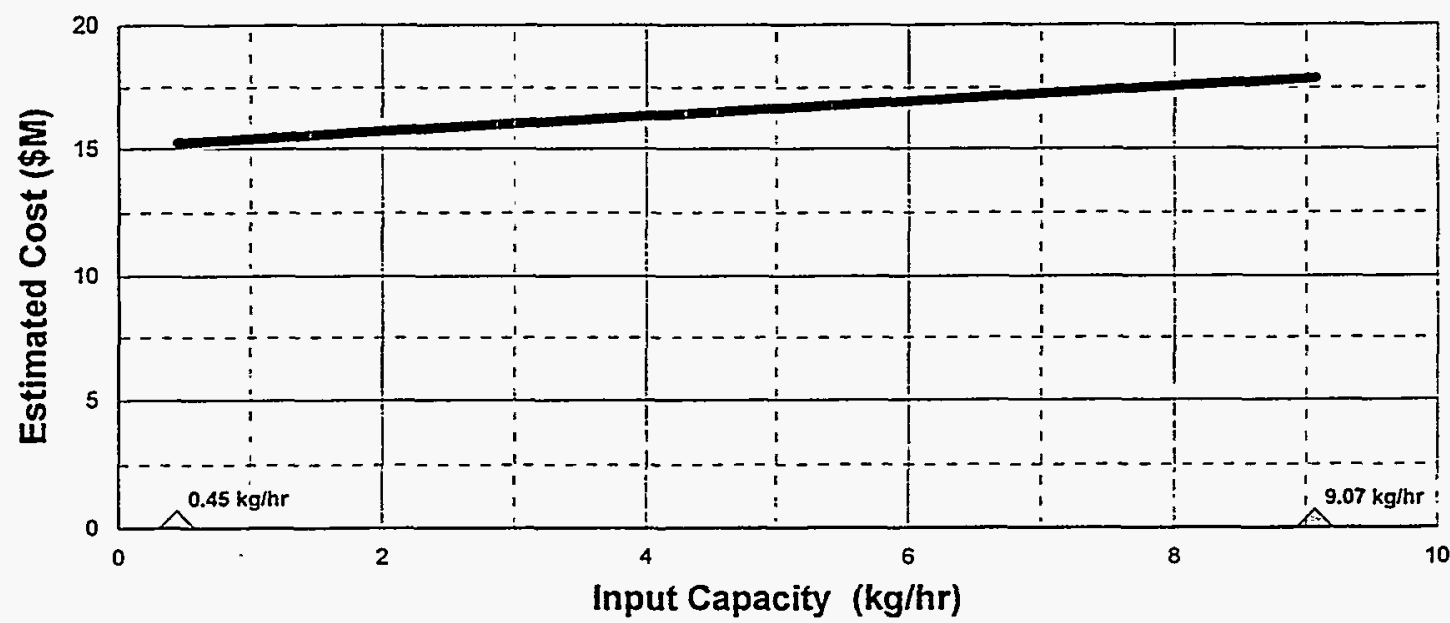

Contact Handled, Remote Handled

NOTE: Basis includes 20 years O\&M

Triangles indicate capacities where detailed cost estimates were developed.

\section{ORGANIC STABILIZATION}

\section{Total Life Cycle Unit Costs}

Module: ORGSB Waste Type: Contact Handled and Remote Handled TRUW

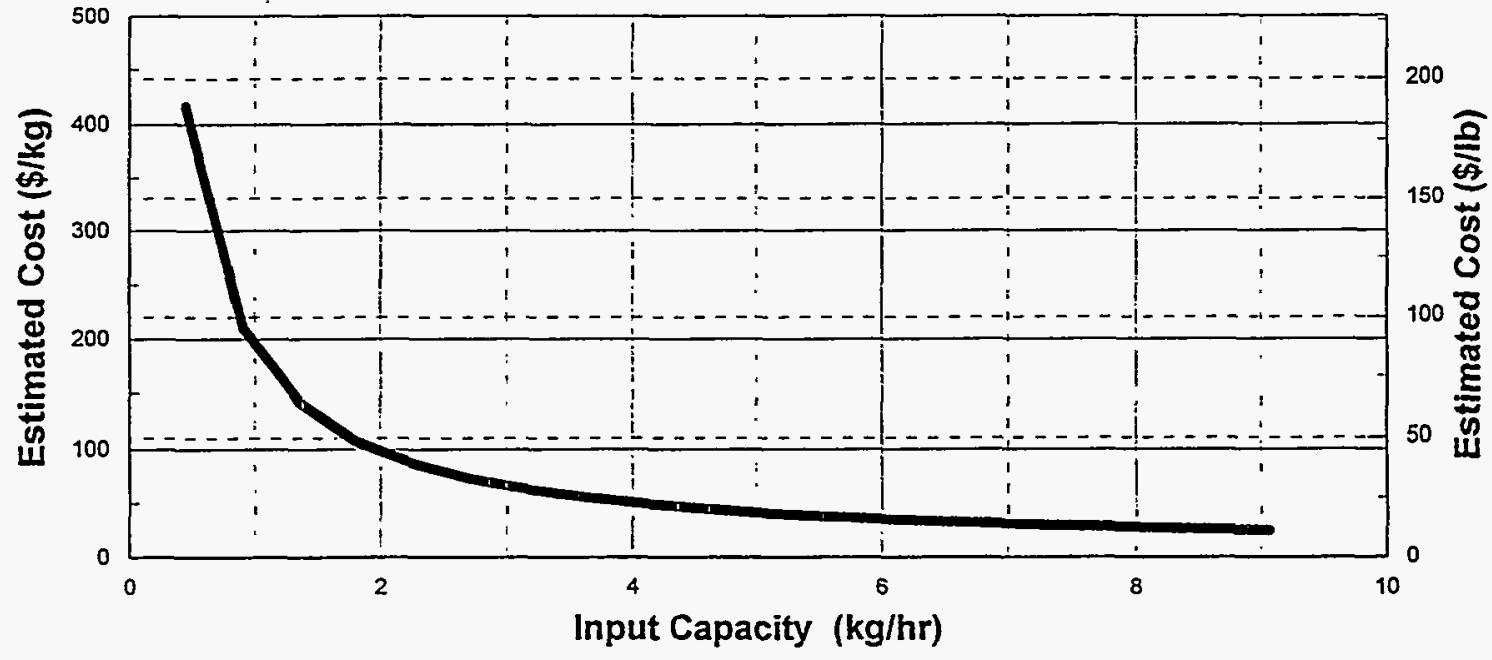

Contact Handled, Remote Handled

NOTE: Basis indudes 20 years O\&M

Figure 17-5. PLCC versus capacity including unit rates for the organic stabilization (ORGSB) module. 


\section{PACKAGING (MODULE PACKG)}

\subsection{Basic Information}

The packaging module, shown in Figure 18-1, consists of 10 unit operations that incorporate all buildings, systems, processes, equipment, controls, and accessories required to repackage incoming drummed solid waste in overpacks. The modules can process solid waste and metal waste of various shapes and forms. Module T-PACKG is intended for CH-TRUW, while module U-PACKG is intended for RH-TRUW. Unit operations are shown in the PFD in Figure 18-2.

The facility is used in conjunction with modules TADMN, RCINS, and AQWTR or is constructed adjacent to an existing facility where similar functions are available.

\subsection{Technical Bases and Assumptions}

\subsubsection{Function and Operation of the Module}

The packaging module is designed to receive drummed waste and to package it in 85-gal overpack containers. In the drum inspection unit operation, drummed waste is inspected for physical integrity. Following inspection, drums that meet the packaging module's acceptance criteria are transported to the overpack, grout, and cap unit operation; drums that fail are returned to the incoming drum storage area for return to their original location.

In the overpack, grout, and cap unit operation, a lift device raises the drums and places them inside 85-gal overpacks. The overpacked drums are then transported to the grouting unit where the void spaces are filled with grout. The overpacks are then capped and transported to the drum washing unit operation, where they are washed and dried before leaving the module.

Liquid waste generated during the operation is collected in a dump and directed to the aqueous waste treatment module.

\subsubsection{Integration of the Module}

Primary input to the module is waste in drums from the receiving and inspection (RCINS) module or from the open, dump, and sort (OSORT) module. Major O\&M materials, such as personal protective equipment, laboratory material, binders, and overpacks, are assumed to be consumable supplies that must be purchased. Their costs are estimated accordingly.

The overpacks (85-gal drums) containing stabilized 55-gal drums of waste are the main output from this facility. Overpacks are transported to the storage (STORE) module.

\subsection{Cost Bases, Assumptions, and Results}

The major equipment capital cost items include inspection equipment (such as RTR), drum handling, and overpack handling equipment. Estimated FTEs and cost versus capacity for this module are shown in Figures 18-3 through 18-7. 
NOTE: AREAS ALLOCATEO TO SUPPORT UNIT OPERATIONS ARE MOT SHOWN ON HHIS PLAN. ENCAPSULATING AGENT STORAGE \& ON THIS PLAN.
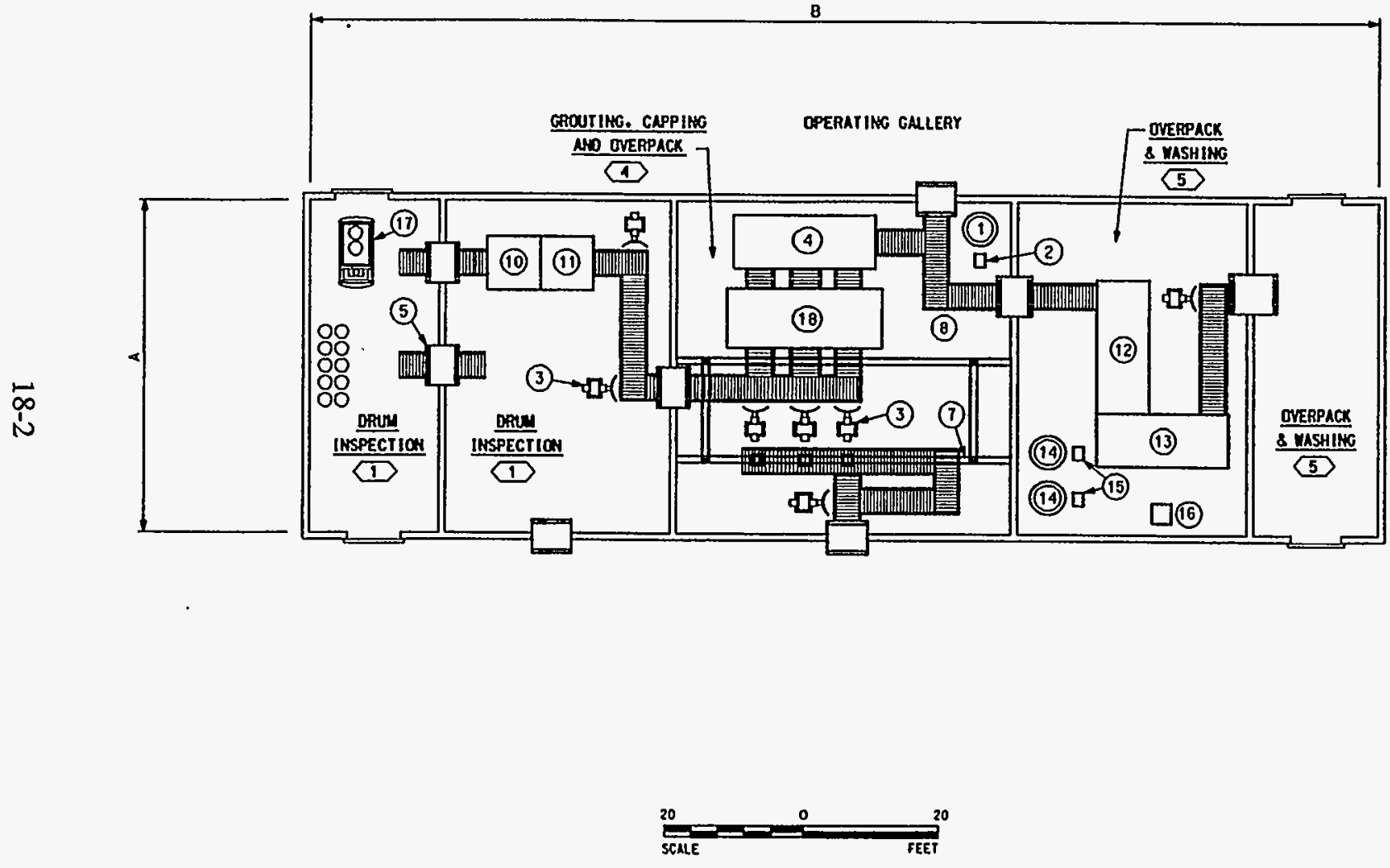

Figure 18-1. Equipment layout for the packaging (PACKG) module.

\section{EQUIPMENT LIST}

\section{(1) grout daY tahK}

(2) GROUT PUIP

(3) ORUM PUSHER

(4) overpack capping oEvice

(5) AIRLOCK (TYP.)

(6) OVERPACK AND GROUtING SYSTEM

(7) OVERHEAd crane

(8) ROLLER CONVEYOR

(9) chemical mix tank

(10) contalner assay unit

(11) glove boX assay UNIT

(12) OVERPACK YaSH UNIT

(13) ORIER UN!T

(14) CHEMICAL STORAGE TANX

(15) Puip

(16) BLOMER

(17) SELF GUIDED VEHICLE

(18) SOLIDIF ICATION UNIT

\begin{tabular}{|c|c|c|c|c|}
\hline \multirow{2}{*}{ FACILITY SIZE } & \multicolumn{2}{|c|}{$\begin{array}{l}\text { DILENSION } \\
\text { IN FEET }\end{array}$} & \multicolumn{2}{|c|}{$\begin{array}{l}\text { DIMENSION } \\
\text { IN UETEAS }\end{array}$} \\
\hline & $A$ & $\mathrm{~B}$ & $\bar{A}$ & $\mathrm{~B}$ \\
\hline SHALL & 75 & 80 & 22.9 & 24.4 \\
\hline MEOIUM & 120 & 160 & 36.6 & 48.8 \\
\hline LARGE & 150 & 210 & 45.8 & 64.1 \\
\hline
\end{tabular}




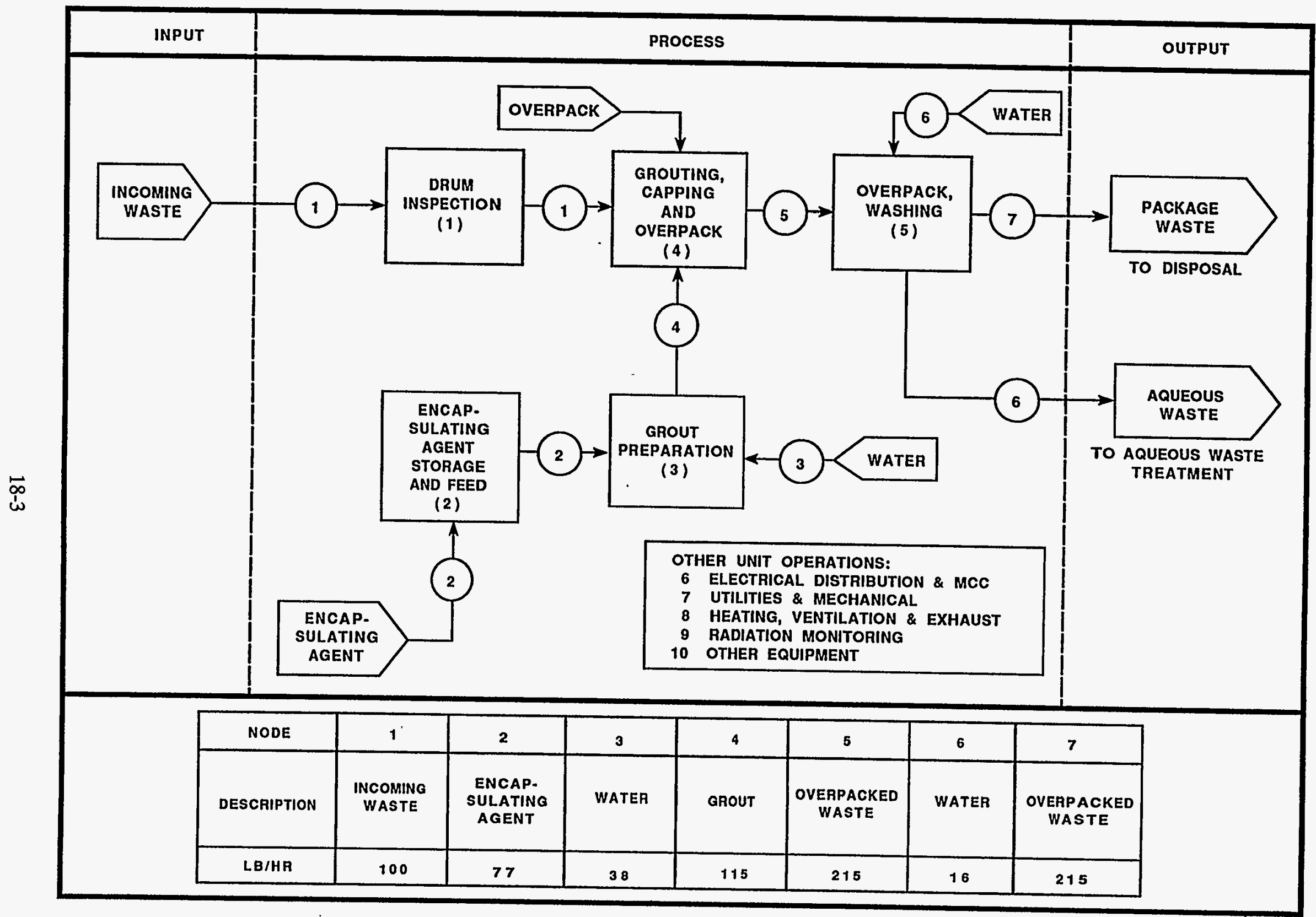

Figure 18-2. Process flow diagram for the packaging (PACKG) module. 


\section{PACKAGING}

FTE by Work Breakdown Structure Element Module: PACKG Waste Type: Contact Handled TRUW

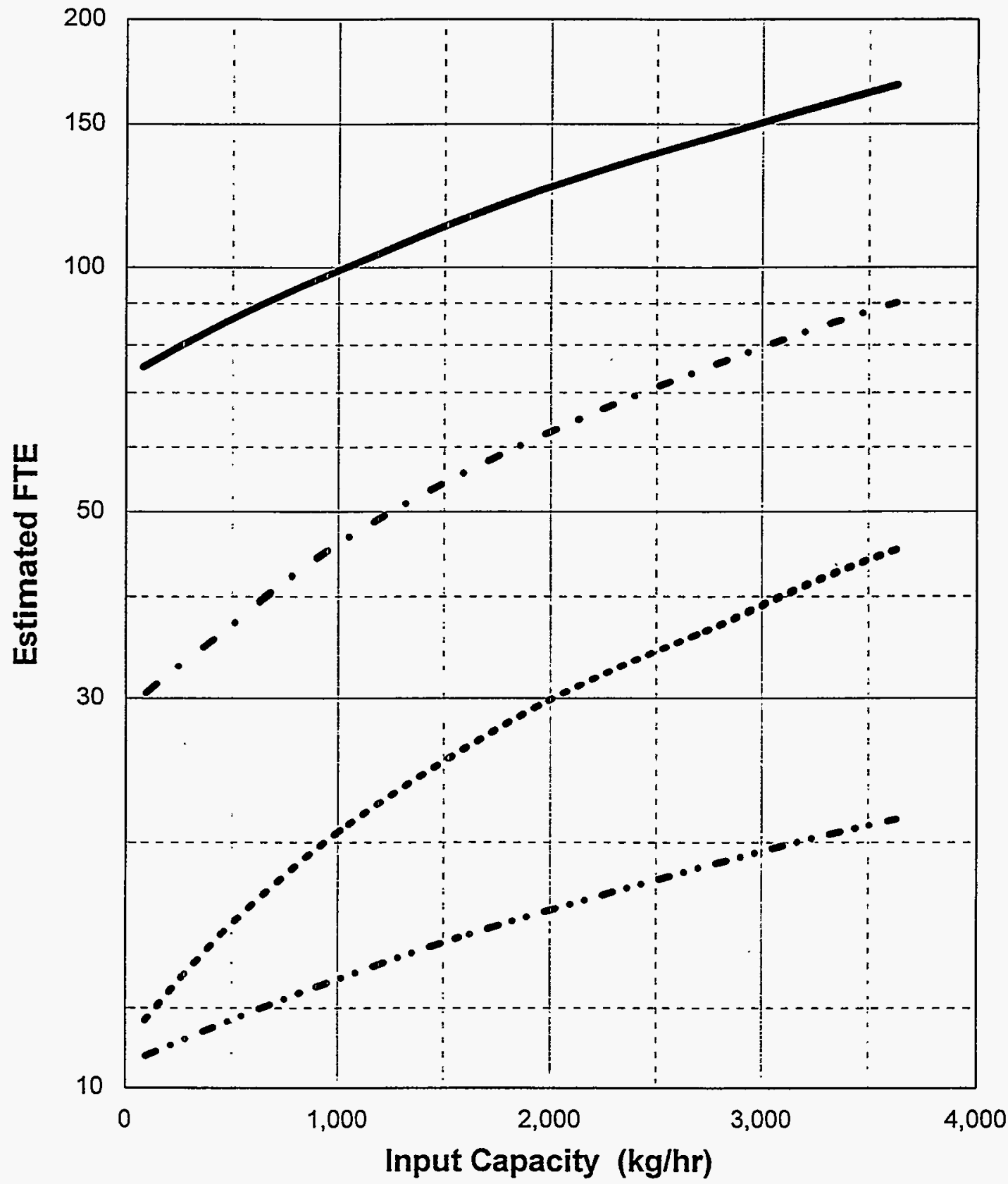

Pre-Operations Construction O\&M (1year) D\&D

Figure 18-3. FTE workers versus capacity for the $\mathrm{CH}$ packaging (T-PACKG) module. 


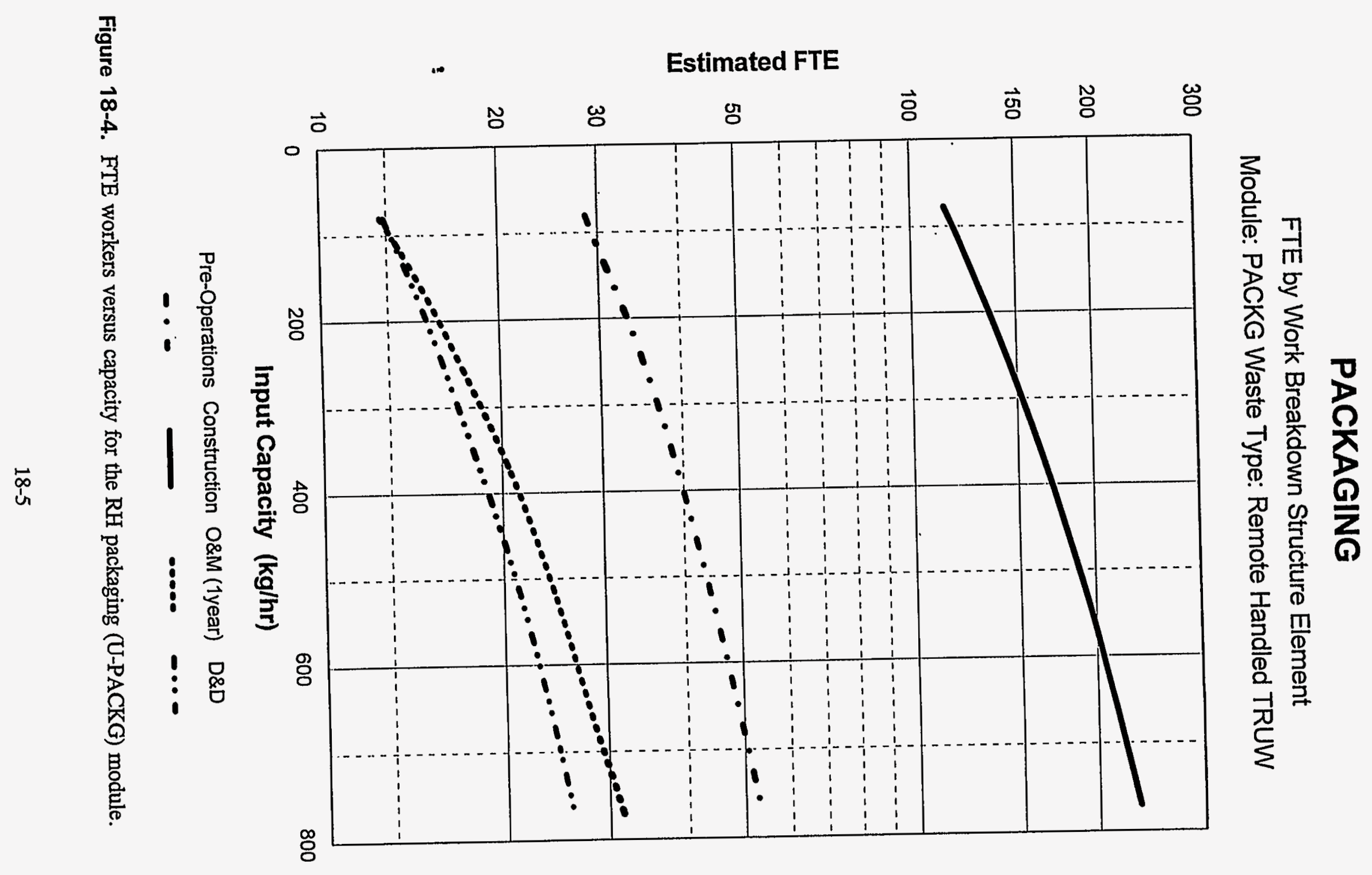




\section{PACKAGING}

Costs by Work Breakdown Structure Element

Module: PACKG Waste Type: Contact Handled TRUW

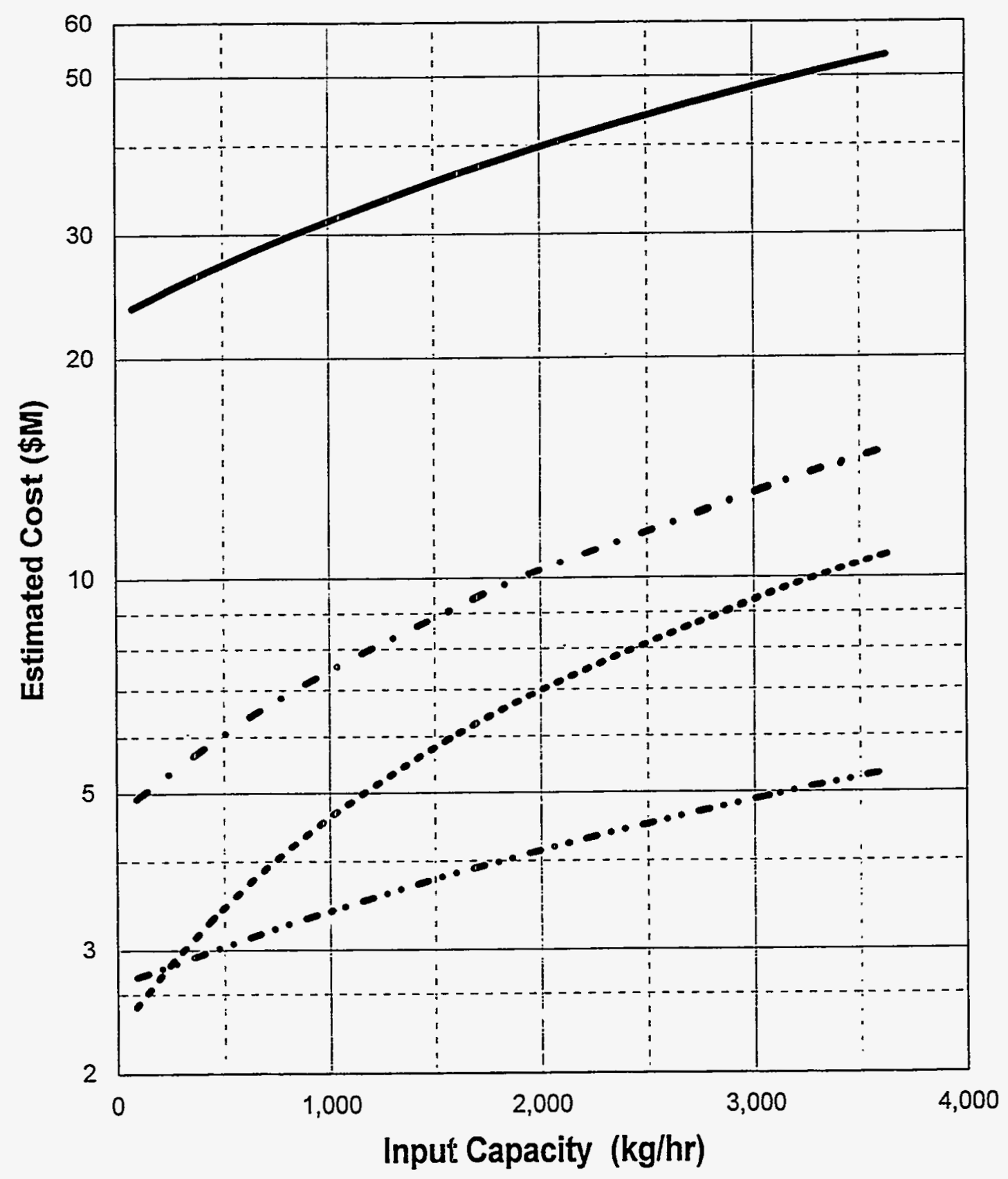

Pre-Operations Construction O\&M (1year) D\&D

Figure 18-5. PLCC versus capacity for the $\mathrm{CH}$ packaging (T-PACKG) module. 


\section{PACKAGING}

Costs by Work Breakdown Structure Element Module: PACKG Waste Type: Remote Handled TRUW

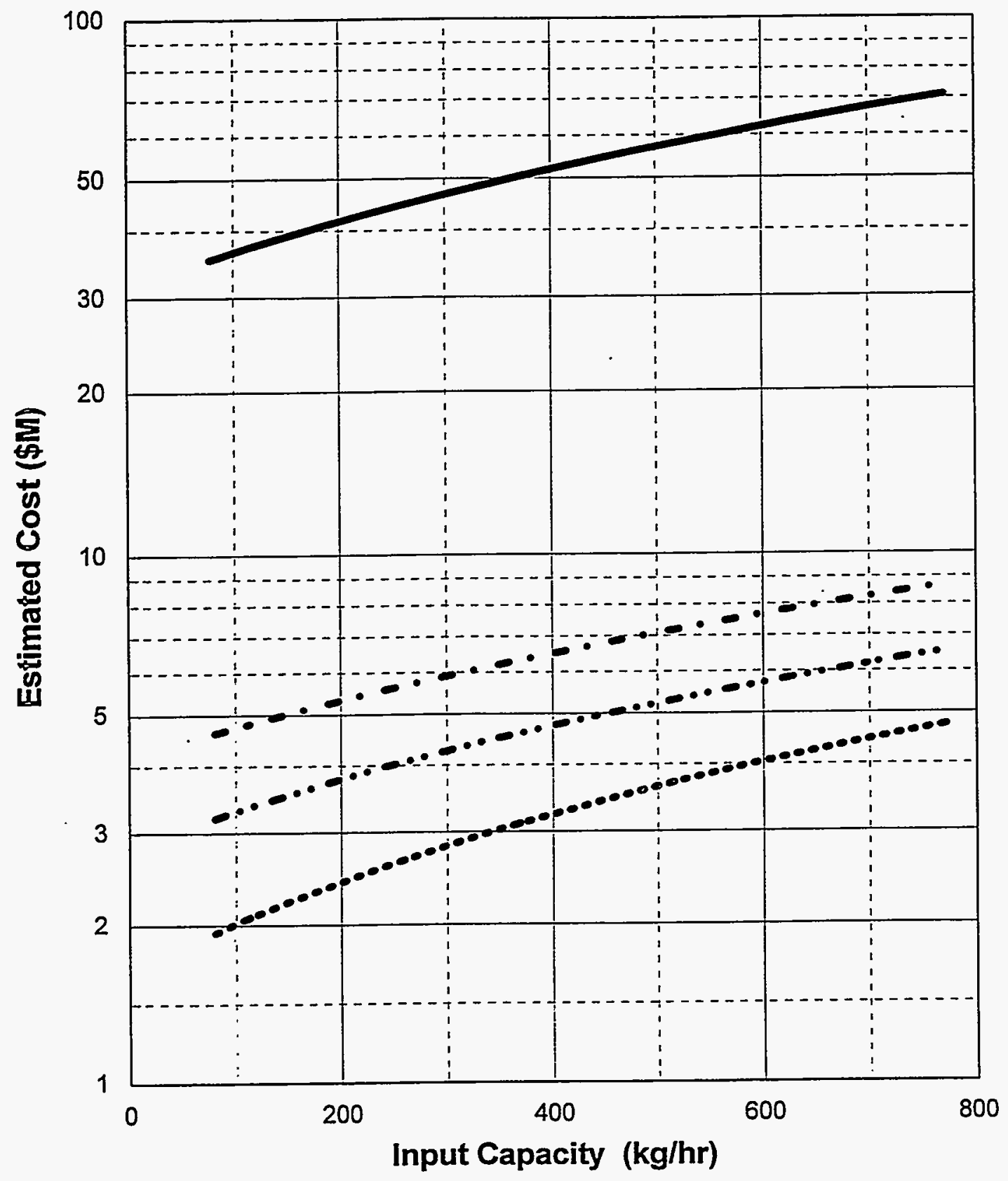

Pre-Operations Construction O\&M (1year) D\&D

Figure 18-6. PLCC versus capacity for the RH packaging (U-PACKG) module. 
PACKAGING

Total Life Cycle Costs

Module: PACKG Waste Type: Contact Handled and Remote Handled TRUW

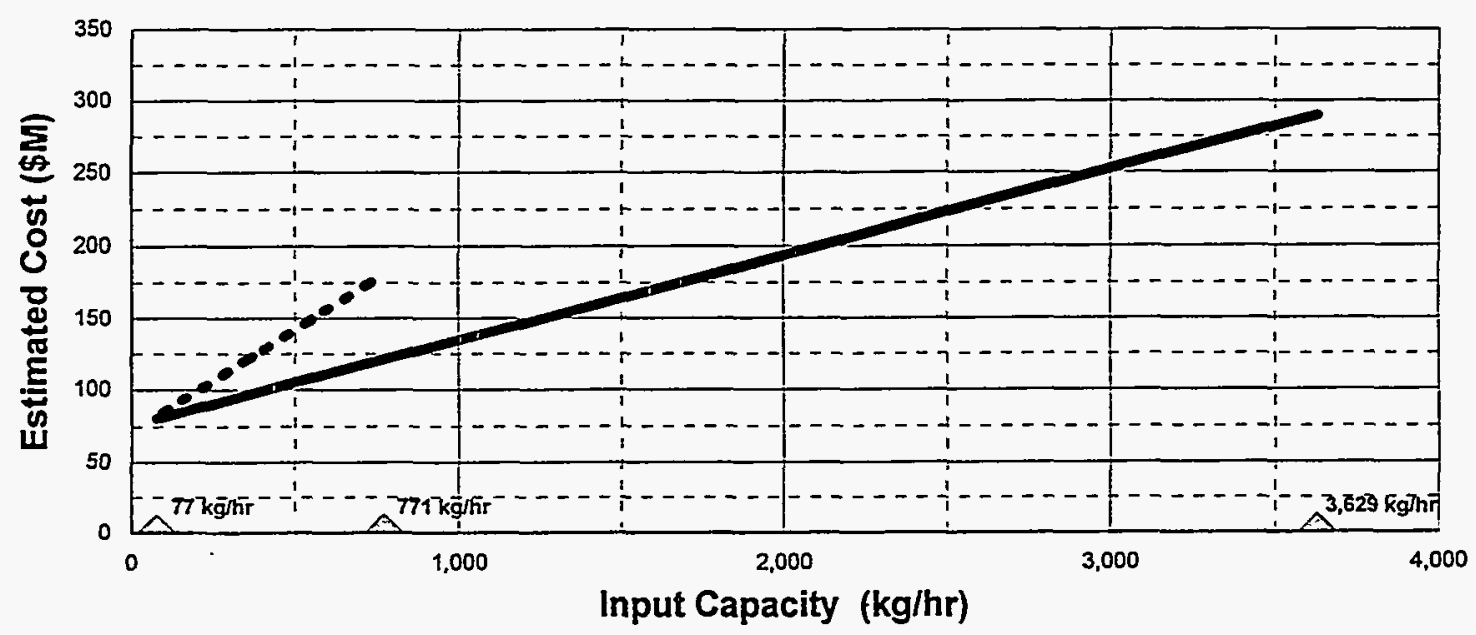

Contact Handled Remote Handled

NOTE: Basis includes 20 years O\&M

Triangles indicate capacities where detailed cost estimates were developed.

PACKAGING

Total Life Cycle Unit Costs

Module: PACKG Waste Type: Contact Handled and Remote Handled TRUW

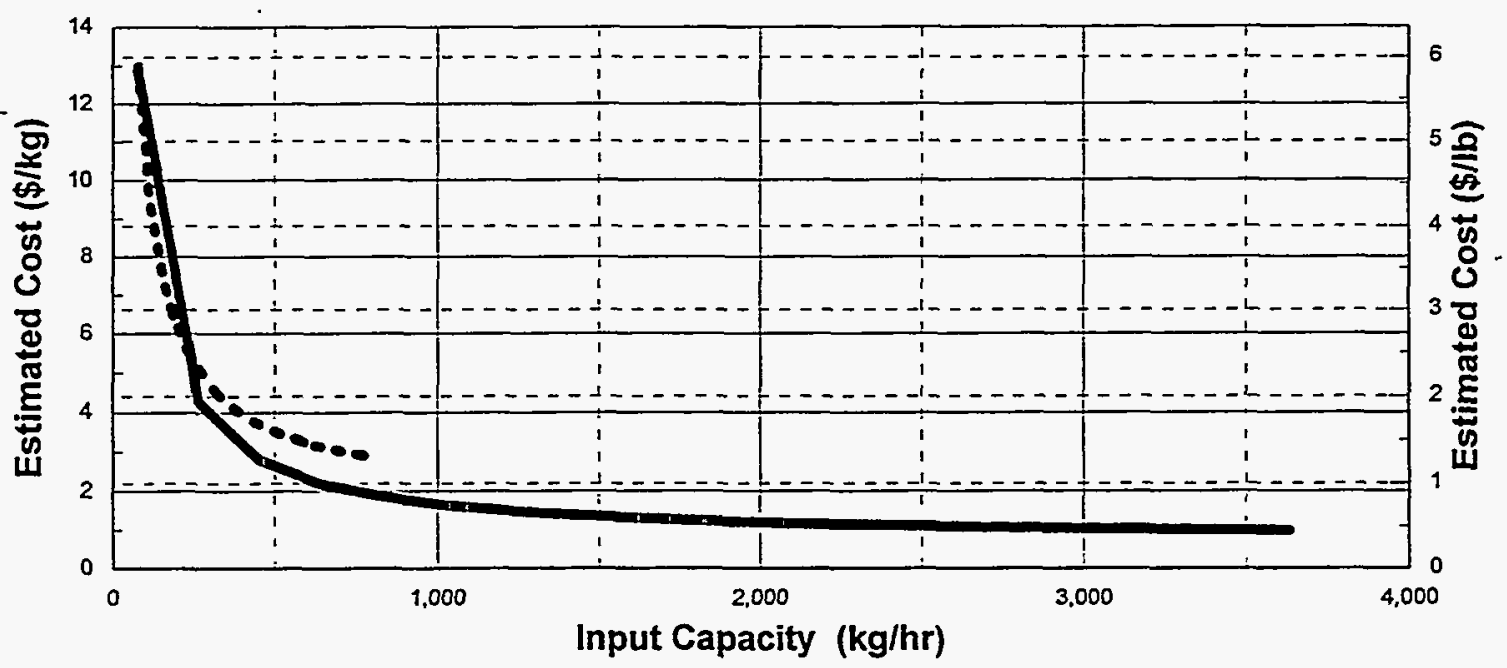

Contact Handied Remote Handled

NOTE: Basis indudes 20 years O\&M

Figure 18-7. PLCC versus capacity including unit rates for the packaging (PACKG) module. 


\section{SPECIAL WASTE PROCESSING (MODULE SPECL)}

\subsection{Basic Information}

The special waste processing module, shown in Figure 19-1, is designed to treat waste streams that are varied in nature, such as compressed gas cylinders, explosives, lab packs, and batteries. This module is designed to accommodate unique waste types on a case-by-case basis. It consists of an area equipped with a number of unit operations that have flexible treatment and handling functions. These unit operations contain material handling equipment, such as master slave manipulators, and hydraulic manipulators mounted inside glove boxes. The unit operations are designed to be operated manually or remotely by personnel working in the operator gallery. The area is also equipped with an overhead crane that is used to install or remove specialized waste treatment unit operations or equipment skids on an as-needed basis. The building space includes all wiring, piping, drains, and ventilation systems required for skid-mounted waste treatment units. The cost of this module includes the building cost, including a lump sum allowance for equipment that must be provided on a case-bycase basis. Module T-SPECL is intended for CH-TRUW, while module U-SPECL is intended for RH-TRUW. Unit operations are shown in the PFD in Figure 19-2.

\subsection{Technical Bases and Assumptions}

\subsubsection{Function and Operation of the Module}

The special waste processing module receives bins containing waste that cannot be treated by the normal process trains included in the facility. When the incoming waste composition is identified, a specific process capable of treating the waste is developed. The process equipment is skid mounted and installed in the module. After treatment, the skid-mounted equipment is decontaminated and either set aside or removed from the module, making space available for skids needed to treat other special wastes.

\subsubsection{Integration of the Module}

The module input is waste that cannot be treated by other treatment trains. Waste is received from the open, dump, and sort (OSORT) module. The system consumables and output are variable and depend on the waste to be processed.

\subsection{Cost Bases, Assumptions, and Results}

Major fixed equipment include cranes, manipulators, glove boxes, and conveyors. Cost allowances are included for unit operations that have to be provided on a case-by-case basis. For CH-TRUW, process equipment allowances are $\$ 4.2$ million for the small module; $\$ 5.3$ million for the medium module; and $\$ 7.6$ million for the large module. Facility operations are based on batch processing. For RH-TRUW processing, equipment costs are one and a half times higher.

Estimated FTEs and cost versus capacity for this module are shown in Figures 19-3 through 19-7. 


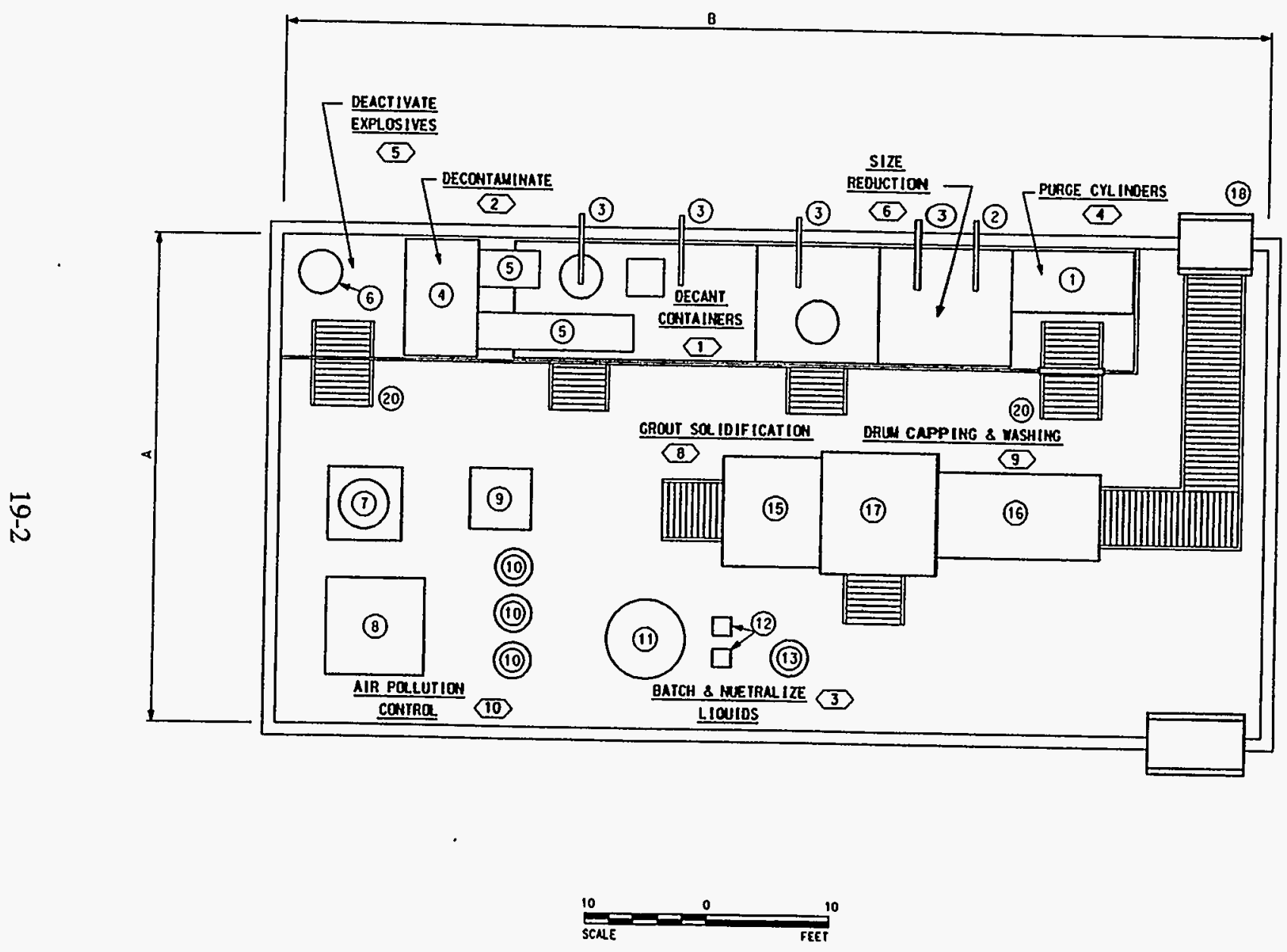

\section{EQUIPMENT LIST}

(1) CYL INDER PIERCING SYSTEM

(2) master slave manipulaton

(3) HYRAULIC MANIPULATOR

(4) oecontamination Boorh

(5) decontamination belt conveyor

(6) Deactivation well

(7) scrubrer

(8) HEPA F ILTERS

(9) BAG F ILTER

(10) CARBBOH FILTERS

(11) MaSte LIOUIDS batch taNK

(12) PUIP

(13) CHEMICAL TANK

(14) OVERHEAD CRANE

(15) SOL IDIFICATION UNIT

(16) YASH UNIT

(17) ORUM CAPPING UNIT

(18) AIRLOCK

(19) GANTRY ROBOT

(20) ROLLER CONVEYOR

\begin{tabular}{|c|c|c|c|c|}
\hline \multirow{2}{*}{ FACILITY SIZE } & \multicolumn{2}{|c|}{$\begin{array}{l}\text { OTHENSION } \\
\text { HEET }\end{array}$} & \multicolumn{2}{|c|}{$\begin{array}{l}\text { DIMENSION } \\
\text { IN HETERS }\end{array}$} \\
\hline & A & B & $\bar{A}$ & $\bar{B}$ \\
\hline SMALL & 30 & 63 & 9.2 & 19.2 \\
\hline MEDIUM & 50 & 89 & 15.3 & 27.2 \\
\hline LARGE & 70 & 90 & 21.4 & 27.5 \\
\hline
\end{tabular}

D2/0527/RRUSPECL. OGN PLOT OATE: S/OS/94

Figure 19-1. Equipment layout for the special waste processing (SPECL) module. 


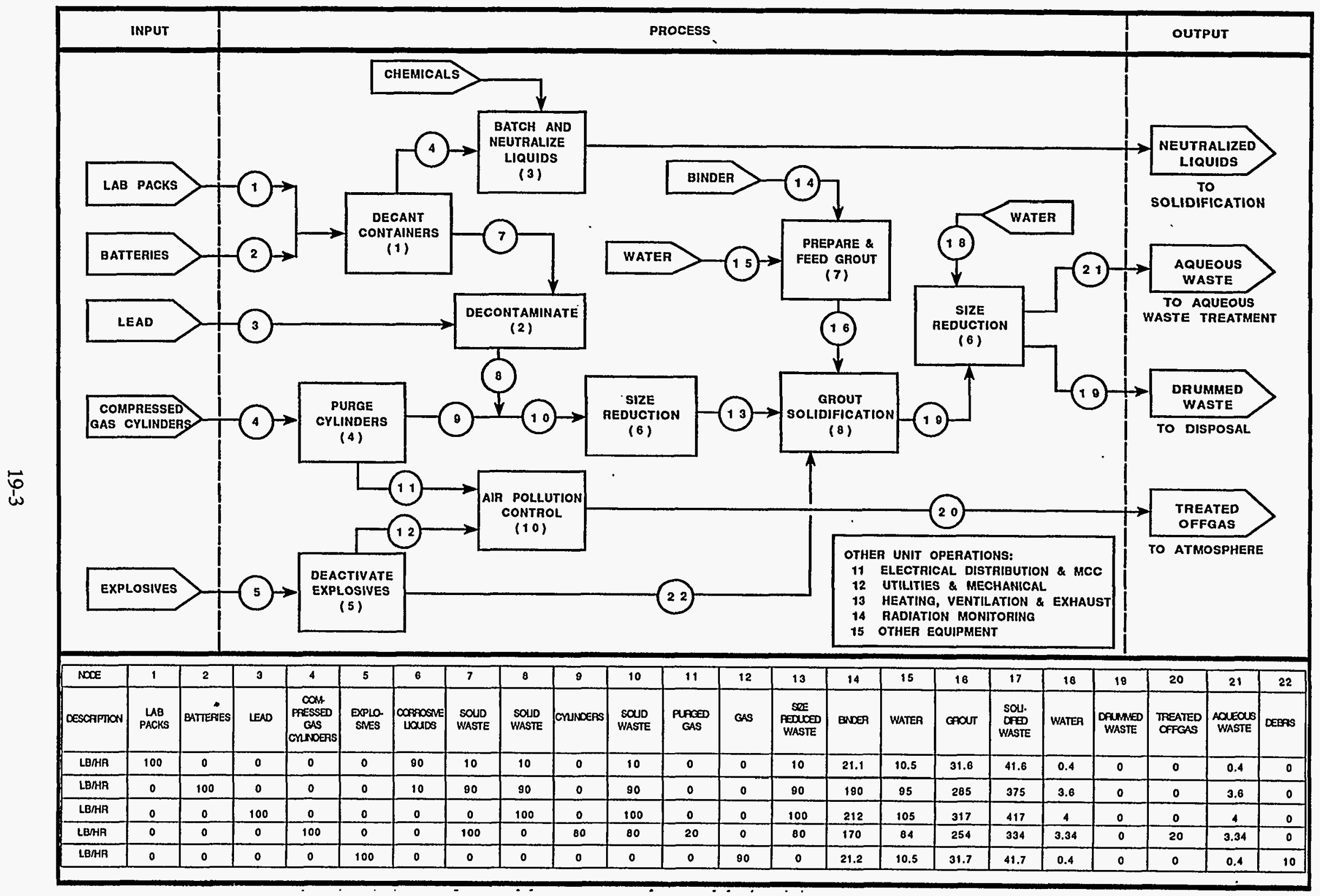

Figure 19-2. Process flow diagram for the special waste processing (SPECL) module. 


\section{SPECIAL WASTE PROCESSING}

FTE by Work Breakdown Structure Element Module: SPECL Waste Type: Contact Handled TRUW

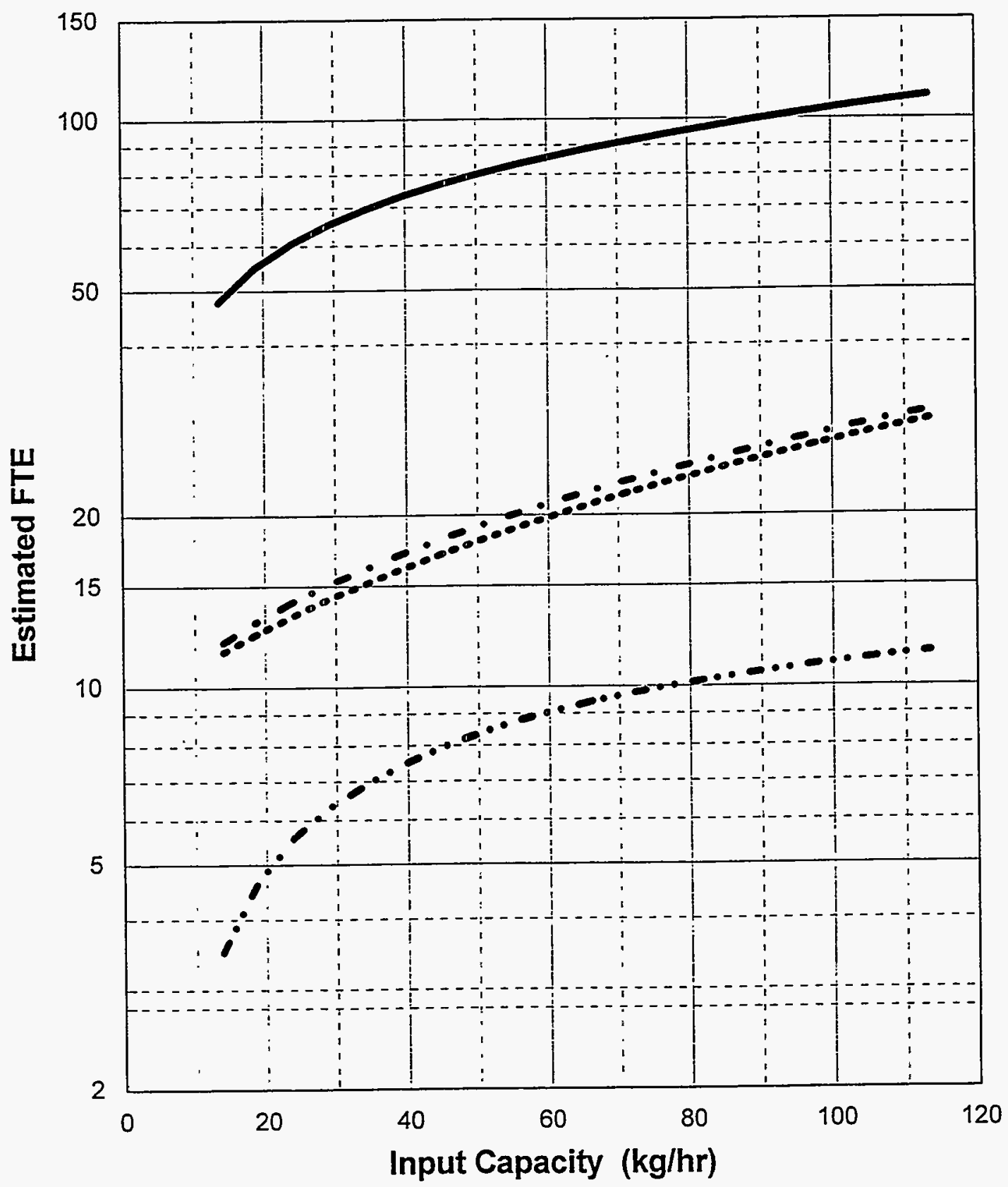

Pre-Operations Construction O\&M (1year) D\&D

Figure 19-3. FTE workers versus capacity for the $\mathrm{CH}$ special waste processing (T-SPECL) module. 


\section{SPECIAL WASTE PROCESSING}

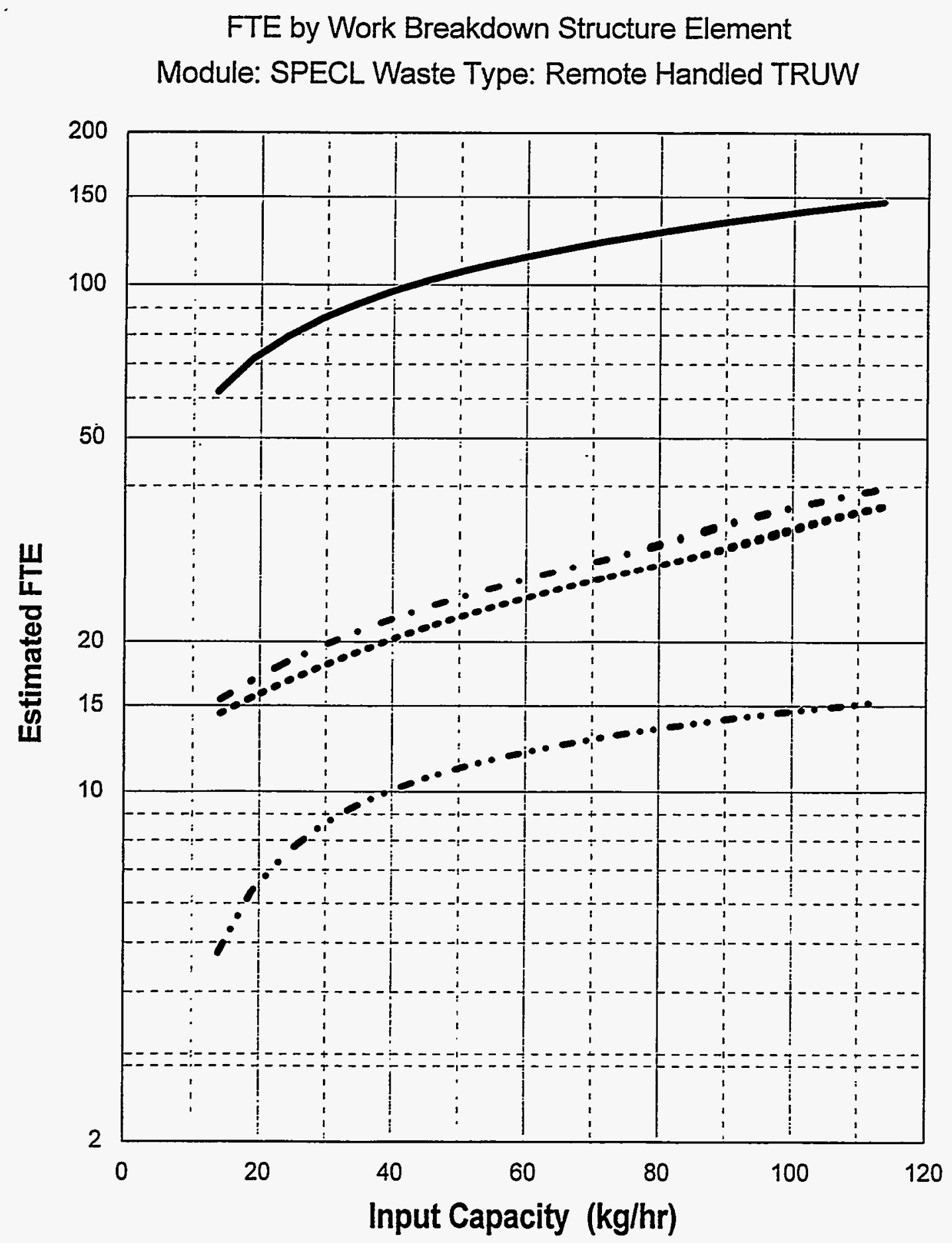

Pre-Operations Construction O\&M (1year) D\&D - -

Figure 19-4. FTE workers versus capacity for the RH special waste processing (U-SPECL) module. 


\section{SPECIAL WASTE PROCESSING}

Costs by Work Breakdown Structure Element Module: SPECL Waste Type: Contact Handled TRUW

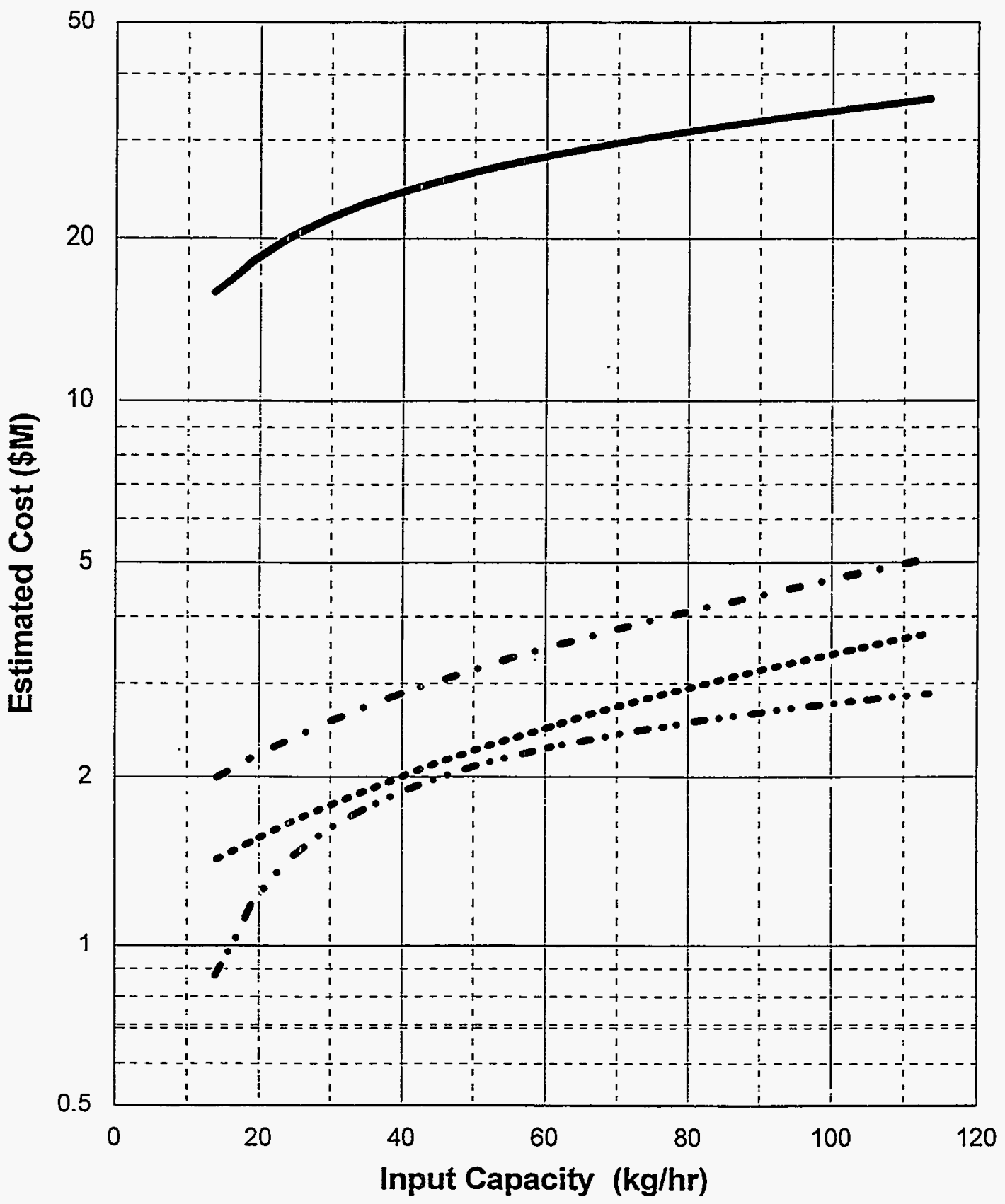

Pre-Operations Construction O\&M (1year) D\&D

Figure 19-5. PLCC versus capacity for the $\mathrm{CH}$ special waste processing (T-SPECL) module. 


\section{SPECIAL WASTE PROCESSING}

Costs by Work Breakdown Structure Element Module: SPECL Waste Type: Remote Handled TRUW

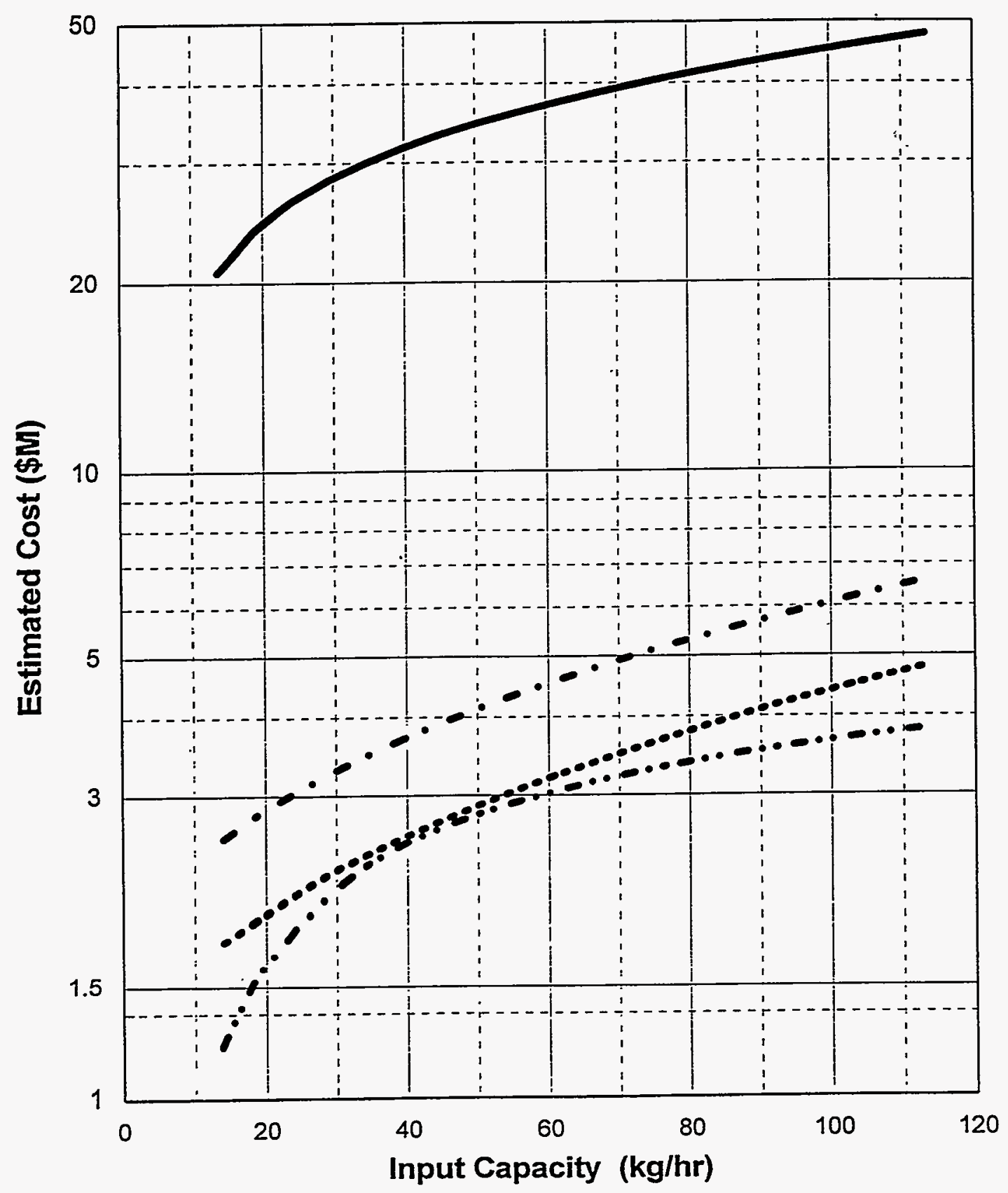

Pre-Operations Construction O\&M (1year) D\&D

Figure 19-6. PLCC versus capacity for the RH special waste processing (U-SPECL) module. 


\section{SPECIAL WASTE PROCESSING}

Total Life Cycle Costs

Module: SPECL Waste Type: Contact Handled and Remote Handled TRUW

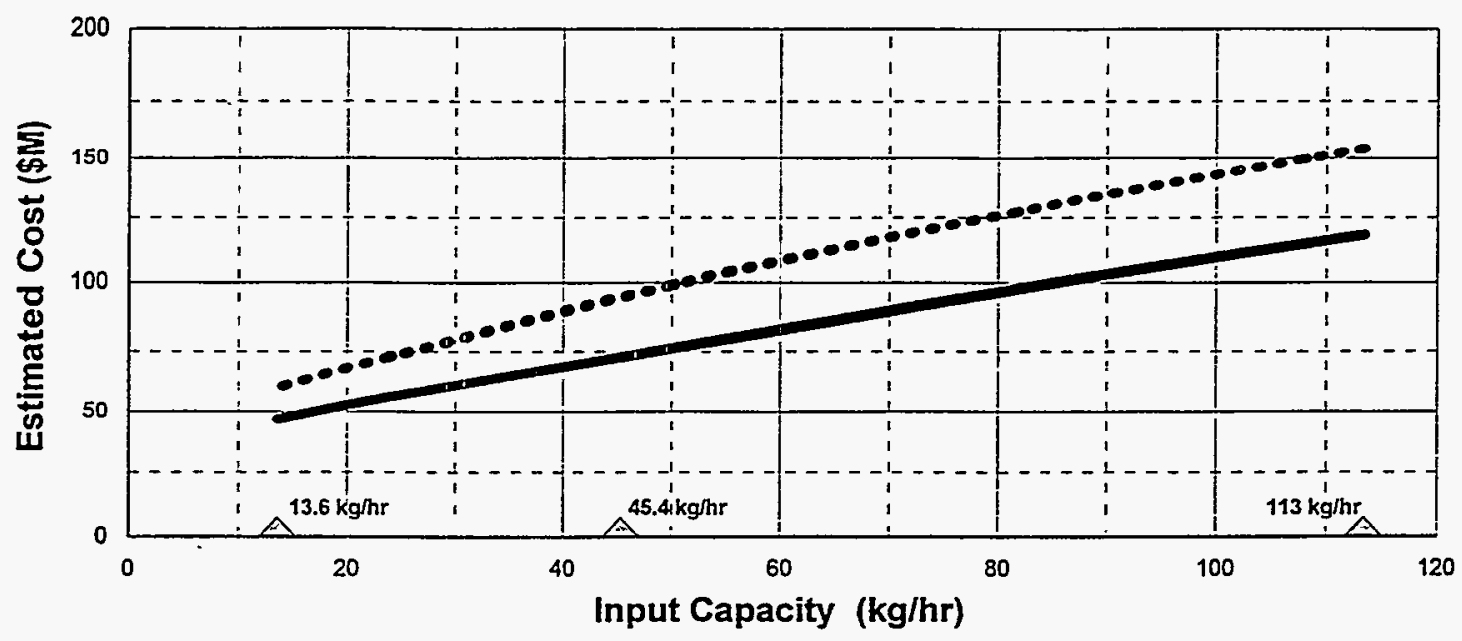

Contact Handled Remote Handled

NOTE: Basis includes 20 years O\&M

Triangles indicate capacities where detailed cost estimates were developed.

\section{SPECIAL WASTE PROCESSING}

Total Life Cycle Unit Costs

Module: SPECL Waste Type: Contact Handled and Remote Handled TRUW

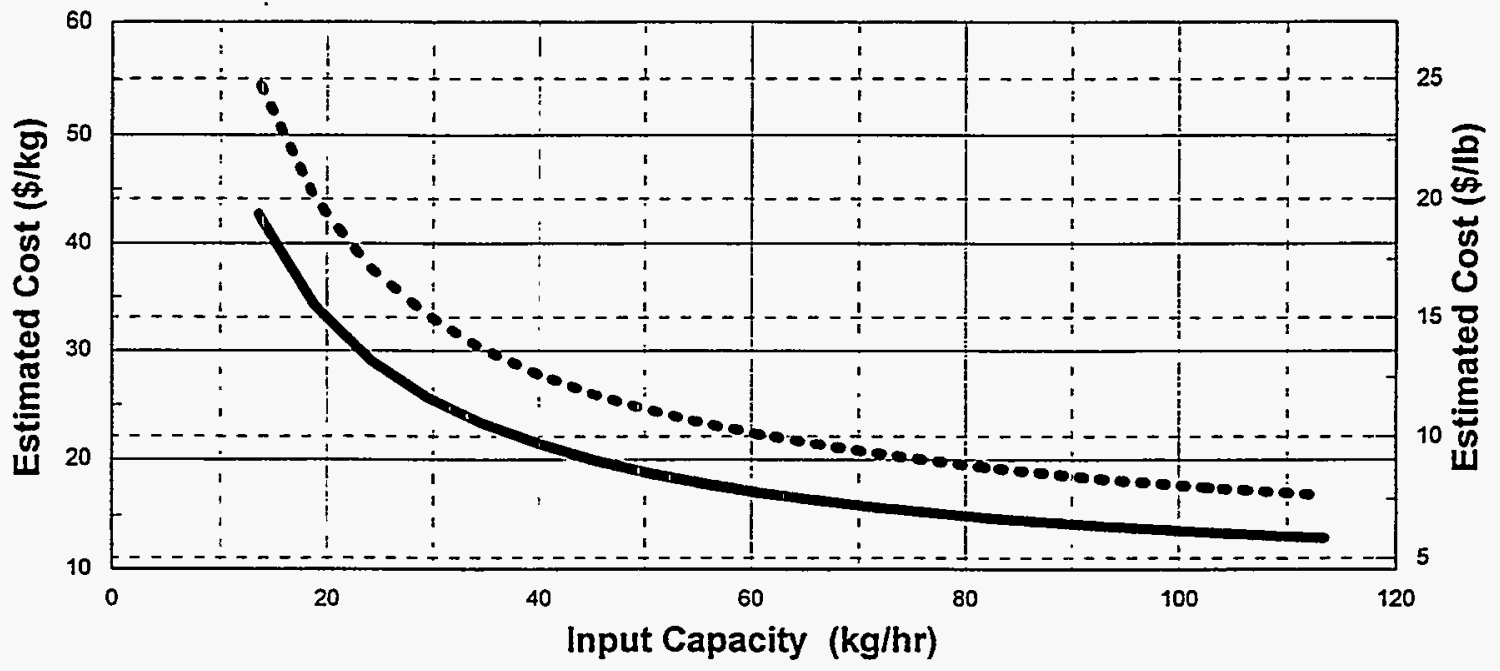

Contact Handled Remote Handled

NOTE: Basis indudes 20 years O\&M

Figure 19-7. PLCC versus capacity including unit rates for the special waste processing (SPECL) module. 


\section{CERTIFICATION AND SHIPPING (MODULE CSHIP)}

\subsection{Basic Information}

The certification and shipping module has been developed as a fixed module for large waste generators, and as a portable module, in a set of trailers, for small waste generators. The fixed module is shown in Figure 20-1; the portable module is shown in Figure 20-2.

The certification and shipping module consists of three unit operations: incoming material storage, assay and certification, and truck loading. Unit operations are shown in the PFD in Figure 20-3. This module receives packaged waste containers from treatment modules and provides temporary storage, radiological and physical characterization of the waste, and shipment of the containers. Module T-CSHIP is intended for CH-TRUW, while module U-CSHIP is intended for RH-TRUW.

The certification and shipping module is used in conjunction with treatment modules when the required functions are not available at existing facilities. The module includes all equipment needed for certification of the waste in compliance with the transportation, storage, and disposal regulations and requirements.

\subsection{Technical Bases and Assumptions}

\subsubsection{Function and Operation of the Fixed Module}

Packaged waste containers arrive from treatment modules on conveyors, carts, or other transport devices. Containers are removed from the transport devices and placed in a staging area. The containers are then visually examined, tagged, logged, recorded, and transported to an assay and certification unit operation. In this unit operation, the containers are examined by radioassay devices to allow both alpha and gamma radioactivity classification in accordance with transportation, storage, and disposal criteria. Various devices, such as PAN counting and SGS instruments, may be used.

Next, the containers are weighed and measured to determine waste density. The presence of material restricted by transportation, storage, and disposal criteria is determined by NDE by ultrasonic instruments or an RTR device. After examination, each container is labeled and its properties are logged and recorded into a computerized database. After inspection, the container is moved to a temporary storage area until readied for shipment to an interim storage or disposal facility. Containers that do not meet the transportation dose criteria are shipped in a truck equipped with shield overpacks.

The shipping and certification module is equipped with a bridge crane and a forklift. Containers can be loaded onto flat-bed trailer or van trucks. Containers can also be loaded into large transportation overpacks (e.g., TRUPACT-II). This module is designed to be installed contiguous to a treatment module.

To allow year-round operations and minimize the effects of a potential spill, it is assumed that the certification and shipping operations will take place indoors. 


\subsubsection{Function and Operation of the Portable Module}

The portable certification and shipping module consists of three trailers. The first trailer receives incoming uncharacterized waste, which arrives in drums, and metal bins. The incoming waste is $\mathrm{CH}$ (no shipping casks are anticipated) and is transported in enclosed vehicles. The trailer has a loading and unloading unit operation that removes waste containers from the incoming vehicles and places them in a staging and interim (surge) storage area.

After storage, the containers are moved to a second trailer equipped with an inspect and assay unit operation. This unit operation determines radioactive properties of the waste as needed for safe handling, processing, transportation, storage, and disposal. This unit operation also categorizes the waste by its chemical and physical properties using criteria established for various treatment, transportation, and disposal requirements. Radioassay functions may be accomplished by PAN and SGS instruments. Chemical characterization may be performed by head space sampling and analysis. Physical properties may be determined by RTR, tomography, and by other appropriate instrumentation (e.g., weigh scales may be used to determine waste density). After examination, each container is labeled, and the properties are logged and entered into a computer database. The container is then moved to the first trailer, which has facilities and equipment for loading and shipment of characterized containers.

A third trailer is equipped with laboratory equipment to analyze head space gas obtained from the drum.

\subsubsection{Integration of the Fixed Module}

Module input includes packaged waste from treatment modules. Input from the site includes utilities, service water, normal and emergency power, and communications. Operation and maintenance consumables including personal protective equipment must be purchased. Module output includes truck shipments of containerized TRUW, which are transported to storage and disposal modules.

\subsubsection{Integration of the Portable Module}

Input to the portable certification and shipping module consists of containers of uncharacterized waste from storage or generator facilities. Output from the module includes waste containers that are characterized for treatment, transportation, storage, or disposal. Secondary waste generated in this module is lab packs. The portable module will be linked with site communication and alarm systems, including telephone, evacuation, security alarm, and public address systems. Consumables, including personal protective equipment, are purchased.

\subsection{Cost Bases, Assumptions and Results}

\subsubsection{Fixed Module}

Major equipment capital cost items for this module are a 20 -ton bridge crane, alpha assay, gamma assay, and RTR units. The equipment estimates were obtained as discussed in this report's 
sections describing the receiving and inspection module. Estimated FTE workers and cost versus capacity for this module are shown in Figures 20-4 through 20-8.

\subsubsection{Portable Module}

Major equipment capital cost items for the portable module include a testing laboratory, SGS, PAN assay system, RTR, and forklifts. All waste is $\mathrm{CH}$, and O\&M activities are manual. Emergency showers, personnel decontamination, breathing air, and maintenance, mechanical, and instrument shop equipment are included in one of the trailers. The main characterization trailer is estimated to cost $\$ 3.5$ million. The laboratory analytical equipment trailer is estimated to be $\$ 1$ million. One processing campaign in the portable CSHIP module will treat up to $1400 \mathrm{~kg}$ of TRUW. The estimated cost for one campaign is $\$ 341,000$ and the estimated FTE for one campaign is 1.4 . 


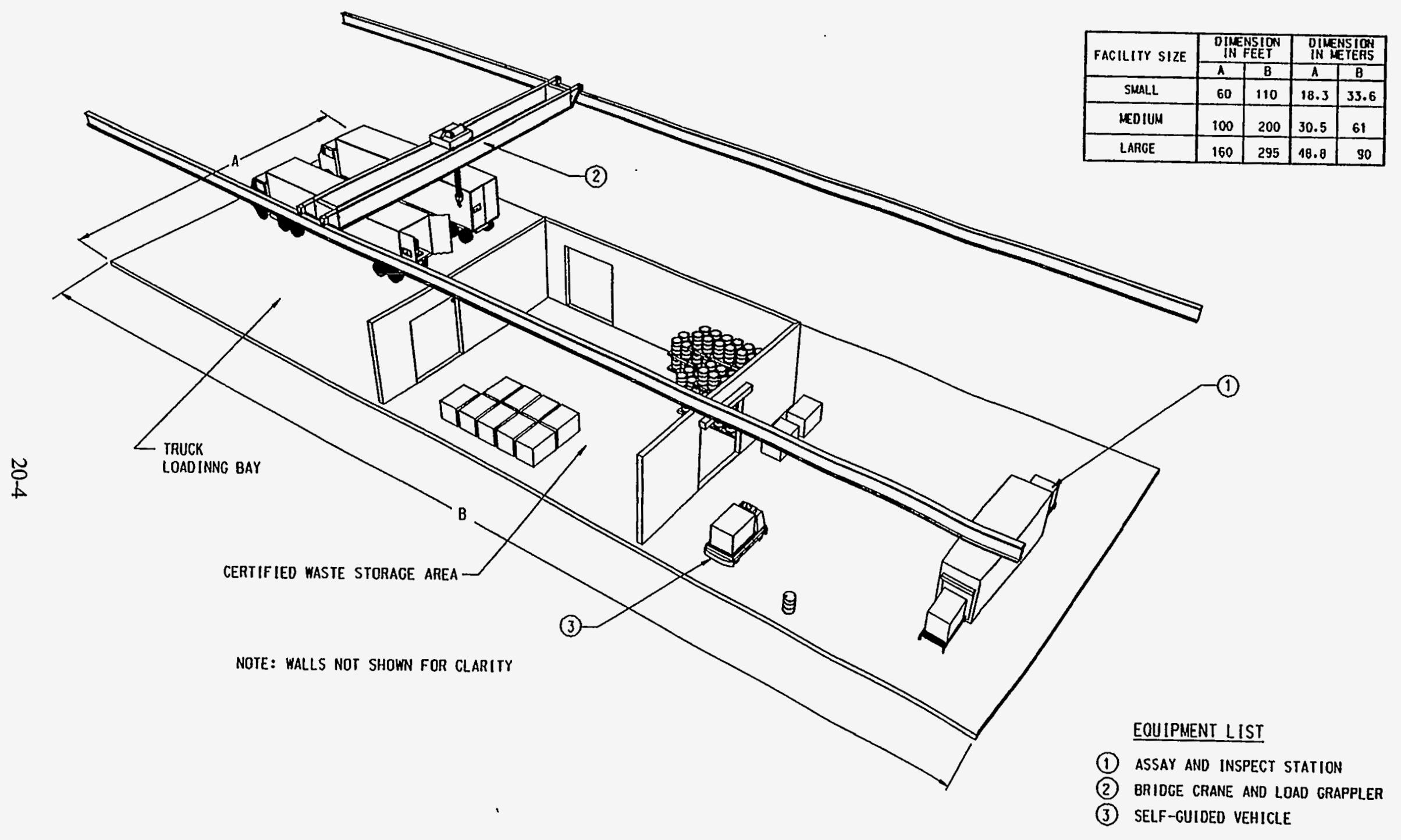

Figure 20-1. Equipment layout for the fixed certification and shipping (CSHIP) module.

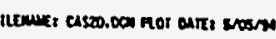




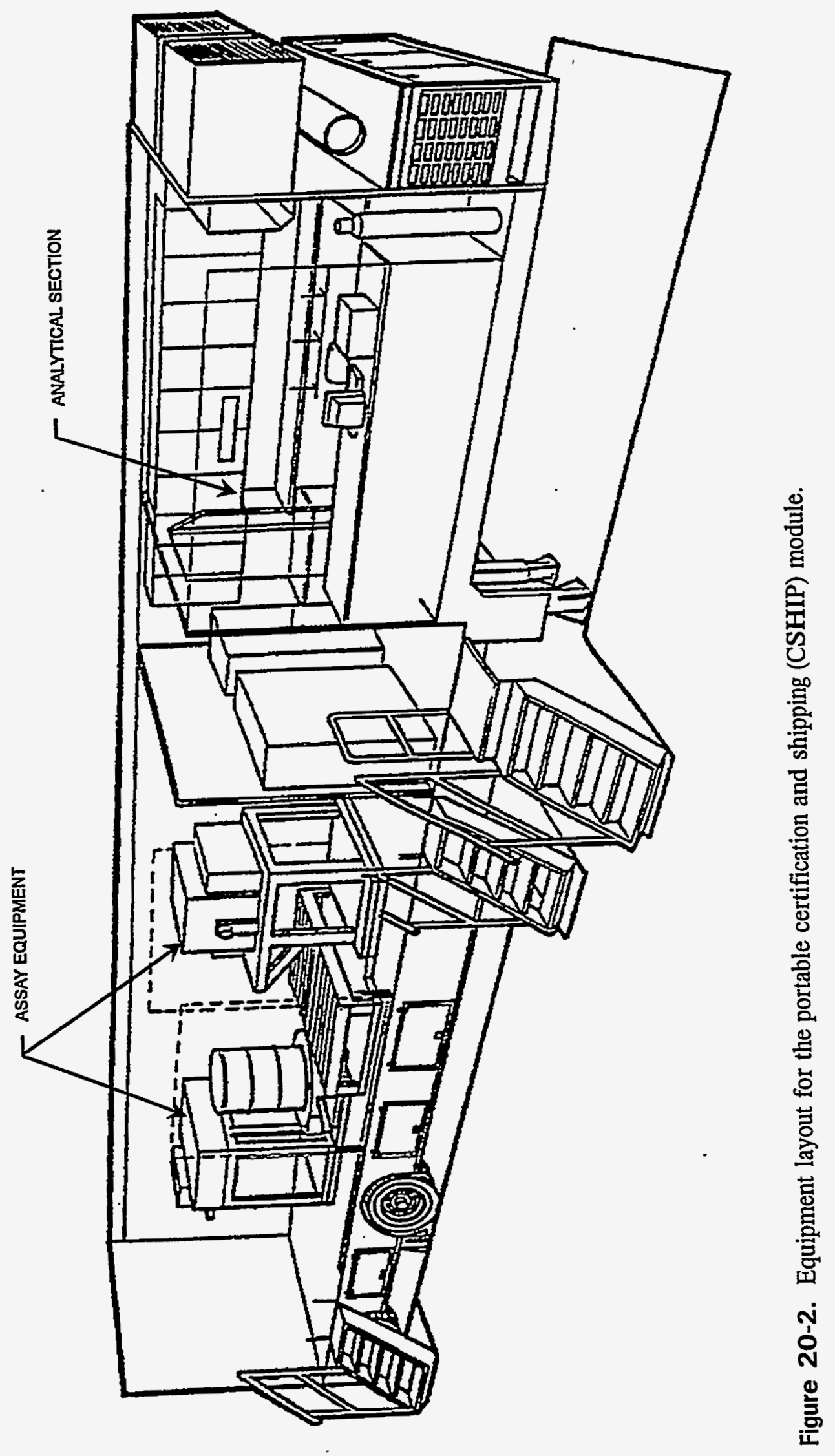




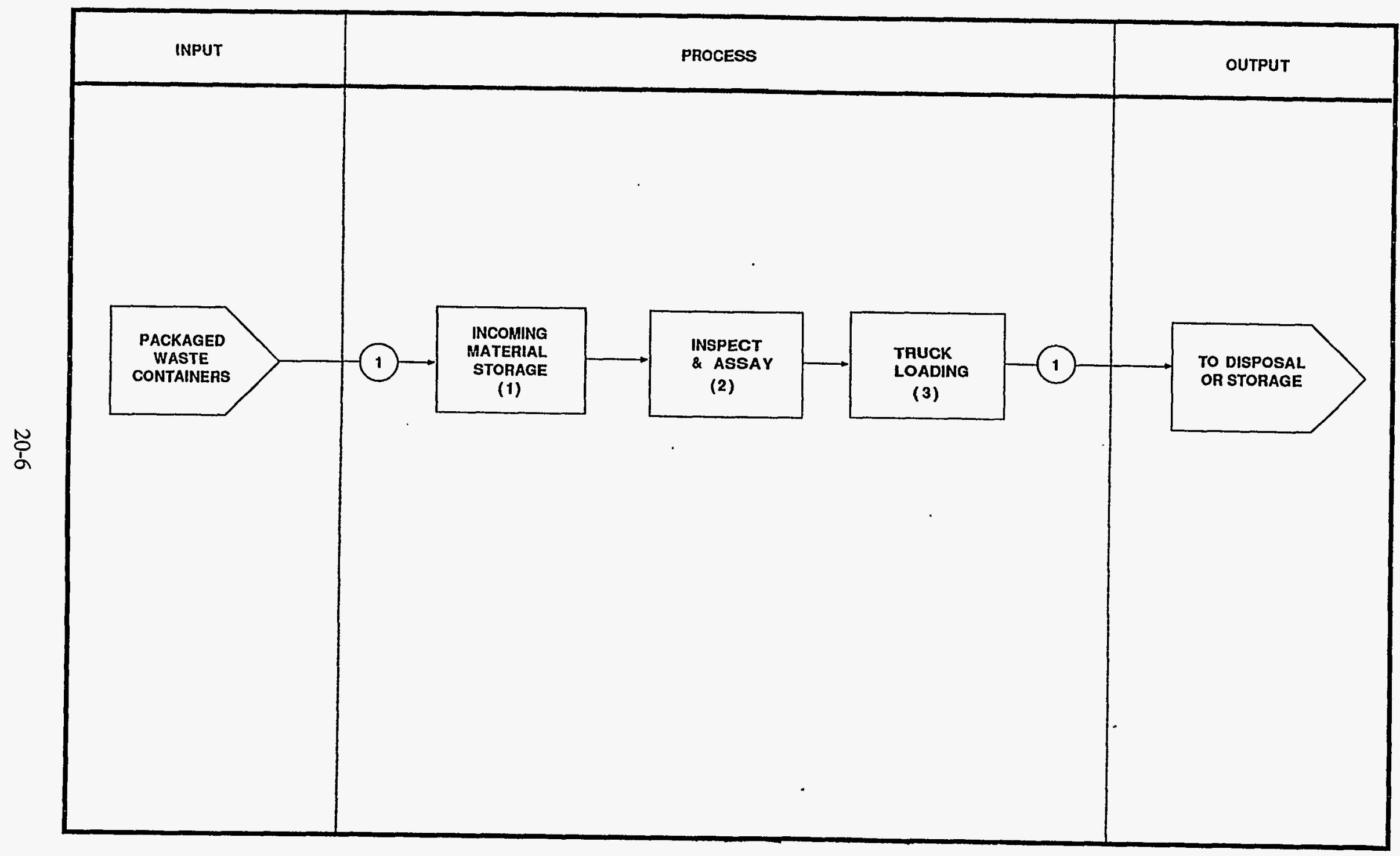

Figure 20-3. Process flow diagram for the certification and shipping (CSHIP) module. 


\section{CERTIFICATION AND SHIPPING}

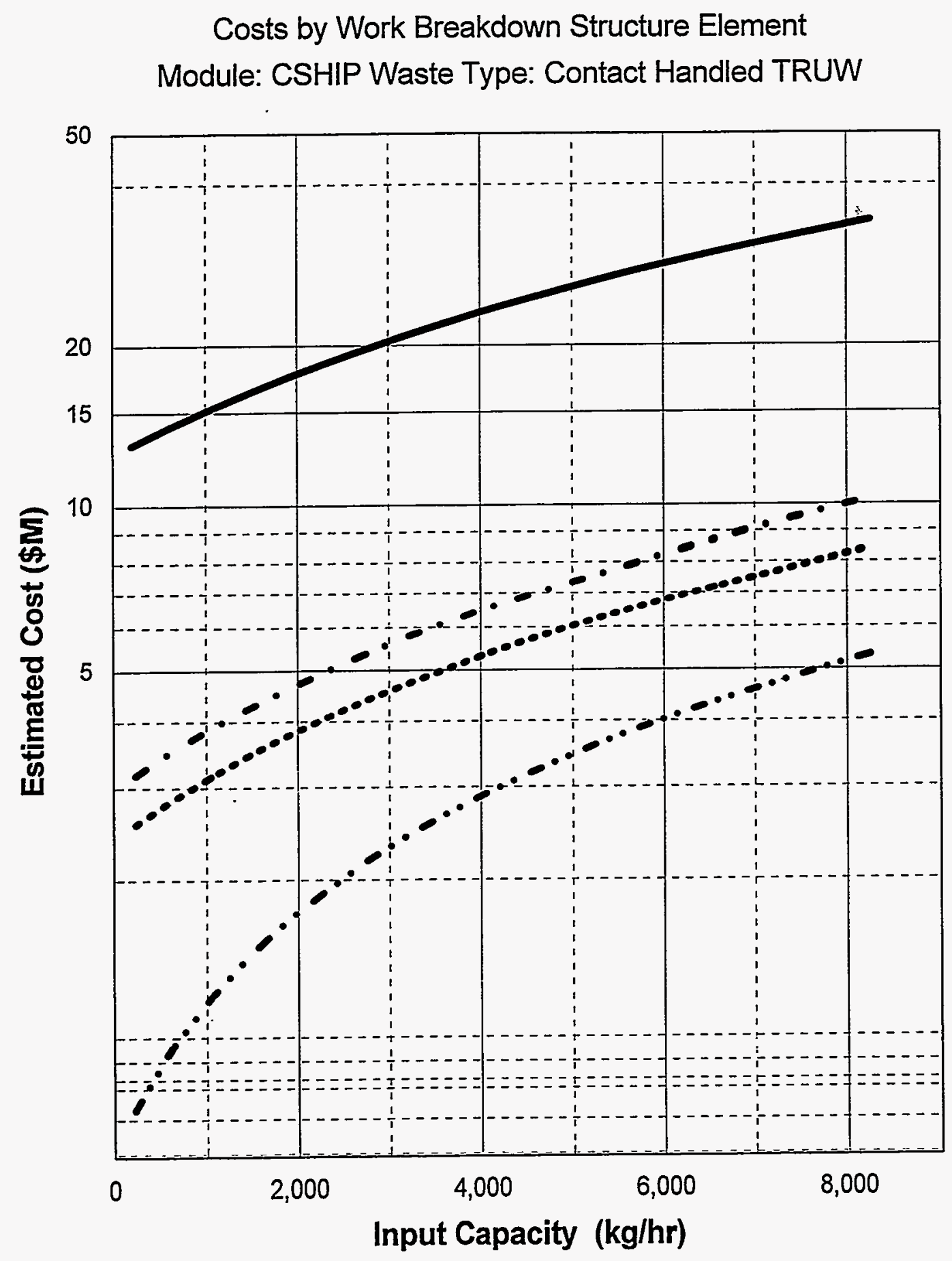

Pre-Operations Construction O\&M (1year) D\&D

Figure 20-4. FTE workers versus capacity for the $\mathrm{CH}$ certification and shipping (T-CSHIP) module. 


\section{CERTIFICATION AND SHIPPING}

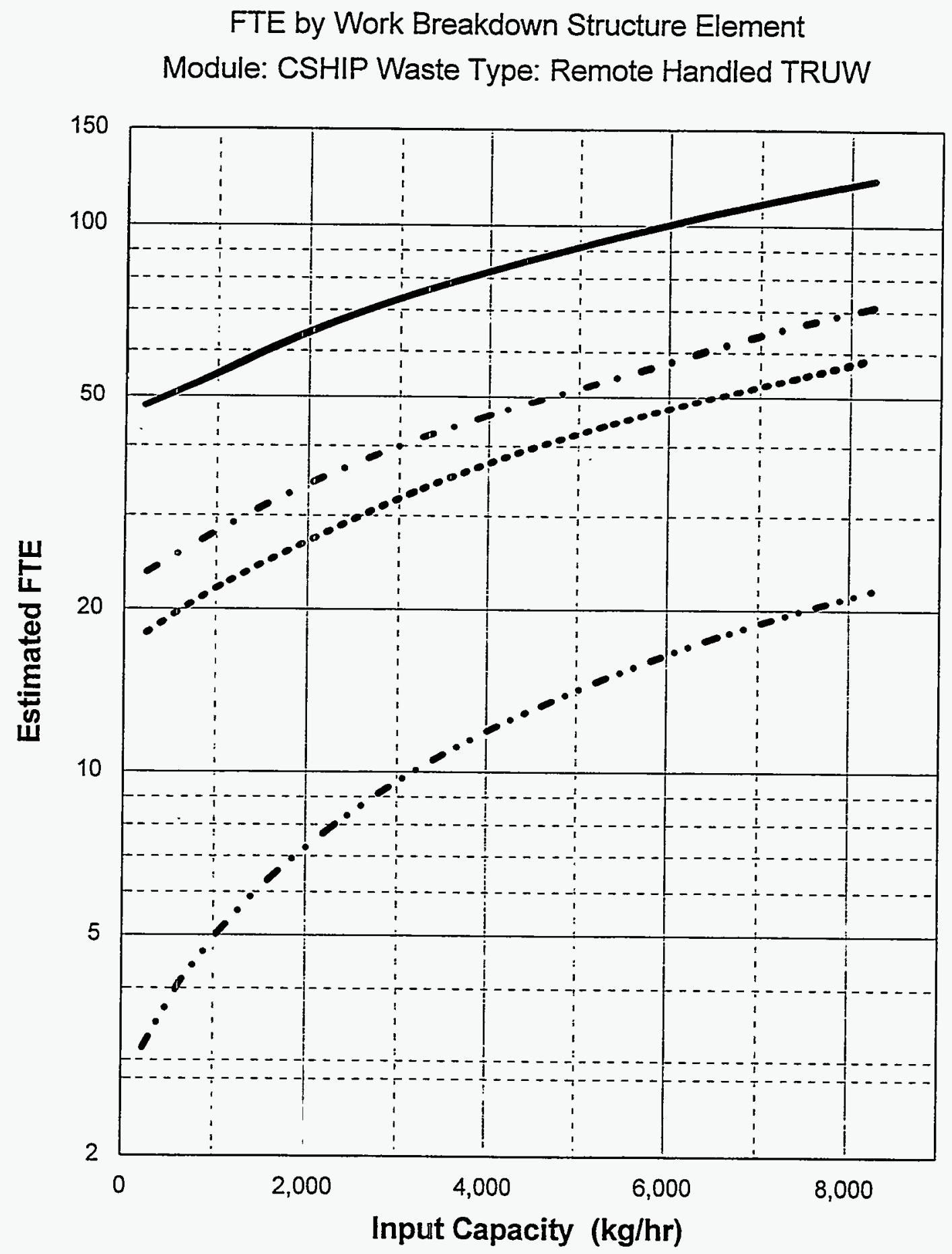

Pre-Operations Construction O\&M (1year) D\&D

Figure 20-5. FTE workers versus capacity for the RH certification and shipping (U-CSHIP) module. 


\section{CERTIFICATION AND SHIPPING}

Costs by Work Breakdown Structure Element Module: CSHIP Waste Type: Contact Handled TRUW

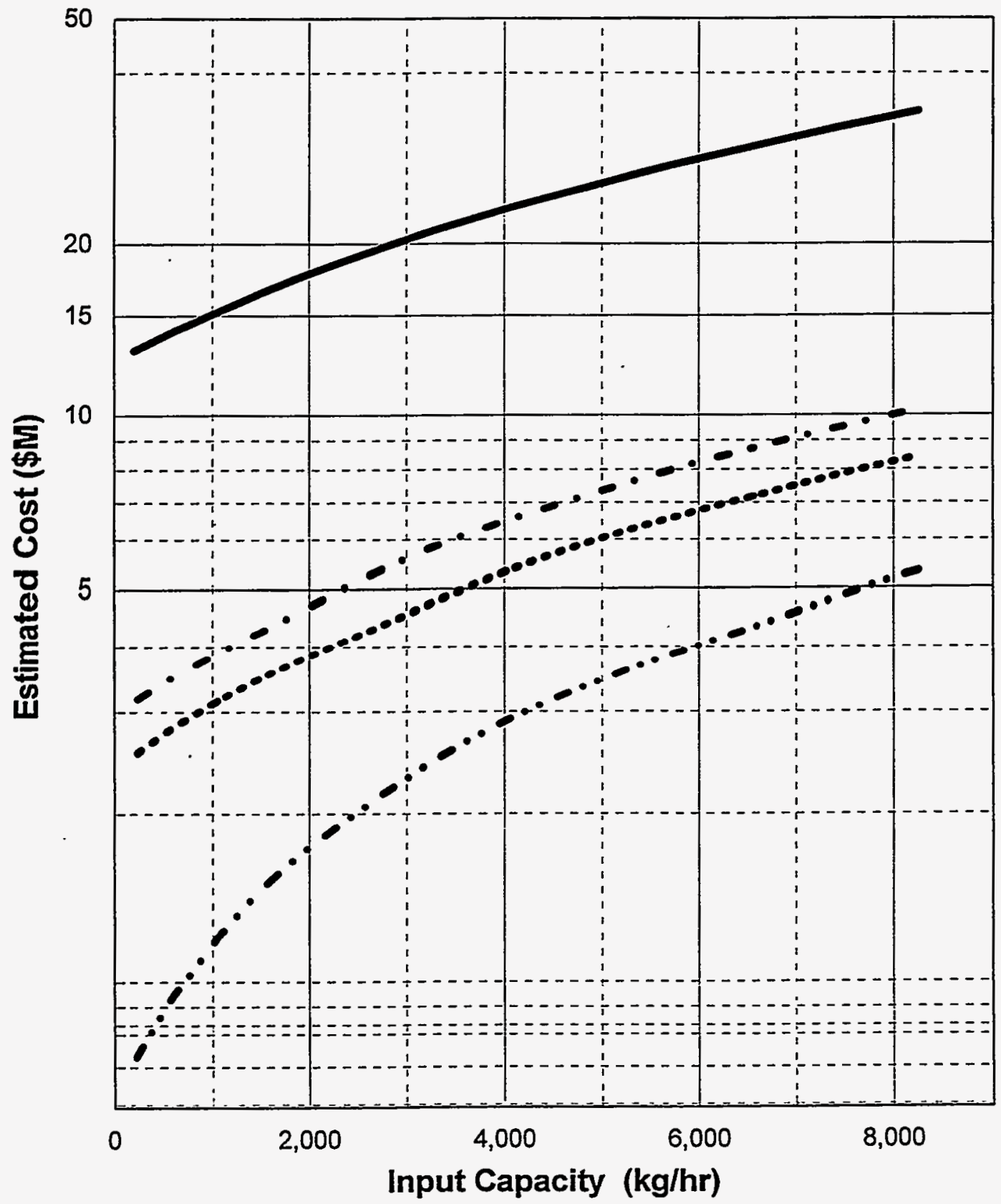

Pre-Operations Construction O\&M (1year) D\&D

Figure 20-6. PLCC versus capacity for the $\mathrm{CH}$ certification and shipping (T-CSHIP) module. 


\section{CERTIFICATION AND SHIPPING}

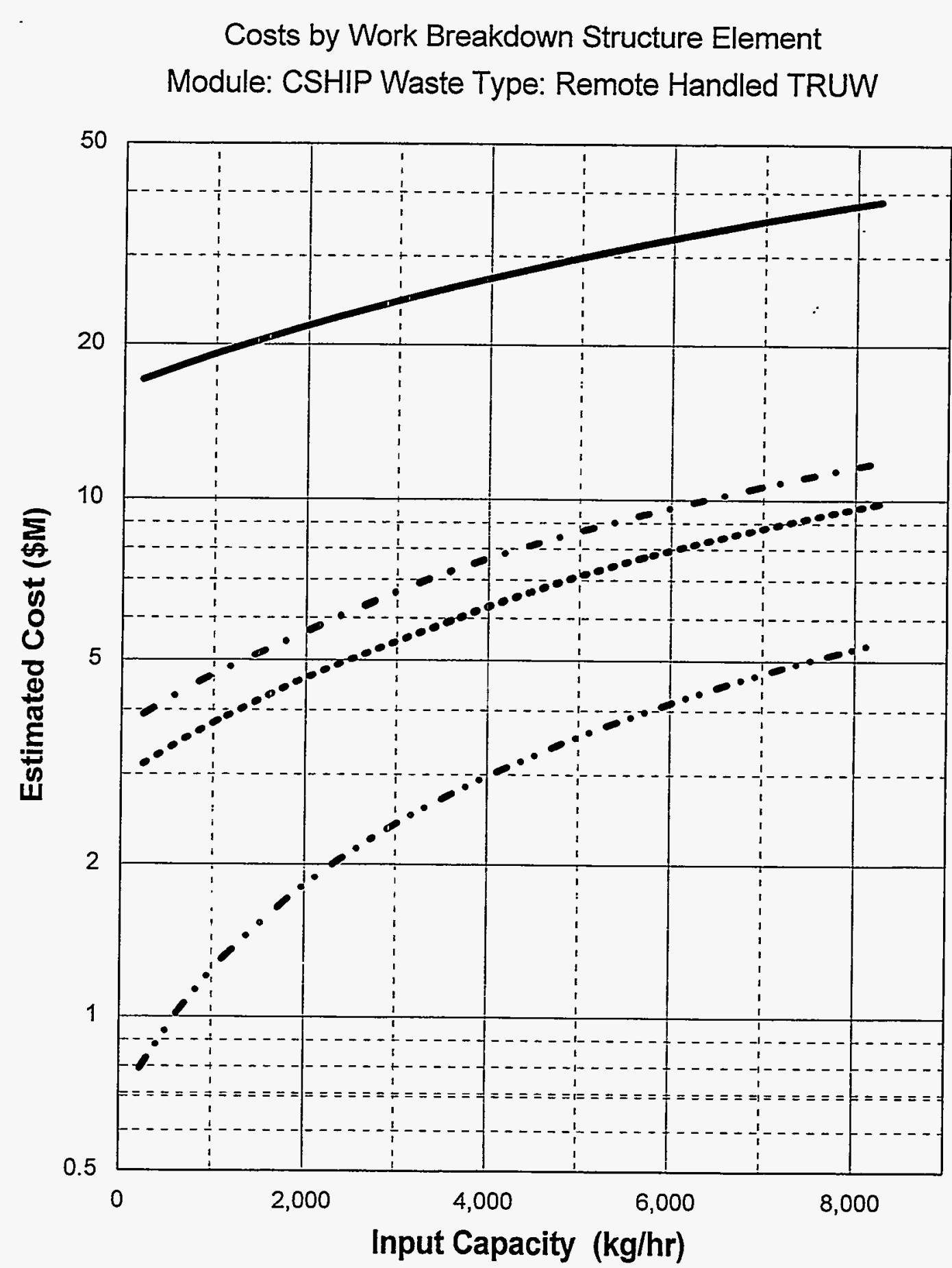

Pre-Operations Construction O\&M (1year) D\&D

Figure 20-7. PLCC versus capacity for the RH certification and shipping (U-CSHIP) module. 


\section{CERTIFICATION AND SHIPPING}

\section{Total Life Cycle Costs}

Module: CHSIP Waste Type: Contact Handed and Remote Handled TRUW

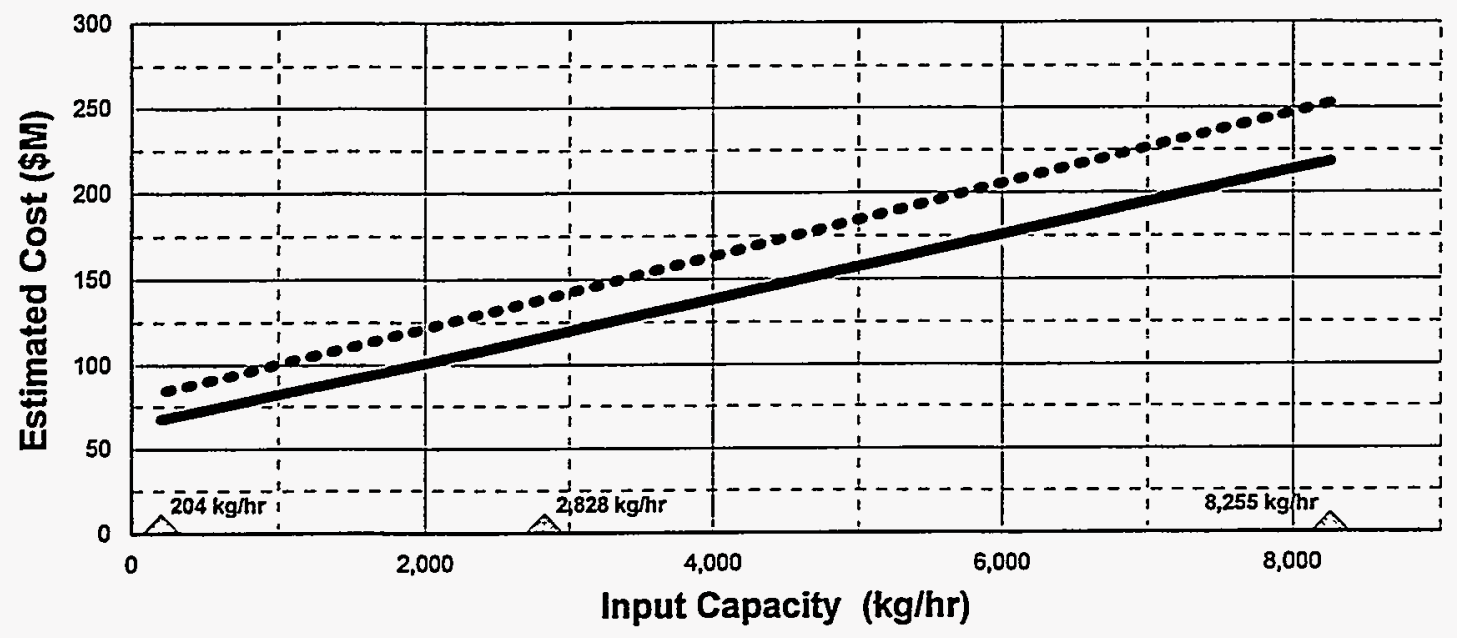

Contact Handled Remote Handled

NOTE: Basis includes 20 years O\&M

Triangles indicate capacities where detailed cost estimates were developed.

\section{CERTIFICATION AND SHIPPING}

Total Life Cycle Unit Costs

Module: CSHIP Waste Type: Contact Handled and Remote Handled TRUW

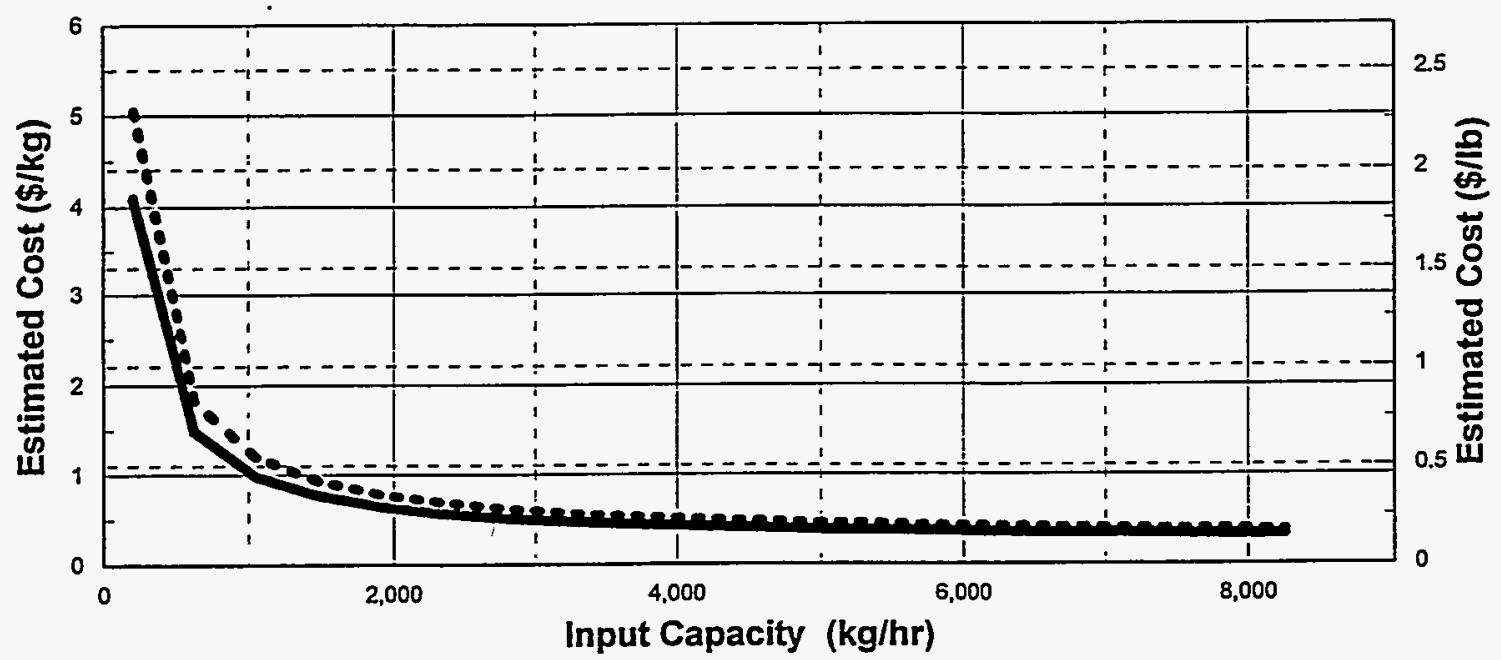

Contact Handled Remote Handled

NOTE: Basis indudes 20 years O\&M

Figure 20-8. PLCC versus capacity including unit rates for the certification and shipping (CSHIP) module. 


\section{STORAGE ADMINISTRATION (MODULE SADMN)}

\subsection{Basic Information}

The storage administration module includes all administrative and laboratory buildings required for waste management support functions. Storage administration should be used whenever a new treatment facility is planned.

\subsection{Technical Bases and Assumptions}

\subsubsection{Function and Operation of the Module}

The storage administration module incorporates all technical and administrative support functions needed to manage the operation of a waste management facility. These functions include security, access control including personnel decontamination (radioactive and hazardous), maintenance of uncontaminated areas and equipment, radiological control and radiation badges, ability access control, sanitary facilities, work control and personnel support, internal and external (public relations) communications, spill or emergency response provisions (hazardous and radioactive), analytical laboratory, environmental field sampling, environmental regulatory reporting, and records management.

\subsubsection{Integration of the Module}

The storage administration module maintains general interfaces with all storage modules. Operation and maintenance consumables include analytical supplies, office supplies, sanitary supplies, and personal protective equipment, which all must be purchased.

\subsection{Cost Bases, Assumptions, and Results}

The storage administration module is the same for CH- and RH-TRUW. The major equipment capital cost item is laboratory analytical equipment. A $\$ 1$ million allowance is made for analytical instruments and components needed for a mixed-waste laboratory. Table 21-1 lists the plan

dimensions of the module. Estimated FTEs and cost versus capacity for this module are shown in Figures 21-1 through 21-3.

Table 21-1. Plan dimensions of the storage administration module (SADMN).

\begin{tabular}{|c|c|c|c|c|}
\hline \multirow[b]{2}{*}{ Module size } & \multicolumn{2}{|c|}{$\begin{array}{c}\text { Dimensions } \\
(\mathrm{ft})\end{array}$} & \multicolumn{2}{|c|}{$\begin{array}{l}\text { Dimensions } \\
\text { (m) }\end{array}$} \\
\hline & Length & Width & Length & Width \\
\hline \multicolumn{5}{|l|}{ Large generator } \\
\hline Small & 50 & 50 & 15.2 & 15.2 \\
\hline Medium & 100 & 50 & 30.5 & 15.2 \\
\hline Large & 156 & 50 & 47.5 & 15.2 \\
\hline
\end{tabular}




\section{STORAGE ADMINISTRATION}

FTE by Work Breakdown Structure Element Module: SADMN Waste Type: Contact Handled and Remote Handled TRUW

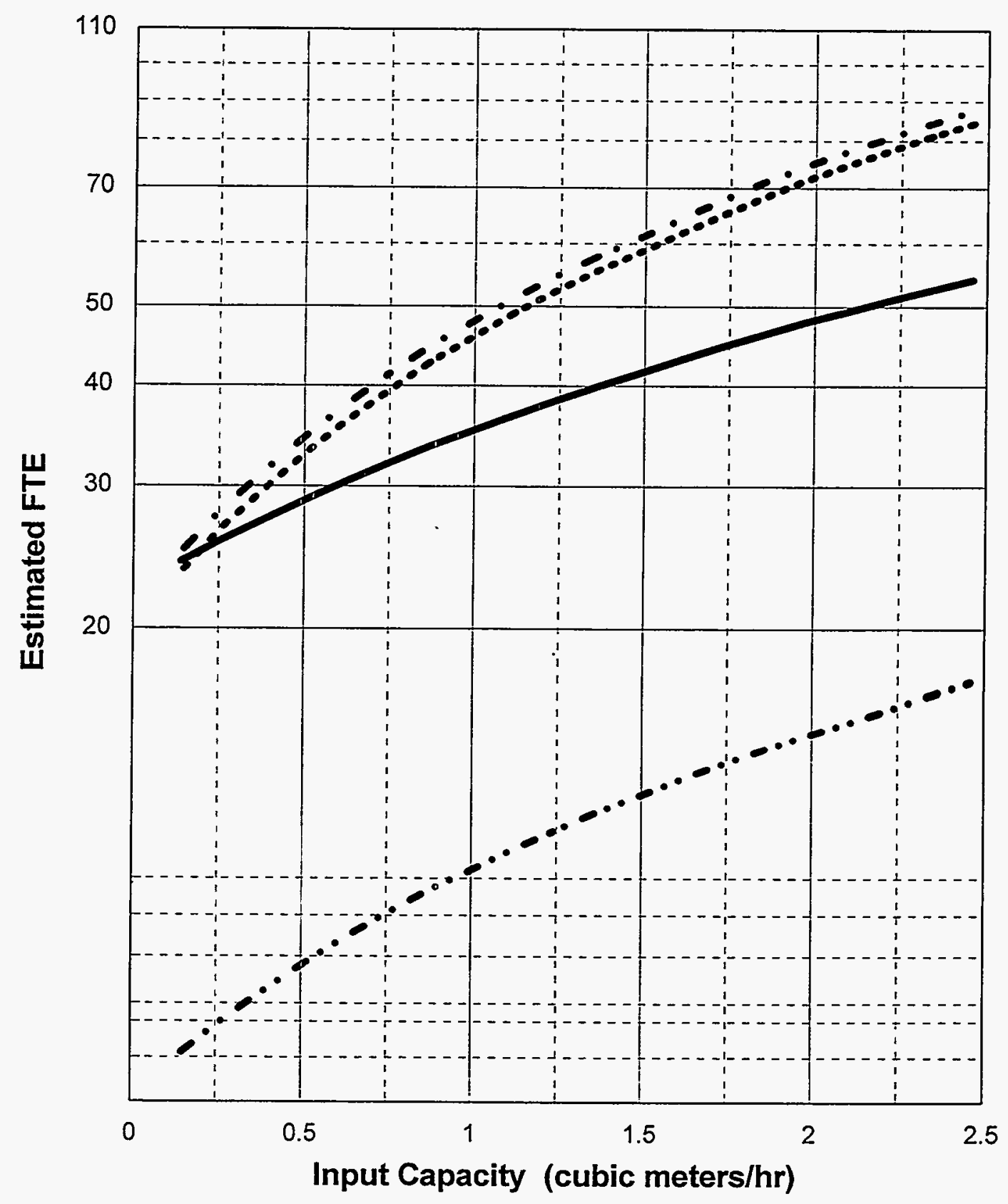

Pre-Operations Construction O\&M (1year) D\&D - -

Figure 21-1. FTE workers versus capacity for the storage administration (SADMN) module. 


\section{STORAGE ADMINISTRATION}

Costs by Work Breakdown Structure Element

Module: SADMN Waste Type: Contact Handled and Remote Handled TRUW

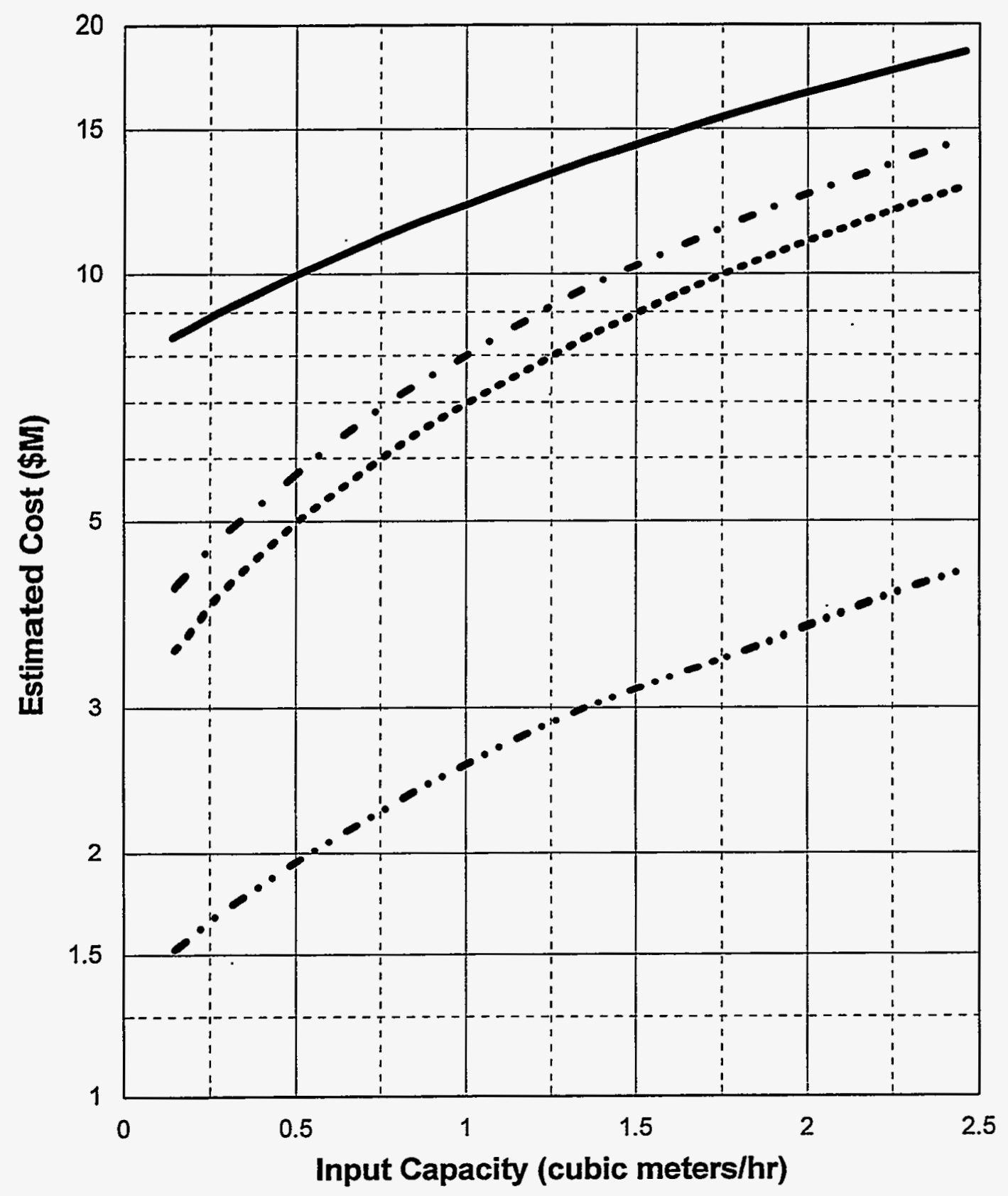

Pre-Operations Construction O\&M (1year) D\&D $\cdots$

Figure 21-2. PLCC versus capacity for the storage administration (SADMN) module. 


\section{STORAGE ADMINISTRATION}

\section{Total Life Cycle Costs}

Module: SADMN Waste Type: Contact Handled and Remote Handled TRUW

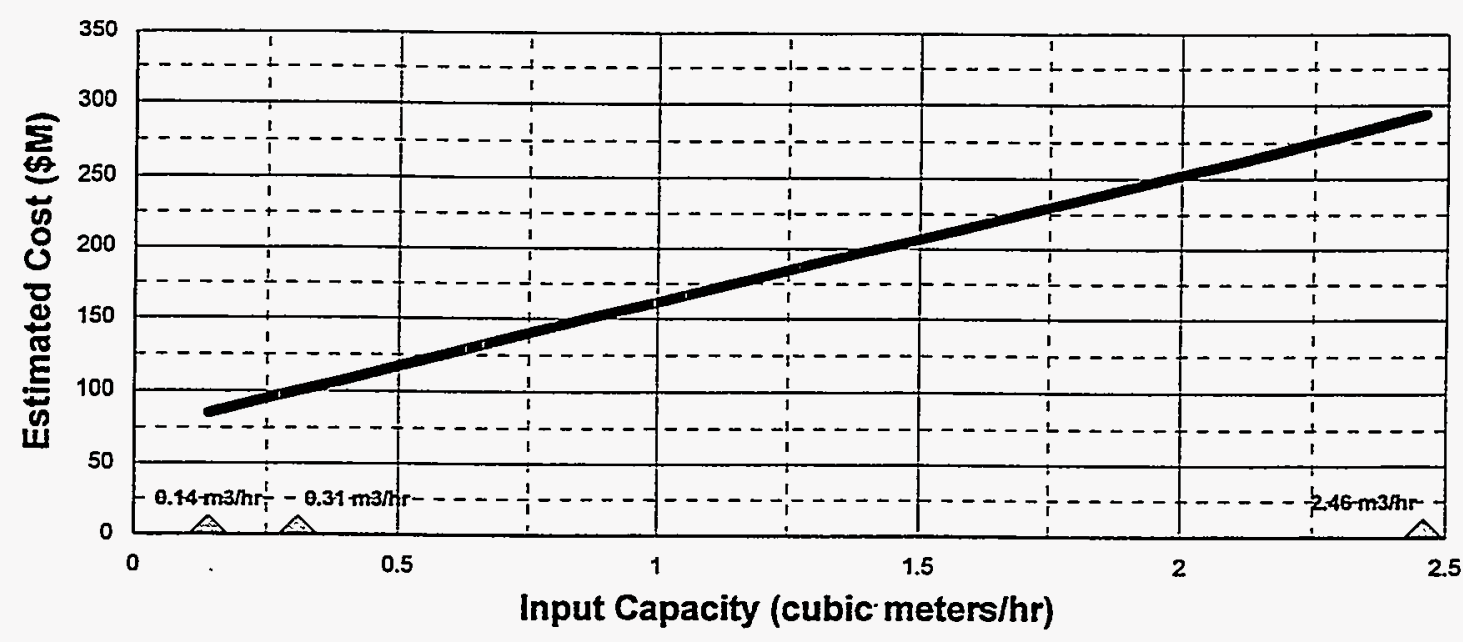

Contact Handled, Remote Handled

NOTE: Basis indudes 20 years O\&M

Triangles indicate capacities where detailed cost estimates were developed.

\section{STORAGE ADMINISTRATION}

Total Life Cycle Unit Costs

Module: SADMN Waste Type: Contact Handled and Remote Handled TRUW

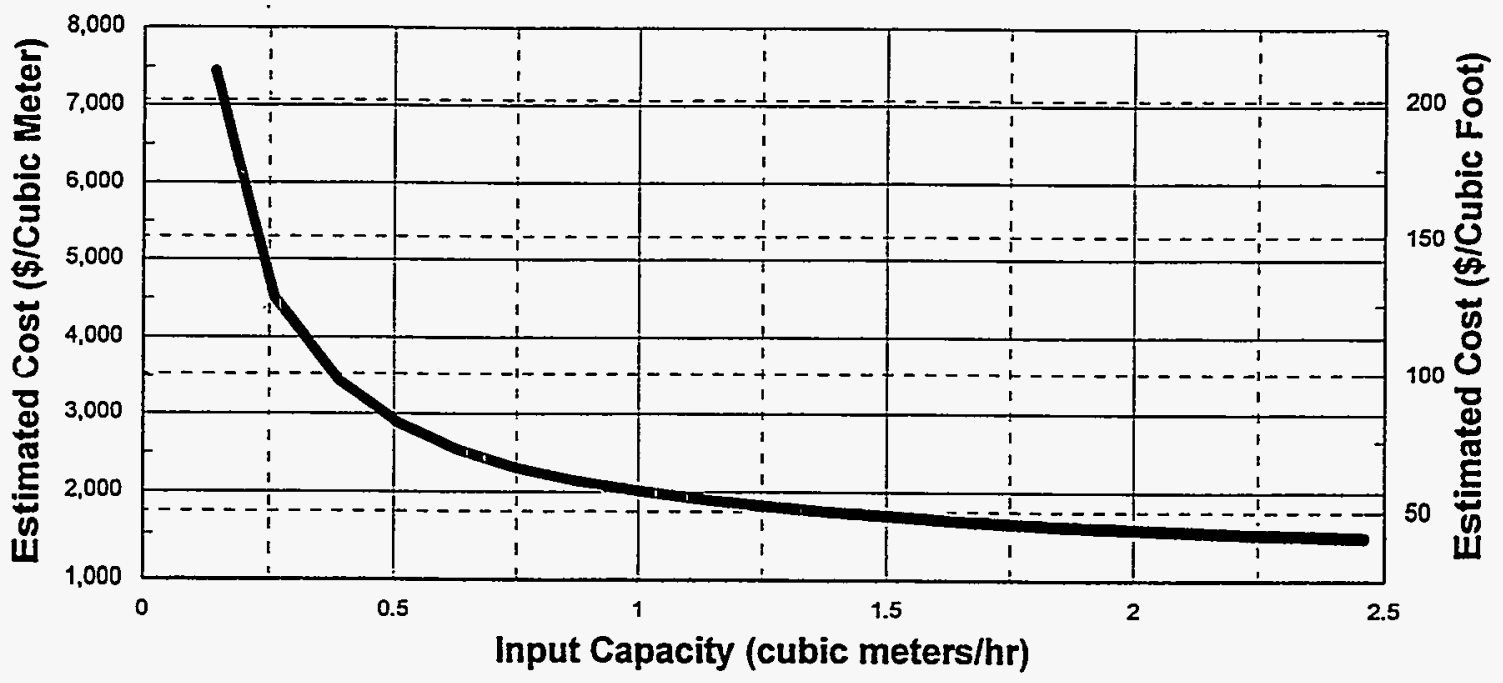

Contact Handled, Remote Handled

NOTE: Basis incudes 20 years O\&M

Figure 21-3. PLCC versus capacity including unit rates for the storage administration (SADMN) module. 


\section{STORAGE RECEIVING AND SHIPPING (MODULE SRCSH)}

\subsection{Basic Information}

The storage receiving and shipping module is used in conjunction with the storage (STORE) module and supplies all the necessary accommodations for receiving truck shipments, unloading containers, transporting containers to the storage, and the reverse operations, as needed, for shipping containers out of the storage facility.

\subsection{Technical Bases and Assumptions}

\subsubsection{Function and Operation of the Module}

Containers arrive on a transport vehicle and are unloaded using a forklift or overhead bridge crane, and placed in a staging area. The containers are visually examined, labeled, logged, recorded, and transported for inspection and assay. At the inspection and assay operation, the category of the received waste is verified against the results obtained from the back-end treatment module. After inspection, the containers are moved to a storage area. The module is also used for shipping and loading containers that are ready for transport to disposal modules. The loading and shipping operations are the reverse of receiving and unloading steps.

The technical bases and requirements for the storage receiving and shipping module are the same as those outlined in the treatment receiving and inspection, and shipping and certification modules, except that the assay, inspection, and certification functions are for verification purposes only. In addition, the storage receiving and shipping module is equipped with a computer inventory system that tracks the incoming and outgoing waste, as well as types of sampling and analysis that may be performed at the staging area (nondestructive).

\subsubsection{Integration of the Module}

Module input includes vehicles that carry waste from the treatment module or forklift trucks that carry waste containers from storage areas (module STORE). Module output is containerized TRUW, which is transferred to the storage bays or loaded onto trucks in containers for transport to disposal sites.

\subsection{Cost Bases, Assumptions, and Results}

Major equipment capital cost items for this module are the equipment and overhead bridge crane. The crane cost is estimated based on vendor quotes. Table 22-1 lists plan dimensions of the storage receiving and shipping module. Estimated FTEs and cost versus capacity for this module are shown in Figures 22-1 through 22-3. 
Table 22-1. Plan dimensions of storage receiving and shipping module (SRCSH).

\begin{tabular}{|c|c|c|c|c|c|}
\hline \multirow[b]{2}{*}{ Module size } & & \multicolumn{2}{|c|}{$\begin{array}{c}\text { Dimensions } \\
\text { (ft) }\end{array}$} & \multicolumn{2}{|c|}{$\begin{array}{c}\text { Dimensions } \\
(\mathrm{m})\end{array}$} \\
\hline & & Length & Width & Length & Width \\
\hline \multicolumn{6}{|c|}{ Large generator } \\
\hline & Small & 40.9 & 19.5 & 12.5 & 5.9 \\
\hline & Medium & 37.8 & 36.6 & 11.5 & 11.1 \\
\hline & Large & 73.2 & 42.4 & 22.3 & 12.9 \\
\hline
\end{tabular}




\section{STORAGE RECEIVING AND SHIPPING}

FTE by Work Breakdown Structure Element Module: SRCSH Waste Type: Contact Handled and Remote Handled TRUW

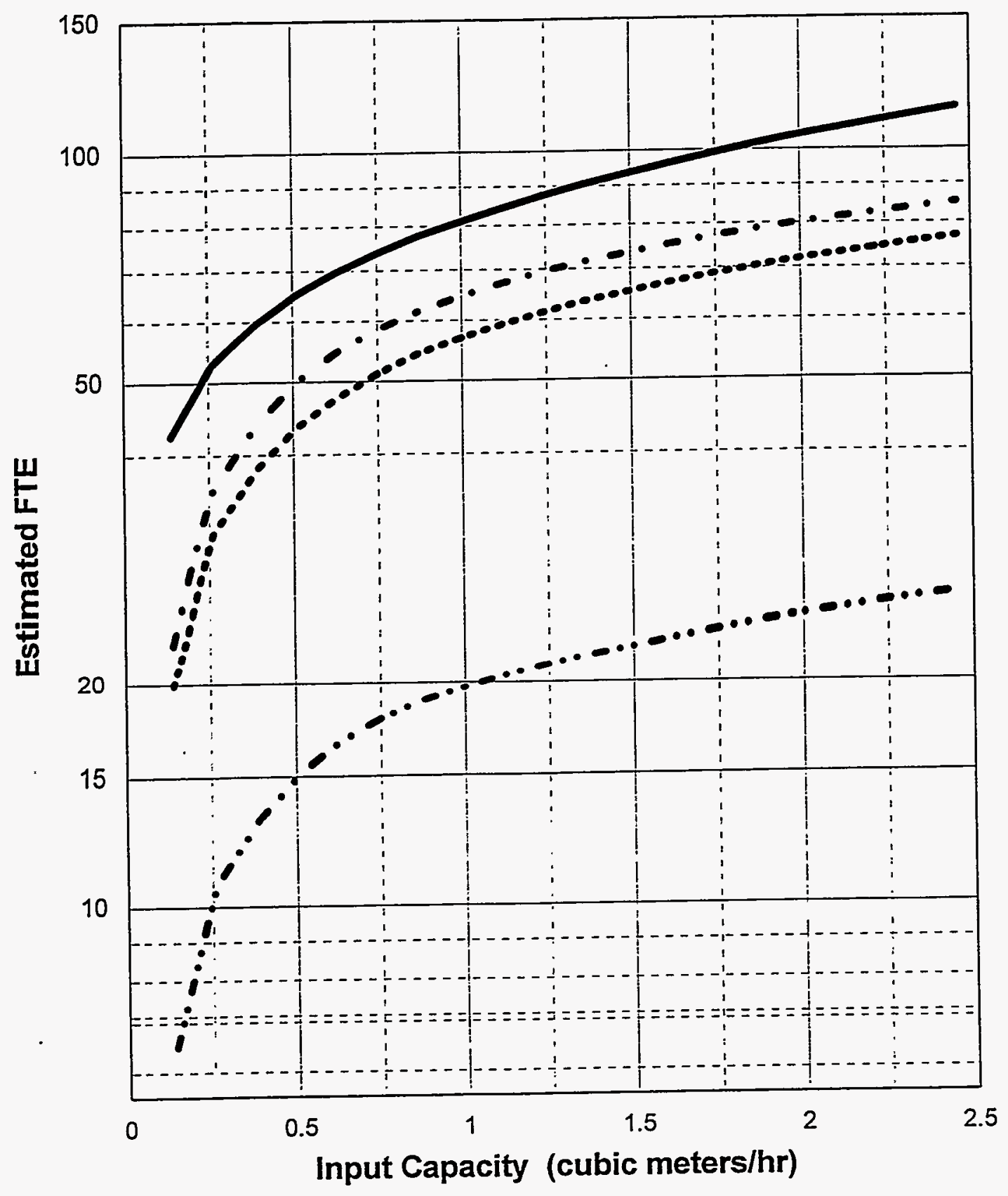

Pre-Operations Construction O\&M (1year) D\&D

Figure 22-1. FTE workers versus capacity for the storage receiving and shipping (SRCSH) module. 


\section{STORAGE RECEIVING AND SHIPPING}

Costs by Work Breakdown Structure Element

Module: SRCSH Waste Type: Contact Handled and Remote Handled TRUW

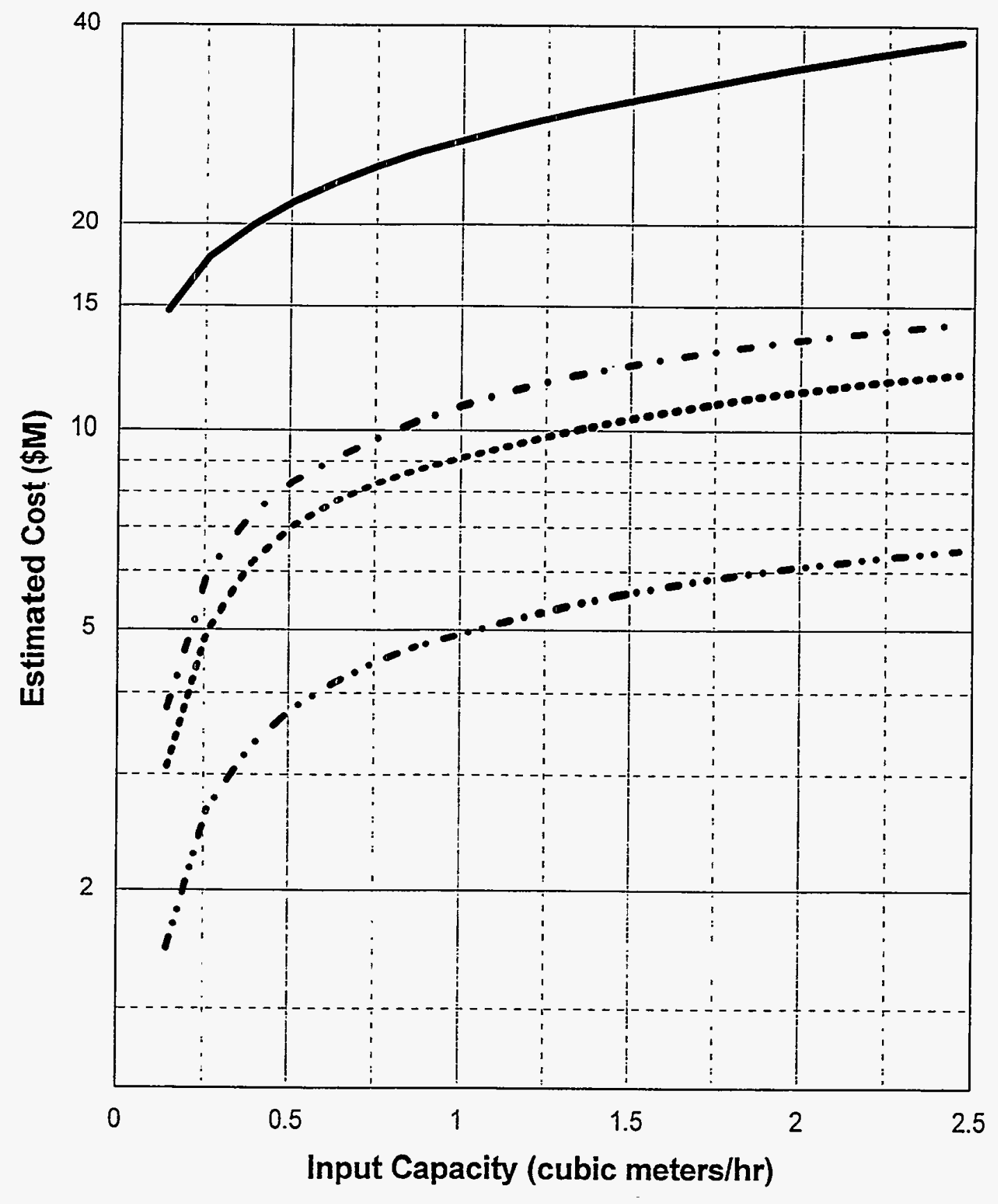

Pre-Operations Construction O\&M (1year) D\&D

Figure 22-2. PLCC versus capacity for the storage receiving and shipping (SRCSH) module. 


\section{STORAGE RECEIVING AND SHIPPING}

Total Life Cycle Costs

Module: SRCSH Waste Type: Contact Handled and Remote Handled TRUW

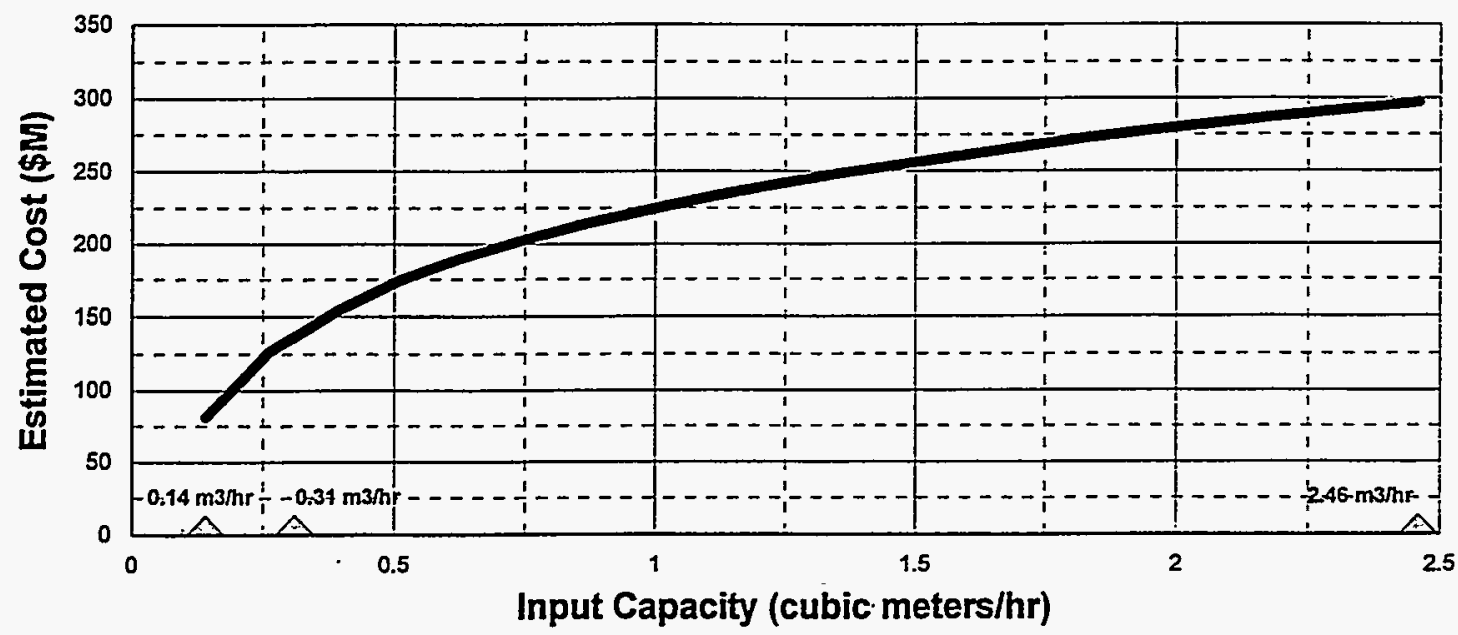

Contact Handled, Remote Handled

NOTE: Basis includes 20 years O\&M

Triangles indicate capacities where detailed cost estimates were developed.

\section{STORAGE RECEIVING AND SHIPPING}

Total Life Cycle Unit Costs

Module: SRCSH Waste Type: Contact Handled and Remote Handled TRUW

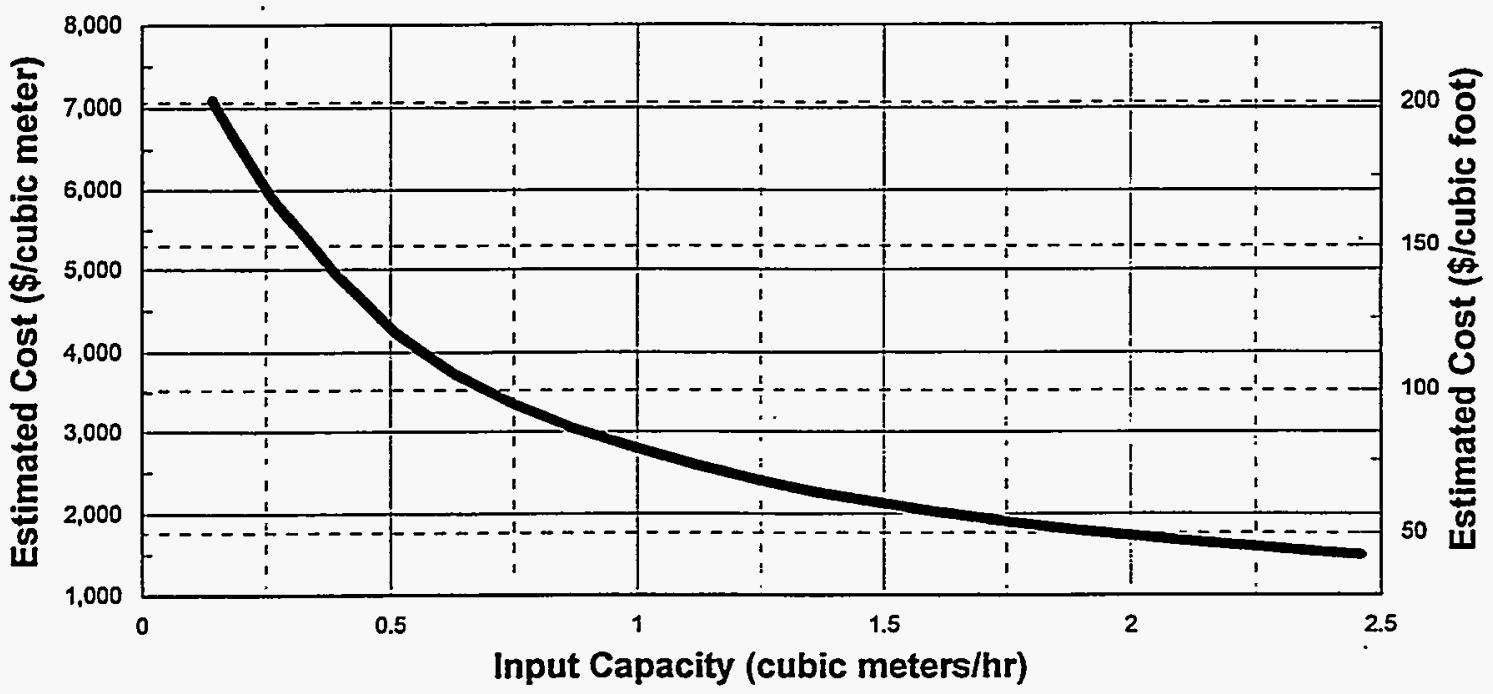

Contact Handled, Remote Handled

Figure 22-3. PLCC versus capacity plus unit rates for the storage receiving and shipping (SRCSH) module. 


\section{SILO STORAGE (MODULE STOSI)}

\subsection{Basic Information}

The silo storage module shown in Figure 23-1, is used in conjunction with the storage administration module and storage receiving and shipping module of the TRUW storage facilities. In addition, the facility can accept packaged waste from generators or other sources. The facility receives RH-TRUW in metal drums and holds them in a shielded storage silo for long-term storage. The unit operations that accomplish these functions are shown in the PFD in Figure 23-2.

\subsection{Technical Bases and Assumptions}

\subsubsection{Function and Operation of the Module}

A transport vehicle brings drums loaded in a radiation shielding cask to the storage yard where prefabricated storage silos are located. The designated storage silo is prepared in advance to accept the drums.

At the storage yard, an unload and stage unit operation receives and inspects the transportation vehicle and shield cask and removes the cask cover. Using remote-handling techniques, the TRUW drum is transferred from the transportation cask to a storage pallet. When a drum removal operation is completed, the pallet is remotely placed inside the silo. The empty cask and trailer is then inspected, the cask lid attached, and the trailer is transported either to the parking area or back to the treatment facility.

The vault safely stores the drums for the desired period. A monitoring unit operation continuously monitors the storage confinement system and drum leakage. It will be able to determine. when corrective action needs to be taken to maintain safe storage conditions.

Operation steps for shipment of the drums out of the storage facility are the reverse of the incoming drum operation steps discussed above. The storage facility does not generate secondary waste.

\subsubsection{Integration of the Module}

This module interfaces directly with the TRUW storage administration (SADMN) module; the TRUW storage receiving and shipping (SRCSH) module; and the waste generator facilities. Operations and maintenance consumables, including personal protective equipment, must be purchased. Facility input is the incoming TRUW drums in casks mounted on transport devices. The output is the same as the input. The facility includes security fence, monitoring, and security and access control features. 


\subsection{Cost Bases, Assumptions and Results}

Each storage silo holds 16 drums in four pallets. It is assumed that prefabricated silos will be a complete package supplied by vendors. Hence, design cost is estimated at $6 \%$ of the silo construction costs. Inspection cost is $2 \%$. Decommissioning costs are estimated at $\$ 1,500$ per fabricated concrete silo. Estimated FTEs and cost versus capacity for this module are shown in Figures 23-3 through 23-5. 

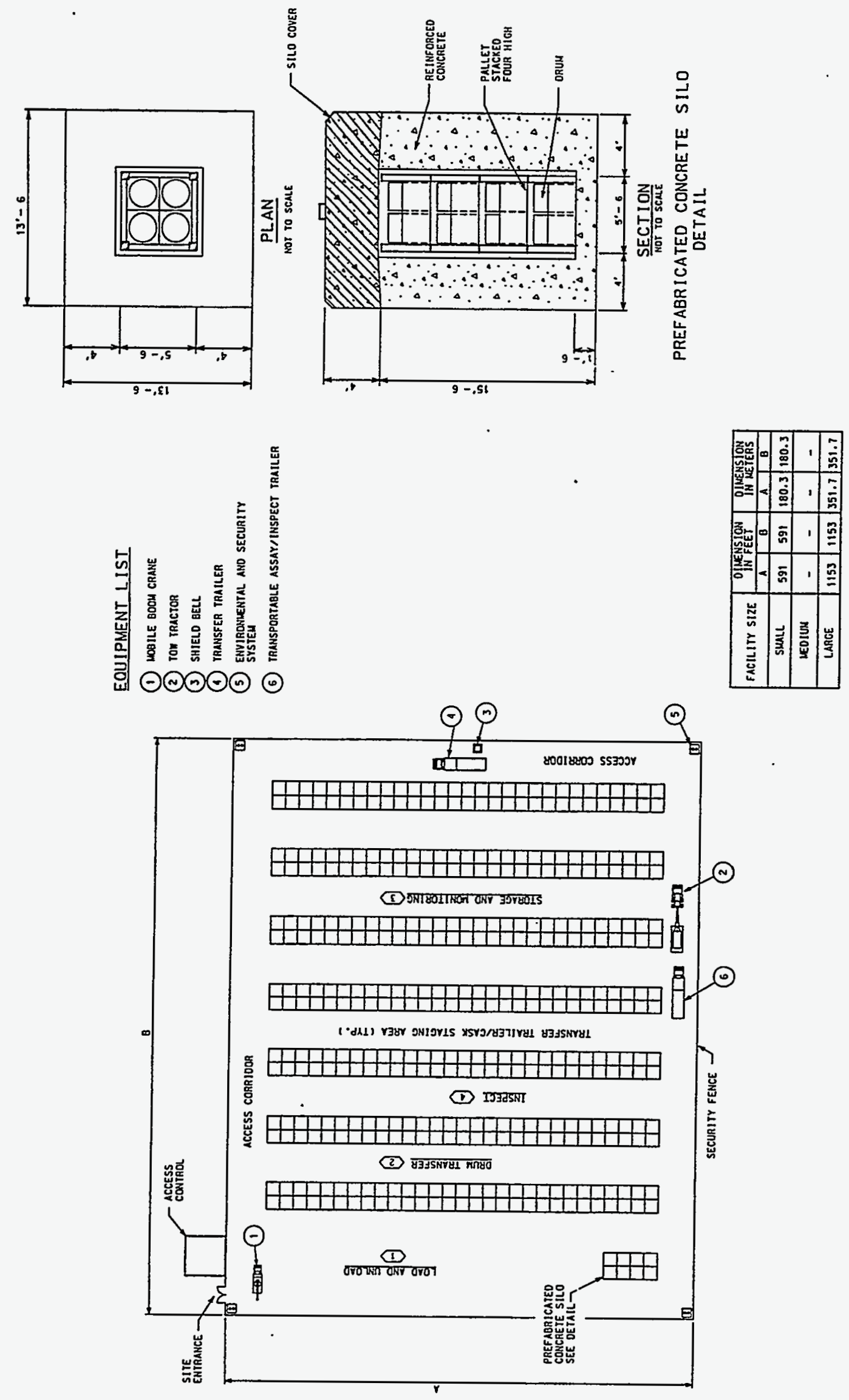

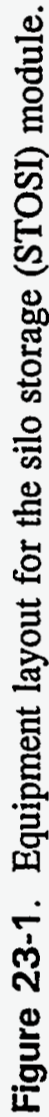




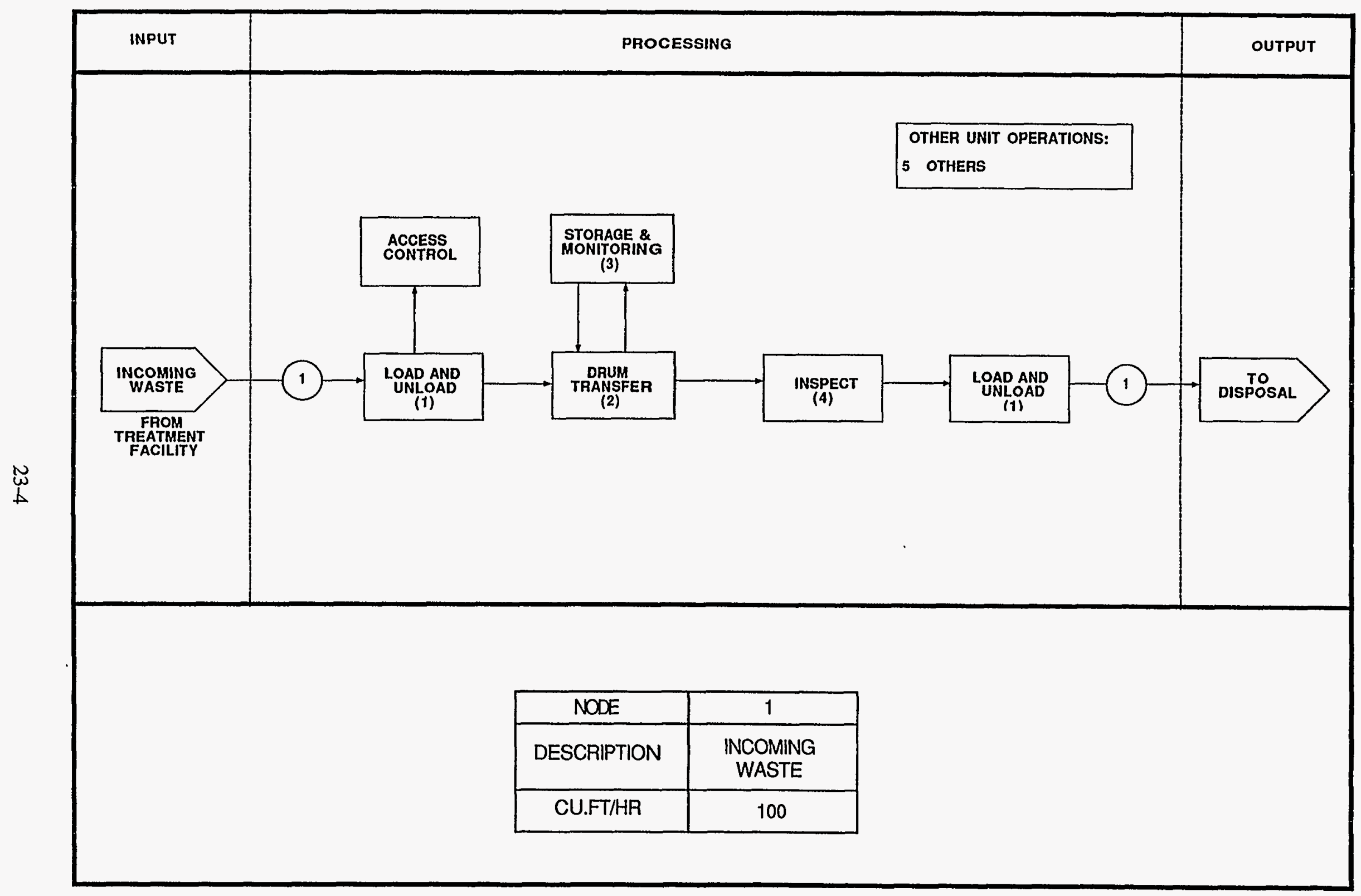

Figure 23-2. Process flow diagram for the silo storage (STOSI) module. 


\section{SILO STORAGE}

FTE by Work Breakdown Structure Element Module: STOSI Waste Type: Contact Handled and Remote Handled TRUW

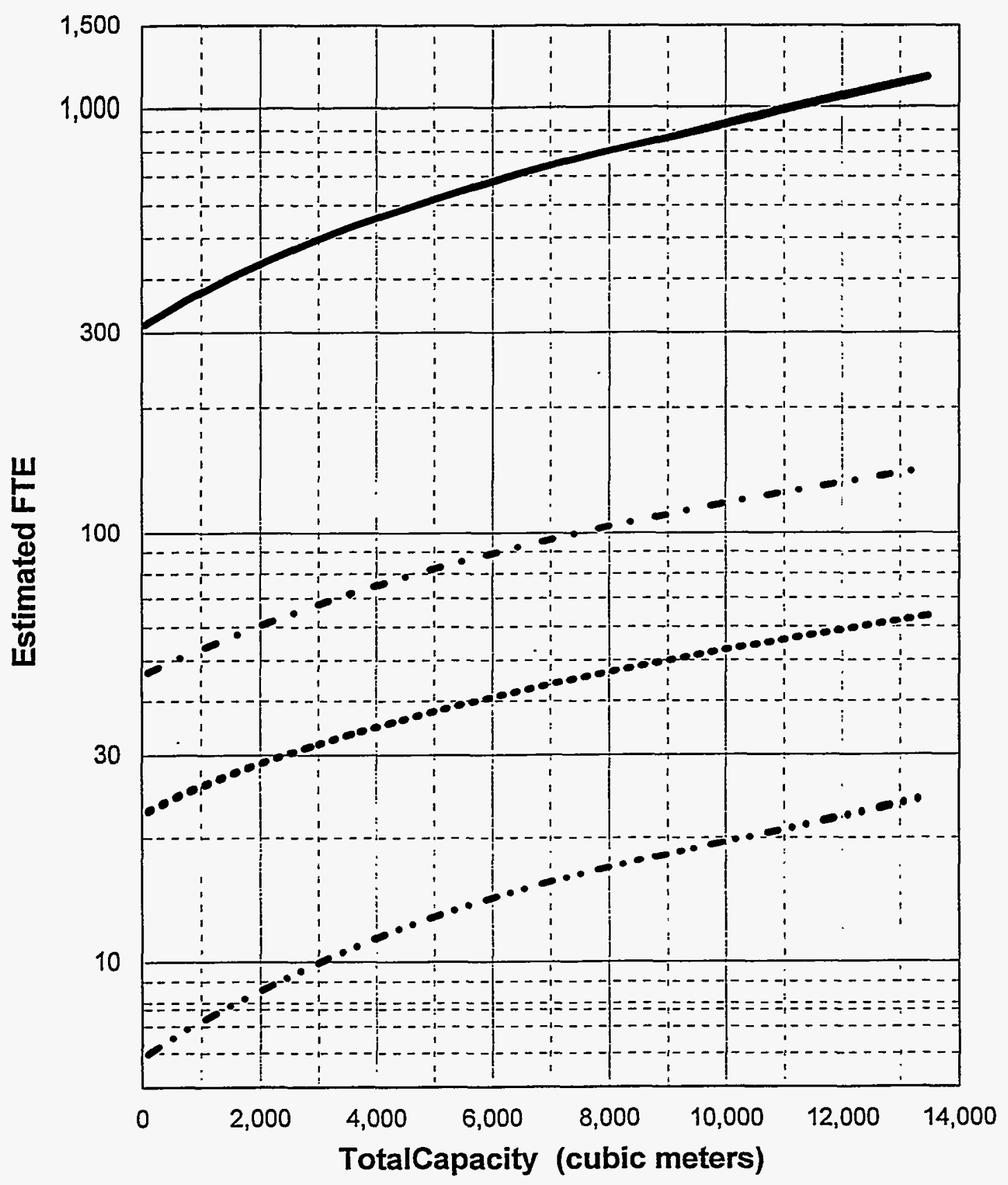

Pre-Operations Construction O\&M (1year) D\&D

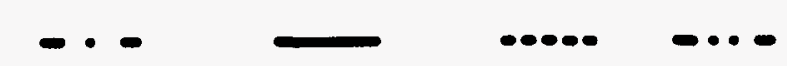

Figure 23-3. FTE workers versus capacity for the silo storage (STOSI) module. 


\section{SILO STORAGE}

Costs by Work Breakdown Structure Element

Module: STOSI Waste Type: Contact Handled and Remote Handled TRUW

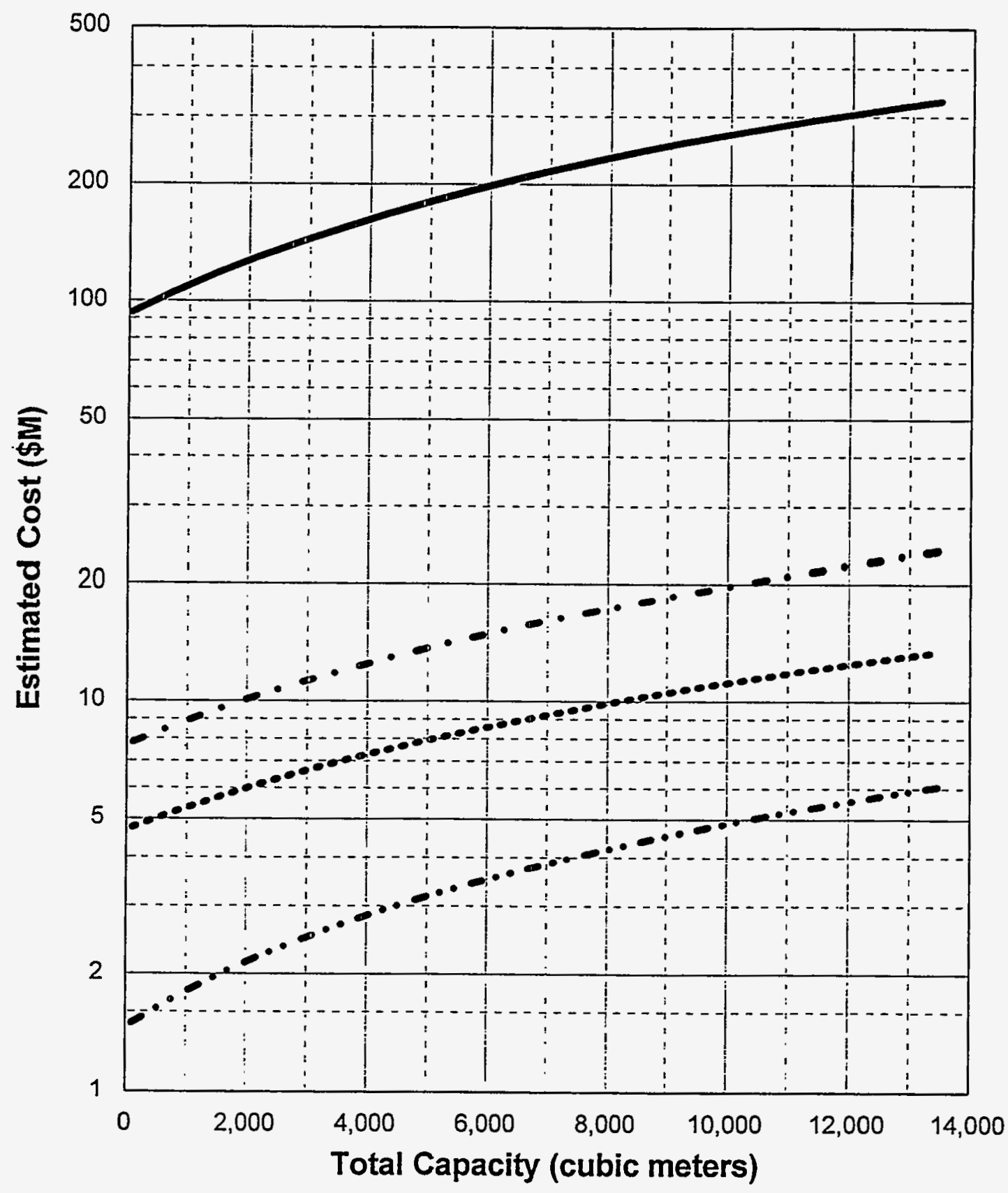

Pre-Operations Construction O\&M (1year) D\&D

Figure 23-4. PLCC versus capacity for the silo storage (STOSI) module. 


\section{SILO STORAGE}

Total Life Cycle Costs

Module: STOSI Waste Type: Contact Handled and Remote Handle TRUW

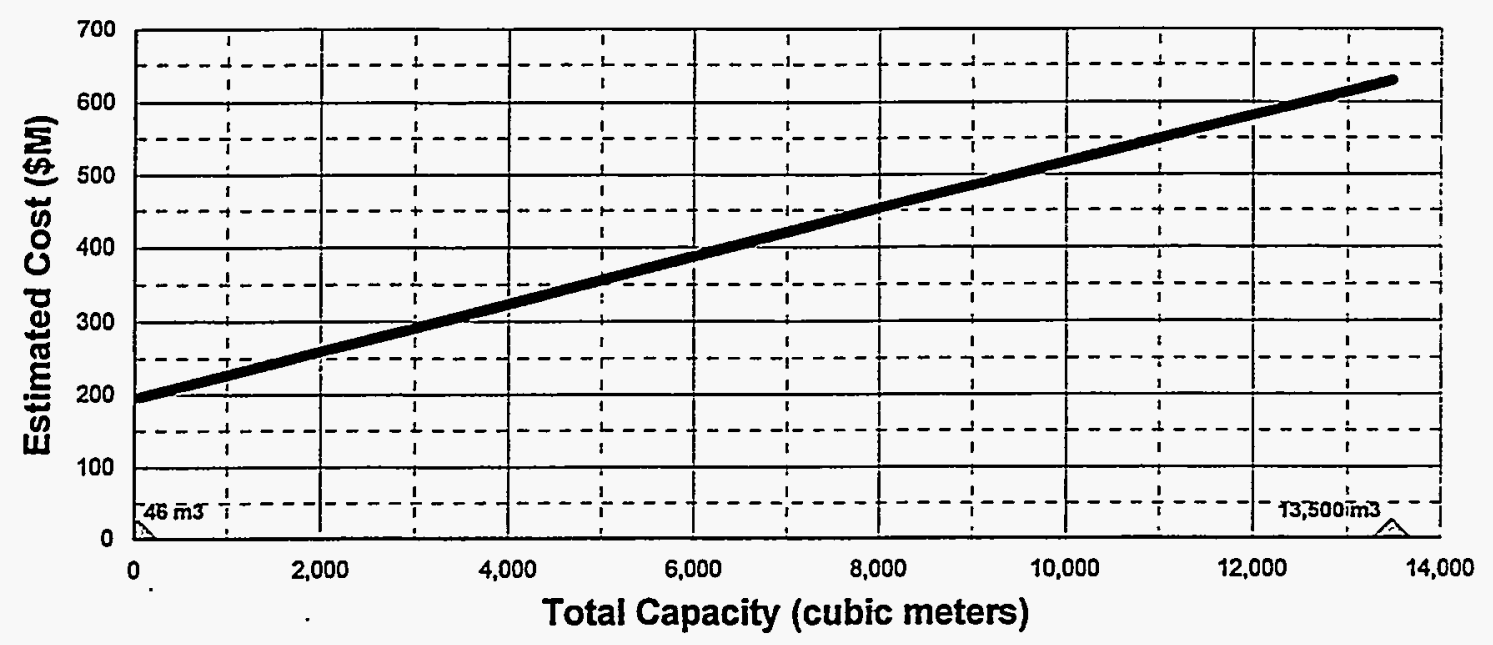

Contact Handled, Remote Handled

NOTE: Basis indudes 20 years O\&M

Triangles indicate capacities where detailed cost estimates were developed.

\section{SILO STORAGE}

Total Life Cycle Unit Costs

Module: STOSI Waste Type: Contact Handled and Remote Handled TRUW

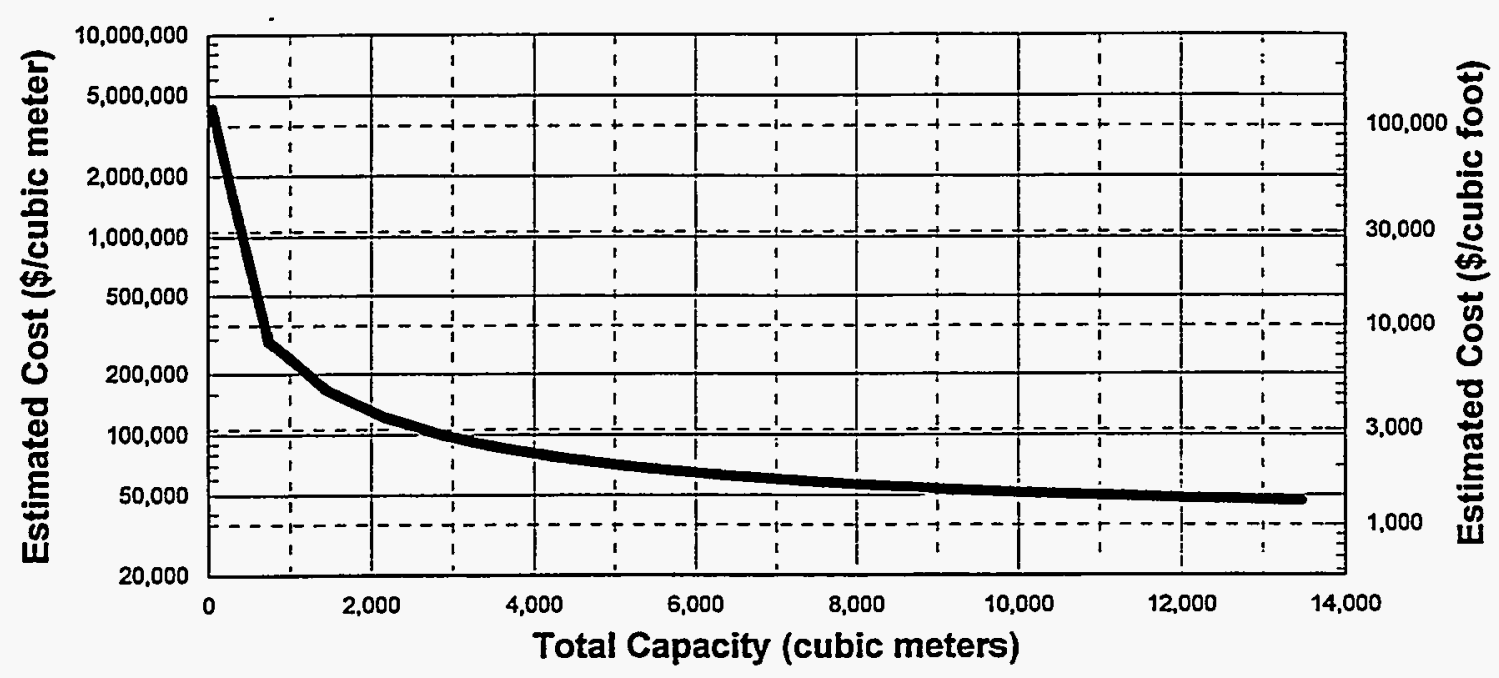

Contact Handled, Remote Handled Remote Handled

NOTE: Basis includes 20 years O\&M

Figure 23-5. PLCC versus capacity including unit rates for the silo storage (STOSI) module. 


\section{STORAGE (MODULE STORE)}

\subsection{Basic Information}

Module STORE is intended for CH-TRUW only. The storage module (Figure 24-1) consists of three unit operations. Waste that arrives from receiving and shipping module is stored at a specified location. The module is equipped with a cleanup unit operation for responding to potential spills. The module also has permanent monitoring capabilities to ensure the integrity of the stored waste containers. The module should be used in conjunction with the storage administration (SADMN) and storage receiving and shipping (SRCSH) modules, or as an addition to an existing facility where similar functions are already available.

\subsection{Technical Bases and Assumptions}

\subsubsection{Function and Operation of the Module}

The storage areas include features, such as spill collection and a combination of sloping floors and sumps, that achieve compliance with the storage requirements of RCRA. Designated storage areas are separated by 6-in.-high (minimum) concrete berms that extend the length of the storage bays. In bays located along the outside walls, floors slope to the rear of the module. Floors in the remainder of the bays are sloped to the center. Area monitors are included for both gamma and alpha radiation control.

\subsubsection{Integration of the Module}

Module interfaces include packaged waste to and from the staging or assay and inspection area at the storage administration (SADMN) and storage receiving and shipping (SRCSH) modules.

\subsection{Cost Bases, Assumptions and Results}

The storage capacity has been sized to handle an accumulation of up to 20 years worth of waste input from treatment modules. This module includes no major equipment capital cost items. The storage building is the only major (cost) element, which in turn, depends on the size of the facility. Accordingly, a preconceptual design of the storage building with concrete walls and concrete roof was developed for several module sizes. These designs were used to generate an estimate. Estimated FTEs and cost versus capacity for this module are shown in Figures 24-2 through 24-4. 


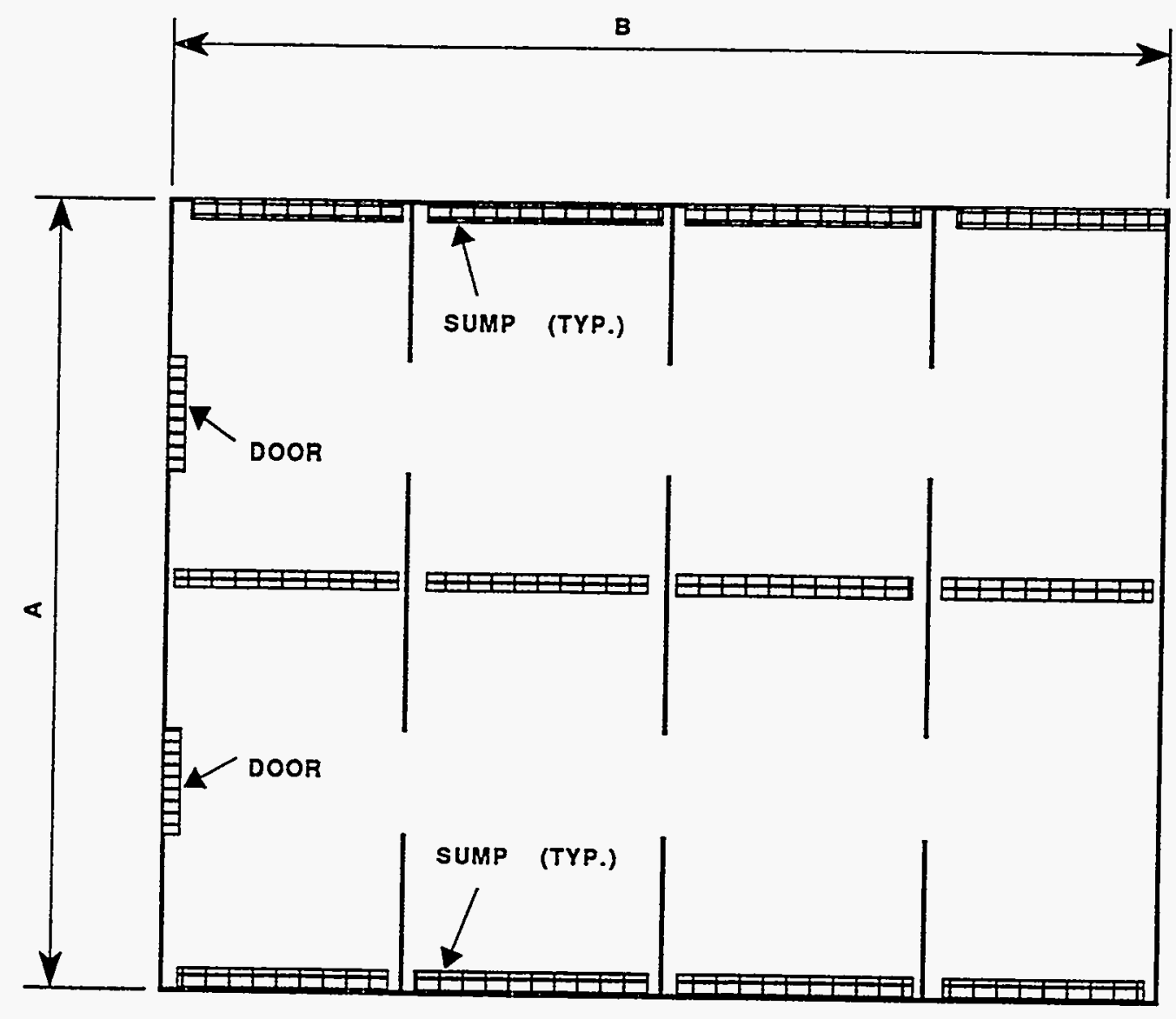

\begin{tabular}{|c|c|c|c|c|c|}
\hline \multirow{2}{*}{\multicolumn{2}{|c|}{ FACIUTYSLE }} & \multicolumn{2}{|c|}{ DMENSIONNFEET } & \multicolumn{2}{|c|}{ DMMENSION N METERS } \\
\hline & & A & B & A & B \\
\hline \multirow{3}{*}{ 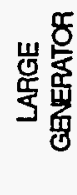 } & SMALL & 64 & 155 & 19.51 & 47.26 \\
\hline & MEQUM & 120 & 157 & 36.58 & 47.86 \\
\hline & LARGE & 240 & 446 & 73.17 & 135.97 \\
\hline 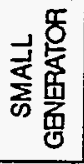 & MINIMLM & -- & -- & - & - \\
\hline
\end{tabular}

Figure 24-1. Equipment layout for the storage (STORE) module. 


\section{STORAGE}

FTE by Work Breakdown Structure Element Module: STORE Waste Type: Contact Handled TRUW

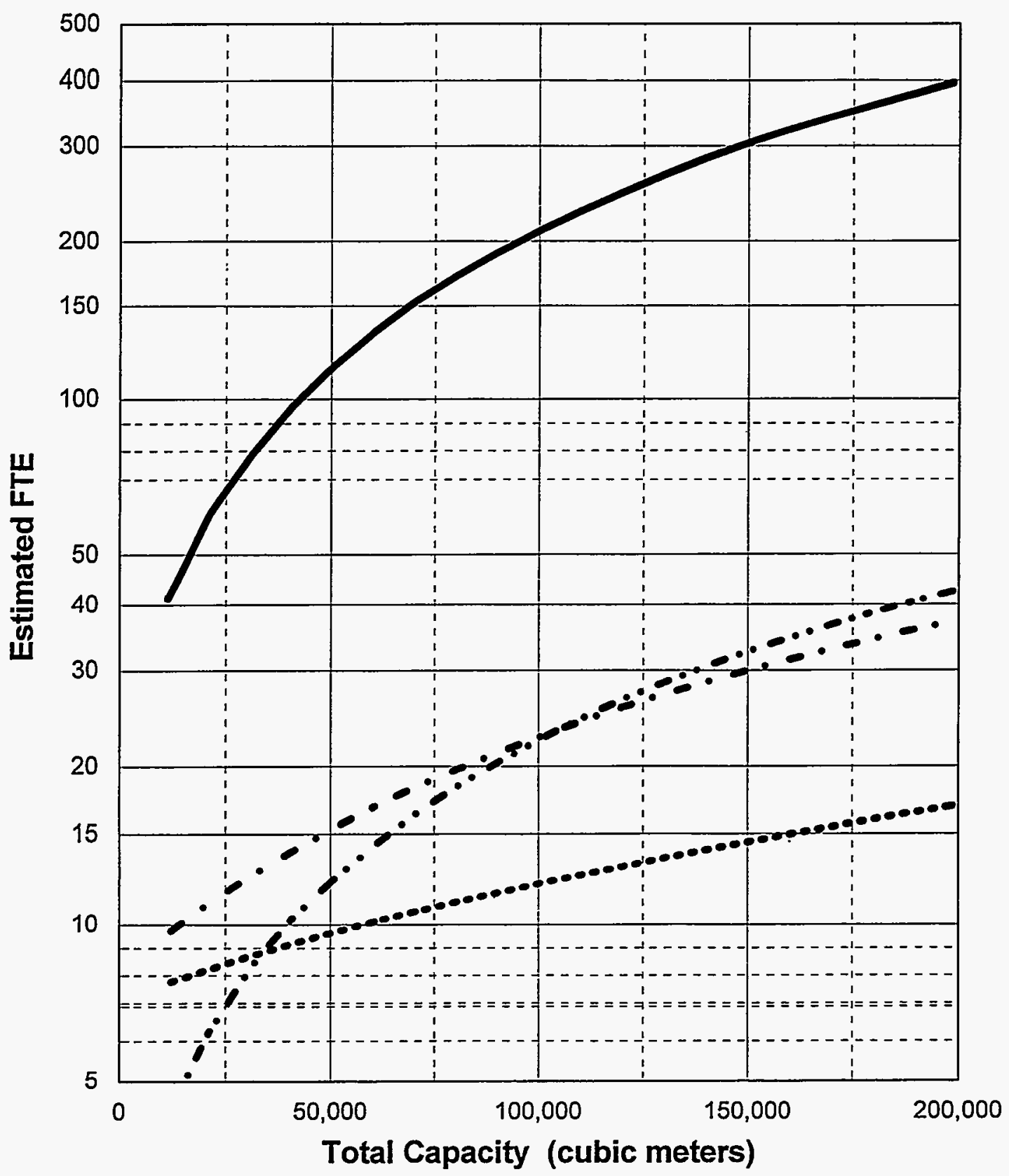

Pre-Operations Construction O\&M (1year) D\&D

Figure 24-2. FTE workers versus capacity for the CH storage (T-STORE) module. 


\section{STORAGE}

Costs by Work Breakdown Structure Element Module: STORE Waste Type: Contact Handled TRUW

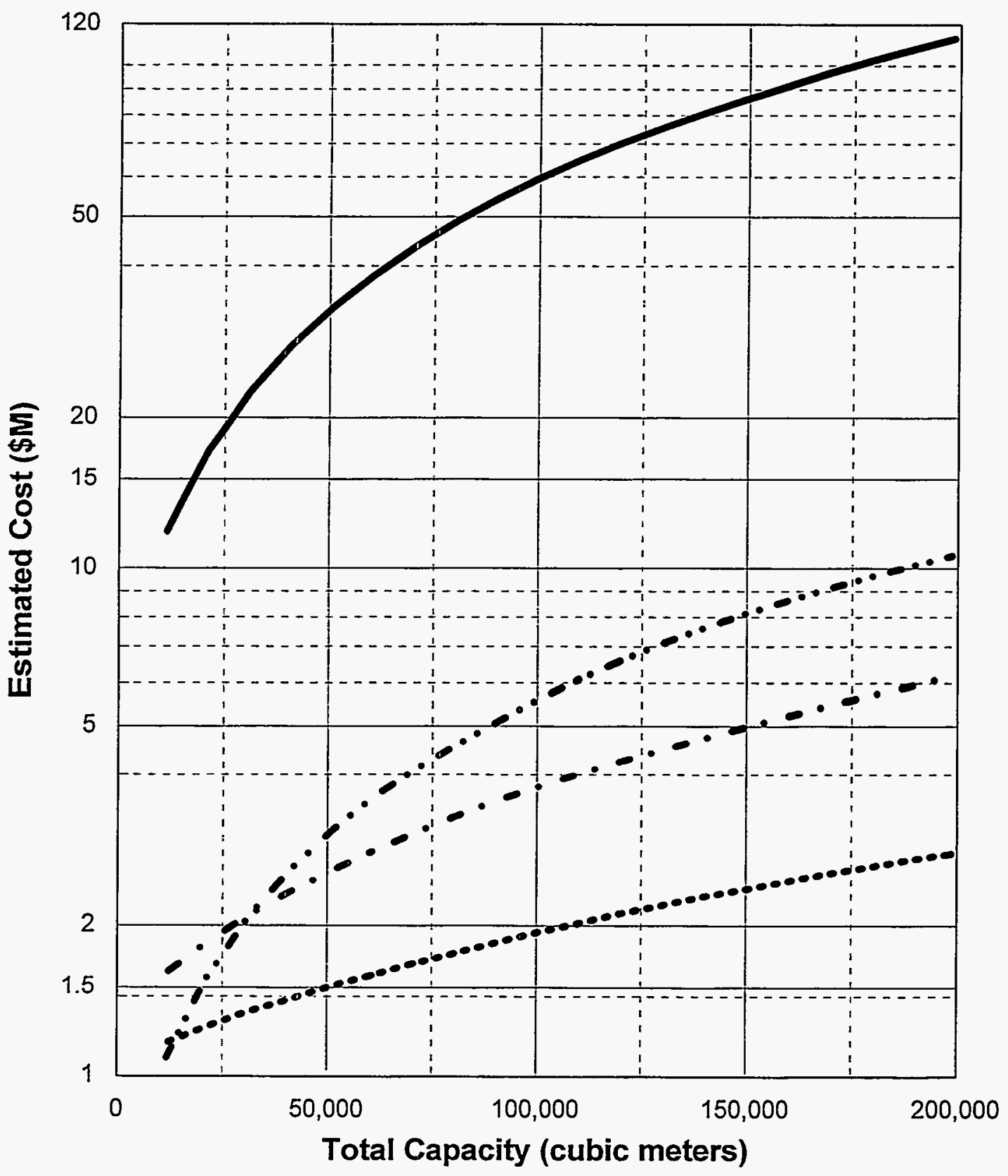

Pre-Operations Construction O\&M (1year) D\&D

Figure 24-3. PLCC versus capacity for the CH storage (T-STORE) module. 


\section{STORAGE}

Total Life Cycle Costs

Module: STORE Waste Type: Contact Handled TRUW

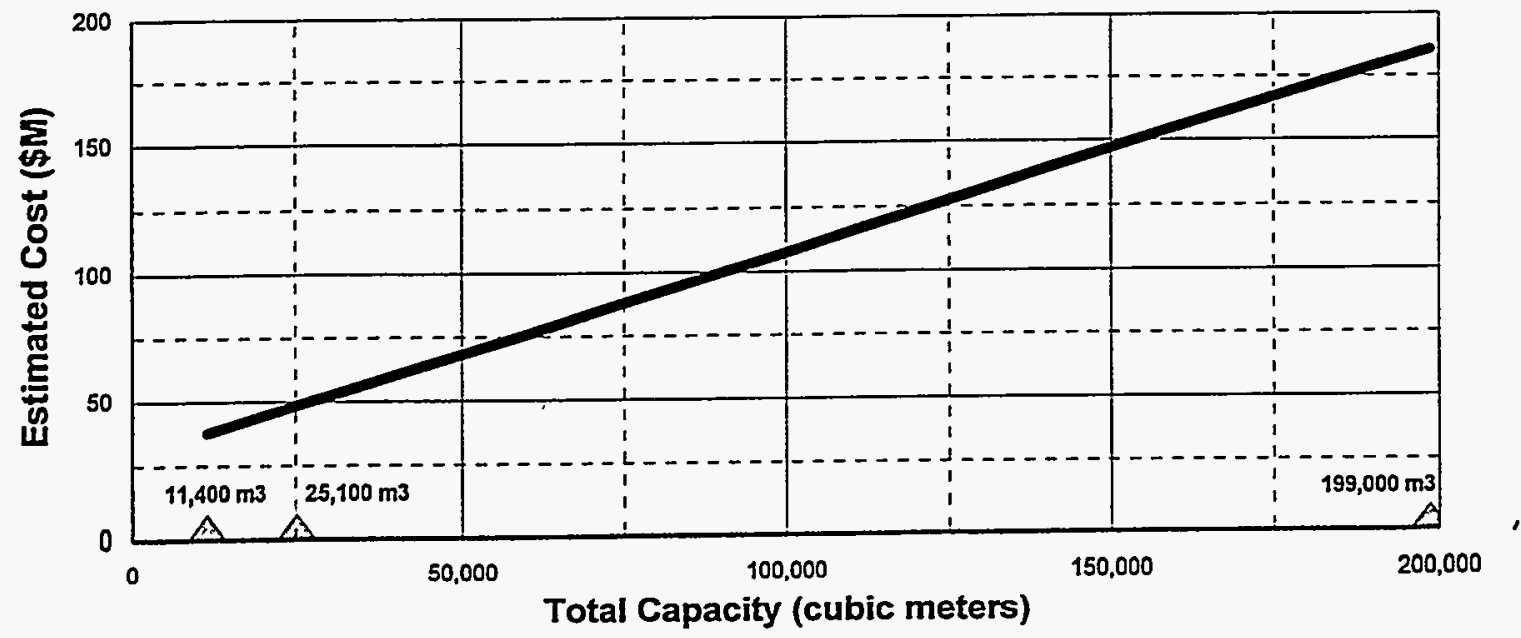

Contact Handled

NOTE: Basis includes 20 years O\&M

Triangles indicate capacities where detailed cost estimates were developed.

\section{STORAGE}

Total Life Cycle Unit Costs

Module: STORE Waste Type: Contact Handled TRUW

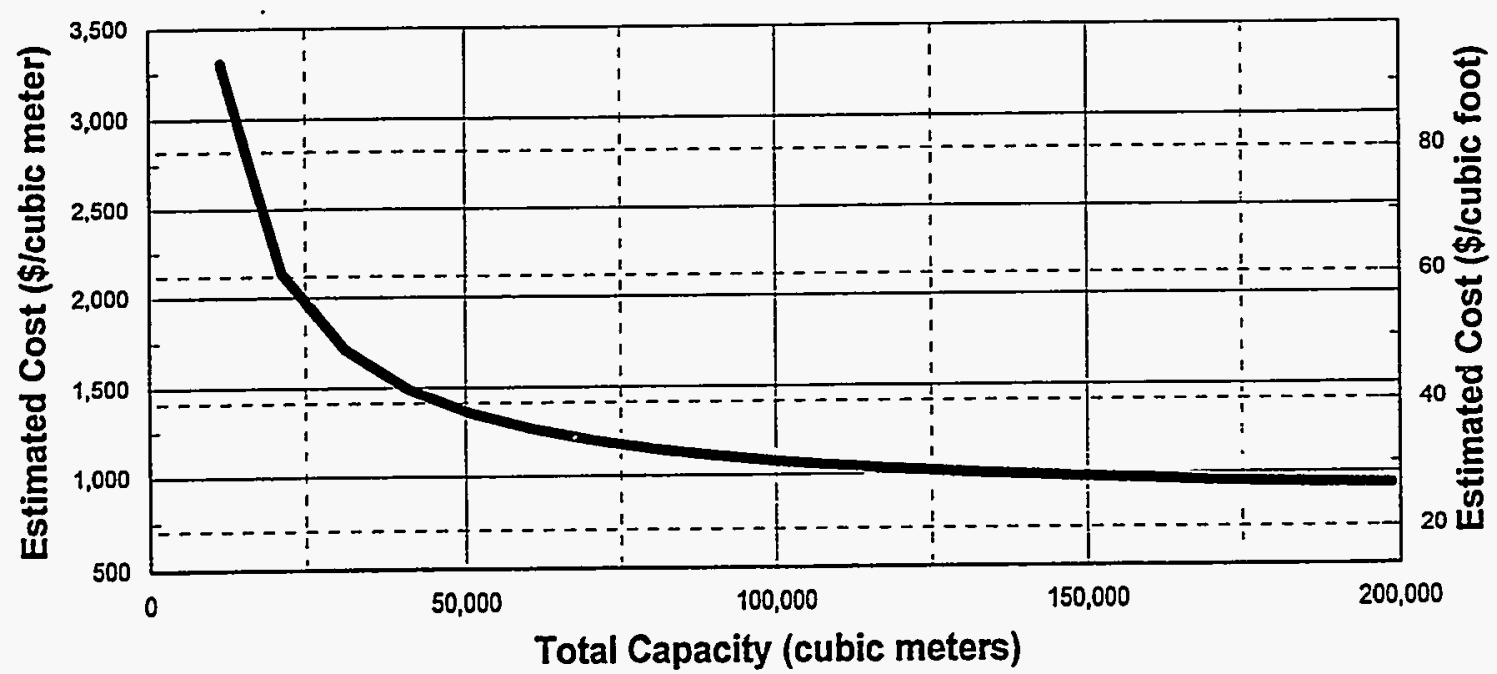

Contact Handled

NOTE: Basis includes 20 years O\&M

Figure 24-4. PLCC versus capacity including unit rates for the storage (STORE) module. 


\section{COST ESTIMATION PROCEDURE}

\subsection{Overview}

Thus far, this report has described how the costs and FTEs of the various TRUW modules were estimated. These costs and FTEs were estimated over a wide range of input capacities. These data were used to define cost and FTE versus capacity relationships for large generator modules, represented by curves on a graph. For the portable module, tables present cost and FTE data for a single capacity. The data in these tables are applicable to a limited capacity range of the lowest end of the given treatment module. From either a curve or a table, one can estimate the costs and FTEs of a module given its capacity. From a group of such curves and tables, one can estimate the FTEs and costs for treating, storing, and disposing of any combination of CH- and RH-TRUW. A combination of modules that treats, stores, and disposes of a given inventory of waste is referred to as a treatment scenario.

Figure 25-1 shows how modules can be combined to create a treatment facility based on Waste Isolation Pilot Plant (WIPP) waste acceptance criteria (WAC) requirements. Figure 25-2 shows a flow sheet of an integrated facility based on the current WIPP WAC treatment requirements, with the exception that features have been added to minimize generation of hydrogen gas during the long-term disposal. Figure 25-3 shows a flow sheet of a RCRA compliance integrated facility; Figure 25-4 shows a flow sheet of an integrated facility based on a vitrified waste form.

The cost estimation procedure has been developed to allow the reader to estimate the total cost of a scenario for treating, storing, and disposing this waste. The cost estimation procedure essentially consists of three major steps: (a) waste loads definition, (b) estimating TRUW facility costs and FTEs, and (c) transportation costs. These are discussed in the following subsections.

\subsection{Waste Loads Definition}

In step one, the waste loads definition, the capacity requirement for each module, is defined. To use the WMFCI and FTE data, the total capacity requirements should be converted into the appropriate processing rate (e.g., $\mathrm{kg} / \mathrm{hr}, \mathrm{m}^{3} / \mathrm{hr}$ ) or total storage capacities (e.g., $\mathrm{m}^{3}$ ) by developing operating assumptions. There are three basic calculations that an estimator may need to use. These calculations are required to establish treatment processing rates, storage input/throughput rates, and storage total volumetric requirements. The basic calculations and examples are as follows:

1. Retrieval, characterization, treatment front-end, and treatment modules. The total unprocessed waste volume $\left(\mathrm{m}^{3}\right)$ can be converted to a treatment input capacity processing rate $(\mathrm{kg} / \mathrm{hr})$ by the following calculations. The total volume in cubic meters $\left(\mathrm{m}^{3}\right)$ is multiplied by the unprocessed waste density $(\mathrm{kg} / \mathrm{hr}$ ) to obtain the total mass in kilograms $(\mathrm{kg})$. This mass is divided by the total hours of facility (module) operations. An example is as follows: $\left(1,000 \mathrm{~m}^{3} \times 1,242 \mathrm{~kg} / \mathrm{m}^{3}\right.$ (density of soil) / (4,032 hours/year $\times 20$ years of operation) $=15.4 \mathrm{~kg} / \mathrm{hr}$ processing rate for 20 years. 
2. Storage administration, storage receiving and shipping, and receiving and inspection modules. The total processed waste $(\mathrm{kg} / \mathrm{hr}) \mathrm{can}$ be converted to a post-treatment storage throughput capacity $\left(\mathrm{m}^{3} / \mathrm{hr}\right)$ by the following calculations. The processed waste rate $(\mathrm{kg} / \mathrm{hr})$ is divided by the processed waste density $\left(\mathrm{kg} / \mathrm{m}^{3}\right)$ to obtain the throughput capacity rate for storage. An example is as follows: $1,000 \mathrm{~kg} / \mathrm{hr} / 2,013 \mathrm{~kg} / \mathrm{m}^{3}$ (density of soils that have been processed and grouted) $=0.50 \mathrm{~m}^{3} / \mathrm{hr}$ storage input/output capacity.

3. Storage modules. The receiving and inspection storage throughput rates $\left(\mathrm{m}^{3} / \mathrm{hr}\right) \mathrm{can}$ be converted into total volumes $\left(\mathrm{m}^{3}\right)$ for storage by the following calculations. The storage input/output capacity is multiplied by the total hours of facility (module) operations. An example is as follows: $\left(0.50 \mathrm{~m}^{3} / \mathrm{hr} \times 4,032\right.$ hours/year $\times 20$ years of operation $)=$ $40,320 \mathrm{~m}^{3}$ total volume for storage.

These calculations should be completed for existing or new facilities. The existing facility capacities are used for estimating O\&M and D\&D costs and FTEs only. New facility capacities are used to define the preoperations, facility construction, O\&M, and D\&D costs, and FTEs.

The three types of modules in the TRUW WMFCI report include: retrieval and characterization, treatment, and storage. Disposal has not been included in the TRUW report. Processing rates (waste loads) for each type of module are described in the following sections.

\subsubsection{Retrieval, Characterization, and Interim Storage Waste Loads}

The retrieval and characterization modules use feed rates as waste load. Both the existing and new facility feed rates must be defined by converting the volumetric data into mass feed rates as explained earlier. Figure 25-5 may be used to document the retrieval, characterization, and interim storage module waste loads.

The stored waste retrieval module is used to exhume waste stored in bermed storage pads. This module should not be applied to waste stored in warehouse buildings.

Waste arriving from retrieval or from the generator may require characterization. The following two types of characterization modules are available in the WMFCI report:

- Receiving and inspection module. This module characterizes the waste by NDE techniques. In this technique, waste is characterized without opening the containers.

- Waste characterization module. This module characterizes waste by physical techniques. Containers are opened, the waste is visually examined, and physical samples of the contents are sent to an analytical laboratory.

It is normally preferred that all waste be characterized by the NDE technique. However, physical techniques will be needed for waste that cannot be characterized by NDE, for containers that have nonconforming waste, or to perform a quality check to verify the NDE characterization results. Hence, physical techniques are performed on a side stream (usually about $10 \%$ to $40 \%$ of the incoming waste) of the input waste. 
After retrieval and characterization, the waste is normally sent to either storage or treatment facilities. Depending on the disposal requirements, some of the waste from the two characterization modules may be sent directly to WIPP.

Four different modules have been included to define the interim storage costs. These include storage administration (administration and laboratory), storage receiving and shipping, storage (CH waste), and silo storage (RH waste). To define the cost for the first two modules (storage administration and storage receiving and shipping), waste volumetric feed rate $\left(\mathrm{m}^{3} / \mathrm{hr}\right.$ ) must be calculated. For the third and fourth modules (storage and silo storage), the total volume of waste to be stored in the facility lifecycle must be calculated.

\subsubsection{Treatment Waste Loads}

Treatment waste loads may be documented in data similar to that shown in Figure 25-6. As shown, the treatment modules are separated into four categories, which are discussed below.

- Treatment front-end modules. To estimate cost and FTEs for the front-end modules, the total processing rate of the treatment facility must be defined. The processing rate of the treatment facility is used to size the treatment front-end modules even though some of the modules (e.g., maintenance module) do not process the input waste per se. There are four front-end modules: treatment administration (analytical laboratory and administration building); receiving and inspection; open, dump and sort; and maintenance modules. The user must define both the existing and new module loads for each of the four modules.

- Primary treatment modules. The total treatment processing rate must be subdivided according to the processing needs. The treatment modules in this report are designed to satisfy the processing needs of 32 waste matrix categories. The waste matrix categories are defined in Kirkpatrick 1995. Primary treatment modules are selected based on the processing requirements and the contaminants present in the waste. Processing rates for each module identified in the treatment train need to be specified.

- Secondary treatment and stabilization modules. The processing rate for the secondary treatment and stabilization modules must be defined by considering two sources. The first source is the input unprocessed waste that bypasses the primary treatment modules. For example, the vitrification module will receive inorganic solids that do not need primary treatment. The second source is the secondary waste from the primary treatment systems. For example, the ash discharged from the incineration module will have to be treated by the vitrification module. The secondary waste generation rates can be determined from the mass balance data depicted on the PFDs.

- Treatment back-end modules. The waste loads for the back-end modules are defined by summing the output waste from the secondary treatment and stabilization modules. There are also some wastes that do not require secondary treatment (e.g., amalgamated waste from the mercury separation module), which must be added to the output from the secondary treatment and stabilization modules. 


\subsubsection{Portable Treatment Waste Loads}

The portable certification and shipping trailer concept is useful for installations requiring an overall processing rate of less than approximately $20 \mathrm{~m}^{3} / \mathrm{yr}\left(706 \mathrm{ft}^{3} / \mathrm{yr}\right)$. The portable module capacity is defined by determining the number of treatment campaigns. Assuming 12 campaigns per year, each campaign is approximately $2.5 \mathrm{~m}^{3}\left(88 \mathrm{ft}^{3}\right)$. The FTEs and cost data in this report are included for portable module in an existing building space.

\subsubsection{Storage Waste Loads}

Unlike the treatment modules, which use mass feed rates as waste loads, storage capacities are expressed in volumetric feed rates or as total volumes (i.e., stored, disposal). Figure 25-6 may be used to document the storage feed rates. As shown, there are four storage and disposal module categories: storage administration, storage receiving and shipping, storage (warehouse), and silo storage. As with treatment, the existing and new capacities must be defined for each of the four categories.

\subsection{Estimating Treatment Storage and Disposal Facility Cost and FTEs}

In step two, estimates of FTEs and PLCC for treatment, storage, and disposal (TSD) facilities are prepared based on the processing requirements developed in the waste loads definition, step one. The corresponding FTEs and cost for each module are developed by referring to the FTEs and cost versus capacity curves and tables given in this report. For existing capacities, operating costs (which consist of O\&M and D\&D costs) will need to be defined. For new capacity needs, the facility construction and preoperation estimates must be added to the facility O\&M and D\&D costs. To obtain total TSD facilities cost, a sum of the cost or FTEs from all TSD modules must be prepared.

\subsection{Transportation Costs}

In step three, transportation costs can be estimated by defining the total volume of waste to be transported and the distance in each of the potential transport segments (e.g., from generator to treatment facility, from treatment facility to storage facility, or from storage facility to disposal facility). Once the volumes and mileages are defined for each transportation segment, the cost data presented in Feizollahi et al. 1995 can be used to calculate the number of shipments and the associated transportation costs. 


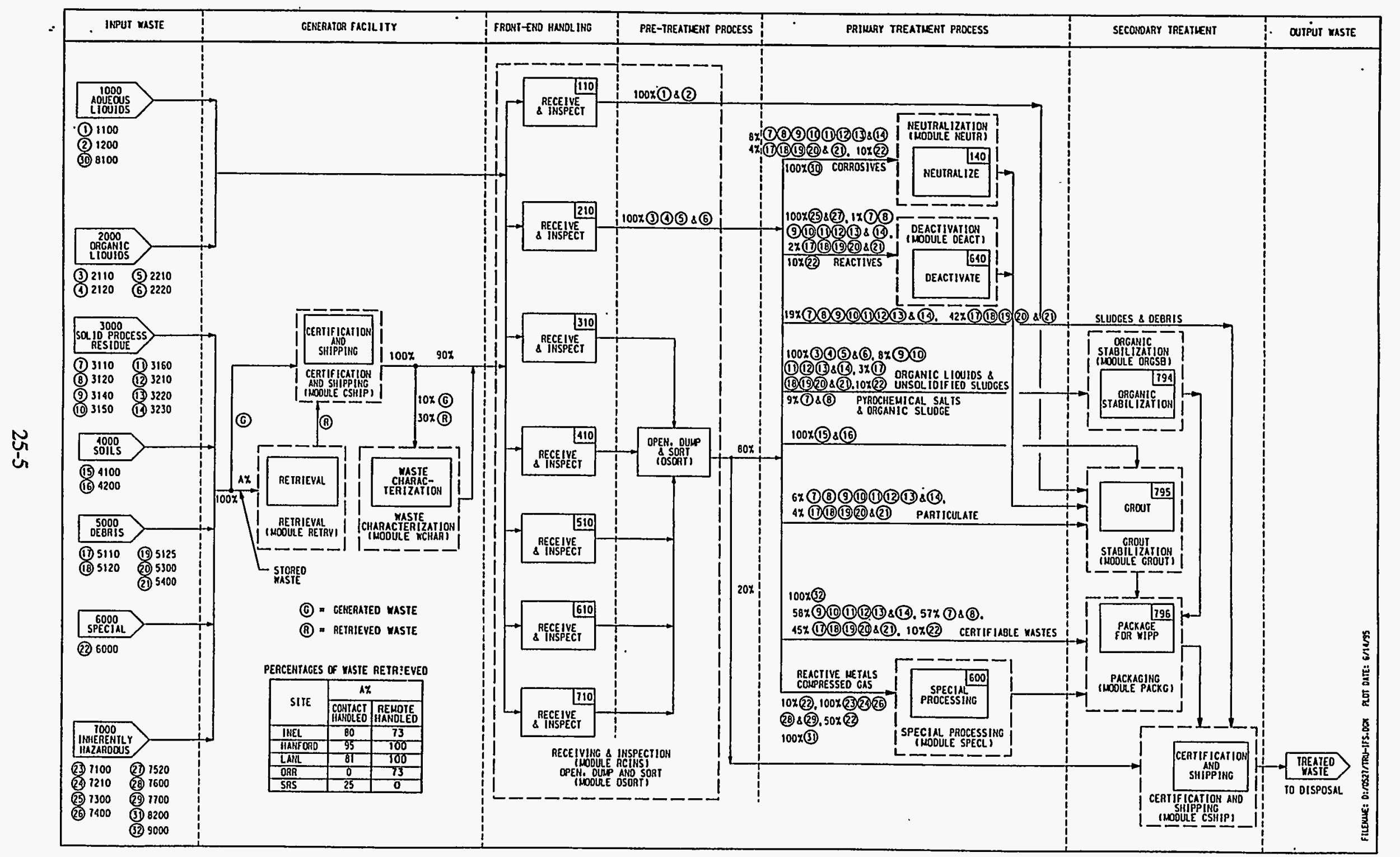

Figure 25-1. Combined modules based on the WIPP WAC requirements. 


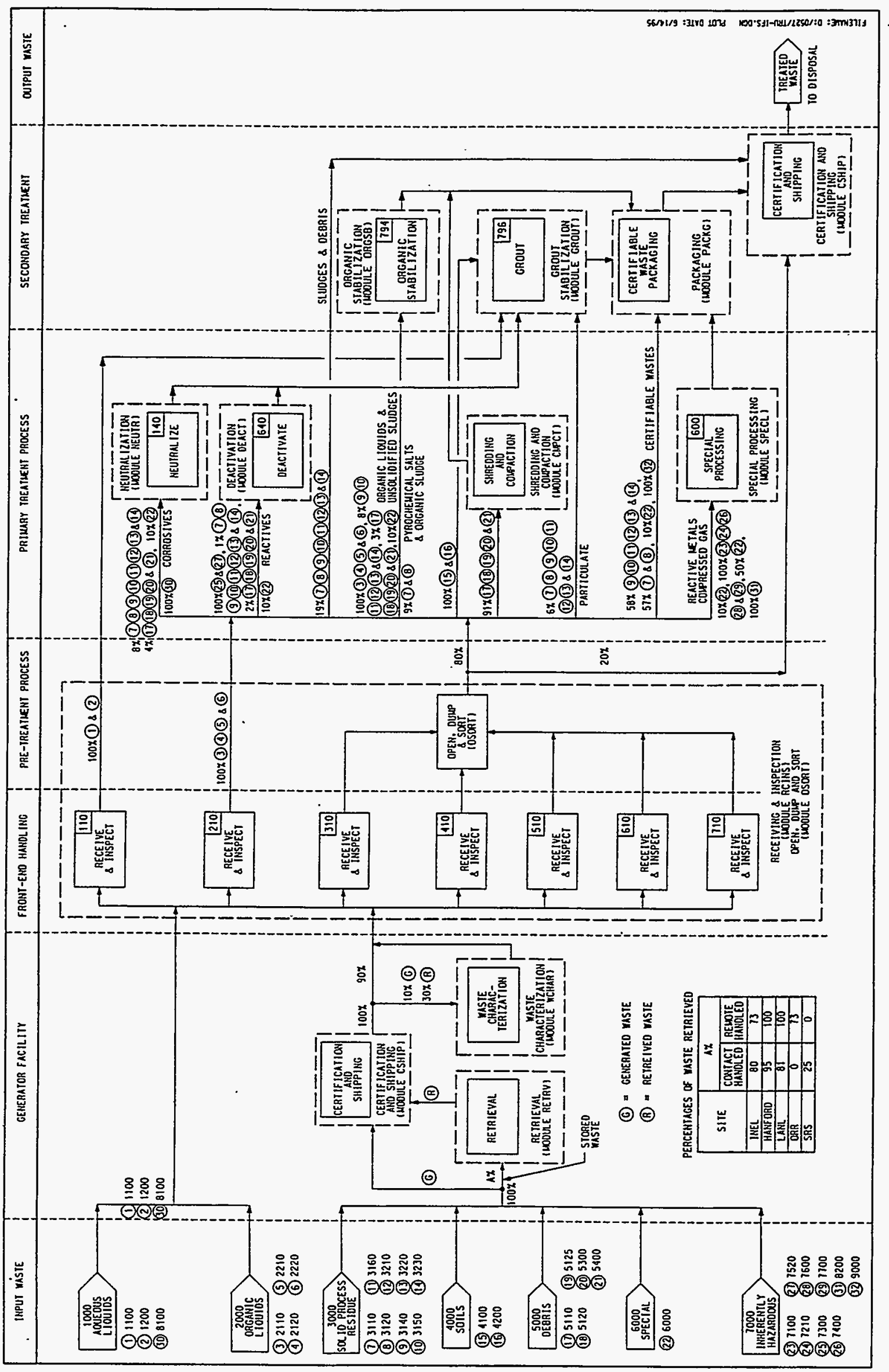

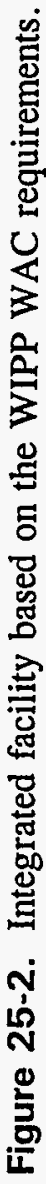




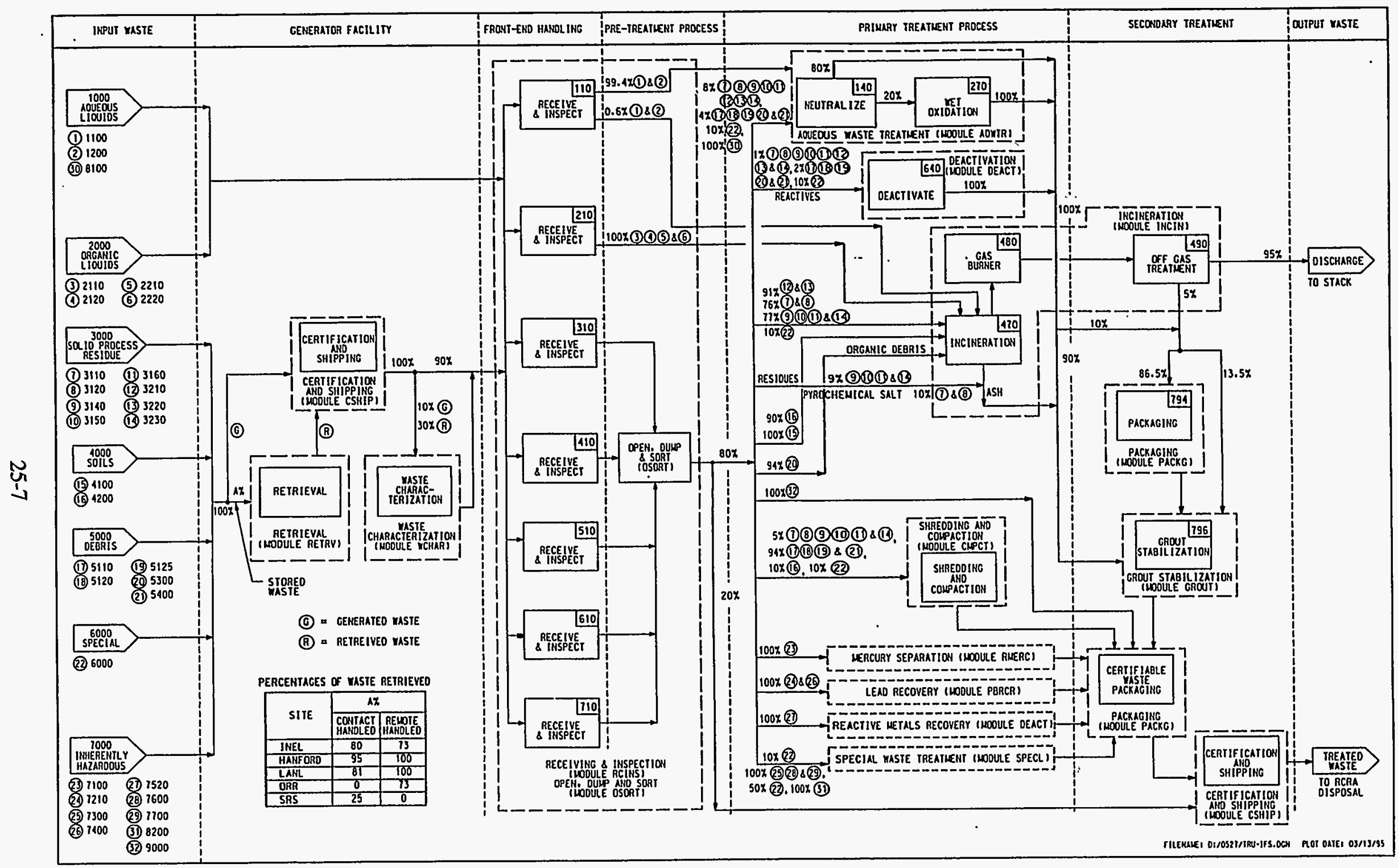

Figure 25-3. Integrated facility based on the RCRA requirements. 


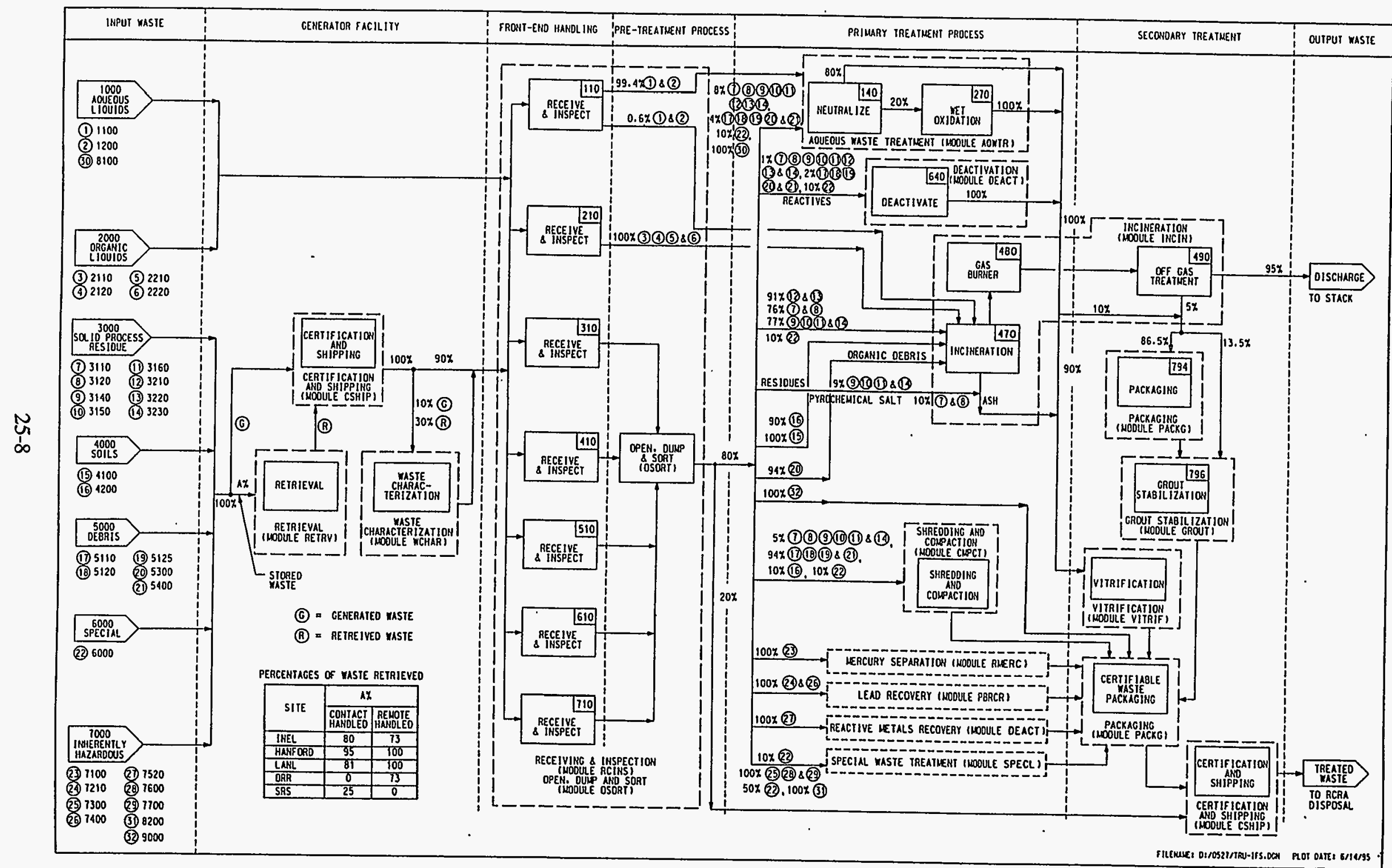

Figure 25-4. Integrated facility based on a vitrified waste form. 


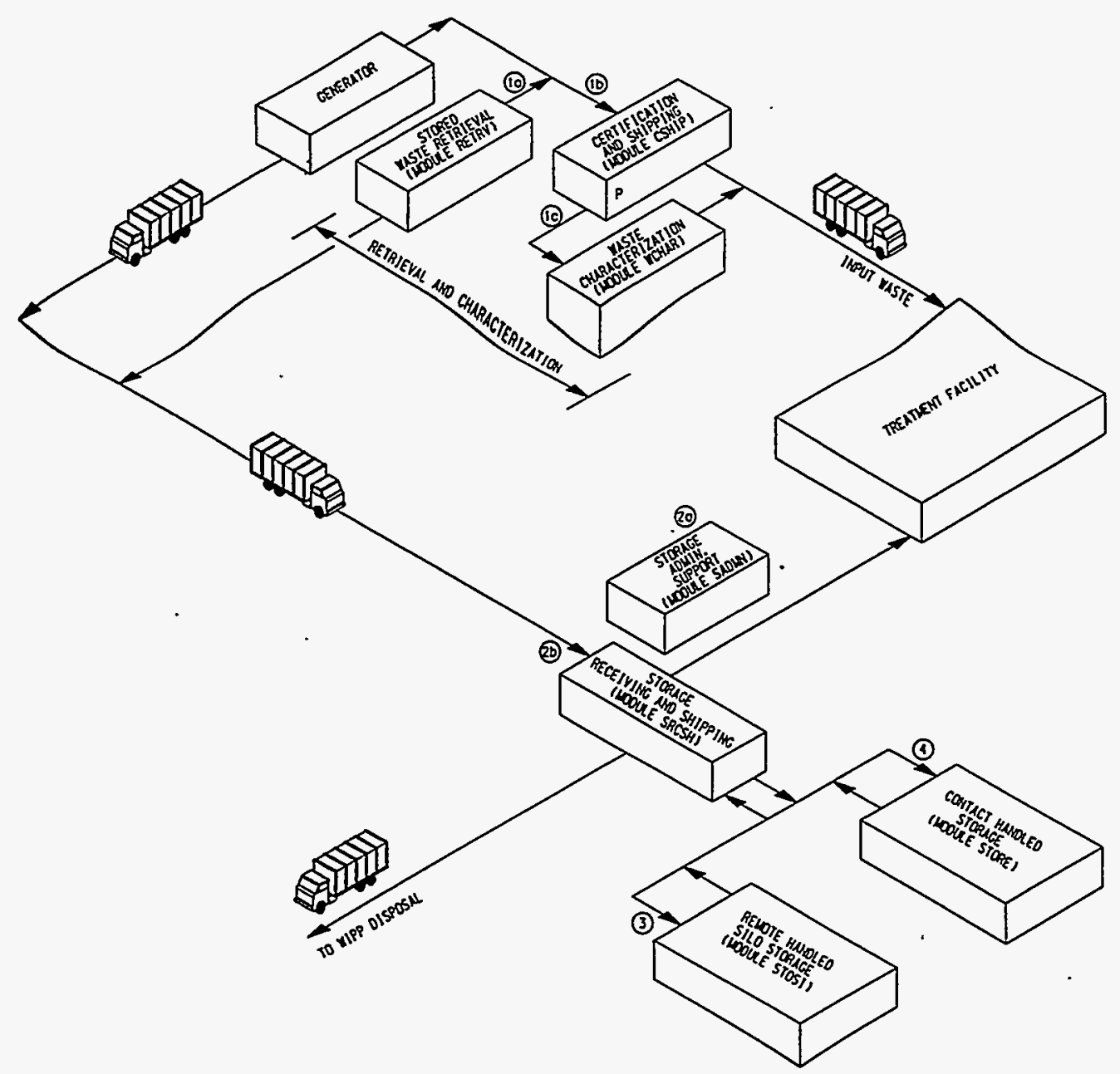

\begin{tabular}{|c|c|c|c|c|}
\hline MODULES & UNIT & $\begin{array}{c}\text { TOTAL } \\
\text { CAPACITY }\end{array}$ & $\begin{array}{l}\text { EXISTING } \\
\text { CAPACITY }\end{array}$ & $\stackrel{\text { NEW }}{\text { CAPACITY }}$ \\
\hline \multicolumn{5}{|c|}{ I. RETRIEVAL AND CHARACTERIZATION } \\
\hline (10) STRREO YISTE RETRIEVUL & kotr & & & \\
\hline (1D) CERIIFICAIIDN NOO SHIPPIKS & kg-tr & & & \\
\hline (10) YASTE CHUSACTERILATION & kgor & & & \\
\hline \multicolumn{5}{|c|}{ 11. STORAGE FRONT-END AND BACK-END SUPPQRT } \\
\hline (20) STQRuce ADUIMISTRUTIOF" & $m^{3} / r$ & & & \\
\hline (2D) SIDRUCE RECEIVING NO SHIPPING & $w^{3} / \pi$ & & & \\
\hline \multicolumn{5}{|l|}{ III. STORAGE } \\
\hline (3) RENOTE-HNOLED SLLO STORLCE & $a^{3}$ & & & \\
\hline (4) CONISCI-HANOLED STORAGE & $m^{3}$ & & & \\
\hline
\end{tabular}

FILENLYE:47/TRU-OATA.DGN PLOT DATE: 6/20/95

Figure 25-5. Retrieval, characterization, and interim storage module waste loads. 


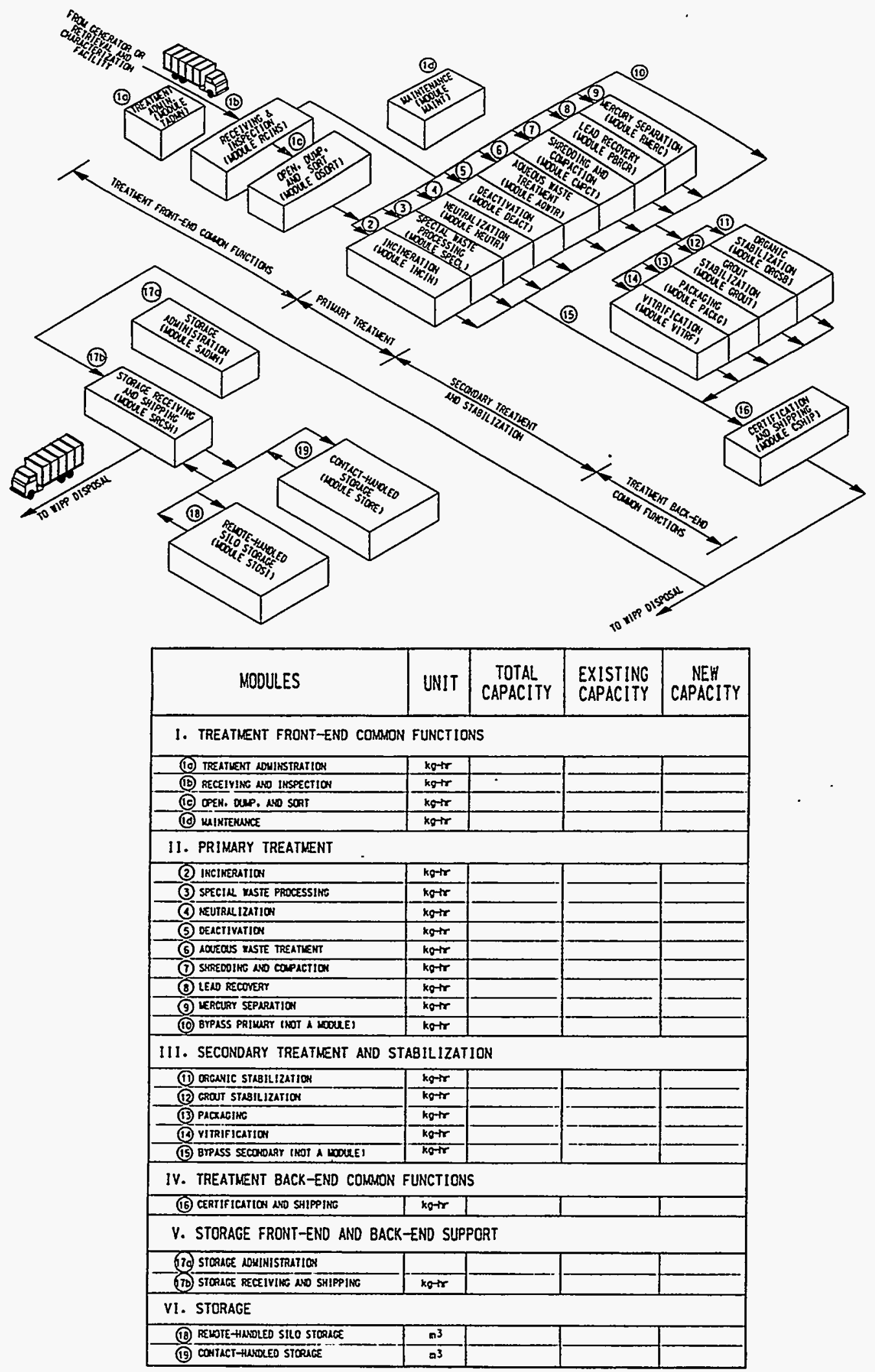

Figure 25-6. Treatment waste loads. 


\section{REFERENCES}

Feizollahi, F. and D. Shropshire, 1994, Interim Report: Waste Management Facilities Cost Information for Transuranic Waste, EGG-WM-11274, June.

Feizollahi, F. and D. Shropshire, 1992, Waste Management Facilities Cost Information Report Data, EGG-WTD-10443, October.

Feizollahi, F., D. Shropshire, and D. Burton, 1995, Waste Management Facilities Cost Information for Transportation of Radioactive and Hazardous Materials, INEL-95/0300, Rev. 1, (formerly EGG-WM-10877, Rev. 1), June.

Kirkpatrick, T. D., 1995, DOE Waste Treatability Group Guidance, DOE/LLW-217, Rev. 0, January.

Roads, A. S., 1992, A Performance Assessment of Radioactive Waste Encapsulated in Iron-Enriched Basalt and Disposed at the Idaho National Engineering Laboratory's Radioactive Waste Management Complex, Proceedings at Spectrum 92 International Topical Meeting, Nuclear and Hazardous Waste Management, v. 2, p. 1442, August 23-27, 1992, Boise, Idaho.

Shropshire, D., M. Sherick, and C. Biagi, 1995a, Waste Management Facilities Cost Information for Hazardous Waste, INEL-95/0016, Rev. 1, (formerly EGG-WM-11432), June.

Shropshire, D., M. Sherick, and C. Biagi, 1995b, Waste Management Facilities Cost Information for Low-Level Waste, INEL-95/0013, Rev. 0, June.

Shropshire, D., M. Sherick, and C. Biagi, 1995c, Waste Management Facilities Cost Information for Mixed Low-Level Waste, INEL-95/0014, Rev. 1, (formerly EGG-WM-10962), June. 